\title{
Watts Bar Unit 2 Startup Results with VERA
}

Andrew Godfrey Benjamin Collins Cole Gentry Shane Stimpson Oak Ridge National Laboratory John Ritchie Tennessee Valley Authority

March 31, 2017
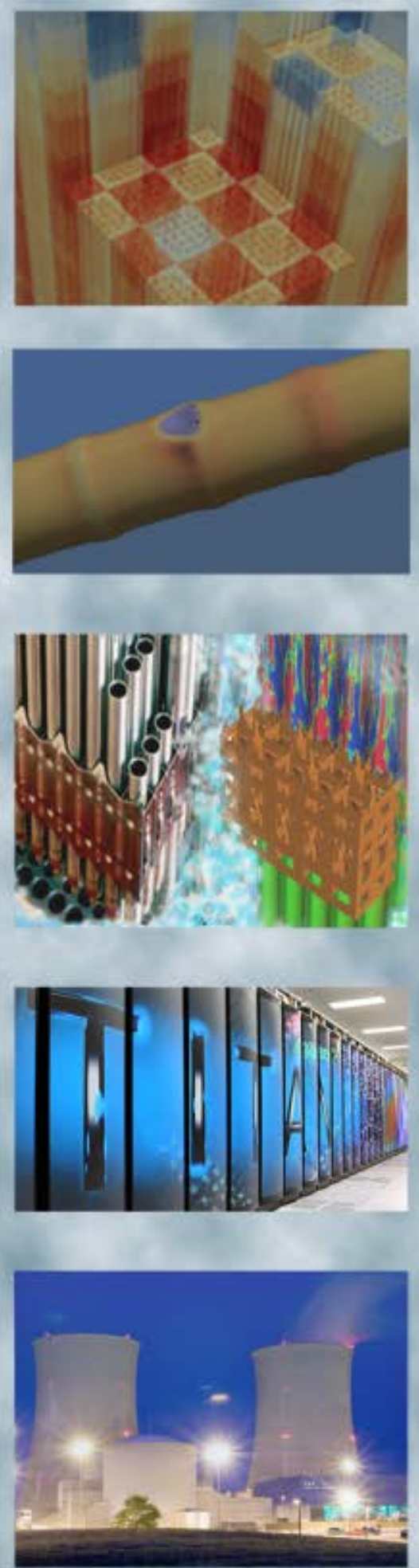

Approved for public release. 
REVISION LOG

\begin{tabular}{|c|c|c|l|}
\hline Revision & Date & Affected Pages & \multicolumn{1}{c|}{ Revision Description } \\
\hline 0 & $3 / 31 / 2017$ & All & Original release \\
\hline & & & \\
\hline & & & \\
\hline & & & \\
\hline
\end{tabular}

\section{Document pages that are:}

Export Controlled __None

IP/Proprietary/NDA Controlled__None

Sensitive Controlled__ None

Unlimited_All Pages

This report was prepared as an account of work sponsored by an agency of the United States Government. Neither the United States Government nor any agency thereof, nor any of their employees, makes any warranty, express or implied, or assumes any legal liability or responsibility for the accuracy, completeness, or usefulness of any information, apparatus, product, or process disclosed, or represents that its use would not infringe privately owned rights. Reference herein to any specific commercial product, process, or service by trade name, trademark, manufacturer, or otherwise, does not necessarily constitute or imply its endorsement, recommendation, or favoring by the United States Government or any agency thereof. The views and opinions of authors expressed herein do not necessarily state or reflect those of the United States Government or any agency thereof.

\section{Requested Distribution:}

To: N/A

Copy: N/A 


\section{EXECUTIVE SUMMARY}

CASL members TVA, Westinghouse, and Oak Ridge National Laboratory have successfully completed a detailed simulation of the initial startup of Watts Bar Nuclear Unit 2 (WBN2) using the advanced reactor simulation tools known as VERA. WBN2 is the first commercial power reactor to join the nation's electrical grid in over two decades, and the modern core design and availability of data make it an excellent benchmark for CASL. Calculations were performed three months prior to the startup, and in the first blind application of VERA to a new reactor, predicted criticality and physics parameters very close to those later measured by TVA. Subsequent calculations with the latest version of VERA and using exact measurement conditions improved the results even further.

The escalation to full power required approximately five months, including several intermediate testing power plateaus. The entire power, temperature, and control rod history was simulated with VERA by the hour, requiring 4,130 time steps, and included isotopic depletion and decay through ten additional shutdown intervals. TVA provided the startup data, as well as measured boron concentrations, reactor temperatures, ex-core axial flux difference (AFD), and twelve measured incore neutron flux distributions. The entire simulation required 892,837 core-hours, or 13.5 days on 2,784 cores. This included 16,605 neutronics/thermal-hydraulic iterations.

The VERA simulation was performed twice. At first the recommended BISON fuel temperature table was used, but large diverging axial power oscillations occured at many of the power plateaus. In order to dampen these oscillations, a modified temperature set was generated with an increased fuel temperature response to power. This was effective in dampening the axial power oscillations, significantly improving the axial results, but the error in the critical boron predictions and radial power distributions increased. More research into the source of the oscillations is still needed.

A summary of the final comparisons with VERA 3.6 is included in the table below. All results are good, except for the operating critical boron concentrations. Also, the in-core power distribution comparisons were not very good initially at low power, but the recent results are very good and consistent with the performance of VERA for WBN1 Cycle 1, notwithstanding the significant difference in detector type (state-of-the-art self-powered vanadium detector for WBN2 vs. standard movable detectors for WBN1).

Table 1. Summary of VERA Performance for WBN2 Startup

\begin{tabular}{ll}
\hline Parameter & Difference from Measurement \\
\hline Initial Critical Boron & $-2 \mathrm{ppmB}$ \\
Total / Max Bank Worth & $0.7 \pm 1.4 \%$ / 3.0\% \\
Isothermal Temperature Coefficient & $-0.8 \mathrm{pcm} /{ }^{\circ} \mathrm{F}$ \\
HZP Critical Boron Concentrations & $-7 \pm 3.3 \mathrm{ppmB}$ \\
At-Power Critical Boron Concentrations & $-37 \pm 11.1 \mathrm{ppmB}$ \\
In-Core Detector Segments: & $4.4 \%$ / 2.6\% / 2.5\% \\
Total / Radial / Axial RMS & $3.3 \%$ / 2.7\% \\
\hline In-Core Detector Currents: & \\
\hline All wires / Long Wires RMS &
\end{tabular}

This activity would not have been possible without the collaborative efforts enabled by the CASL consortium. The joint commitment by CASL members to share data, expertise, and computational resources continues to demonstrate high value to the participants and many others in the nuclear power industry. 



\section{CONTENTS}

FIGURES vii

TABLES xii

ACRONYMS xiii

1.INTRODUCTION .14

2.WATTS BAR NUCLEAR PLANT - UNIT 2 …………........................................................15

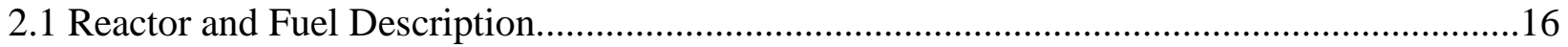

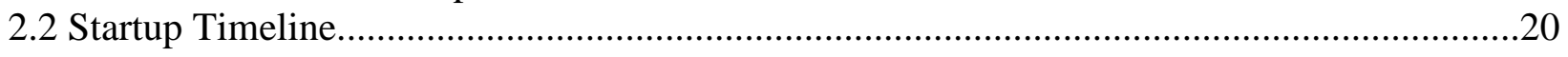

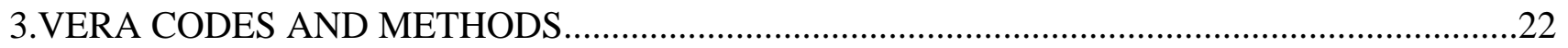

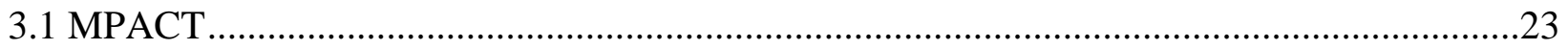

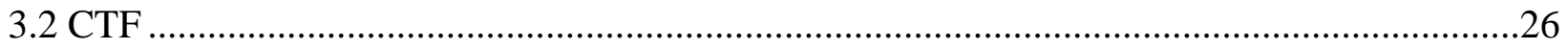

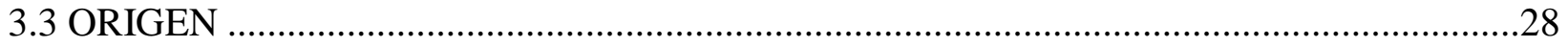

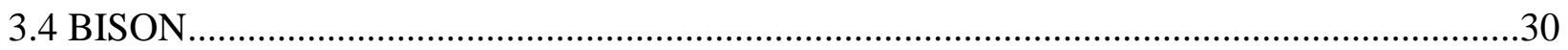

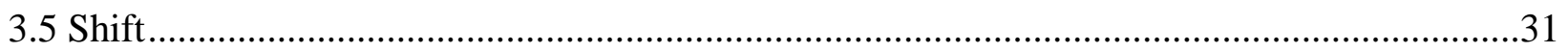

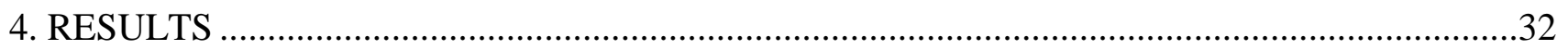

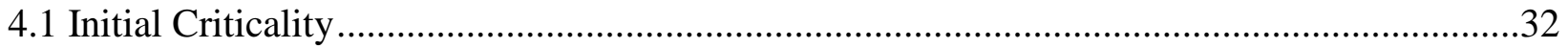

4.2 Control Bank Worth Measurements ....................................................................................32

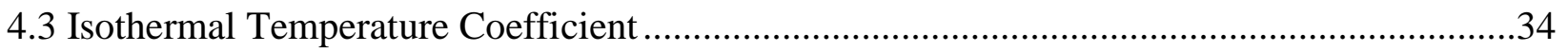

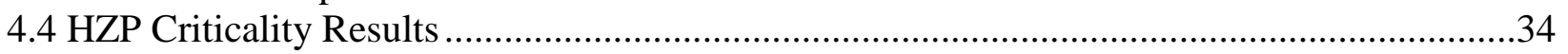

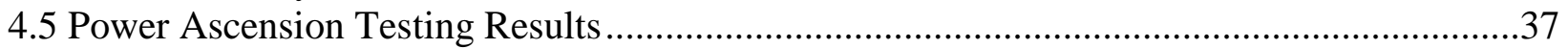

4.5.1 Reactor Thermal Power .........................................................................................38

4.5.2 Control Bank D Position ..........................................................................................39

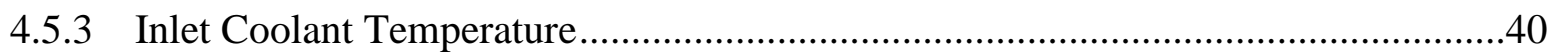

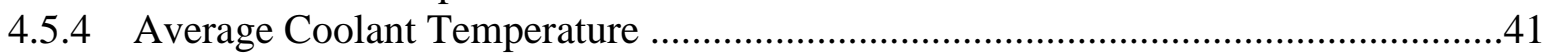

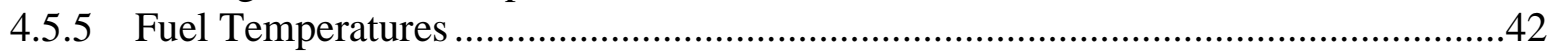

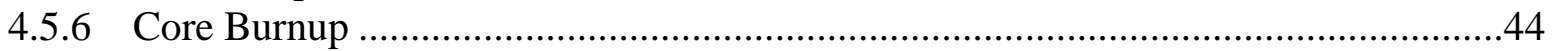

4.5.7 Transient Fission Product Concentrations...............................................................

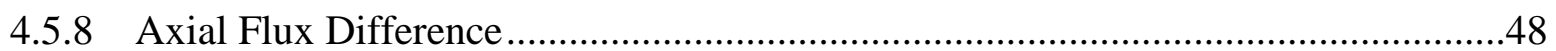

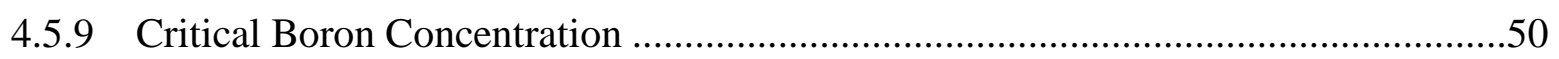

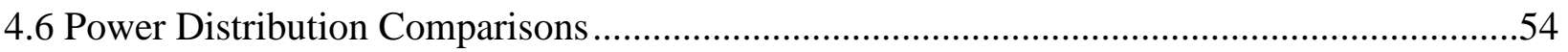

4.6.1 Flux Map Critical Boron Concentrations …………......................................................66

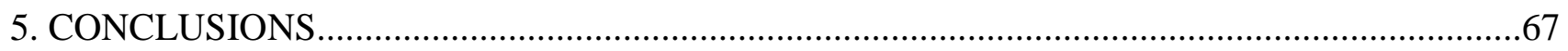

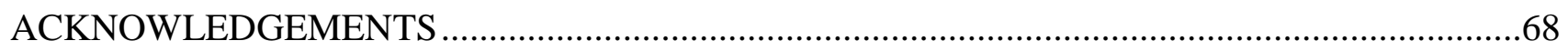

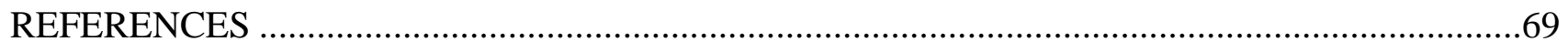

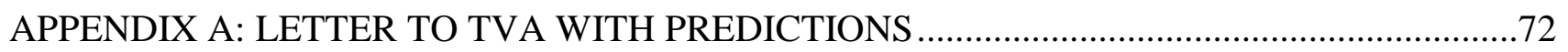

APPENDIX B: POWER DISTRIBUTION COMPARISONS...........................................................74

APPENDIX C: ASSYMETRIC POWER DISTRIBUTION CALCULATIONS …………................110 


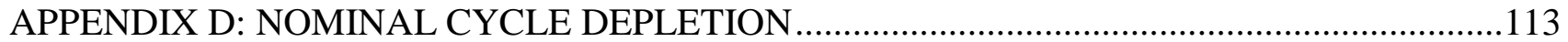




\section{FIGURES}

Figure 1-1. The CASL Founding Partners.................................................................................14

Figure 2-1. TVA’s Watts Bar Nuclear Plant [1] .....................................................................15

Figure 2-2. The WBN2 Core Barrel which houses the Reactor Core [1].....................................16

Figure 2-3. WBN2 Reactor Core with 193 Fuel Assemblies, Shown Partially Loaded in Dec.

2015 [1].

Figure 2-4. A TVA employee inspects a nuclear fuel assembly before being loaded into the WBN2 reactor core [1]......

Figure 2-5. Sample 17x17 Fuel Rod Lattice with 264 fuel rods, 104 with IFBA coatings, and 20 WABA rods [6].... .18

Figure 2-6. WBN2 Core Loading Pattern. ..................................................................................19

Figure 2-7. WBN2 Control Rod Banks. ..................................................................................19

Figure 2-8. WBN2 In-Core Detector Locations. ..................................................................19

Figure 2-9. Power Ascension Testing Plan for WBN2..............................................................20

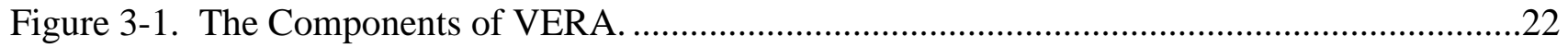

Figure 3-2. Depiction of the MPACT Radial Transport Mesh at each Axial Plane in each

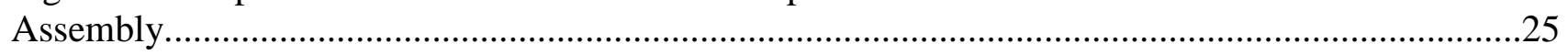

Figure 3-3. The MPACT Fission Rate Distribution for WBN2 at 28\% Power Flux Map. ................26

Figure 3-4. The CTF Coolant Temperature Distribution for WBN2 at 28\% Power Flux Map...........27

Figure 3-5. Relative Changes in Pin-Wise Xenon-135 and Power Following a RCCA

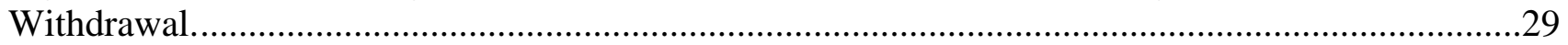

Figure 3-6. The ORIGEN Transient Xe-135 Distribution for WBN2 at 28\% Power Flux Map........29

Figure 3-7. Original BISON Fuel Temperature Model for RFA Fuel [5] ......................................30

Figure 3-8. Shift Eigenvalue Comparison to Serpent for AP1000 Lattice Depletions [15]...............31

Figure 4-1. Control Rod Bank Worth Errors (\%).....................................................................33

Figure 4-2. WBN2 Power History Showing Dates of Return to Criticality. ....................................35

Figure 4-3. WBN2 Critical Boron Differences following each Shutdown....................................36

Figure 4-4. VERA Power Ascension Runtime Fractions by Component......................................37 
Figure 4-5. Core Power History (\% of Rated Power) .............................................................38

Figure 4-6. Control Bank D History (Step Withdrawn). ..............................................................39

Figure 4-7. Inlet Temperature History $\left({ }^{\circ} \mathrm{F}\right)$ for Each Primary Loop. .............................................40

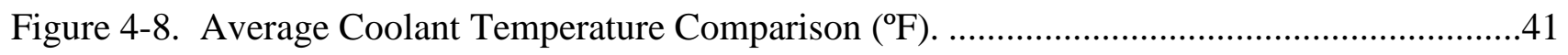

Figure 4-9. Original and Modified Fuel Temperature Sets (at 1 GWd/MTU). .............................42

Figure 4-10. Effects of Original and Modified Fuel Temperature Sets on AFD............................43

Figure 4-11. Calculated Average Fuel Temperature................................................................44

Figure 4-12. Calculated Cycle Burnup Comparison (MWd/MTU) .............................................45

Figure 4-13. Calculated Core Average Xenon-135 Concentration...............................................46

Figure 4-14. Calculated Core Average Samarium-149 Concentration..........................................46

Figure 4-15. Calculated Core Average Neptunium-239 Concentration. .......................................47

Figure 4-16. Calculated Core Average Plutonium-239 Concentration..........................................47

Figure 4-17. Calculated and Measured Axial Flux Difference Comparison. .................................49

Figure 4-18. Calculated and Measured Axial Flux Difference Comparison near HFP....................49

Figure 4-19. Boron-10 Depletion Model used for WBN2 Critical Boron Comparisons....................51

Figure 4-20. Soluble Boron Concentrations during Power Ascension Testing. ..............................52

Figure 4-21. Critical Boron Concentration Differences during Power Ascension Testing. ..............53

Figure 4-22. Critical Boron Concentration Differences as a Function of Core Power.....................53

Figure 4-23. Raw Detector Response Output from VERA for the first WBN2 Flux Map................55

Figure 4-24. Example Cubic Spline Fit of Raw Detector Response Output from VERA.................56

Figure 4-25. Comparison Calculated Detector Currents in F-7 of Flux Map 1..............................57

Figure 4-26. Comparison of Detector Segments F-7 of Flux Map 1..........................................58

Figure 4-27. WBN2 Power History Showing Dates of Measured Flux Maps.................................59

Figure 4-28. Radial Detector Segment Response Differences (C-M,\%) for Map 12......................61

Figure 4-29. Axial Detector Segment Response Differences (C-M,\%) for Map 12........................61

Figure 4-30. Long Wire Relative Current Ratios (C/M) for Map 12..........................................63 
Figure 4-31. Relative Current Comparison in Each Wire Length for Map 12.............................63

Figure 4-32. Statistical Summary of the Detector Segment Comparisons for All Cases. .................65

Figure 4-33. Statistical Summary of the Relative Detector Current Comparisons for All Cases. 65

Figure B-1. Raw and Vanadium Detector Response Results from VERA for Case 1....................75

Figure B-2. Radial Detector Segment Differences (C-M,\%) for Case 1.....................................75

Figure B-3. Axial Detector Segment Differences (C-M,\%) for Case 1........................................76

Figure B-4. Detector Relative Current Comparisons (C/M-1,\%) for Case 1................................76

Figure B-5. Raw and Vanadium Detector Response Results from VERA for Case 2. ....................78

Figure B-6. Radial Detector Segment Differences (C-M,\%) for Case 2. ....................................78

Figure B-7. Axial Detector Segment Differences (C-M,\%) for Case 2 ......................................79

Figure B-8. Detector Relative Current Comparisons (C/M-1,\%) for Case 2.................................79

Figure B-9. Raw and Vanadium Detector Response Results from VERA for Case 3. ....................81

Figure B-10. Radial Detector Segment Differences (C-M,\%) for Case 3. ...................................81

Figure B-11. Axial Detector Segment Differences (C-M,\%) for Case 3....................................82

Figure B-12. Detector Relative Current Comparisons (C/M-1,\%) for Case 3...............................82

Figure B-13. Raw and Vanadium Detector Response Results from VERA for Case 4. ...................84

Figure B-14. Radial Detector Segment Differences (C-M,\%) for Case 4. ....................................84

Figure B-15. Axial Detector Segment Differences (C-M,\%) for Case 4......................................85

Figure B-16. Detector Relative Current Comparisons (C/M-1,\%) for Case 4...............................85

Figure B-17. Raw and Vanadium Detector Response Results from VERA for Case 5. ..................87

Figure B-18. Radial Detector Segment Differences (C-M,\%) for Case 5. ...................................87

Figure B-19. Axial Detector Segment Differences (C-M,\%) for Case 5.......................................88

Figure B-20. Detector Relative Current Comparisons (C/M-1,\%) for Case 5................................88

Figure B-21. Raw and Vanadium Detector Response Results from VERA for Case 6...................90

Figure B-22. Radial Detector Segment Differences (C-M,\%) for Case 6. ...................................90

Figure B-23. Axial Detector Segment Differences (C-M,\%) for Case 6......................................91 
Figure B-24. Detector Relative Current Comparisons (C/M-1,\%) for Case 6...............................91

Figure B-25. Raw and Vanadium Detector Response Results from VERA for Case 7. ..................93

Figure B-26. Radial Detector Segment Differences (C-M,\%) for Case 7. ...................................93

Figure B-27. Axial Detector Segment Differences (C-M,\%) for Case 7.....................................94

Figure B-28. Detector Relative Current Comparisons (C/M-1,\%) for Case 7...............................94

Figure B-29. Raw and Vanadium Detector Response Results from VERA for Case 8. ..................96

Figure B-30. Radial Detector Segment Differences (C-M,\%) for Case 8. ...................................96

Figure B-31. Axial Detector Segment Differences (C-M,\%) for Case 8.....................................97

Figure B-32. Detector Relative Current Comparisons (C/M-1,\%) for Case 8...............................97

Figure B-33. Raw and Vanadium Detector Response Results from VERA for Case 9. ...................99

Figure B-34. Radial Detector Segment Differences (C-M,\%) for Case 9. ....................................99

Figure B-35. Axial Detector Segment Differences (C-M,\%) for Case 9....................................100

Figure B-36. Detector Relative Current Comparisons (C/M-1,\%) for Case 9..............................100

Figure B-37. Raw and Vanadium Detector Response Results from VERA for Case 10. ...............102

Figure B-38. Radial Detector Segment Differences (C-M,\%) for Case 10 .................................102

Figure B-39. Axial Detector Segment Differences (C-M,\%) for Case 10..................................103

Figure B-40. Detector Relative Current Comparisons (C/M-1,\%) for Case 10............................103

Figure B-41. Raw and Vanadium Detector Response Results from VERA for Case 11. ...............105

Figure B-42. Radial Detector Segment Differences (C-M,\%) for Case 11.................................105

Figure B-43. Axial Detector Segment Differences (C-M,\%) for Case 11..................................106

Figure B-44. Detector Relative Current Comparisons (C/M-1,\%) for Case 11............................106

Figure B-45. Raw and Vanadium Detector Response Results from VERA for Case 12. ...............108

Figure B-46. Radial Detector Segment Differences (C-M,\%) for Case 12 ................................108

Figure B-47. Axial Detector Segment Differences (C-M,\%) for Case 12..................................109

Figure B-48. Detector Relative Current Comparisons (C/M-1,\%) for Case 12............................109

Figure C-1. Asymmetrical Effects (\% power) of Source Rods on Pin Power Distribution..............110 
Figure C-2. Asymmetrical Effects (\% power) of Source Rods on Quarter-Core Assembly Powers. 111

Figure C-3. Pin Power Differences between Full and Quarter-Core Simulations for Map 10. .111

Figure C-4. Assembly Power Differences between Full and Quarter-Core Simulations for Map 10.112

Figure D-1. Calculated Fuel Rod Exposures at End-of-Cycle 1 113

Figure D-2. Calculated Fuel Assembly Exposures at End-of-Cycle 1. 


\section{TABLES}

Table 1. Summary of VERA Performance for WBN2 Startup................................................... iii

Table 3-1. VERA Capability Comparison for Reactor Simulation ...............................................24

Table 4-1. Initial ARO Critical Boron Results .....................................................................32

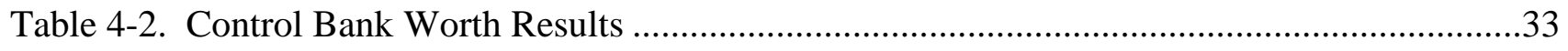

Table 4-3. Isothermal Temperature Coefficient Results........................................................34

Table 4-4. HZP Critical Boron Concentrations ..............................................................................36

Table 4-5. Power Ascension Testing Computer Performance........................................................37

Table 4-6. Summary of Measured Flux Map Cases and Conditions .............................................59

Table 4-7. Segment Comparison Statistics for Case 12.........................................................60

Table 4-8. Wire-based Relative Current Comparison Statistics for Case 12 .................................62

Table 4-9. Approximate Critical Boron Comparisons for Each Flux Map.....................................66

Table D-1. WBN2 Cycle 1 Nominal Depletion Summary .......................................................114 


\section{ACRONYMS}

$\begin{array}{ll}\text { AFD } & \text { Axial Flux Difference } \\ \text { AIC } & \text { Silver-Indium-Cadmium } \\ \text { AMA } & \text { Advanced Modeling Applications Focus Area } \\ \text { API } & \text { Application programming interface } \\ \text { BOC } & \text { Beginning-of-cycle } \\ \text { CASL } & \text { Consortium for Advanced Simulation of Light Water Reactors } \\ \text { CFD } & \text { Computational Fluid Dynamics } \\ \text { DOE } & \text { US Department of Energy } \\ \text { DRWM } & \text { Dynamic Rod Worth Measurement } \\ \text { EFPD } & \text { Effective Full Power Days } \\ \text { EOC } & \text { End-of-cycle } \\ \text { HFP } & \text { Hot Full Power } \\ \text { HPC } & \text { High Performance Computing } \\ \text { HZP } & \text { Hot Zero Power } \\ \text { INL } & \text { Idaho National Laboratory } \\ \text { ITC } & \text { Isothermal Temperature Coefficient of Reactivity } \\ \text { M\&S } & \text { Modeling and Simulation } \\ \text { OLCF } & \text { Oak Ridge Leadership Computing Facility } \\ \text { ORNL } & \text { Oak Ridge National Laboratory } \\ \text { PHI } & \text { Physics Integration Focus Area } \\ \text { PWR } & \text { pressurized water reactor } \\ \text { RCCA } & \text { Rod Cluster Control Assembly } \\ \text { RMS } & \text { Root Mean Square } \\ \text { RTM } & \text { Radiation Transport Methods } \\ \text { T/H } & \text { thermal-hydraulics } \\ \text { TVA } & \text { Tennessee Valley Authority } \\ \text { VERA } & \text { Virtual Environment for Reactor Applications } \\ \text { PHI } & \text { Physics Integration Focus Area } \\ \text { WBN1 } & \text { Watts Bar Nuclear Plant Unit 1 } \\ \text { WBN2 } & \text { Watts Bar Nuclear Plant Unit 2 } \\ \text { WEC } & \text { Westinghouse Electric Company } \\ & \end{array}$




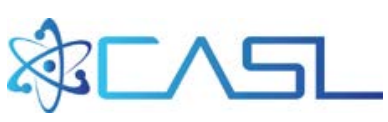

\section{INTRODUCTION}

On October 19, 2016, Tennessee Valley Authority's (TVA) Watts Bar Nuclear Plant entered its new Unit 2 (WBN2) into commercial operation and became the first new nuclear power generation facility in the United States in 20 years. This accomplishment required approximately eight years and $\$ 4.6$ billion dollars in construction, and finished with approximately five months of operational testing [1]. This is a timely event for the Consortium for Advanced Simulation of Light Water Reactors (CASL) (Fig. 1-1), which was established in 2010 for the advancement of methods and software capabilities for improved reactor analysis. WBN2 has provided CASL with valuable data for the validation of its primary software product known as VERA, the Virtual Environment for Reactor Applications. CASL partners TVA, Westinghouse Electric Company (WEC), and Oak Ridge National Laboratory (ORNL) have closely collaborated for a very detailed reactor core simulation of the entire plant startup. This project has continued for over a year, beginning with VERA predictions of the plant startup in March, 2016, and culminating now in this milestone report.

With the cooperation of the Oak Ridge Leadership Computing Facility (OLCF), CASL has prepared rigorous models of the Unit 2 reactor core and has executed VERA for over 4,000 hours of the plant's power history, including all power ramps and shutdown intervals. This is the largest timedependent simulation ever performed by CASL, with over 16,600 neutronic/thermal-hydraulic iterations and providing hundreds of data points for validation against measured plant data. VERA's performance for this simulation is documented in this report, including comparisons to critical boron concentrations, control rod worth, temperature coefficient, and in-core power distribution measurements.

In addition to the validation of VERA, this document also identifies strengths and weaknesses of the current CASL methods in the scope of this application and several areas of improvement and research have been identified based on these results.

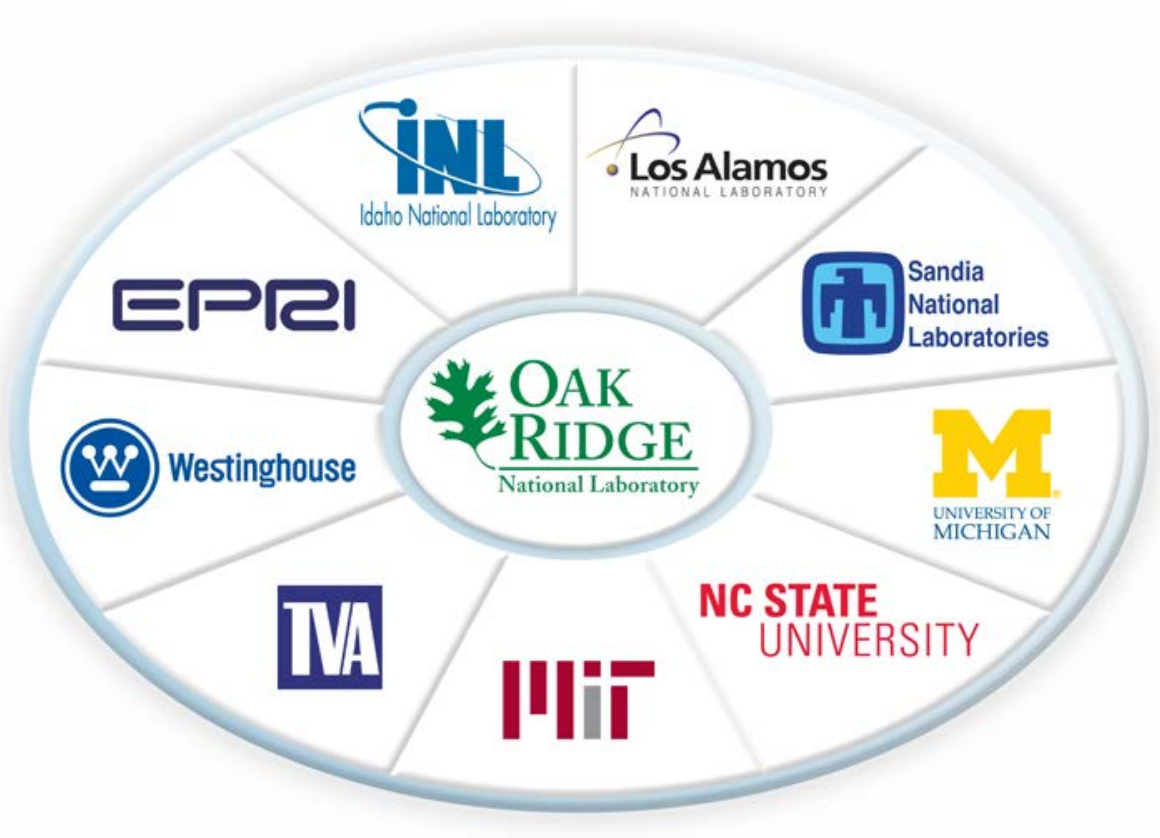

Figure 1-1. The CASL Founding Partners. 


\section{WATTS BAR NUCLEAR PLANT - UNIT 2}

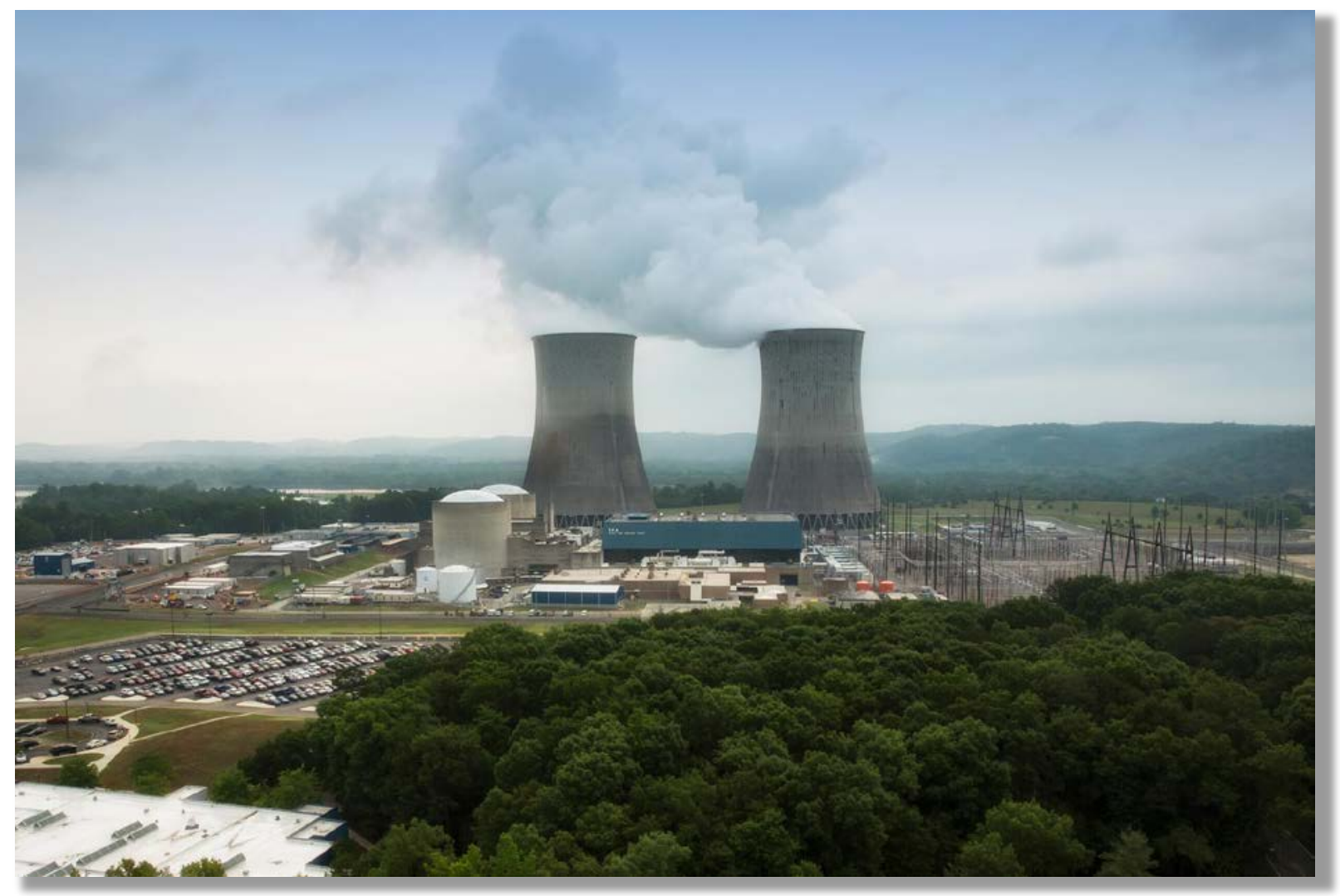

Figure 2-1. TVA's Watts Bar Nuclear Plant [1].

WBN2 is the newest commercial nuclear power reactor to generate electricity in the United States. Located in Spring City, Tennessee, the Watts Bar Nuclear Plant (Fig. 2-1) has been successfully operating Unit 1 (WBN1) for the last 21 years, producing 1,170 MW of clean electricity for the Tennessee valley at capacity factors up to $99 \%$. The initial construction permits were each obtained in 1973, but construction of Unit 2 was suspended in 1985 with much of the major components and equipment already installed [2]. In 2007, TVA decided to complete the project in order to meet the growing energy demands in the region [3]. Completion of construction required an additional eight years, followed by another year of extensive testing and power escalation before reaching commercial full power operation on October 19, 2016. The $\$ 4.6$ billion dollar construction project is now generating as much electricity as $1 / 3^{\text {rd }}$ of the nation's wind turbines 24 hours per day, and offsetting the emission of about 15 million metric tons of $\mathrm{CO}_{2}$ from fossil fuel plants [4].

TVA is a founding member of the CASL project and has been actively working with CASL partners to use the operating history and measured data from WBN1 to validate the capabilities of the CASL high-fidelity software known as VERA [5]. CASL has performed industrial-grade benchmarking activities for all fourteen of the WBN1 fuel cycles and has shown good agreement with a variety of reactor physics parameters, including criticality measurements, control bank reactivity worth, temperature coefficient of reactivity, critical boron concentrations, and in-core measured neutron flux distributions. WBN1 is also the model for a rigorous set of publicly available benchmarks that have been developed by CASL and utilized by organizations around the world for reactor simulation code verification and validation [6]. WBN1 has played a vital role in standing up the CASL capabilities and ensuring that all commercial utilities and fuel vendors can benefit from this DOE investment. 


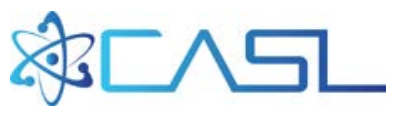

\subsection{Reactor and Fuel Description}

WBN2 is a traditional Westinghouse four-loop pressurized water reactor (PWR) with an ice condenser containment design, much like its sister unit. It has a thermal power rating of 3,411 $\mathrm{MW}_{\text {th. }}$ Its reactor core consists of 193 nuclear fuel assemblies of the Westinghouse 17x17 design in a cylindrical arrangement within a large stainless steel core barrel (Fig. 2-2) inside of a reactor pressure vessel. A cross section of the reactor core is depicted in Figure 2-3, showing the fuel locations and radial layout of the core supporting structures.

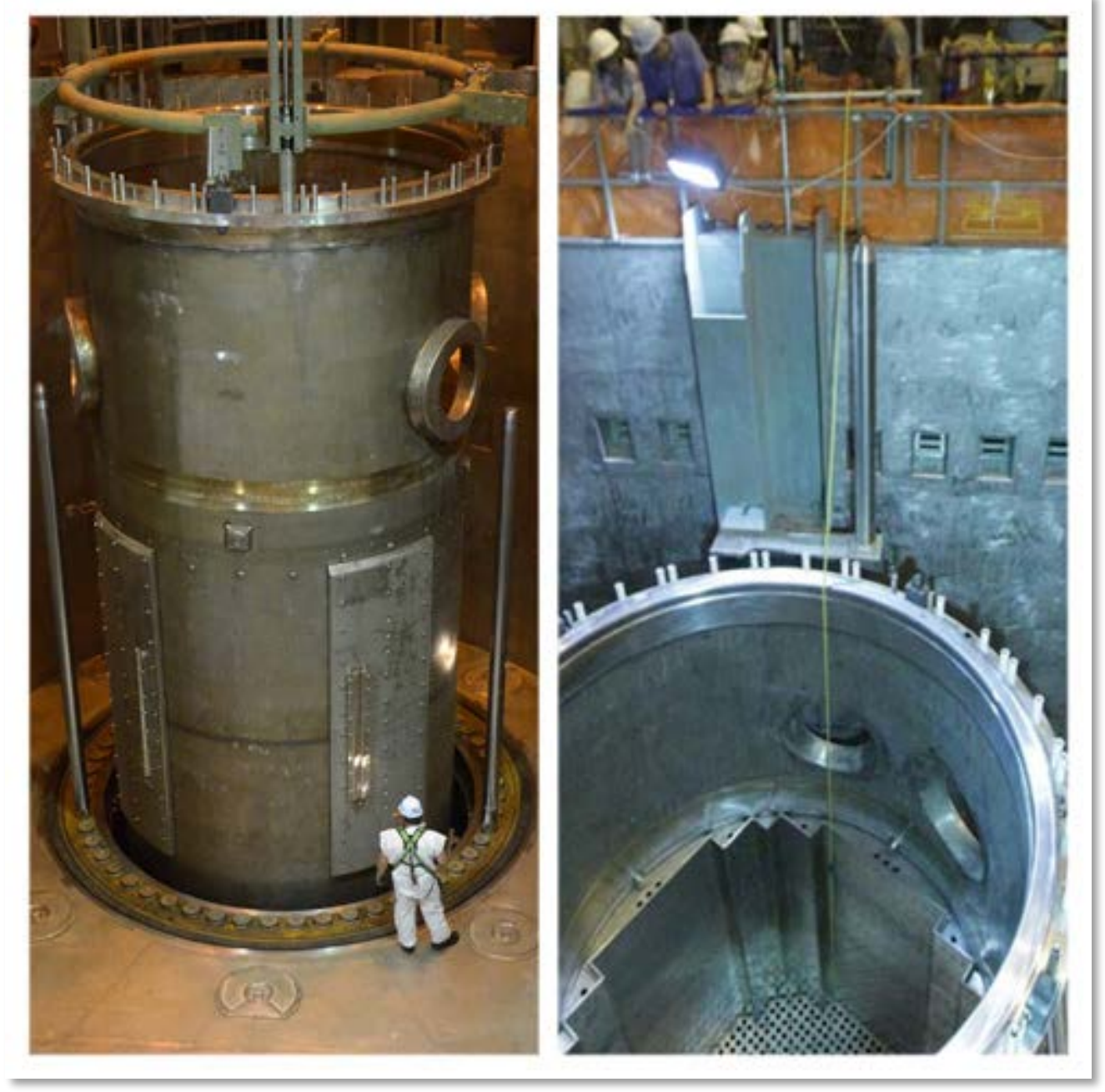

Figure 2-2. The WBN2 Core Barrel which houses the Reactor Core [1].

WBN2 Cycle 1 is designed to operate for approximately 400 effective full power days. It operates at a pressure of 2,250 psi and at temperatures greater than $557^{\circ} \mathrm{F}$. The fuel assemblies are cooled by borated water driven through the pressurized reactor vessel at 410,000 gallons per minute by four reactor coolant pumps. The boric acid injected into the coolant provides a chemical shim for reactivity control that can be nearly continuously removed by dilution as the reactor fuel depletes over the cycle. This boron "letdown" is commonly used for validation of the reactivity prediction of reactor core simulators. 

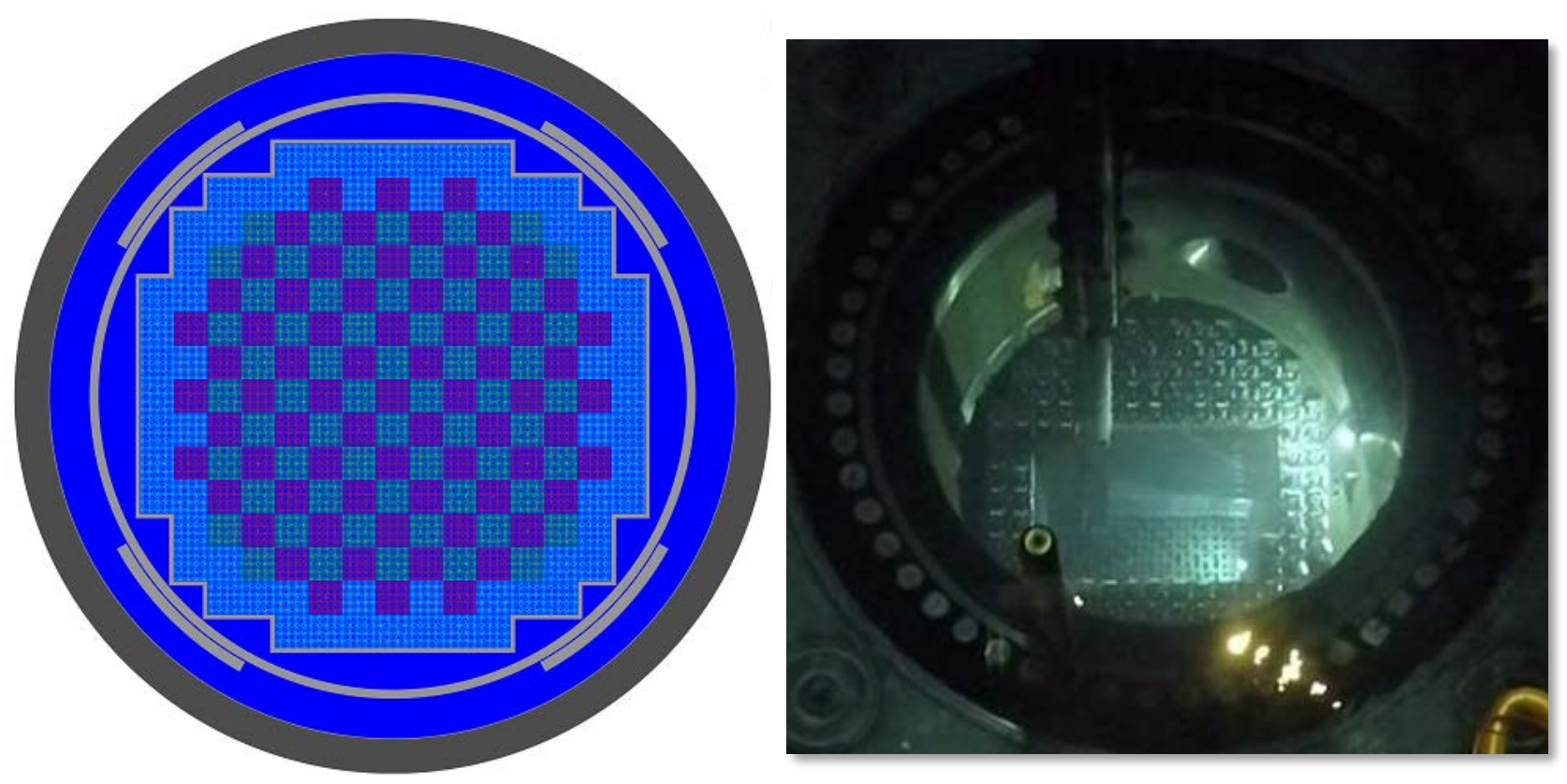

Figure 2-3. WBN2 Reactor Core with 193 Fuel Assemblies, Shown Partially Loaded in Dec. 2015 [1].

The WBN2 reactor core was loaded in December 2015 with 193 new ("fresh") Robust Fuel Assembly (RFA-2) nuclear fuel assemblies manufactured by Westinghouse. Each fuel assembly is approximately thirteen feet tall (Fig. 2-4) and contains 264 cylindrical fuel rods arranged in a 17x17 lattice configuration (Fig. 2-5). The non-fuel locations are empty cylindrical guide tubes that provide channels for movement of control rods, discrete burnable absorbers, or instrumentation through the assembly. Each assembly utilizes twelve spacer grids which provide lateral support to the fuel rods to maintain their position and spacing while also improving the coolant flow characteristics as it travels up through the reactor core. The axial locations of these spacer grids are visible in Figure 2-4.

Each of the 50,952 fuel rods is composed of a twelve foot stack of sintered $\mathrm{UO}_{2}$ fuel pellets inside a zirconium alloy cladding. The fuel pellets are enriched in ${ }^{235} \mathrm{U}$ to 2.1, 2.6 and $3.1 \mathrm{wt} \%$, depending on the assembly location. The higher enriched assemblies utilize low enriched regions in the top and bottom six inches of each rod. These regions, referred to as axial blankets, are $2.6 \%{ }^{235} \mathrm{U}$ rather than the higher central region enrichment. The assemblies in WBN2 are loaded into the core in three regions based on enrichment, shown in Figure 2-6, in order to minimize fuel costs and flatten the inter-assembly power distribution. When fully loaded the WBN2 reactor core houses nearly 90 metric tons of uranium.

In Cycle 1, burnable neutron absorbers are used to control excess reactivity and reduce power peaking early in the fuel cycle. Unlike the reactor startups from 20-30 years ago, WBN2 utilizes the most modern poison designs known as Integral Fuel Burnable Absorber (IFBA) and Wet Annular Burnable Absorber (WABA), both of which are designed to improve fuel economy by limiting the residual reactivity penalty at the end of the fuel cycle.

- IFBA is an ultra-thin coating of the neutron absorbing compound $\mathrm{ZrB}_{2}$, which is sprayed on the fuel pellets with thicknesses on the order of 10 microns [6]. In WBN2, only 32 rods within a given assembly have IFBA, and the IFBA is used in the entire central region of the fuel stack, covering a total of 132 inches of fuel. 


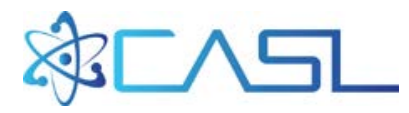

- WABAs are discrete rods containing the neutron absorber $\mathrm{B}_{4} \mathrm{C}-\mathrm{Al}_{2} \mathrm{O}_{3}$ that are placed into the empty guide tubes of some assemblies. Optimized patterns of $8,12,16,20$, and 24 rods are used to control the amount and distribution of flux suppression (20 is shown in Figure 2-5). WABA is used heavily in WBN2 in approximately every other fuel assembly, with a "cutback" length of 120 inches and a two inch downward axial offset from centered.

Both burnable absorbers are fully depleted of ${ }^{10} \mathrm{~B}$ in the first cycle which maximizes the length of time the reactor can operate before refueling.

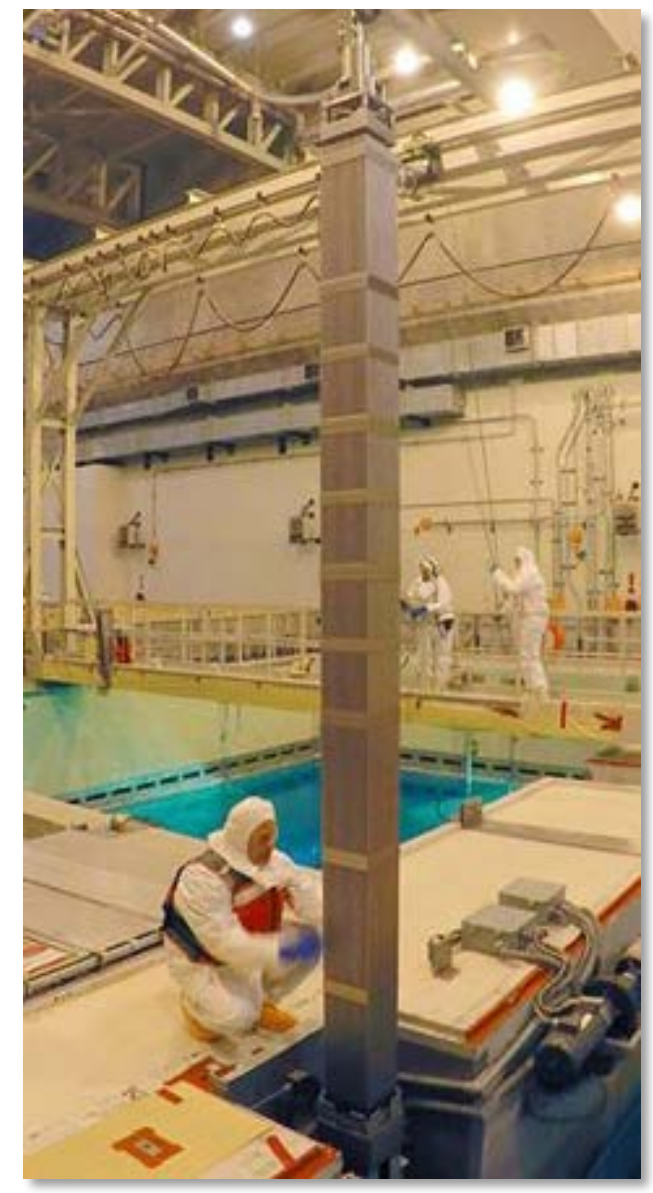

Figure 2-4. A TVA employee inspects a nuclear fuel assembly before being loaded into the WBN2 reactor core [1].

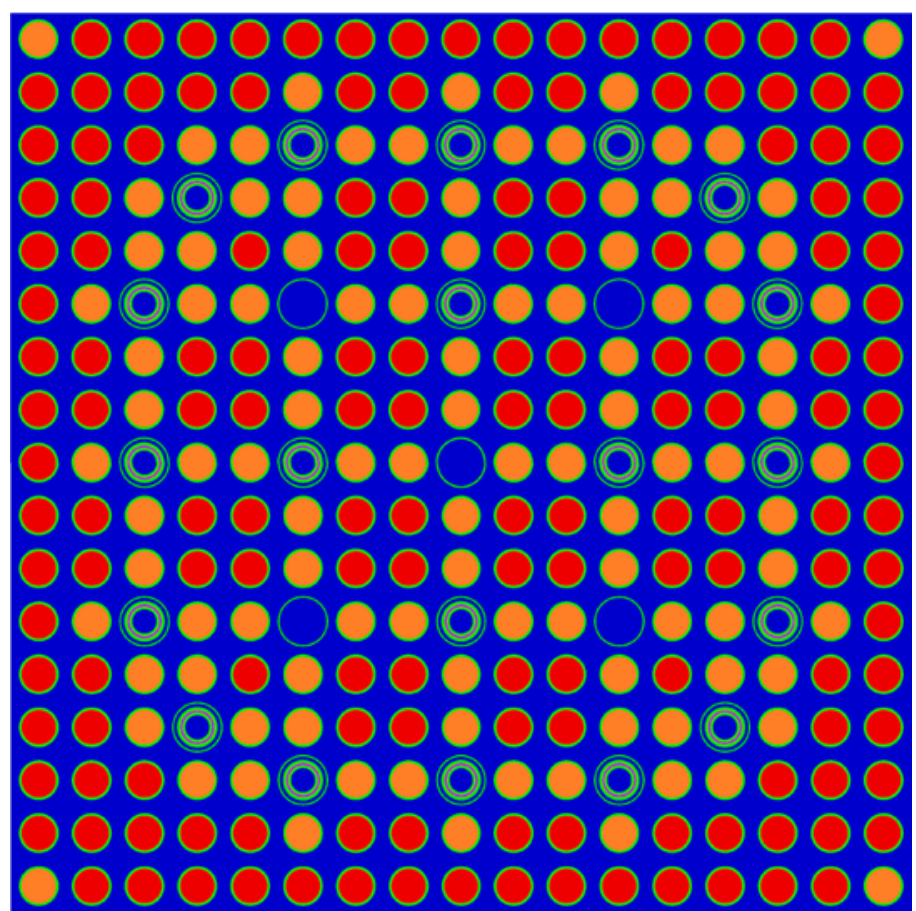

Figure 2-5. Sample 17x17 Fuel Rod Lattice with 264 fuel rods, 104 with IFBA coatings, and 20 WABA rods [6].

In addition to the chemical shim, neutron-absorbing Ag-In-Cd (AIC) control rods are utilized for instantaneous reactivity control and for assured shutdown margin of the reactor. The rods are clustered into assemblies with 24 rodlets connected to a central spider hub at the top of the assembly. There are 57 total Rod Cluster Control Assemblies (RCCAs) grouped into eight separate "banks". These banks can be positioned at any elevation in the reactor core using the control rod drives, which allow the RCCAs to traverse the height of the reactor core in approximately 230 discrete 0.625 ” steps. Four of the banks are reserved for shutdown, while the other four are used for reactivity control. Only one bank, Bank D, is positioned slightly in the core during nominal operation. The WBN2 control bank locations are shown in Figure 2-7, using quarter-core symmetry. 


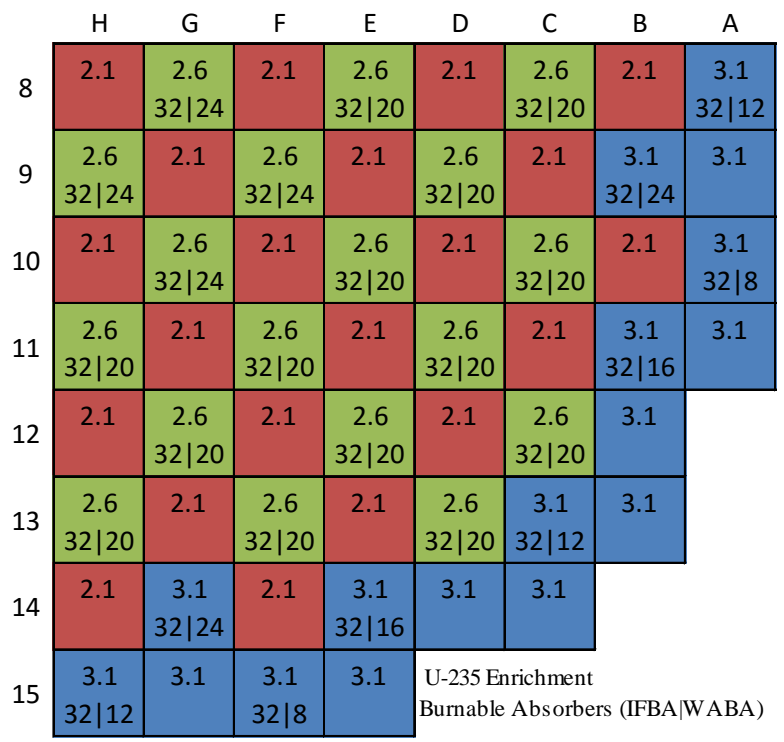

Figure 2-6. WBN2 Core Loading Pattern.

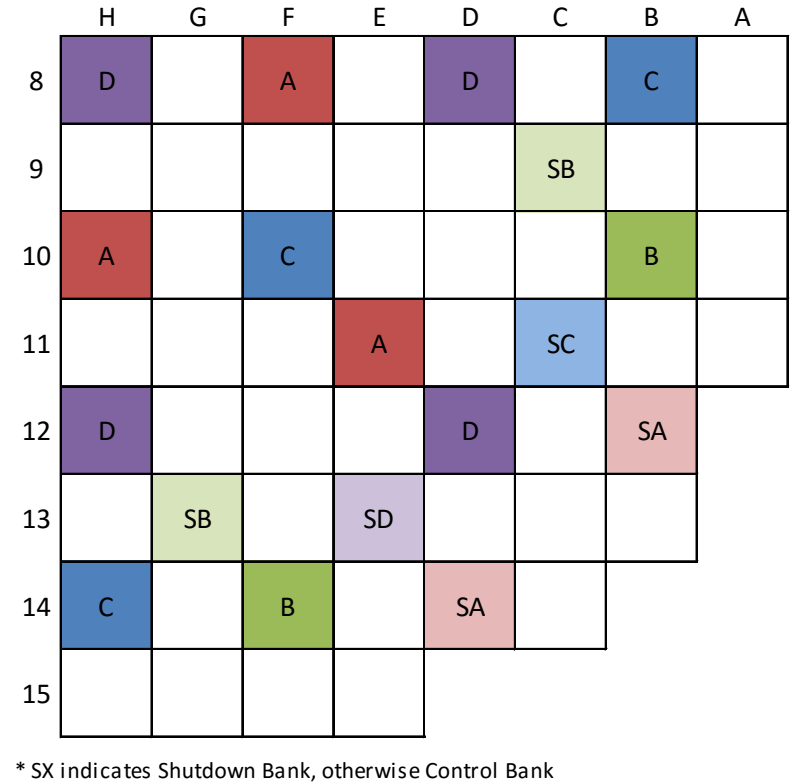

Figure 2-7. WBN2 Control Rod Banks.

WBN2 utilizes both in-core and ex-core instrumentation to monitor the power distribution in the reactor. Unlike WBN1, which uses moveable fission chambers, WBN2 uses fixed five-level selfpowered vanadium detectors. They are placed in the reactor core at the beginning of the fuel cycle and are available continuously for performing core surveillance activities and ex-core detector calibration. The detectors are driven into the reactor core through installed thimble tubes in the center of 58 fuel assemblies, shown in Figure 2-8. Each detector includes five emitter wires of different lengths, with the longest length approximately coinciding with the active fuel height. The wires produce a current proportional to the interaction with neutron flux by an $(n, \beta)$ reaction with ${ }^{51} \mathrm{~V}$, with a half-life of 3.8 minutes. More information on the in-core neutron detectors is provided in Section 4.6.

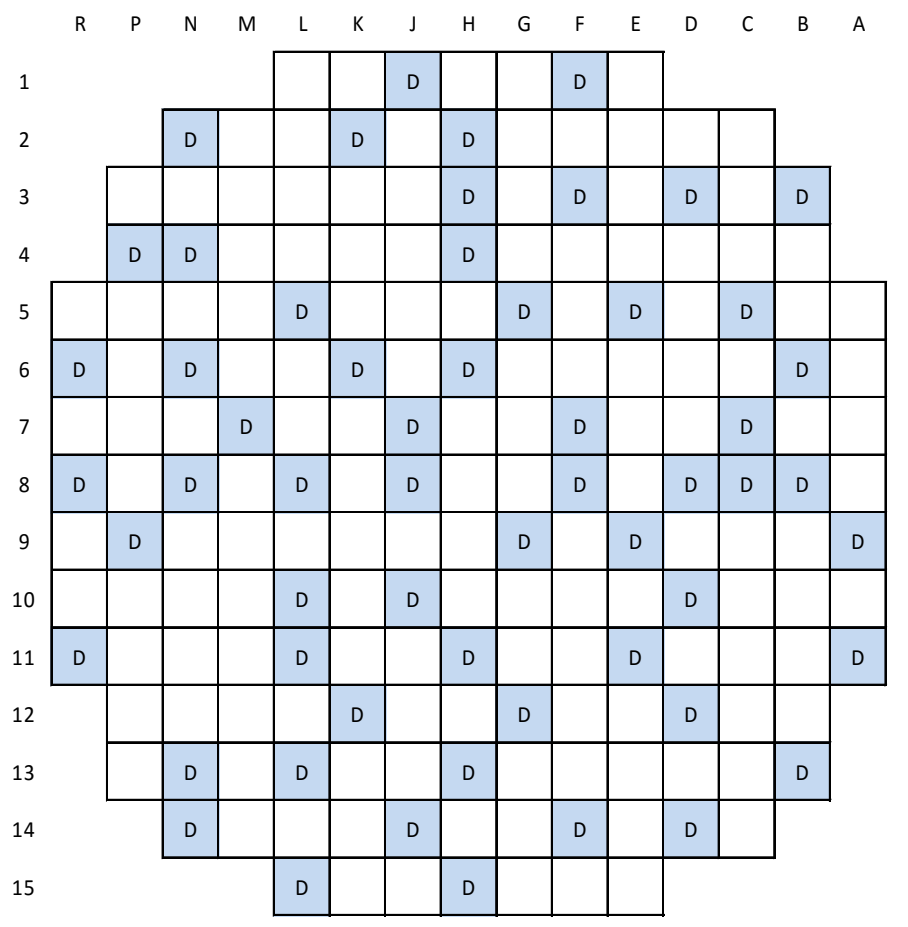

Figure 2-8. WBN2 In-Core Detector Locations. 
Two primary neutron source rods are installed in WBN2 to provide the needed source range detector count rate when approaching criticality. These rods displace two WABAs in asymmetric core locations and each contains small capsules of californium. Additionally, two locations have six rods each of Sb-Be pellets for secondary neutron sources in subsequent fuel cycles. The secondary sources do not displace WABAs. The sources are relevant for this analysis because the majority of the core calculations are done with quarter-core symmetry and therefore cannot include the direct effects of the asymmetric sources. See Appendix C for more information.

\subsection{Startup Timeline}

WBN2 achieved initial criticality at 2:16 AM on May 23, 2016. Startup physics testing was performed immediately, and initial power ascension began later that day. The reactor was first synced to the power grid on June 3, and then preceded with power escalation through $30 \%$, 50\%, and $75 \%$ power plateaus. Power ascension testing (PAT) was completed and commercial operation was declared on October 19, 2016 [1]. The official plan for power ascension testing is shown in Figure 2-9.

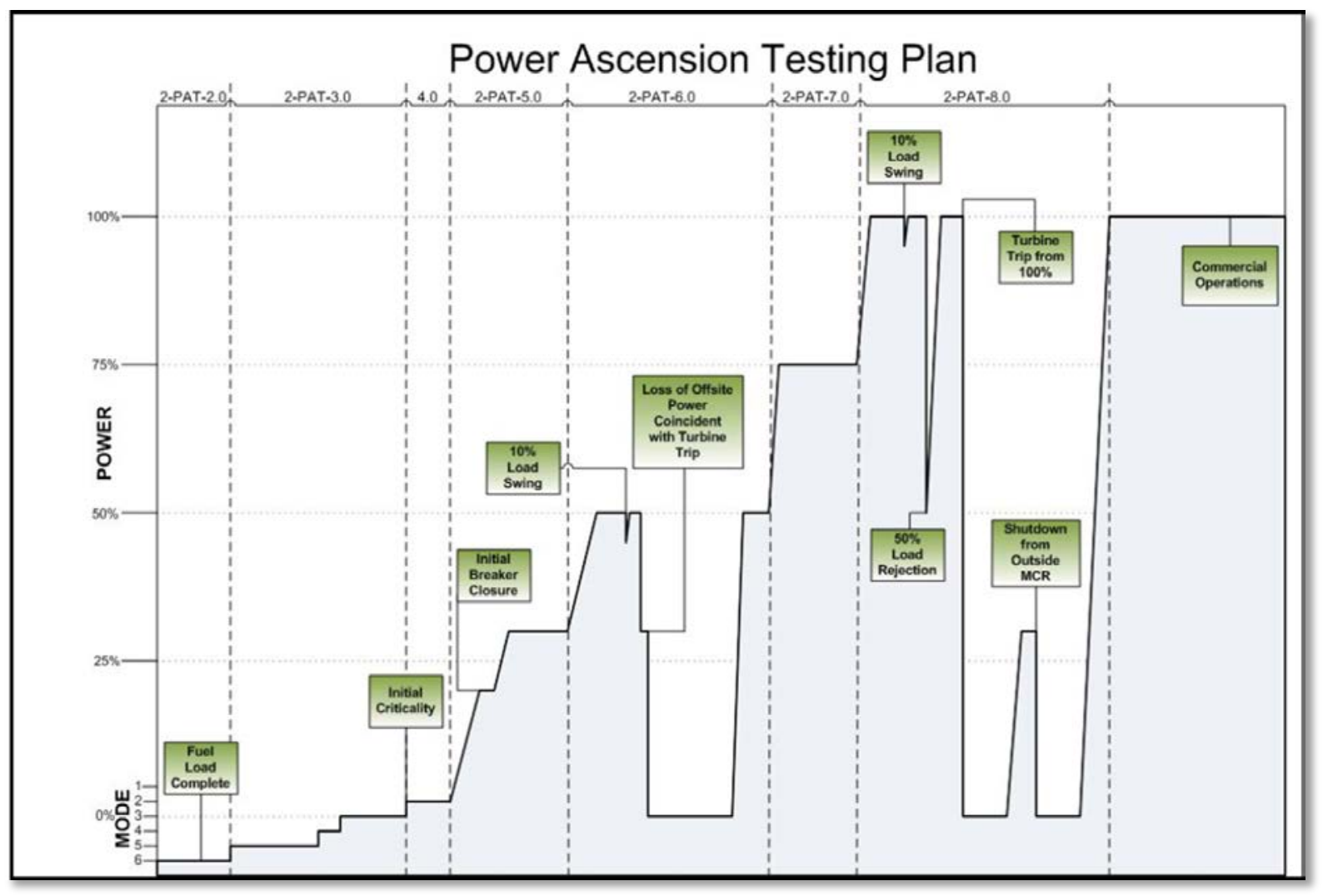

Figure 2-9. Power Ascension Testing Plan for WBN2. 
The actual power history for the startup is shown in Figure 4-5. It includes the following additional shutdown periods:

- Turbine generator coupling making excessive noise $(5 / 28 / 2016)$

- Automatic trip and safety injection on steam pressure low (6/5/2016)

- Automatic trip from Lo-Lo level in number 4 steam generator (6/20/2016)

- Turbine trip (6/26/2016)

- Planned loss of offsite power trip from 30\% (7/14/2016)

- Planned trip from outside of main control room (8/3/2016)

- Manual trip due to low steam generator levels caused by a loss of feedwater flow from main feedwater pump (8/23/2016)

- Turbine trip from a main bank transformer failure $(8 / 30 / 16)$

As of the time of this document, WBN2 is operating at nominal conditions and has completed approximately half of its first fuel cycle. 


\section{VERA CODES AND METHODS}

CASL's Virtual Environment for Reactor Applications (VERA) continues to advance the state-ofthe-art for commercial reactor simulations. Developments in the past year have resulted in improved accuracy, significantly reduced computational requirements, and further expansion in capabilities. Additionally, rapid increases in industry engagement have led to more opportunities to apply and benchmark the VERA tools, which in turn have led to important user feedback and further improvements. The development and collaboration models in CASL have been very successful in establishing a mature, reliable foundational capability for advanced reactor analysis. The current state of VERA is depicted in the figure below, followed by a brief description of the individual codes that have been employed for the WBN2 startup simulation.

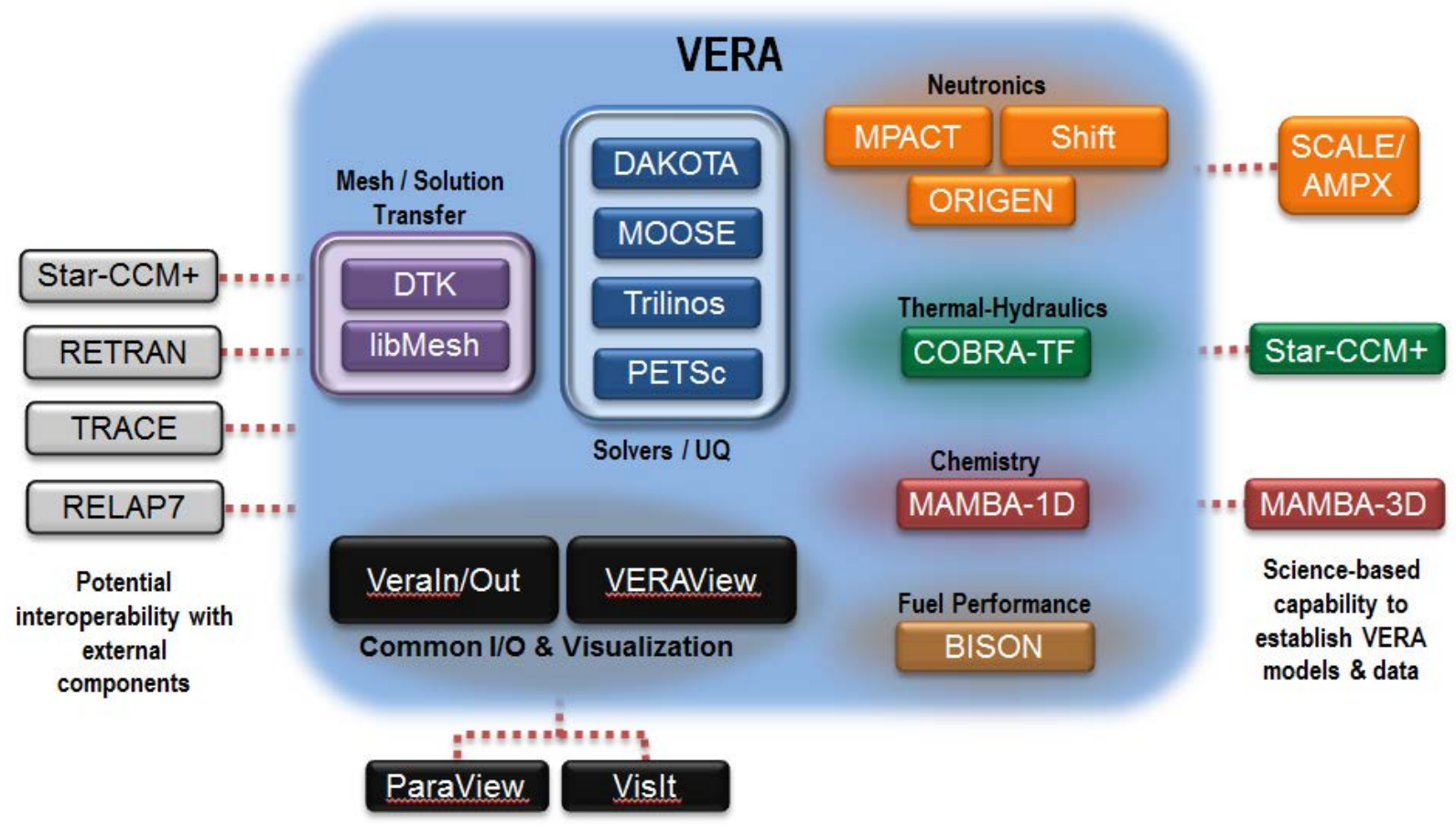

Figure 3-1. The Components of VERA.

The items inside the blue VERA box in Figure 3-1 represent the current methods and software being developed and coupled by CASL. Each of the important physics areas needed for reactor simulation and addressing the CASL Challenge Problems is included, including neutronics, thermal-hydraulics, fuel mechanics, and coolant chemistry (CRUD). In each physics area, there are multiple levels of fidelity in order to provide both a science-based accuracy when needed, but also a performancefocused counterpart to enable solution of large, realistic problems. In these cases, the higher fidelity component can be used on smaller scales to inform and improve the development of the workhorse tool. In addition to providing new and improved individual methods, VERA also enables direct multi-way couplings for exchange of data. This capability and resolution is unprecedented in the nuclear industry, and will lay the foundation for methods development for decades to come.

The red dotted lines in Figure 3-1 represent CASL's goal of interoperability with existing tools that are outside the current scope of the CASL program. These include reactor system codes, commercial CFD codes, and publicly available visualization tools. CASL has also developed customized input and output utilities which make VERA very easy to use. In fact, because it relies on a single common input from the user, and due to the nature of direct simulation with fewer approximations, VERA is as easy to use and as quick to learn as any modern reactor analysis tool available today [7]. 
VERA has been designed to eliminate the barriers facing modern methods for improved accuracy on smaller spatial scales. Its tools provide direct and fully coupled solutions at the fuel rod (and intrarod) level for neutronics and T/H without any spatial homogenization. The local power distribution can be determined directly for highly heterogeneous geometries without any need for reconstruction, and the impacts of local changes on the fly, such as boron deposition in CRUD, can easily be directly simulated. Isotopic depletion and decay occur within a fuel pellet at local conditions within the once-through 3-D calculation, avoiding the need for macroscopic spectral corrections to simplified history models. The effects of sub-cooled boiling and two-phase flow can be directly obtained from the core simulation, and the fuel rod temperatures and pressures can be calculated with precise axial power histories for every fuel rod in the entire core.

VERA also manages the calculation flow, data transfer, and solution convergence between methods automatically, and is capable of computational scaling from leadership-class supercomputers (hundreds of thousands of computing cores) to engineering-grade compute clusters (fewer than a thousand cores), enabling access for scientists and engineers across many application areas. Recently, VERA has been installed on the Westinghouse computing cluster Binford and has been used for reactor calculations with as few as 300-500 cores.

To summarize these and other differences between VERA and modern tools, Table 3-1 is included from Reference 5, including some updates for recent and planned development activities. In the following sections, each VERA code used for the WBN2 startup calculations is briefly summarized. For a more detailed summary, please see Reference 5.

\subsection{MPACT}

MPACT is an advanced pin-resolved whole-core multi-group deterministic neutron transport capability based on the 2-D/1-D synthesis method, on the frame of a 3-D coarse mesh finite difference method, for which radial and axial correction factors are obtained from 2-D method-ofcharacteristics and 1-D $\mathrm{P}_{\mathrm{N}}$, respectively [8]. The transport is performed using 51 energy-group cross sections, based on the subgroup method of on-the-fly resonance self-shielding [9]. The discretization of the core is typically three radial and eight azimuthal flat source regions per fuel pellet (See Fig. 32) at each of approximately 60 axial planes, explicitly treating such features as spacer grids, fuel and absorber plena, and end plugs. MPACT performs the same neutron transport calculations in the upper, lower, and radial reflector regions of the core, explicitly modeling the baffle, core barrel, neutron pads, nozzles, and core plates, requiring no a priori approximations of the core boundary conditions as is needed for nodal diffusion methods. MPACT also controls the functional application features of the VERA core simulator, such as critical boron search, equilibrium xenon calculations, predictor-corrector depletion, in-core detector response calculations, reading and writing restart files, and performing fuel shuffling, decay, and discharge. Figure 3-3 demonstrates the fine resolution in fission rates which is obtained from MPACT for one of the WBN2 flux map statepoints. 


\section{Table 3-1. VERA Capability Comparison for Reactor Simulation}

\section{(italics represents items under development)}

\begin{tabular}{|c|c|c|}
\hline Capability & VERA & Typical Industry Methods \\
\hline $\begin{array}{l}\text { Neutron } \\
\text { Transport }\end{array}$ & $\begin{array}{l}\text { 3-D (2-D/1-D) whole-core pin-resolved } \\
\text { transport based on actual fuel, core, and } \\
\text { support structure geometry }\end{array}$ & $\begin{array}{l}\text { Transport-based 2-D infinite lattice physics }+3-\mathrm{D} \\
\text { nodal diffusion theory with approximate reflectors }\end{array}$ \\
\hline Cross Sections & $\begin{array}{l}\text { Microscopic shielded cross sections in fine } \\
\text { energy group structure ( } 51 \text { groups) but } \\
\text { minimized for performance }\end{array}$ & $\begin{array}{l}\text { Microscopic in 2-D lattice physics in hundreds of } \\
\text { groups with 3-D diffusion with macroscopics in } \\
\text { few energy groups (2-3) }\end{array}$ \\
\hline $\begin{array}{l}\text { Pin-by-pin } \\
\text { Powers }\end{array}$ & $\begin{array}{l}\text { Explicit 3-D pin and intra-pin powers on } \\
\text { fine axial mesh with direct capability for } \\
\text { very heterogeneous geometries }\end{array}$ & $\begin{array}{l}\text { 3-D pin average powers reconstructed from 2D } \\
\text { infinite single lattice calculations and nodal } \\
\text { solution. }\end{array}$ \\
\hline $\begin{array}{l}\text { Thermal- } \\
\text { Hydraulics }\end{array}$ & $\begin{array}{l}\text { Directly coupled multi-phase sub-channel } \\
\text { for each flow channel (between fuel rods) } \\
\text { with lateral cross flow }\end{array}$ & $\begin{array}{l}\text { Simplified single-phase lumped channel models } \\
\text { for nodal neutronics with detailed sub-channel } \\
\text { bounding analyses uncoupled }\end{array}$ \\
\hline $\begin{array}{l}\text { Fuel } \\
\text { Mechanics }\end{array}$ & $\begin{array}{l}\text { Directly coupled for intra-pin fuel } \\
\text { temperature feedback and cladding stress } \\
\text { calculations. }\end{array}$ & $\begin{array}{l}\text { Simplified average fuel temperature models for } \\
\text { nodal neutronics with detailed risk analyses } \\
\text { uncoupled }\end{array}$ \\
\hline Instrumentation & $\begin{array}{l}\text { Direct in-core and ex-core instrument } \\
\text { response models }\end{array}$ & $\begin{array}{l}\text { In-core response from 2-D infinite lattice } \\
\text { calculations; no ex-core models }\end{array}$ \\
\hline $\begin{array}{l}\text { Short Lived } \\
\text { Fission Product } \\
\text { Poisons }\end{array}$ & $\begin{array}{l}\text { Explicit pin-by-pin buildup, decay, and } \\
\text { depletion of Xenon and all fission products } \\
\text { via detailed decay chains }\end{array}$ & $\begin{array}{l}\text { Average Xenon and Samarium concentrations } \\
\text { tracked nodally without feedback to pin powers }\end{array}$ \\
\hline $\begin{array}{l}\text { Depletion and } \\
\text { Isotopics }\end{array}$ & $\begin{array}{l}\text { Explicit intra-pin depletion at actual local } \\
\text { spectral conditions, including component } \\
\text { depletion such as control rods and } \\
\text { instrumentation, and tracking all isotopics } \\
\text { explicitly pin-by-pin, including shutdown } \\
\text { decay calculations }\end{array}$ & $\begin{array}{l}\text { Depletion performed explicitly at 2-D lattice } \\
\text { levels for various anticipated spectral and } \\
\text { geometric conditions and pin exposures inferred } \\
\text { at 3-D level from node-average exposure for } \\
\text { approximate spectral conditions. Most isotopics } \\
\text { are not tracked at the core level. }\end{array}$ \\
\hline Spacer Grids & $\begin{array}{l}\text { Direct effects on neutron flux, depletion, } \\
\text { instrument response, coolant pressure } \\
\text { drop, and flow mixing. }\end{array}$ & $\begin{array}{l}\text { Typically not explicitly resolved or included in } \\
\text { neutronics calculations }\end{array}$ \\
\hline $\begin{array}{l}\text { CRUD / } \\
\text { Chemistry }\end{array}$ & $\begin{array}{l}\text { Direct accumulation of CRUD and boron } \\
\text { deposits based on sub-channel steaming } \\
\text { and critical boron calculations, with } \\
\text { feedback to neutronics and depletion }\end{array}$ & $\begin{array}{l}\text { CRUD not modeled directly but assessed for risk } \\
\text { as an uncoupled, post-processing step to the } \\
\text { analyses. }\end{array}$ \\
\hline $\begin{array}{l}\text { Safety } \\
\text { Analysis }\end{array}$ & $\begin{array}{l}\text { Direct calculations for parameters such as } \\
\text { DNB, PCI, CFM, etc }\end{array}$ & $\begin{array}{l}\text { Bounding analyses performed separate from } \\
\text { neutronics, sometimes with manual iteration } \\
\text { between physics }\end{array}$ \\
\hline $\begin{array}{l}\text { Gamma } \\
\text { Transport }\end{array}$ & $\begin{array}{l}\text { 3D gamma transport for local energy } \\
\text { deposition and instrumentation response }\end{array}$ & $\begin{array}{l}\text { Gamma transport in 2-D at the lattice physics } \\
\text { level and included only in the relative pin power } \\
\text { distributions }\end{array}$ \\
\hline $\begin{array}{l}\text { Neutron } \\
\text { Fluence }\end{array}$ & $\begin{array}{l}\text { Direct accumulation in vessel and } \\
\text { structural components for lifetime } \\
\text { evaluations }\end{array}$ & $\begin{array}{l}\text { Approximated from few group nodal flux in } \\
\text { nearest fuel locations, or calculated off-line with } \\
\text { uncoupled particle transport codes }\end{array}$ \\
\hline $\begin{array}{l}\text { Neutron } \\
\text { Sources }\end{array}$ & $\begin{array}{l}\text { Included in the core model for source } \\
\text { range detector response }\end{array}$ & $\begin{array}{l}\text { Typically not included in core simulation } \\
\text { capability }\end{array}$ \\
\hline $\begin{array}{l}\text { User } \\
\text { Interface }\end{array}$ & $\begin{array}{l}\text { Single input and single output format with } \\
\text { common interface to all codes }\end{array}$ & $\begin{array}{l}\text { Multiple uncoupled codes (lattice physics, cross } \\
\text { section tabulation, nodal neutronics, sub-channel, } \\
\text { fuel performance, and chemistry) each with } \\
\text { different input format and user-required domain } \\
\text { knowledge }\end{array}$ \\
\hline $\begin{array}{l}\text { Computer } \\
\text { Resources }\end{array}$ & $\begin{array}{l}\text { Single statepoint calculations in } \sim 60 \\
\text { minutes on } \sim 1000 \text { cores, in quarter } \\
\text { symmetry }\end{array}$ & $\begin{array}{l}\text { Neutronics single statepoint calculations in }<1 \\
\text { minute on } 1 \text { core following a few hours to pre- } \\
\text { tabulate cross sections. Detailed T/H and fuel } \\
\text { mechanics calculated separately. }\end{array}$ \\
\hline
\end{tabular}




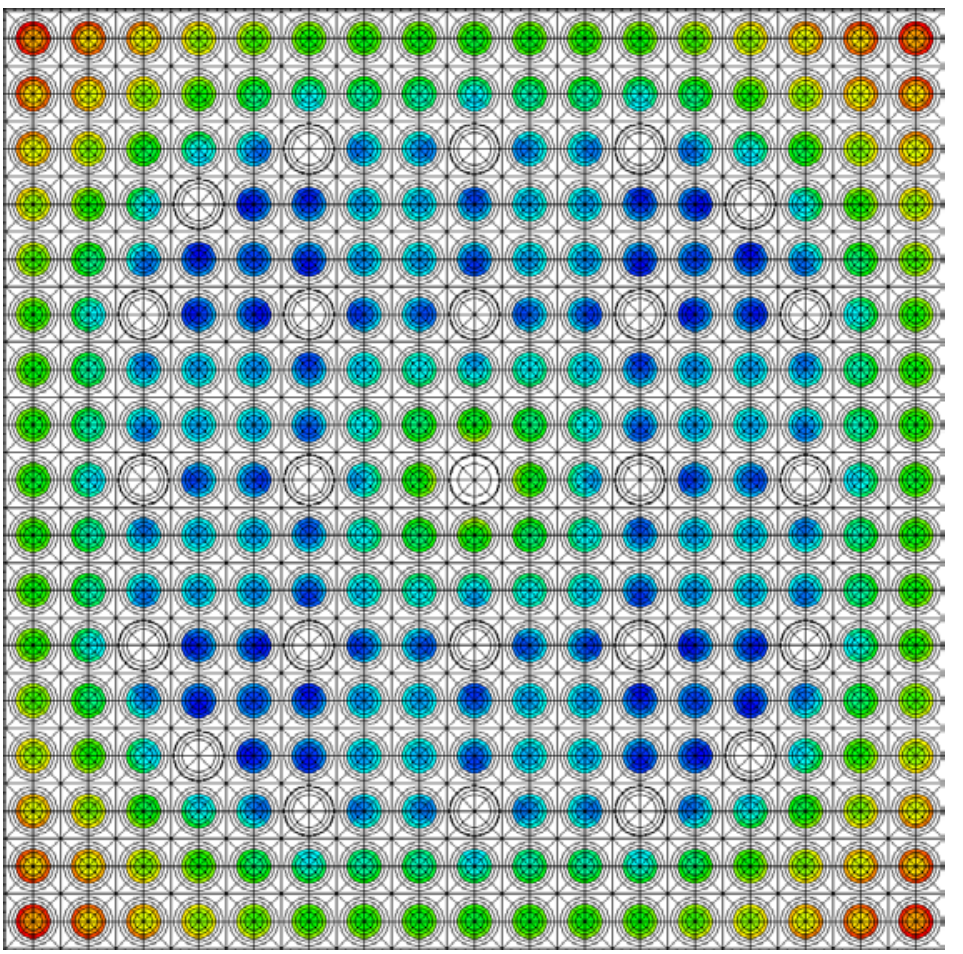

Figure 3-2. Depiction of the MPACT Radial Transport Mesh at each Axial Plane in each Assembly.

The 2-D/1-D method has become popular for many practical reactor calculations because its computational costs are considerably lower than those of full 3-D transport and Monte Carlo based transport methods. The 2-D/1-D equations approximate the 3-D Boltzmann equation more accurately than the conventional 3-D diffusion equation; they preserve exact transport physics in the radial directions, but they use 1-D $P_{N}$ transport in the axial direction. The 2-D/1-D equations can be systematically discretized to yield accurate simulation results for many 3-D reactor core problems. Continued research and development in CASL has led to significant reductions in the frequency of stability issues with the 2-D/1-D method. The success of this is clearly demonstrated by the number of cases and large axial power shape changes accomplished in the WBN2 startup simulations.

Like any deterministic transport solver, the accuracy of the methods in MPACT is highly dependent on the quality of the cross section library. The AMPX code package [10] has been used to develop a significantly improved 51 energy group cross section library based on previous group structures from HELIOS [11]. In order to accommodate higher order scattering accuracy with a transport corrected P0 (TCP0) calculation, transport cross sections have been generated for light nuclides by using various transport correction methods $[12,13]$. Continuous and significant levels of testing and validation have been performed with this new library that provides significant confidence in its accuracy and ability to simulate typical PWR conditions [14]. CASL continuously tests the performance of MPACT for a large variety of problems with continuous-energy Monte Carlo references [6], and recently significant validation of the current MPACT cross section library has been done by comparison to Shift and Serpent continuous-energy 2-D lattice depletions [15]. 


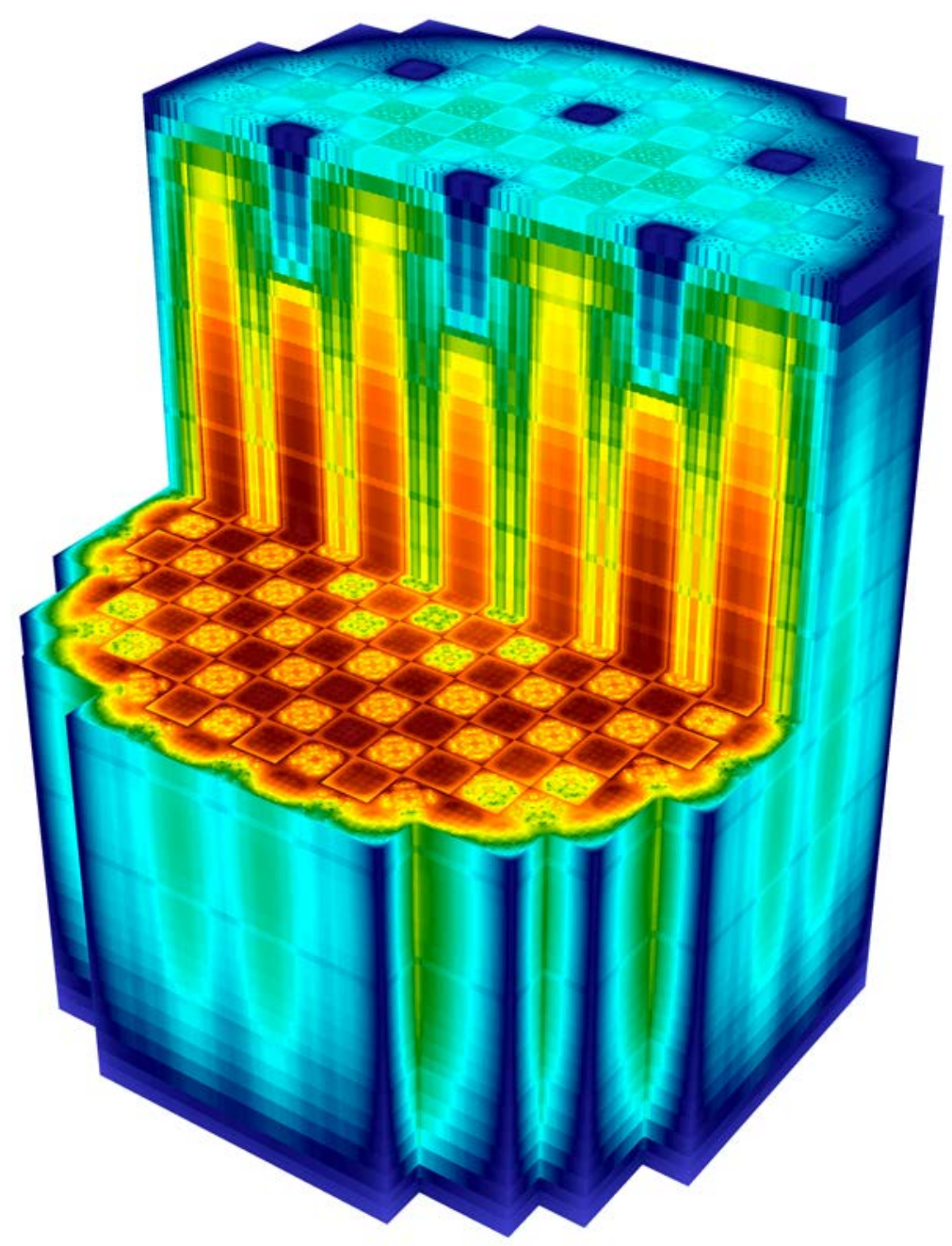

Figure 3-3. The MPACT Fission Rate Distribution for WBN2 at 28\% Power Flux Map.

\subsection{CTF}

CTF is an improved version of the COBRA-TF sub-channel T/H code that uses a transient twofluid, three-field (i.e., liquid film, liquid drops, and vapor) modeling approach to determine the thermodynamic conditions in every coolant channel in the core, including cross-flow effects from turbulent-mixing and lateral pressure gradients. A wide range of flow-regime-dependent closure models are available for capturing complex two-phase flow behavior, which includes rod-to-fluid heat transfer, inter-phase heat and mass transfer, wall and inter-phase drag, and spacer-grid-droplet breakup [16]. The rod-to-fluid heat transfer models were designed to handle the entire boiling curve, including single-phase flow, subcooled and bulk boiling, critical heat flux, and post-critical heat flux heat transfer. It has found many applications before and during the CASL program, including: modeling single-phase normal operating conditions, modeling two-phase flow in accident conditions $[17,18,19,20]$, modeling of BWRs [21], uncertainty quantification [22], and other benchmarking activities [23]. 
The usability of CTF is greatly enhanced by VERA through the use of the simplified VERA common input. A CTF preprocessor automatically generates the entire $\mathrm{T} / \mathrm{H}$ model including all $\sim 56,000$ flow channels in the core such that no specific domain knowledge is required for whole core fuel cycle analyses. Furthermore, recent performance improvements have led to impressive reductions in runtimes for whole core solves. For the WBN2 simulations, a typical statepoint required four neutronic/thermal-hydraulic iterations and about five minutes on 2,784 cores (quartercore). For each statepoint, CTF used only 193 processors (four per assembly) and about 25\% of the clock time, or about 80 seconds per solve. In some cases, such as those later in the convergence process with MPACT, CTF may be able to complete a whole-core solve in just a few seconds. All this is accomplished with channel-wise fidelity and direct local feedback to the neutronics, as demonstrated by Figure 3-4.

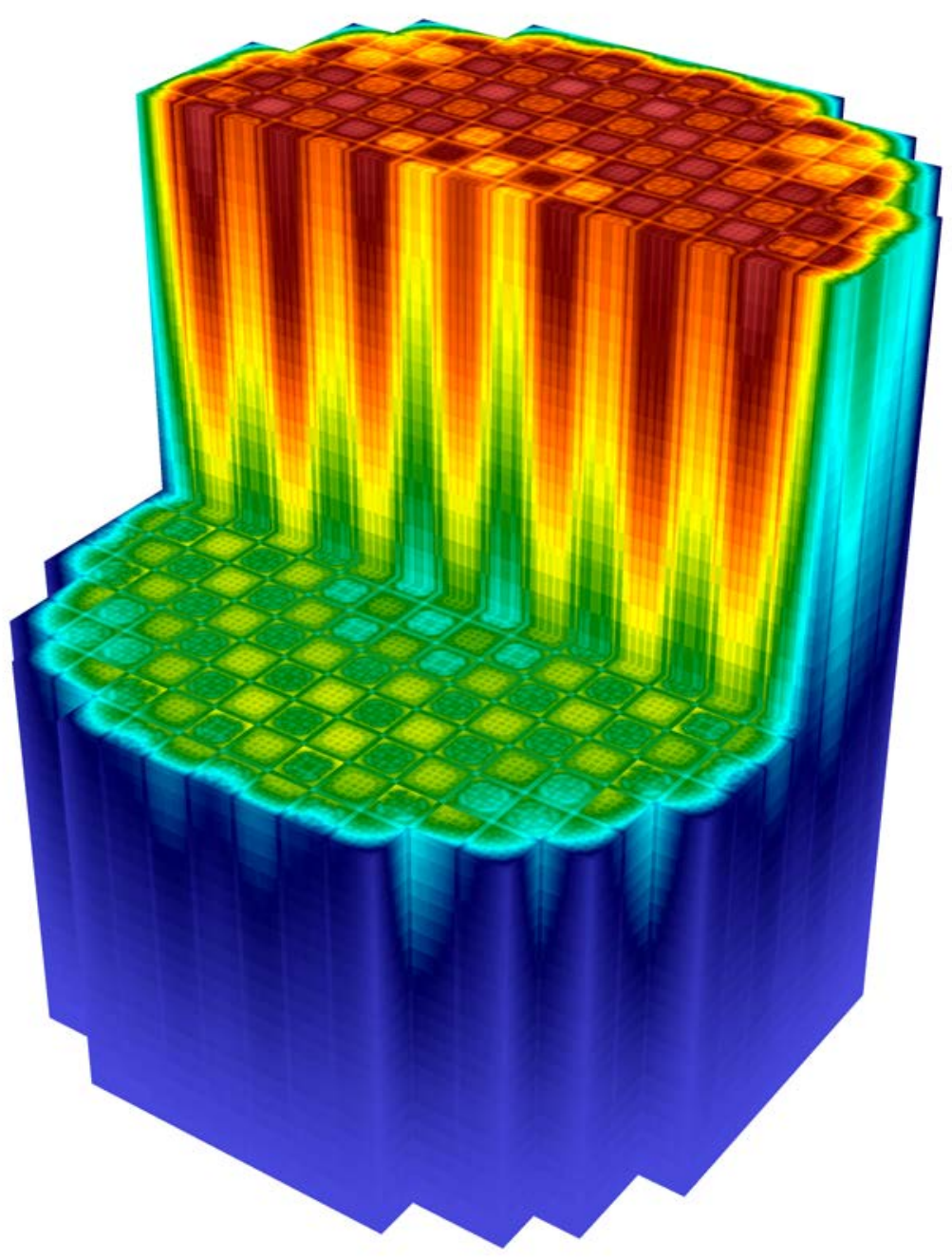

Figure 3-4. The CTF Coolant Temperature Distribution for WBN2 at 28\% Power Flux Map. 


\subsection{ORIGEN}

ORIGEN is a widely used isotopic depletion and decay code in the SCALE 6.2 [24] package with 40 years of application bases. It is capable of generating source terms for accident analyses, characterizing used fuel (including activity, decay heat, radiation emission rates, and radiotoxicity), and activating structural materials [25]. As an integral part of SCALE, ORIGEN has been subject to hundreds of validation cases using measured data from destructive isotopic assays of spent fuel, decay heat of spent fuel, gamma spectra resulting from burst fission, and neutron spectra resulting from spontaneous fission and $(\alpha, n)$ reactions $[26,27]$. In the last few years, a modernization effort has resulted in extensive improvements to the code including a modern application programming interface (API)[28], more efficient software design, and enhanced solvers [29]. The API enables a direct coupling to MPACT for simulation of the fuel depletion and decay in all of the approximately eight million unique depletion regions of the WBN2 reactor core. An optimized 263 nuclide burnup chain for LWRs enables whole core depletion and decay calculations with $1 / 10^{\text {th }}$ of the runtime of the full 2,200 general-purpose chain while preserving such quantities as total energy production, activity, mass, and macroscopic cross sections.

The application of a detailed isotopic depletion and decay code like ORIGEN to a complex power history like the initial startup of WBN2 is unprecedented, especially on this spatial scale. Modern industrial methods are capable of such a calculation only at the 2-D fuel lattice level, but the nature of the macroscopic cross section homogenization means that transient power histories at the core level can only be captured with a few on-the-fly nodal macroscopic corrections (typically ${ }^{135} \mathrm{Xe}$ and ${ }^{149} \mathrm{Sm}$ ). On this scale, it is impossible to capture local power distribution effects for transient fission products, or the combined effects of multiple isotopic changes simultaneously.

For example, consider a control rod withdrawal scenario between a standard industry code that tracks ${ }^{135} \mathrm{Xe}$ on a quarter-assembly basis, versus VERA where it is tracked on an intra-rod basis. When the control rod is moved out of a fuel assembly, the local power increase initially depletes the ${ }^{135}$ Xe before it has time to build back up to equilibrium at the new power level. As demonstrated in Figure 3.5, the fuel rod adjacent to the control rodlet has an initial ${ }^{135}{ }^{X e}$ depletion that is $~ 30 \%$ greater than the average, while the depletion of the ${ }^{135} \mathrm{Xe}$ in the rod farthest from the control rodlet is over $50 \%$ less. This change in ${ }^{135} \mathrm{Xe}$ distribution within the assembly results in increased local power changes compared to modern codes. In this case, the rod with largest decrease in ${ }^{135} \mathrm{Xe}$ also has the largest increase in power level, which is 20\% higher than the power change in the average rod. Clearly this effect is important when considering PCI risks during control rod maneuvering.

Finally, the nodal macroscopic corrections for shutdown isotopic decay in modern industrial methods are also approximate and are designed for single shutdowns after long periods of nominal operation (fuel reloads), rather than repeated periods of shutdowns after short periods of operation like the WBN2 startup. In VERA, ORIGEN is used to explicitly track all 263 isotopes as a function of time in $\sim 8$ million depletion regions. Hourly decay calculations are performed explicitly as part of the simulation to account for localized transient fission product and transuranic decay and production of all isotopes impacting core reactivity after shutdown. Several of the most interesting of these are ${ }^{135} \mathrm{Xe},{ }^{149} \mathrm{Sm},{ }^{239} \mathrm{Pu}$, and ${ }^{105} \mathrm{Rh}$, and long term isotopes ${ }^{155} \mathrm{Gd}$ and ${ }^{241} \mathrm{Am}$. This capability results in very good accuracy and consistency when performing HZP criticality calculations after multiple periods and various durations of being at power and shutdown.

Figure 3-6 demonstrates the detailed ${ }^{135}$ Xe distribution when the reactor was at $28 \%$ of full power for the second power distribution measurement. 

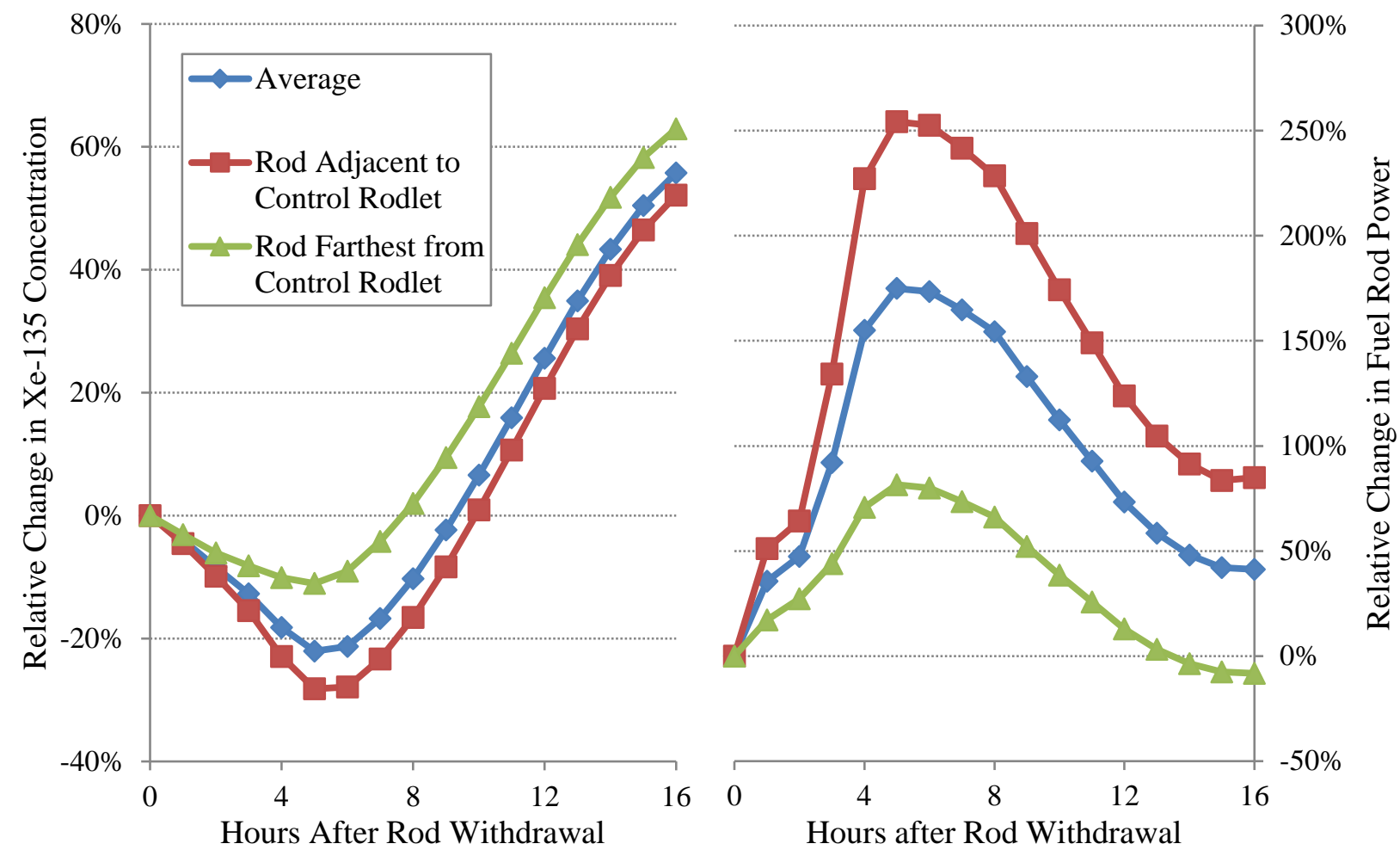

Figure 3-5. Relative Changes in Pin-Wise Xenon-135 and Power Following a RCCA Withdrawal.

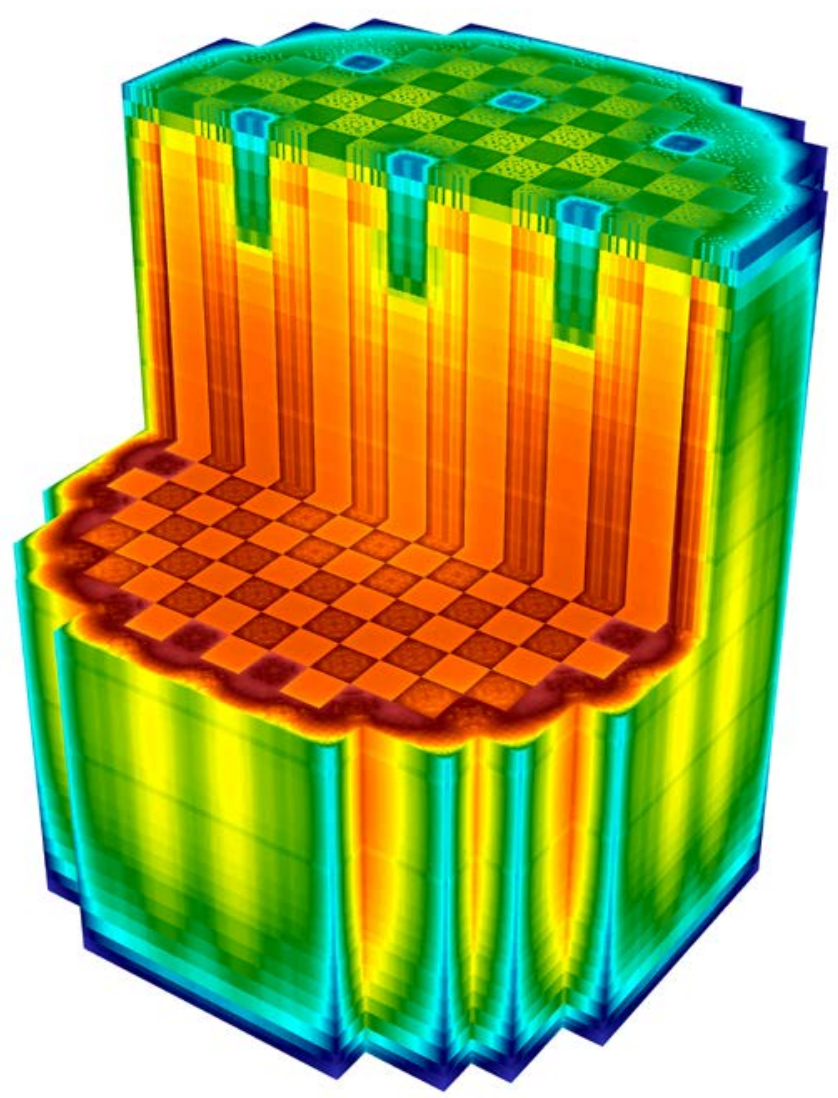

Figure 3-6. The ORIGEN Transient Xe-135 Distribution for WBN2 at 28\% Power Flux Map. 


\subsection{BISON}

BISON is an advanced fuel rod performance code for calculating the fuel thermomechanical behavior during normal operation and transients of LWRs, based on the Multiphysics ObjectOriented Simulation Environment (MOOSE) framework developed at Idaho National Laboratory (INL). MOOSE is a massively parallel finite element computational system that uses a Jacobianfree, Newton-Krylov method for solving partial differential equations. BISON leverages the MOOSE capabilities to model a single fuel rod in 2-D full-length R-Z or planar R- $\theta$ geometric representations, as well as local effects 3-D models [30,31]. BISON uses detailed physics-based material models for $\mathrm{UO}_{2}$ fuel and zirconium alloys consisting of irradiation induced clad creep and growth, clad corrosion, hydrogen pickup and hydride precipitation in the clad, and the release and transport of fission gases.

The fuel mechanics coupling between BISON, MPACT, and CTF is currently under development with plans for initial applications in FY18. For this analysis, BISON was used to pre-generate correlations of volume-average fuel temperature as a function of fuel rod linear heat rate and exposure, which are used by MPACT to determine the local fuel rod temperature at all locations in the reactor. This is considered an improvement when compared to use of the current CTF fuel rod conduction model because the correlations can effectively account for fuel rod burnup effects on pellet-clad gap closure, fission gas release, and the evolution and degradation of material properties (e.g., $\mathrm{UO}_{2}$ thermal conductivity)[5]. The fuel temperature correlation employed by MPACT uses the following form:

$$
T_{\text {fuel }}=T_{\text {mod }}+a(\exp ) \times P+b(\exp ) \times P^{2}
$$

where $T_{\text {mod }}$ is the local coolant temperature from CTF, $a$ and $b$ are burnup-dependent constants, and $P$ is the fuel rod local linear heat deposition rate. The coefficients were generated for Westinghouse RFA fuel for WBN1 using results from BISON and were reused for this analysis. Examples of these temperatures are shown in Figure 3-7, based on a moderator temperature of $585 \mathrm{~K}$, and with burnups ranging from 0 to $10 \mathrm{GWd} / \mathrm{MTU}$. However, these temperatures were modified to improve the axial power stability for the power ascension simulation, as described in Section 4.5.5.

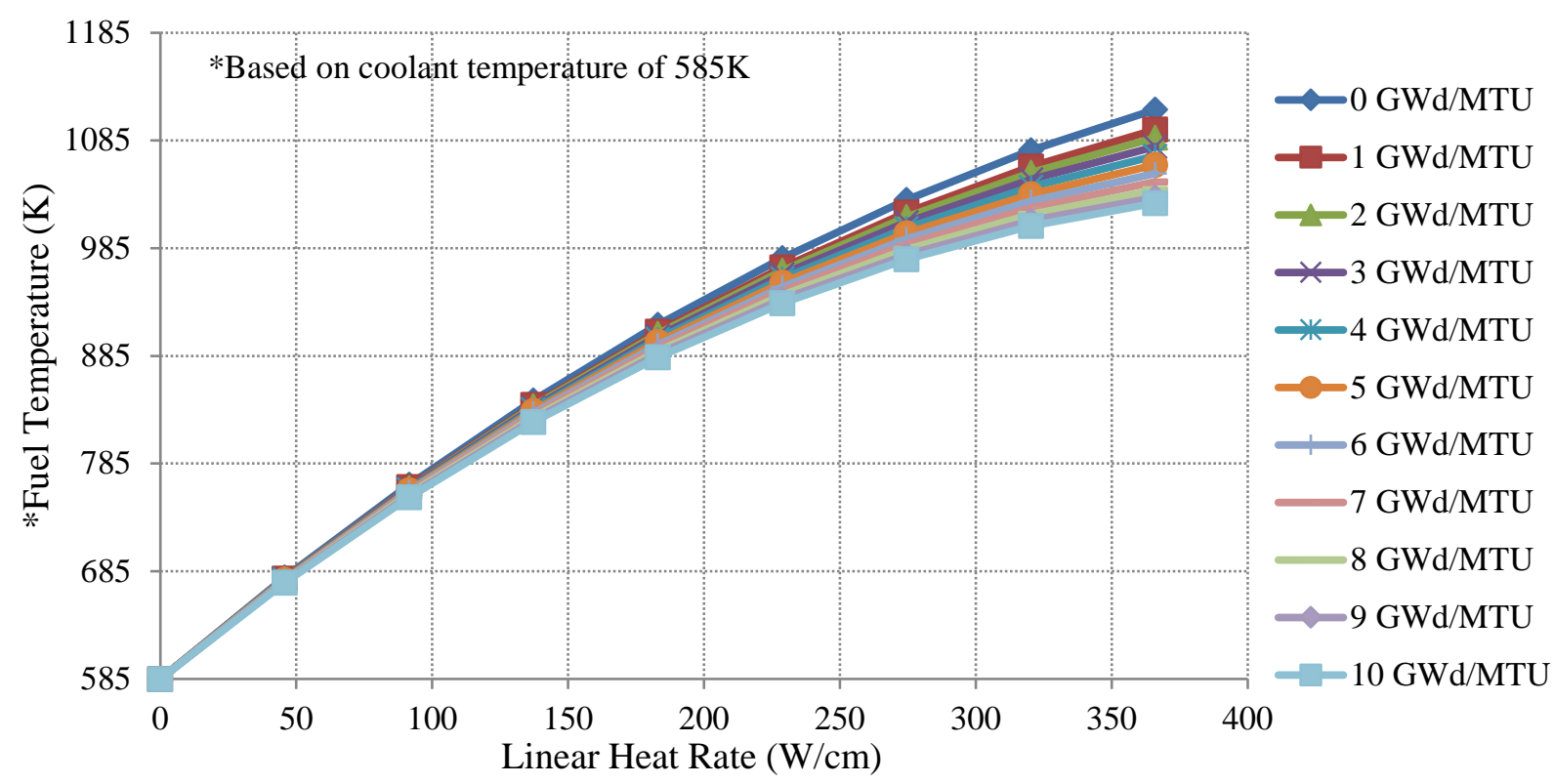

Figure 3-7. Original BISON Fuel Temperature Model for RFA Fuel [5]. 


\subsection{Shift}

Shift is a massively parallel, continuous-energy Monte Carlo radiation transport code within VERA that has been designed and optimized for reactor applications on leadership class high performance computers (HPC). For CASL it employs a high-speed internal geometry package for light water reactors (LWRs) for solving both multi-group and continuous-energy neutron, photon, and coupled neutron-photon transport problems. The continuous-energy physics model, an implementation of the physics used in CE-KENO, provides a high fidelity reference solution for comparison to MPACT's deterministic multi-group solutions [32]. Reactor models in Shift are constructed from the same simple VERA input used by the other physics codes and fission rate tallies and estimated uncertainties are written to the same pin-wise output format as MPACT and CTF.

Both fixed-source and eigenvalue solutions can be obtained for the reactor dependent on the application and available resources. Stand-alone k-eigenvalue cases have been executed on OLCF's Titan supercomputer [33] using up to 300,000 processors and over a trillion particle histories. New development, however, will enable coupled fast running ex-core neutron and photon fluence calculations using the fission source distribution from MPACT on a time and power-dependent basis. This capability will also be extended to ex-core detector response calculations, where Shift can employ several Monte Carlo variance reduction techniques, and will be capable of calculating a detector adjoint solution for any reactor operating condition.

Recently Shift has undergone extensive verification and validation by performing both experimental and code-to-code comparisons. Eigenvalues, pin powers, and rod worth have been benchmarked against the B\&W 1810 critical experiments, as well as the initial startup physics testing for WBN1. Additionally, Westinghouse utilized Shift for comparison to CE KENO-VI for its new AP1000 ${ }^{\circledR}$ reactor, and excellent agreement between the two codes was obtained [34,35]. A depletion capability has also been added to Shift and excellent agreement in 2-D lattice eigenvalue and pin powers was obtained with the continuous-energy Monte Carlo depletion code Serpent, with eigenvalue differences of about 50 pcm (Figure 3-8) and pin power distributions of $0.05 \%$ RMS over the life of the depleted assemblies [15].

At the time of this report, the Shift coupling to MPACT is under development and testing so its results for WBN2 are limited to the BOC HZP criticality and startup physics testing. In the future it will be used while coupled to MPACT to account for the depletion and transient fission products for the criticality measurements after each shutdown, and for the flux map conditions as well. This work will be published at a later date.

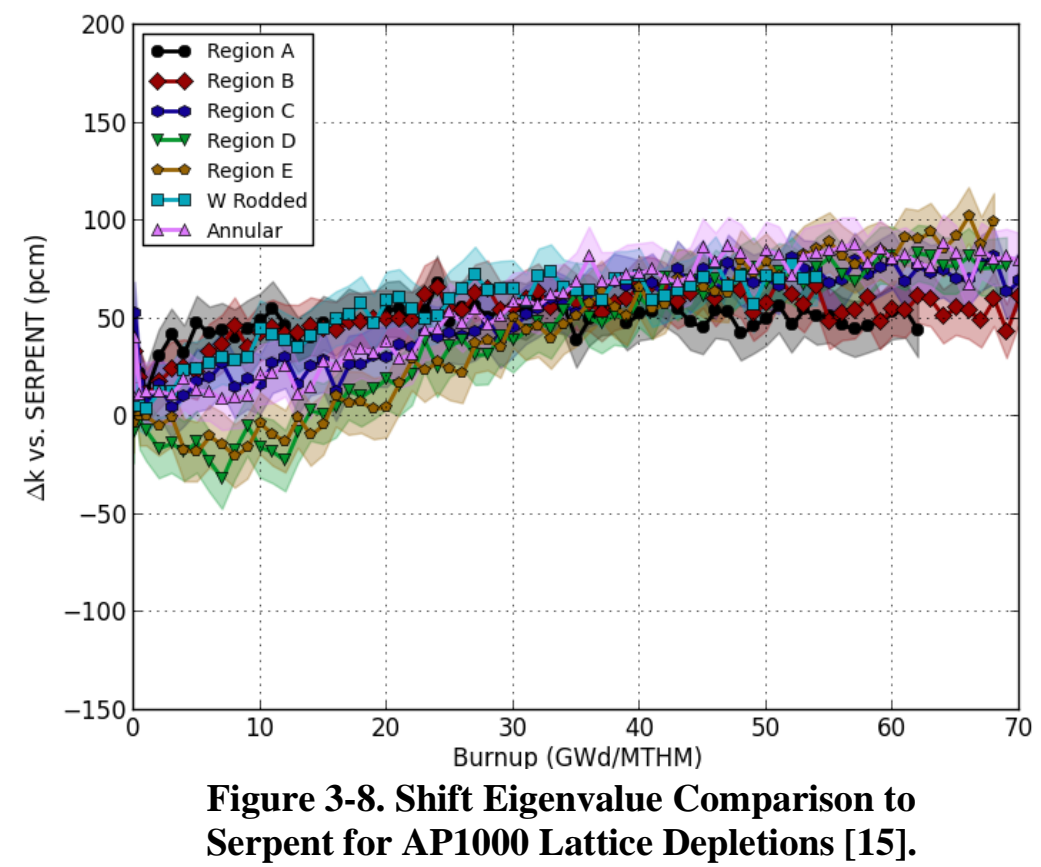




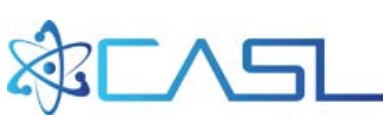

\section{RESULTS}

\subsection{Initial Criticality}

WBN2 first achieved criticality at 2:14 AM on May 23, 2016 by dilution of the primary coolant system (reducing the soluble boron concentration) and withdrawal of the regulating control rod bank (Bank D. The measured boron "endpoint” following complete Bank D withdrawal was 1089 ppmB, with a measured ${ }^{10} \mathrm{~B}$ abundance of 19.76 at\%. Comparisons to results from VERA, including the values predicted on March 1, 2016, but adjusted to the measured ${ }^{10} \mathrm{~B}$ content, are included in the table below. The original predicted values were from an older version of VERA with a previous cross section library, but are included here as evidence of the predictive capability of VERA when used in a blind test (See Appendix A). The Shift result is calculated by eigenvalue calculation but converted to a boron difference using the MPACT calculated boron worth.

Table 4-1. Initial ARO Critical Boron Results

\begin{tabular}{lcc}
\hline & $\begin{array}{c}\text { Critical Boron } \\
\text { Concentration (ppmB) }\end{array}$ & Difference (ppmB) \\
\hline Measured & 1089 & -- \\
Original Prediction & 1072 & $\mathbf{- 1 7}$ \\
Latest MPACT & 1087 & $\mathbf{- 2}$ \\
Shift & 1087 & $\mathbf{- 1}$ \\
\hline
\end{tabular}

Though all results are good, recent enhancements in the MPACT cross section library have improved consistency with continuous-energy Monte Carlo results, resulting in excellent agreement with the initial plant measurement of criticality conditions. The measurement uncertainty is assumed to be approximately 5 ppmB, plus uncertainty in the measured ${ }^{10} \mathrm{~B}$ abundance.

\subsection{Control Bank Worth Measurements}

Following initial criticality, WBN2 commenced with typical startup physics testing in which control banks worth and the temperature coefficient of reactivity were measured. Bank worth measurements were performed using the Dynamic Rod Worth Measurement (DRWM) technique, in which the control banks are moved quickly in and out of the reactor core individually, and a reactivity computer estimates the reactivity worth from the ex-core detector response and time-dependent kinetics data provided by licensed core design methods. The VERA bank worths were performed instead by calculation of steady-state eigenvalues with each bank fully inserted and fully withdrawn. The table below provides the measured, original predictions, and latest VERA bank worths and their relative errors compared to measurements. The total bank worth is simply the sum of the individual bank values.

The Shift calculations were performed with 10 billion particles histories, using 2000 cycles and 500 inactive cycles. This required approximately 30 minutes on OLCF's Titan using 10,000 cores each, and resulting in a reported eigenvalue uncertainty of $1.1 \mathrm{pcm}$. 
Table 4-2. Control Bank Worth Results

\begin{tabular}{lc|ccc|ccc}
\hline $\begin{array}{l}\text { Control } \\
\text { Bank }\end{array}$ & $\begin{array}{c}\text { Measured } \\
(\mathrm{pcm})\end{array}$ & $\begin{array}{c}\text { Original } \\
\text { Prediction } \\
(\mathrm{pcm})\end{array}$ & $\begin{array}{c}\text { Latest } \\
\text { MPACT } \\
(\mathrm{pcm})\end{array}$ & $\begin{array}{c}\text { Shift } \\
(\mathrm{pcm})\end{array}$ & $\begin{array}{c}\text { Original } \\
\text { Prediction } \\
\text { Error }\end{array}$ & $\begin{array}{c}\text { Latest } \\
\text { VERA } \\
\text { Error }\end{array}$ & $\begin{array}{c}\text { Shift } \\
\text { Error }\end{array}$ \\
\hline Bank D & 1304 & 1320 & 1311 & 1322 & $1.2 \%$ & $0.5 \%$ & $1.4 \%$ \\
Bank C & 1061 & 1078 & 1065 & 1076 & $1.6 \%$ & $0.4 \%$ & $1.4 \%$ \\
Bank B & 794 & 821 & 815 & 816 & $3.4 \%$ & $2.6 \%$ & $2.7 \%$ \\
Bank A & 910 & 912 & 904 & 913 & $0.2 \%$ & $-0.6 \%$ & $0.3 \%$ \\
Bank SD & 438 & 452 & 451 & 449 & $3.3 \%$ & $3.0 \%$ & $2.6 \%$ \\
Bank SC & 447 & 452 & 450 & 450 & $1.0 \%$ & $0.7 \%$ & $0.6 \%$ \\
Bank SB & 1056 & 1072 & 1063 & 1070 & $1.5 \%$ & $0.7 \%$ & $1.4 \%$ \\
Bank SA & 424 & 420 & 420 & 415 & $-1.0 \%$ & $-1.1 \%$ & $-2.1 \%$ \\
Total & $\mathbf{6 4 3 5}$ & $\mathbf{6 5 2 6}$ & $\mathbf{6 4 7 8}$ & $\mathbf{6 5 1 2}$ & $\mathbf{1 . 4 \%}$ & $\mathbf{0 . 7 \%}$ & $\mathbf{1 . 2 \%}$ \\
St. Dev. & & & & & $\mathbf{1 . 4 \%}$ & $\mathbf{1 . 4 \%}$ & $\mathbf{1 . 5 \%}$ \\
\hline
\end{tabular}

The bank worth are excellent. The measurement uncertainty is unknown, but differences in measurement and calculation technique, as well as the source of kinetics data used for the online calculation, could easily lead to uncertainties on the order of a few percent. Acceptance criteria is typically $15 \%$ for a single bank, and $10 \%$ for the total worth, and the criteria for low worth banks can be even greater. Therefore, these results are considered to be excellent for this type of benchmark.

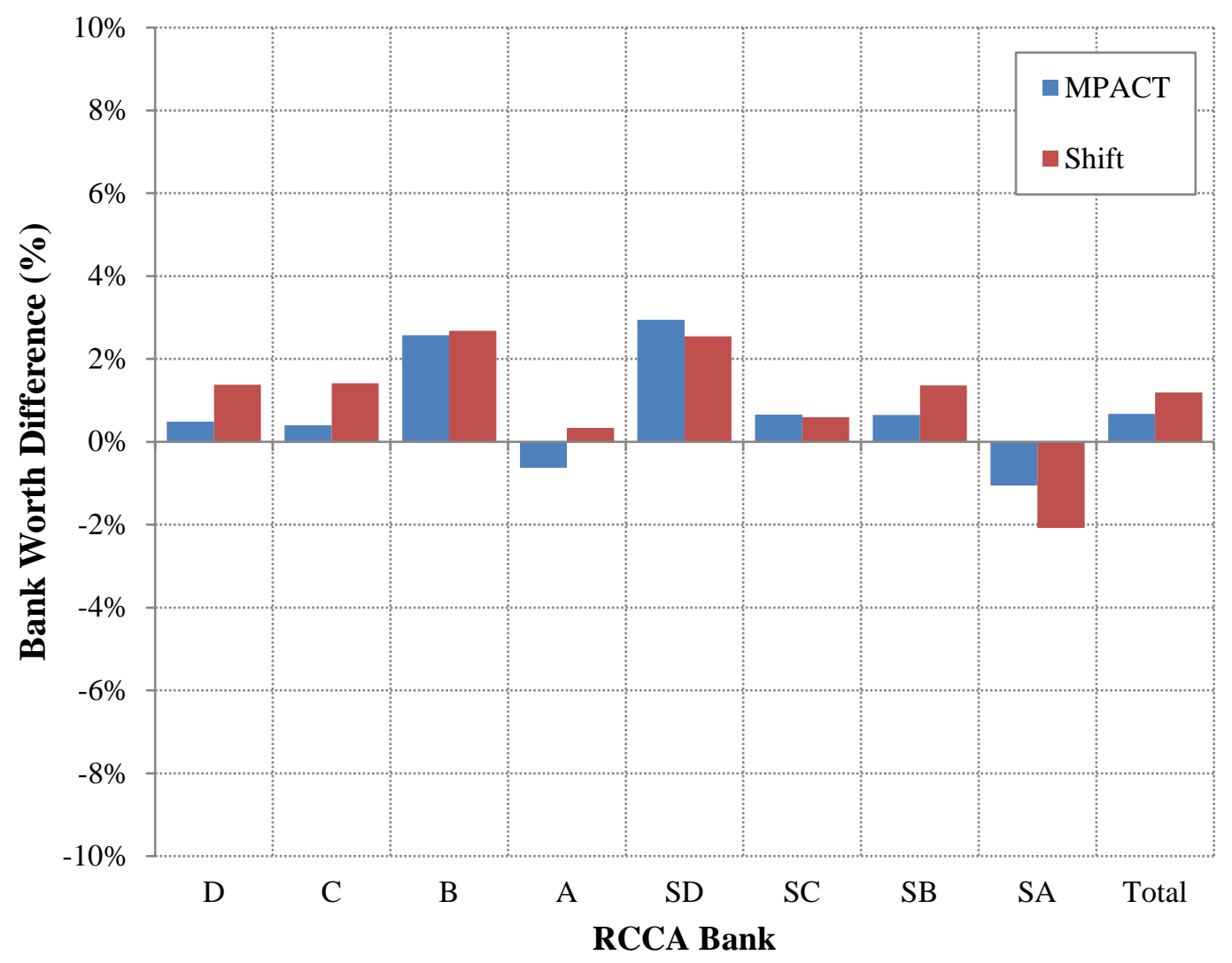

Figure 4-1. Control Rod Bank Worth Errors (\%). 


\subsection{Isothermal Temperature Coefficient}

The WBN2 Isothermal Temperature Coefficient (ITC) was calculated by reactivity measurement during small perturbations in primary coolant temperature. The amount of temperature change (one heatup and one cooldown) was approximately $\pm 1^{\circ} \mathrm{F}$. The original prediction with VERA was based on $\pm 5^{\circ} \mathrm{F}$ perturbations, while the latest result is based on the actual temperature variations.

Table 4-3. Isothermal Temperature Coefficient Results

\begin{tabular}{|c|c|c|}
\hline & $\begin{array}{l}\text { Coefficient } \\
\left(\mathrm{pcm} /{ }^{\circ} \mathrm{F}\right)\end{array}$ & $\begin{array}{c}\text { Difference } \\
\left(\mathrm{pcm} /{ }^{\circ} \mathrm{F}\right)\end{array}$ \\
\hline Measured & -5.3 & -- \\
\hline Original Prediction & -6.1 & -0.8 \\
\hline Latest MPACT & -6.1 & -0.8 \\
\hline
\end{tabular}

These results show good agreement with the plant data, and are well within the typical acceptance criteria of $2 \mathrm{pcm} /{ }^{\circ} \mathrm{F}$. However, recent development efforts have identified a potential error in the cross section library related to temperature dependence that when corrected should slightly improve these results.

Note that Shift results are not available for the ITC prediction because of challenges with consistently calculating eigenvalues with smaller temperature changes in the continuous-energy data. This is ongoing development and comparisons will be made at a later date.

\subsection{HZP Criticality Results}

During the course of the WBN2 power ascension testing, there were ten additional periods of reactor shutdown followed by reestablishing the reactor criticality. The description of these shutdowns is given in Section 2.2. Their lengths varied from approximately 2 to 25 days, providing a variety of transient fission product conditions for comparison. In order to accurately calculate the reactivity of each configuration, VERA was used to explicitly track the decay and production of all important isotopes through the reactor shutdown, the most important of which (in terms of reactivity) are

${ }^{135} \mathrm{Xe},{ }^{149} \mathrm{Sm}$, and ${ }^{239} \mathrm{Pu}$. At the end of each outage, the critical soluble boron concentrations are compared between VERA and measurement, at HZP isothermal conditions with measured inlet temperatures and RCCA positions. Figure 4-2 shows the PAT power history along with the points used for these HZP comparisons. 


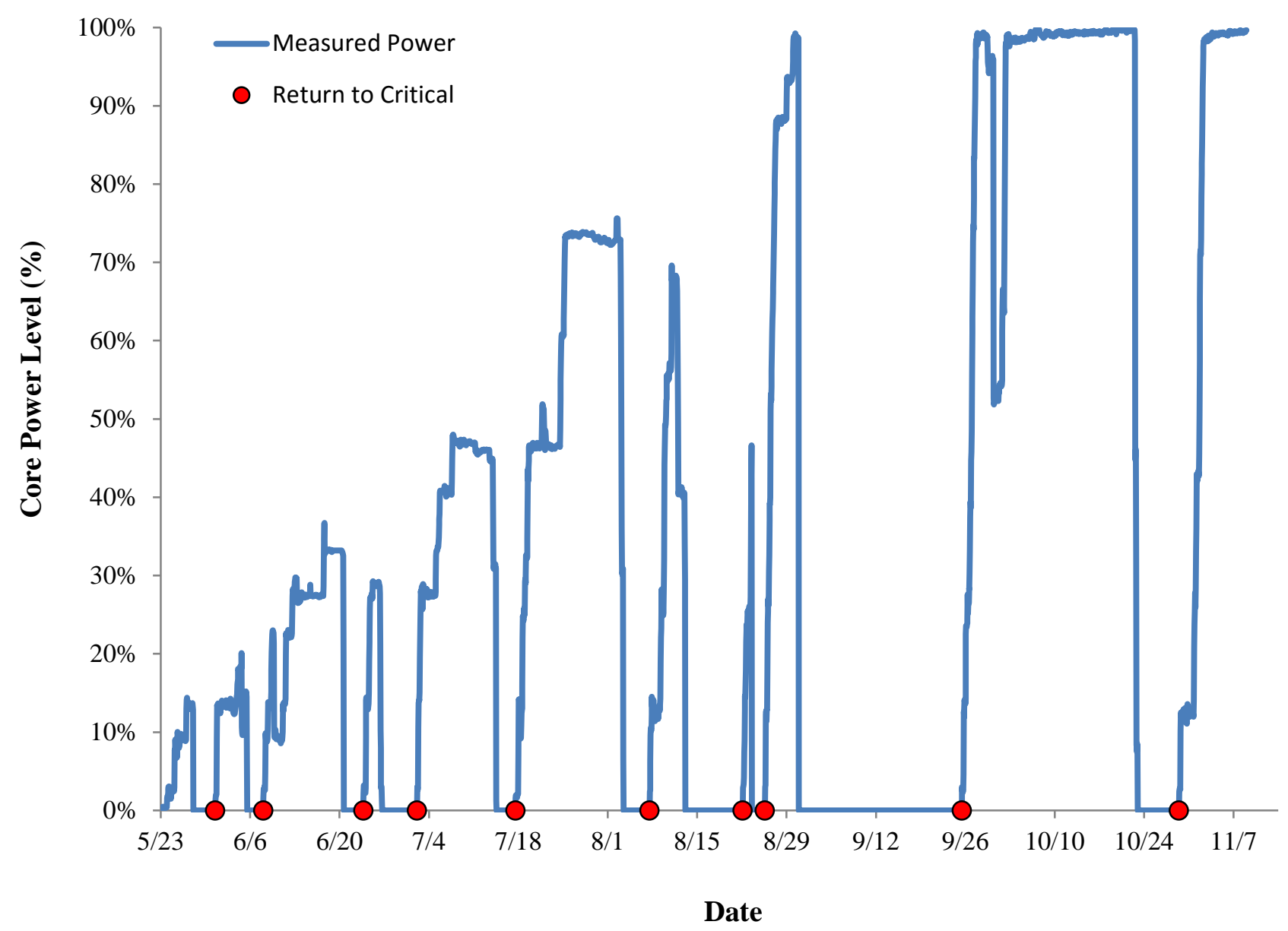

Figure 4-2. WBN2 Power History Showing Dates of Return to Criticality.

Another complexity with these comparisons is determining the measured ${ }^{10} \mathrm{~B}$ abundance in the coolant. Because some of the measurements occurred several months into operation, the soluble boron had become slightly depleted, but also experienced some replenishment during each period of shutdown. Samples from the primary coolant were only analyzed monthly for ${ }^{10} \mathrm{~B}$ content, and if those measurements were not taken during the outage then an estimate must be made. For these results, the ${ }^{10} \mathrm{~B}$ abundance is assumed to be between 19.60 and 19.76 at\%, which in this case could be worth up to a 9 ppmB difference in critical boron concentration. Section 4.5.9 discusses the ${ }^{10} \mathrm{~B}$ depletion model used in more detail.

Table 4-4 provides the measured and calculated critical boron comparisons (at estimated ${ }^{10} \mathrm{~B}$ abundance) for each HZP criticality measurement, and includes the cycle exposure, rod position, and approximate outage length.

Note that Shift is currently unable to perform these criticality calculations with depleted fuel and/or transient fission products. However, the development and testing of a direct coupling between MPACT and Shift is currently underway and soon these results can also be used to benchmark the Shift capability as well. 
Table 4-4. HZP Critical Boron Concentrations

\begin{tabular}{ccccccc}
\hline & $\begin{array}{c}\text { Cycle } \\
\text { Exposure } \\
\text { Date and Time }\end{array}$ & $\begin{array}{c}\text { Bank D } \\
\text { Position } \\
\text { (steps) }\end{array}$ & $\begin{array}{c}\text { Outage } \\
\text { Length } \\
\text { (days) }\end{array}$ & $\begin{array}{c}\text { Measured } \\
\text { (ppmB) }\end{array}$ & $\begin{array}{c}\text { VERA } \\
\text { (ppmB) }\end{array}$ & $\begin{array}{c}\text { Difference } \\
\text { (ppmB) }\end{array}$ \\
\hline 5/31/2016 13:16 & 13 & 147 & 3.5 & 1051 & 1048 & $\mathbf{- 3}$ \\
6/8/2016 2:00 & 38 & 134 & 2.6 & 1036 & 1032 & $\mathbf{- 4}$ \\
6/23/2016 18:11 & 153 & 124 & 3.1 & 1017 & 1012 & $\mathbf{- 5}$ \\
7/2/2016 3:42 & 176 & 130 & 5.5 & 1026 & 1019 & $\mathbf{- 7}$ \\
$7 / 17 / 201614: 00$ & 361 & 134 & 3.1 & 1021 & 1014 & $\mathbf{- 7}$ \\
8/7/2016 12:55 & 730 & 136 & 4.1 & 1043 & 1033 & $\mathbf{- 1 0}$ \\
8/22/2016 3:45 & 810 & 137 & 9.0 & 1056 & 1043 & $\mathbf{- 1 3}$ \\
8/25/2016 15:06 & 821 & 140 & 2.0 & 1030 & 1022 & $\mathbf{- 8}$ \\
\hline 9/25/2016 10:40 & 974 & 149 & 25.5 & 1061 & 1059 & $\mathbf{- 2}$ \\
10/29/2016 11:00 & 1921 & 96 & 6.5 & 1061 & 1053 & $\mathbf{- 8}$ \\
\hline Average & & & & & & $\mathbf{- 7}$ \\
\hline St. Dev. & & & & & & $\mathbf{3 . 3}$ \\
\hline
\end{tabular}

These results are an excellent benchmark of VERA's capability for hourly isotopic depletion and decay, without the additional complexity of thermal-hydraulic feedback and temperature dependences. Over the many HZP criticality comparisons, VERA is only 7 ppmB low on average and displays consistency with only a $3.3 \mathrm{ppmB}$ standard deviation. Assuming a boron measurement uncertainty of $5 \mathrm{ppmB}$ and an additional $5 \mathrm{ppmB}$ uncertainty from estimating the ${ }^{10} \mathrm{~B}$ abundance of each case, these results appear to be excellent and are significantly within the typical acceptance criteria of $50 \mathrm{ppmB}$.

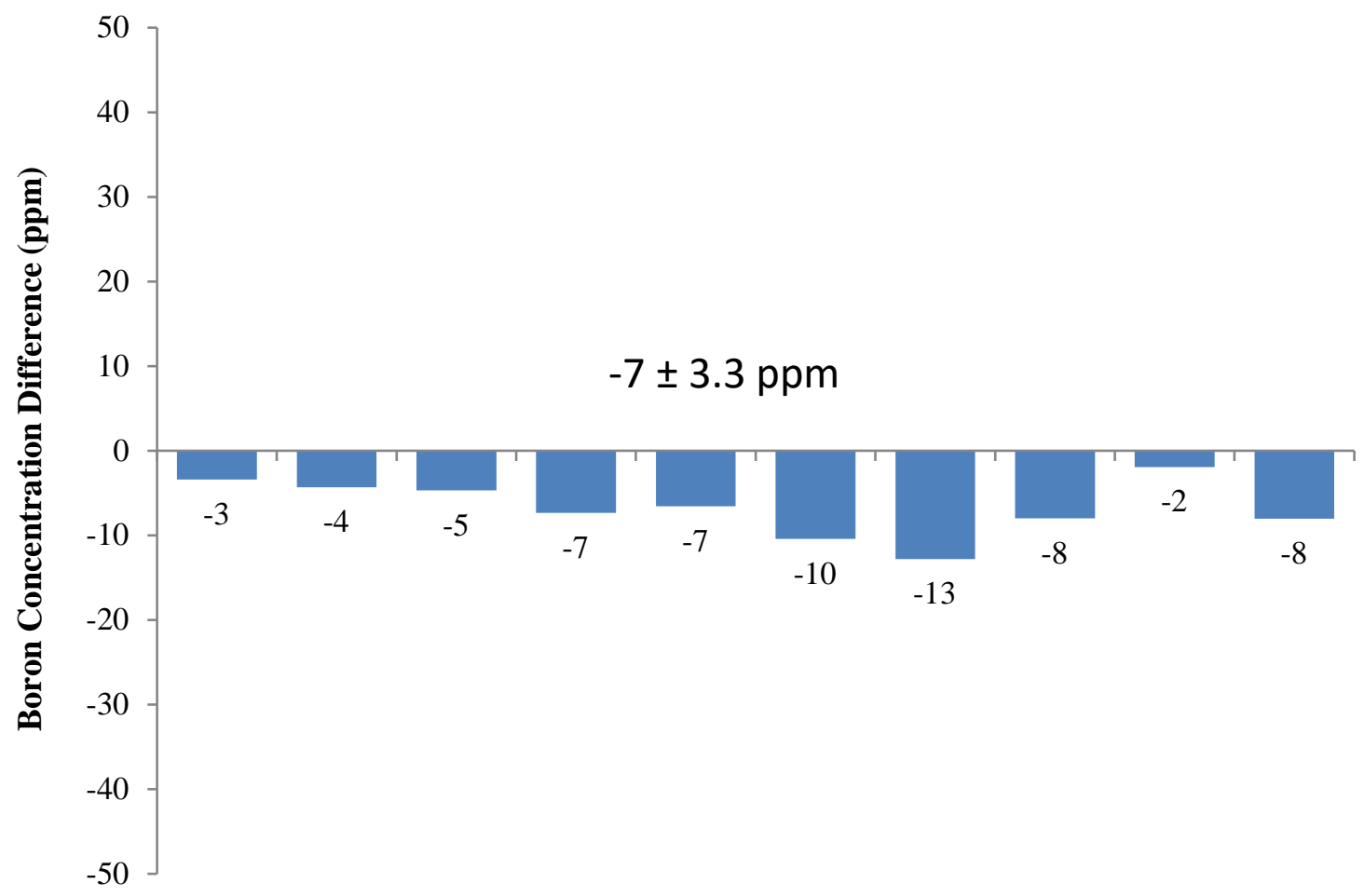

Figure 4-3. WBN2 Critical Boron Differences following each Shutdown. 


\subsection{Power Ascension Testing Results}

The complete power ascension to commercial operation was simulated with VERA in order to accurately capture the burnup distribution and transient fission product conditions throughout the operating history. This activity was also an opportunity to test VERA for a very large and rigorous time-dependent benchmark and assess its stability and performance. TVA provided complete reactor conditions by the hour, including power level, control rod position, and inlet temperatures. Calculated parameters from the site were also provided, including average coolant temperature, excore axial flux difference (AFD), and cycle burnup. Finally, soluble boron concentration measurements were provided at an approximately daily interval, and corresponding ${ }^{10} \mathrm{~B}$ values were provided approximately monthly for reactivity comparisons. In total, about 170 days of hourly operating data was obtained for WBN2, covering a period of five and a half months and 58 effective full power days (EFPDs).

The VERA simulation of the startup consisted of hourly inputs of core relative power, Bank D position, and average inlet temperature as a function of time. The calculation was divided into 35 jobs, connected by restart files. The transient fission product distribution was determined directly by ORIGEN, during both depletion and outage decay periods. The entire simulation was performed using quarter-core symmetry, without inclusion of the in-core detector thimbles or neutron source rods, which would produce a slightly asymmetric radial power distribution. A summary of the final computational performance parameters is shown below, along with a breakdown of the runtimes by component for a typical hourly power ascension case.

Table 4-5. Power Ascension Testing Computer Performance

\begin{tabular}{lc}
\hline Total Number of Jobs & 35 \\
Total Number of Statepoints & 4,130 \\
Total Number of MPACT/CTF Iterations & 16,605 \\
Average Iterations per Statepoint & 4.0 \\
Total Wall Time & 13.5 days \\
Total Number of Core-Hours & 892,837 core-hours \\
Average Wall Time per Statepoint & 4.7 mins \\
Typical number of cores utilized & 2,784 \\
\hline
\end{tabular}

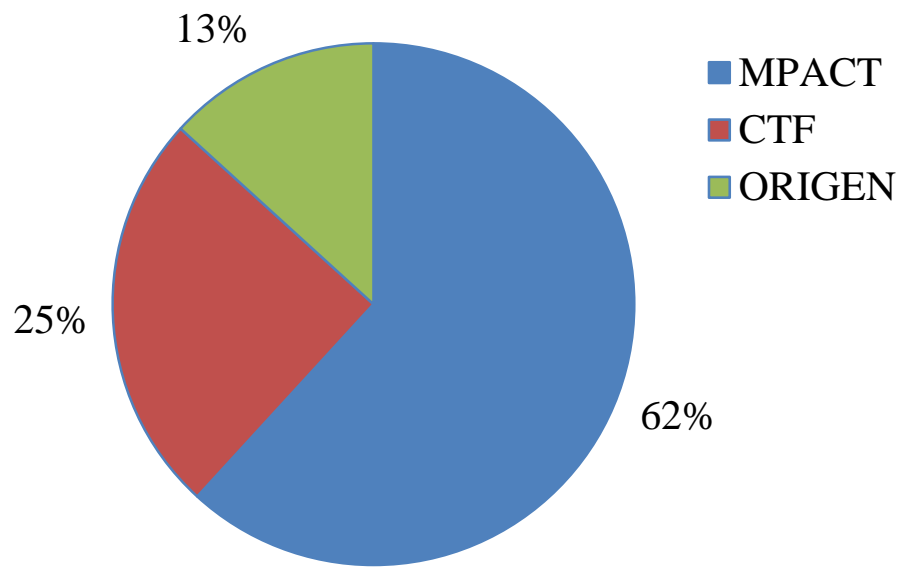

Figure 4-4. VERA Power Ascension Runtime Fractions by Component. 


\subsubsection{Reactor Thermal Power}

WBN2 Cycle 1 is rated at $3411 \mathrm{MW}_{\text {th. The }}$ complete history for the power ascension was provided by TVA and modeled rigorously in VERA, as shown in the figure below, resulting in over 4,000 time steps is provided in the figure below. Note that there are ten reactor shutdowns during the startup sequence.

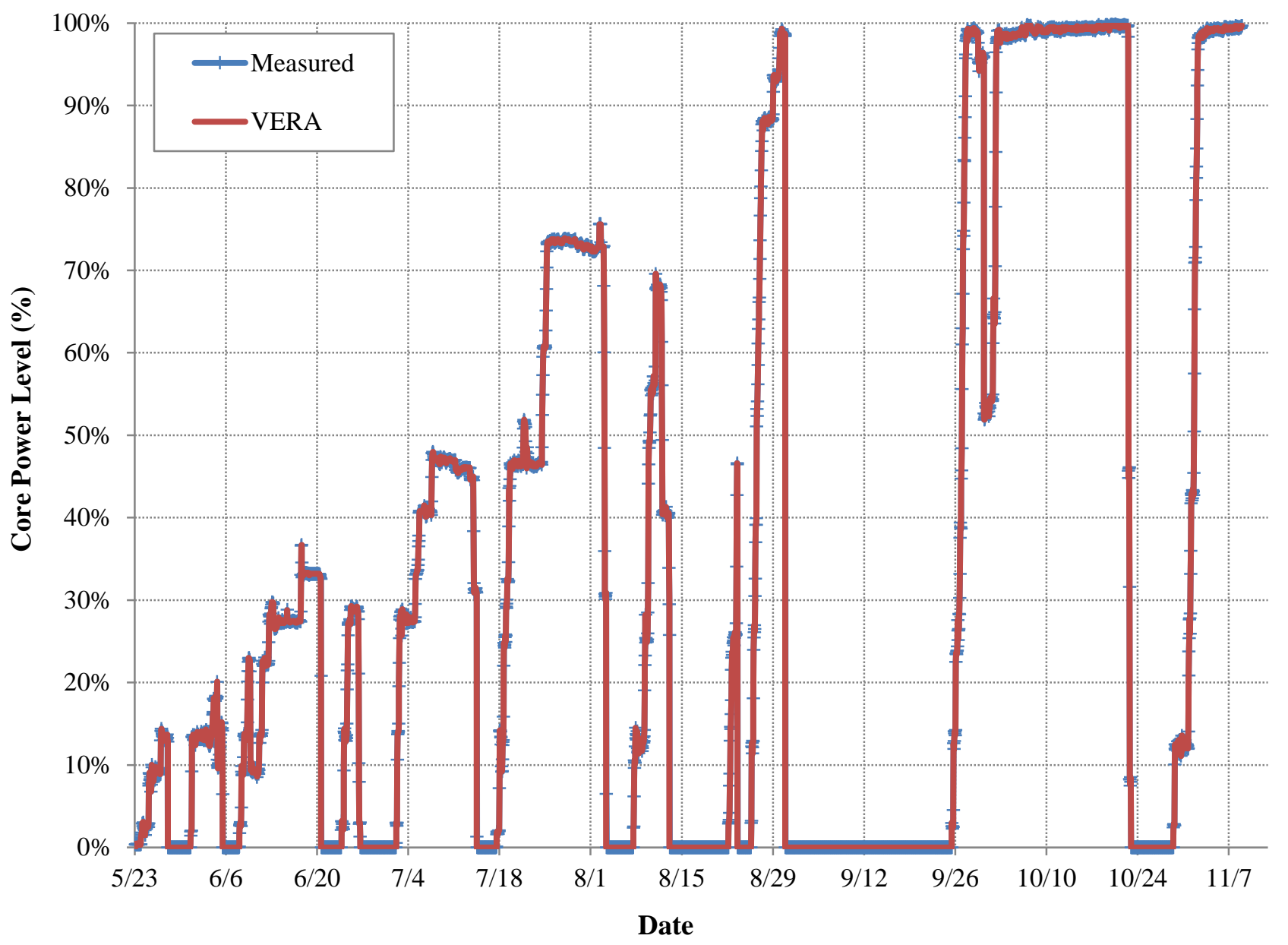

Figure 4-5. Core Power History (\% of Rated Power). 


\subsubsection{Control Bank D Position}

Bank D is the regulating RCCA bank and moves in integer notch positions between 0 and 231 steps withdrawn. At 224 steps and above, the control rod position material is outside of the active fuel region. The Bank D position was provided by TVA for each hour of the power ascension and input directly into the input for VERA. All other other banks are fully withdrawn. The complete Bank D history is provided in the figure below, with both the WBN2 data and VERA positions coinciding perfectly for all times when the reactor is critical. During the ten shutdown periods, the reactor is made subcritical by insertion of many control banks, but this was not needed for the VERA simulation.

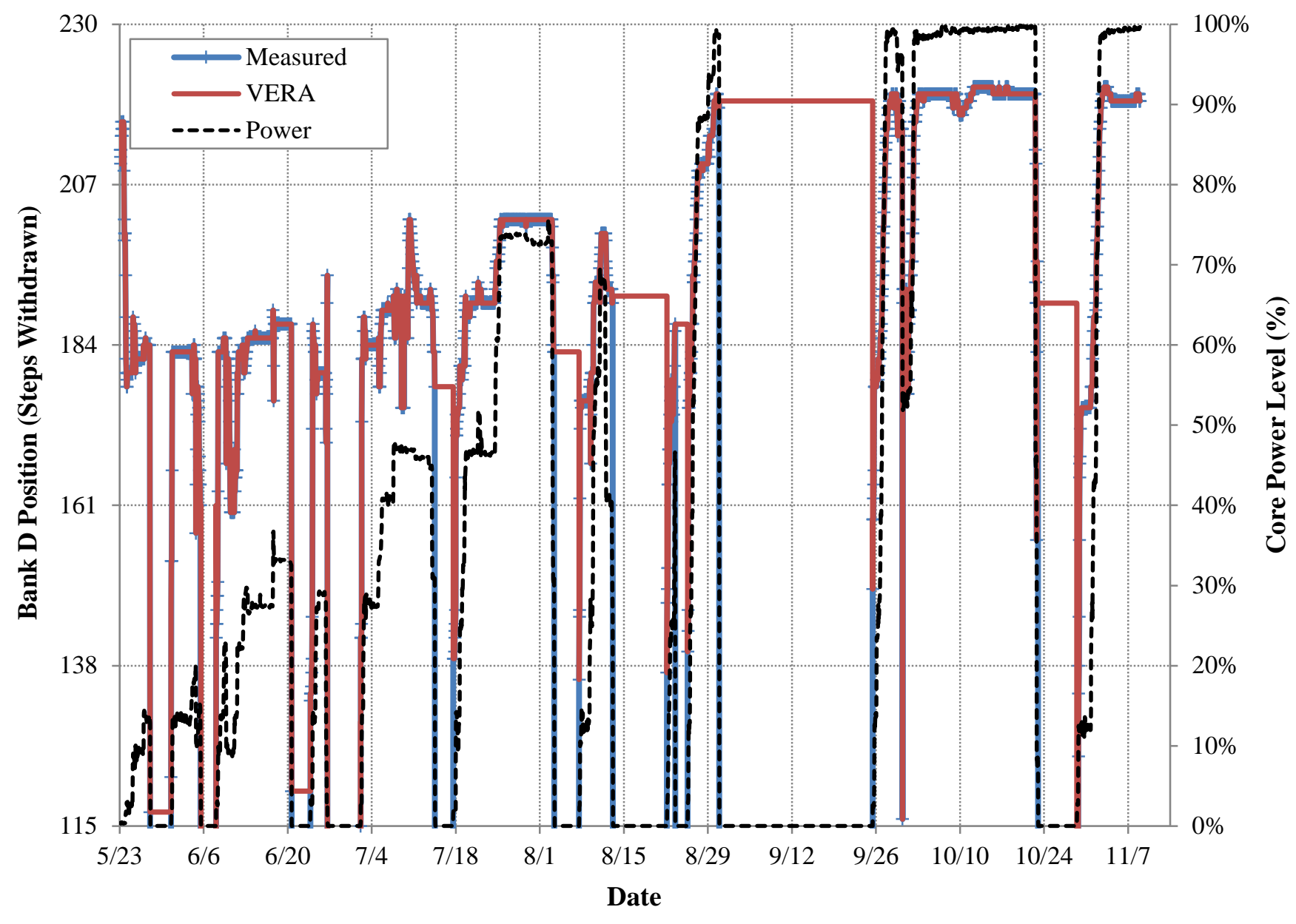

Figure 4-6. Control Bank D History (Step Withdrawn). 


\subsubsection{Inlet Coolant Temperature}

The WBN2 cold leg temperatures were provided by TVA for each hour of the power ascension and averaged in order to provide direct input for VERA. The complete inlet temperature history for each cold leg is provided in the figure below, along with the average temperature input into VERA. During the ten shutdown periods, the reactor is made subcritical and the subsequent shutdown temperatures are not modelled in VERA. During shutdown, the inlet temperature is assumed to stay constant from the last point before the shutdown.

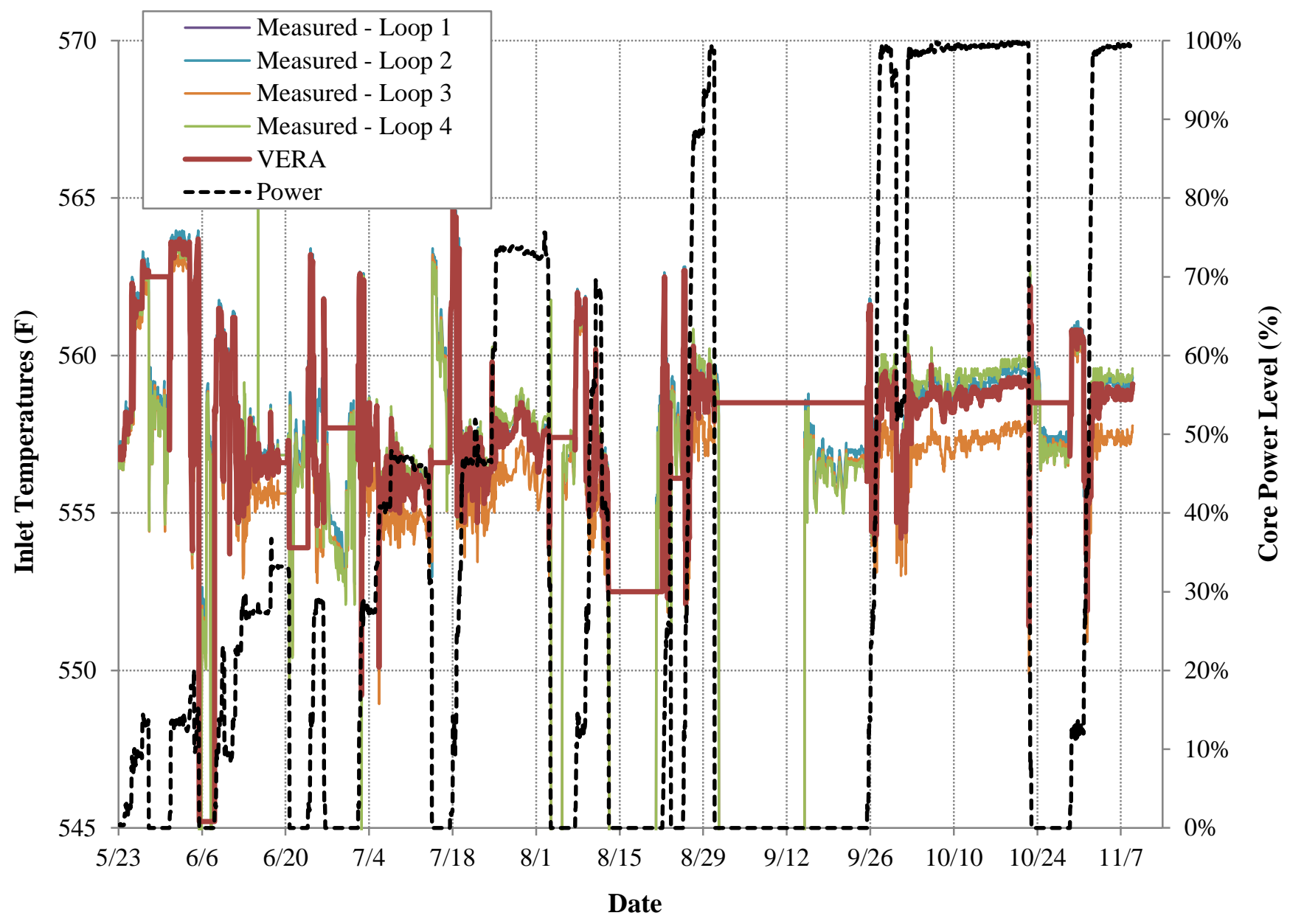

Figure 4-7. Inlet Temperature History $\left({ }^{\circ} \mathrm{F}\right)$ for Each Primary Loop. 


\subsubsection{Average Coolant Temperature}

The measured WBN2 coolant average temperatures were provided by TVA for comparison to VERA calculated values. The measured data represents the average of the cold and hot leg temperatures for every hour, and includes the portion of the coolant flow that bypasses the reactor core. The VERA value is the average of CTF's inlet and outlet values, but excludes bypass flow. In order to make a more consistent comparison, the VERA value is adjusted by calculating a weighted average of the CTF output and bypass temperatures (in this case, bypass is 6\%), and then averaging with the inlet temperature. The core average temperatures for the entire power ascension sequence are provided in the figure below. During the ten shutdown periods, the reactor is made subcritical and no effort was made to model the exact inlet (and thus average) temperatures for these periods. Note also that there is some missing plant data in the period of June and July. The adjusted calculated temperatures match the plant data very well.

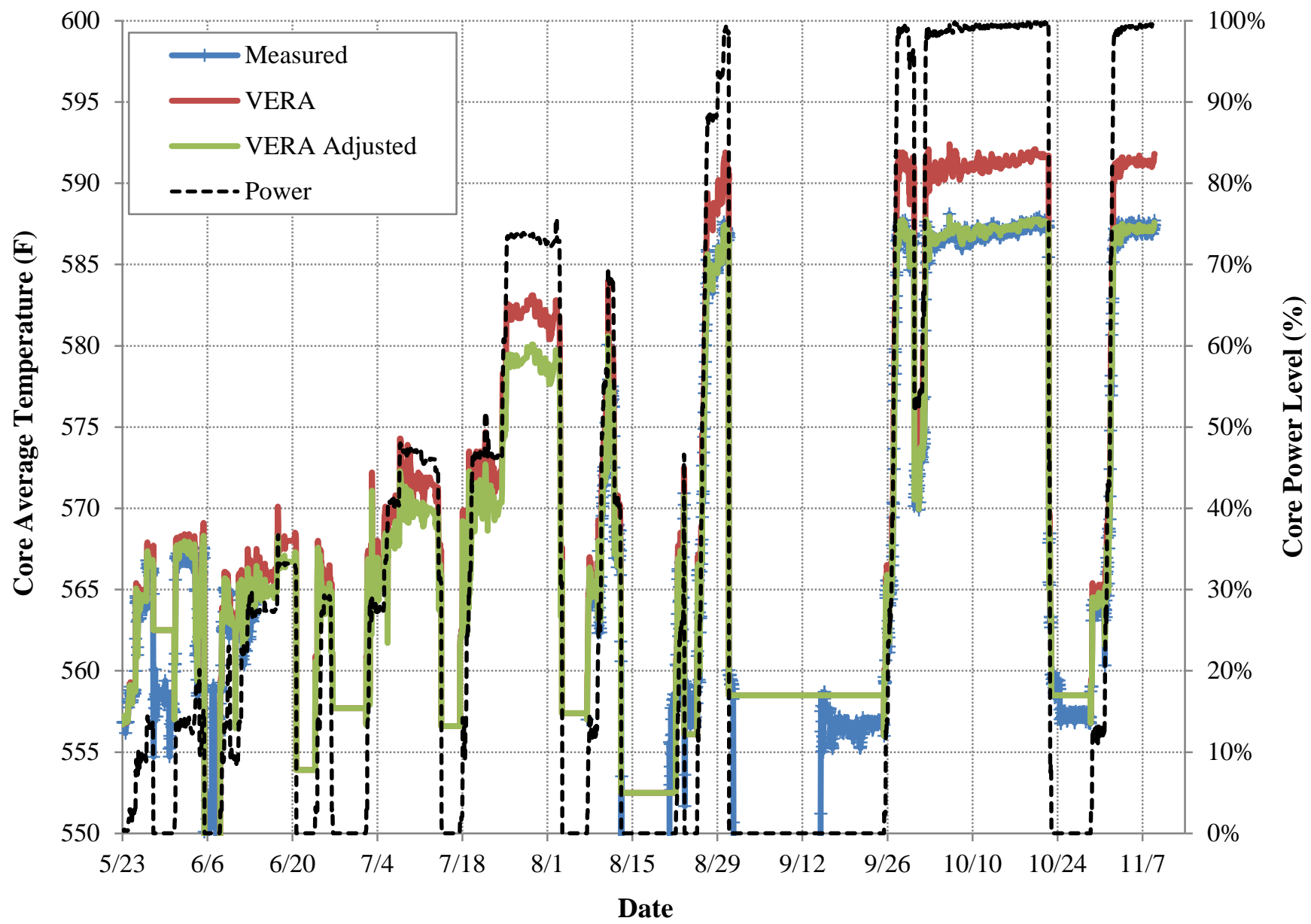

Figure 4-8. Average Coolant Temperature Comparison $\left({ }^{\circ} \mathrm{F}\right)$. 


\section{严口人كட}

\subsubsection{Fuel Temperatures}

The entire power escalation sequence was simulated throughout the summer and fall of 2016 as data from the plant became available. At that time the latest fuel temperature data from BISON was used for tabular input to MPACT (known as the Rev. 6 version in file bison_table_tavg_rev6.tab), as described in Section 3.4. Unfortunately, the first simulations resulted in a large instability in axial power shape during several of the power plateaus, demonstrated by a diverging axial flux difference (AFD) and corresponding axial ${ }^{135}$ Xe distribution. The inaccurate axial power shapes rendered any reactivity or in-core power distribution measurements impossible for comparison. An example of this axial power oscillation is shown in Figure 4-10.

In order to obtain reasonable results, the BISON fuel temperature response as a function of power was artificially increased to provide an artificial dampening of this axial power oscillation. The change resulted in significant improvement in core axial power shape during long periods of steady state operation, but worsened both the core critical boron concentration and the radial power distribution calculations. More research is needed to identify the reason for this axial instability, and this simulation needs to be performed again with best-estimate fuel temperatures once the primary issue has been identified and corrected. In particular, the fuel temperatures generated by BISON need additional scrutiny to ensure accuracy and consistency in the nuclear feedback response to MPACT.

Figure 4-9 below provides examples of the two different sets of fuel temperatures used for the simulation, both at $1 \mathrm{GWd}$ /MTU burnup. Note that the original BISON values are in the form of a quadratic fit, which results in a decreased response at higher power levels. The new values are simply linear with power, which is not consistent with BISON results but is consistent with temperature functions used by many industrial core analysis codes.

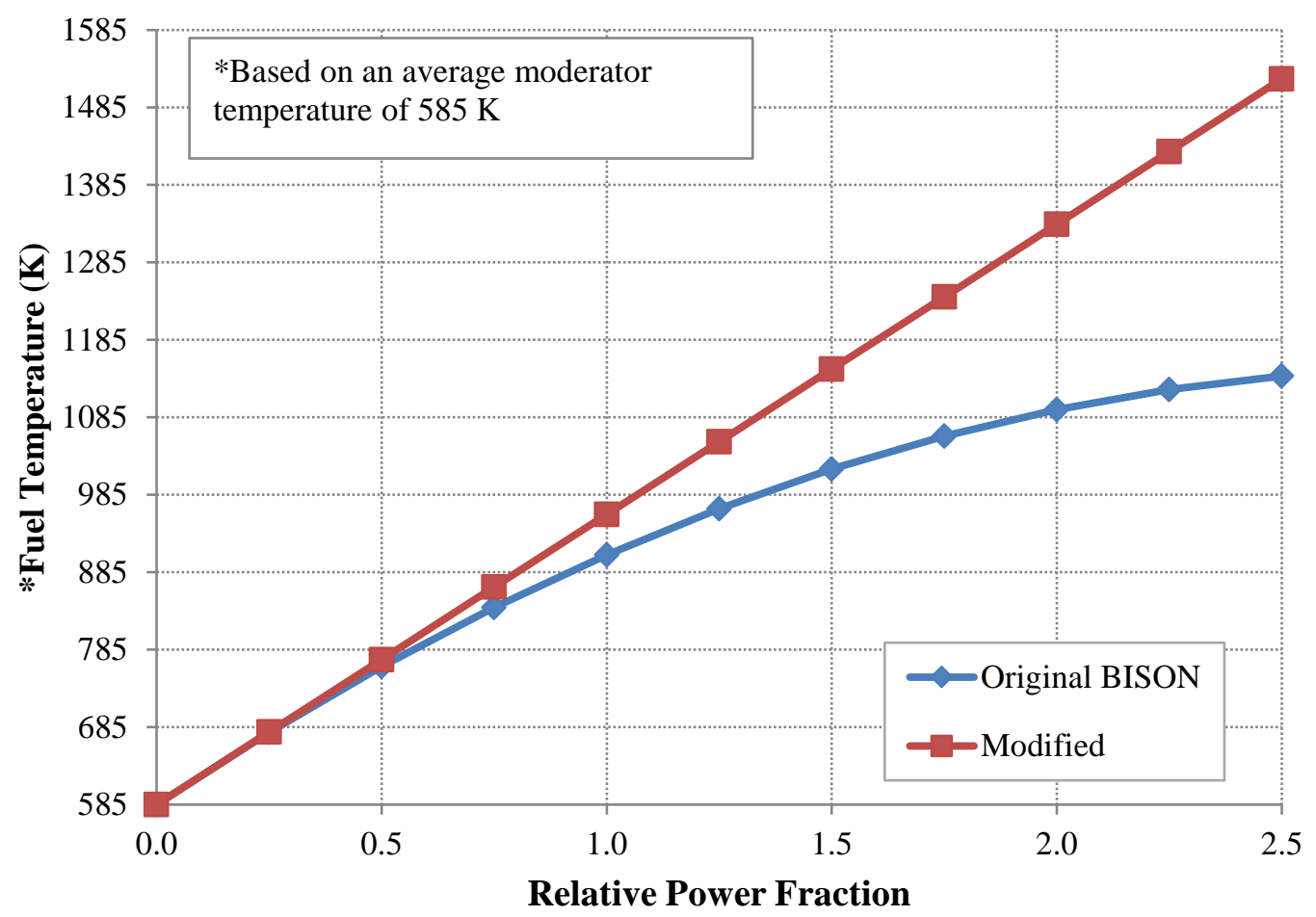

Figure 4-9. Original and Modified Fuel Temperature Sets (at 1 GWd/MTU). 
Figure 4-10 displays the effects these two temperature tables have on the core axial power shape predicted by VERA for the hourly timesteps after WBN2 reached commercial operation. The data is the axial flux difference, AFD (described in detail in Section 4.5.8). The measured values are obtained from signals from the ex-core detectors (top and bottom signals), and the calculated values are a direct volume-weighting of the fission distribution in the fuel from VERA.

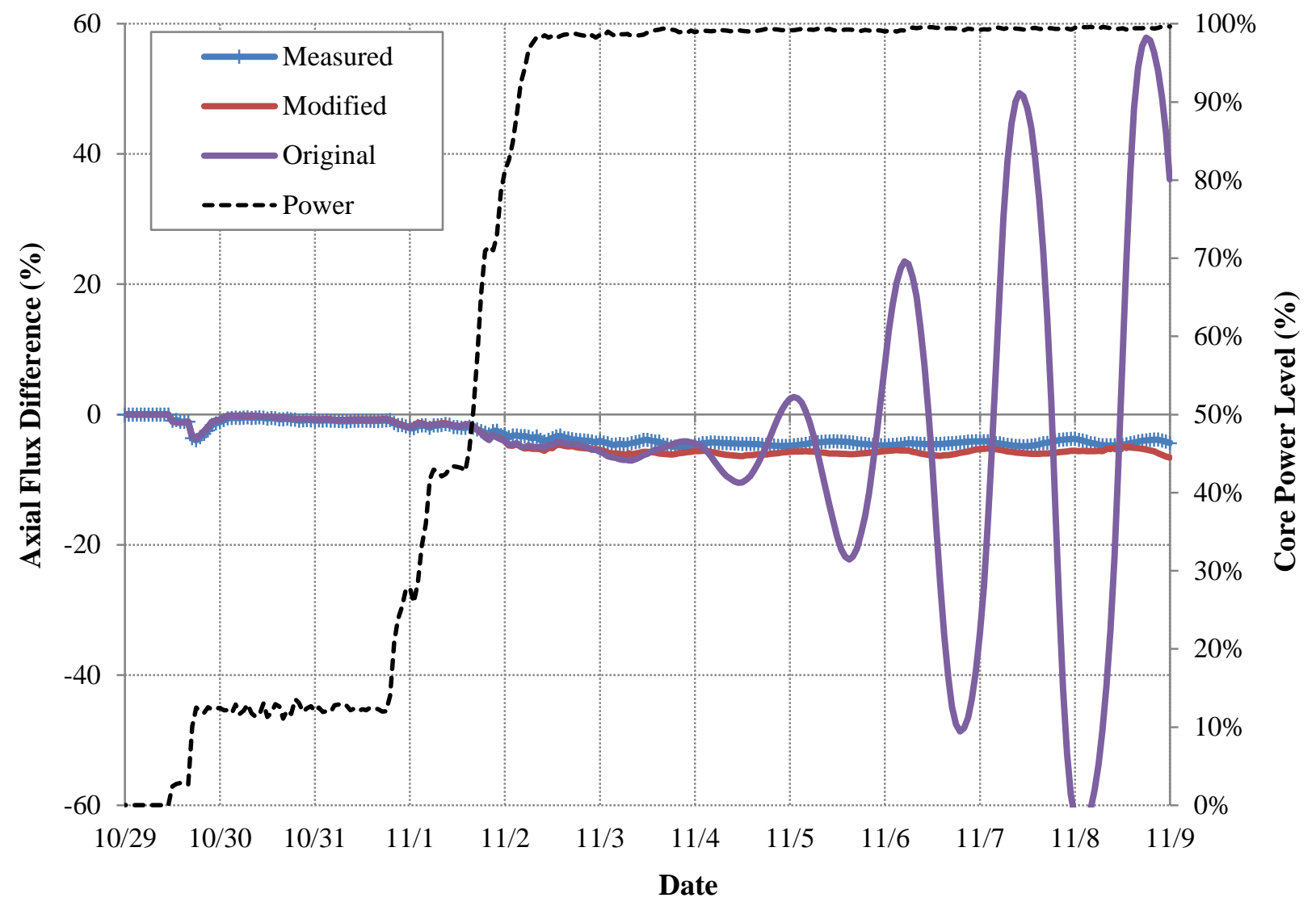

Figure 4-10. Effects of Original and Modified Fuel Temperature Sets on AFD.

Due to the much improved behavior in axial shape, the modified BISON fuel temperatures are used for all subsequent results in this section. The only cases using the original temperatures from this point forward are the flux maps, for which the modified temperatures produce nearly a $1 \%$ worsening in radial power distribution compared to plant measurements. Using the modified fuel temperature table, the core average calculated fuel temperature is shown below as a function of time for the entire startup sequence. 


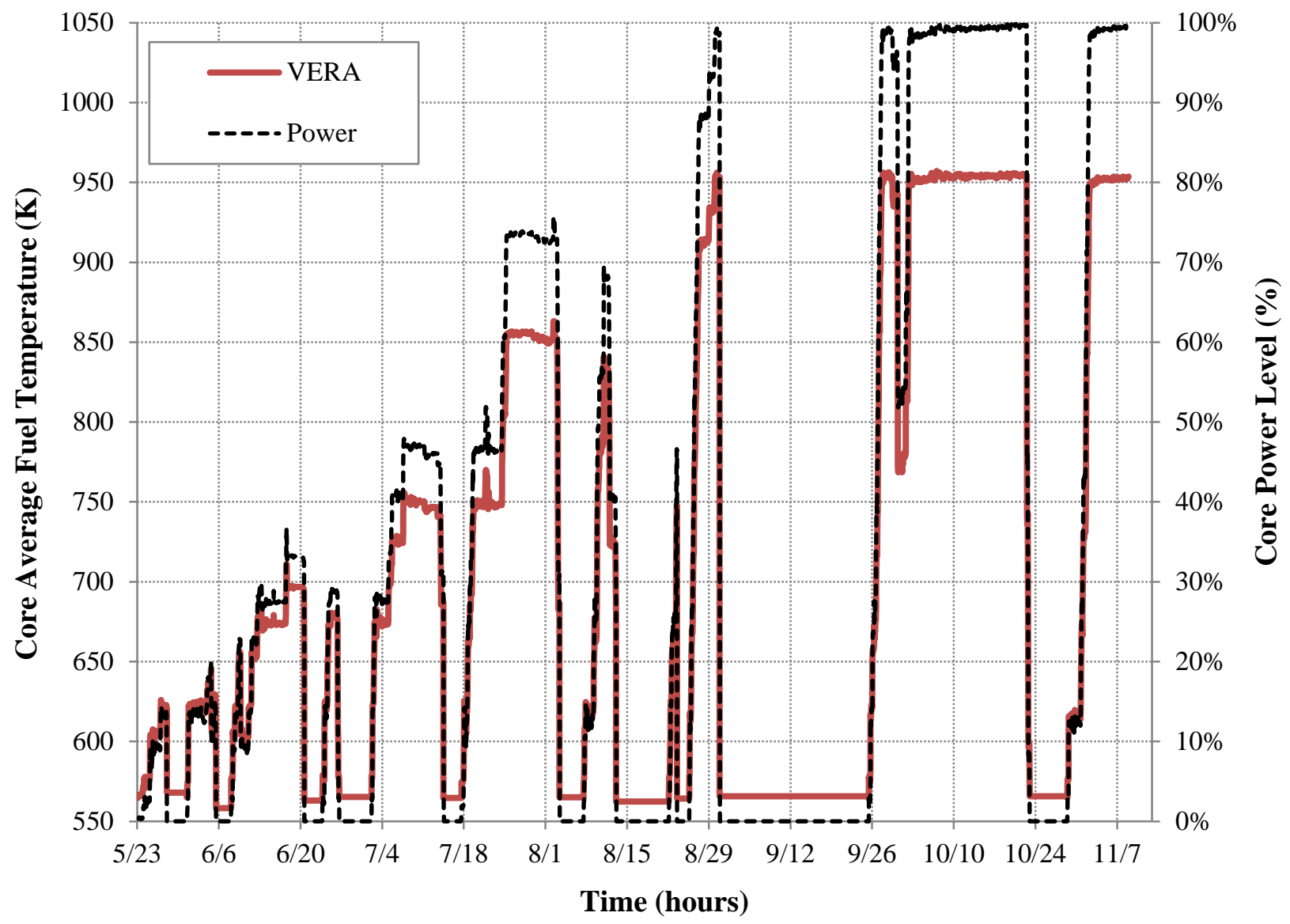

Figure 4-11. Calculated Average Fuel Temperature.

\subsubsection{Core Burnup}

TVA has provided the calculated burnup from the online plant computer for comparison to the hourly results from VERA. Since the power ascension sequence was modeled hourly, the core burnup was also independently calculated by MPACT. These burnups are compared in the Figure 412 and match very well. 


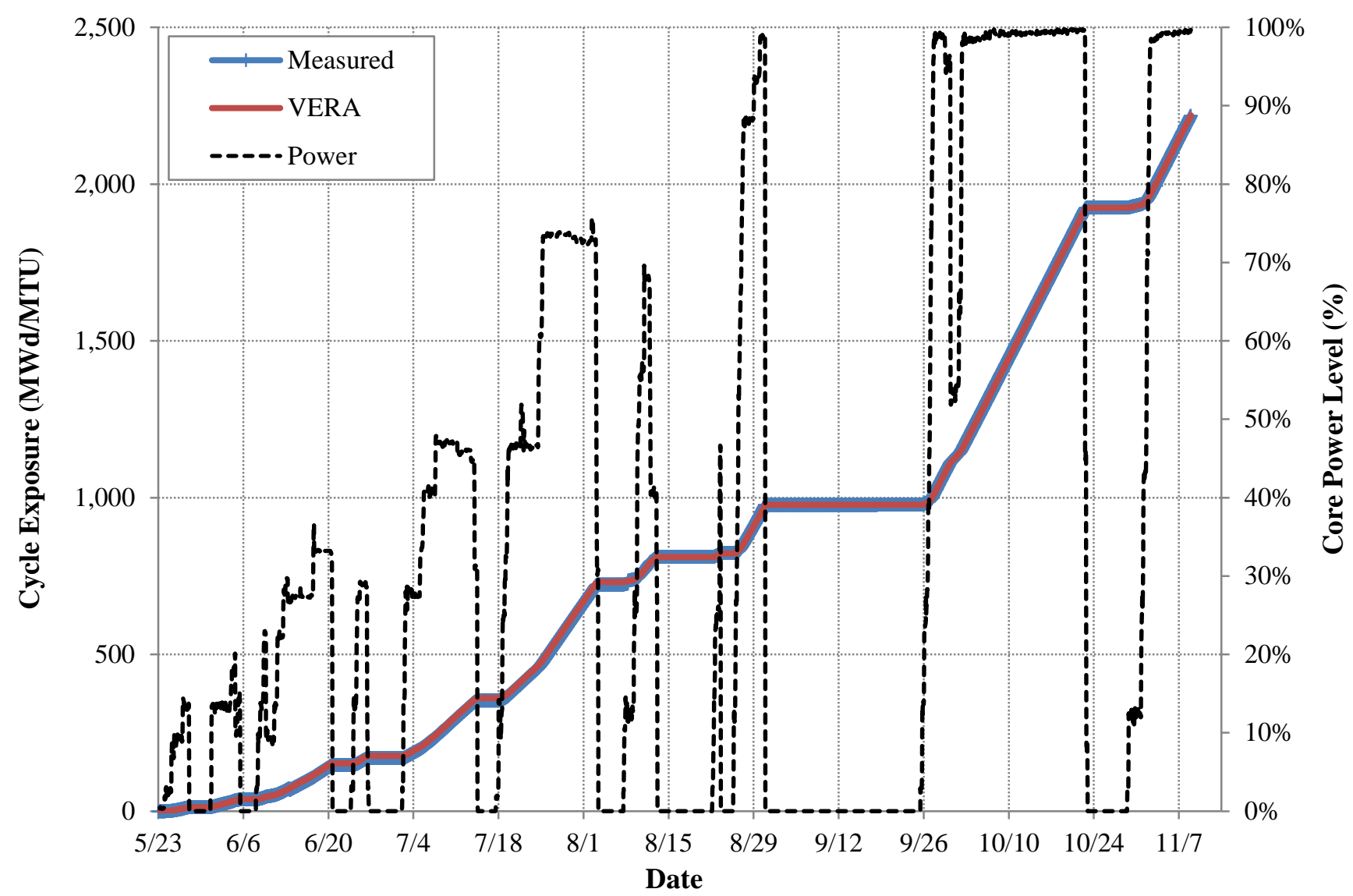

Figure 4-12. Calculated Cycle Burnup Comparison (MWd/MTU).

\subsubsection{Transient Fission Product Concentrations}

This section presents a few of the core average transient fission product and heavy nuclide concentrations from MPACT for the entire power escalation sequence. All isotopics are determined by ORIGEN in every depletion region in the core (3 radial rings per rod, 50 axial levels per rod, 12,738 rods in the quarter-core) for all time steps. Though there are no plant measurements for comparison, it is useful to visualize the behavior of these isotopes as a function of power and time to confirm the expected trends. For each of the ten shutdown periods, it is possible to observe:

1. Initial peak and subsequent decay of ${ }^{135} \mathrm{Xe}$.

2. Buildup of ${ }^{149} \mathrm{Sm}$ from ${ }^{149} \mathrm{Pm}$.

3. Decay of ${ }^{239} \mathrm{~Np}$ and corresponding buildup of ${ }^{239} \mathrm{Pu}$.

A bug in VERA 3.6 prevented the editing of the isotopics, so these results are from the initial calculations using the original BISON fuel temperatures. The artificial axial oscillations discussed in Section 4.5.5 are also apparent in the core average ${ }^{135} \mathrm{Xe}$ data. Note also that the core average values are calculated using volume weighting. 


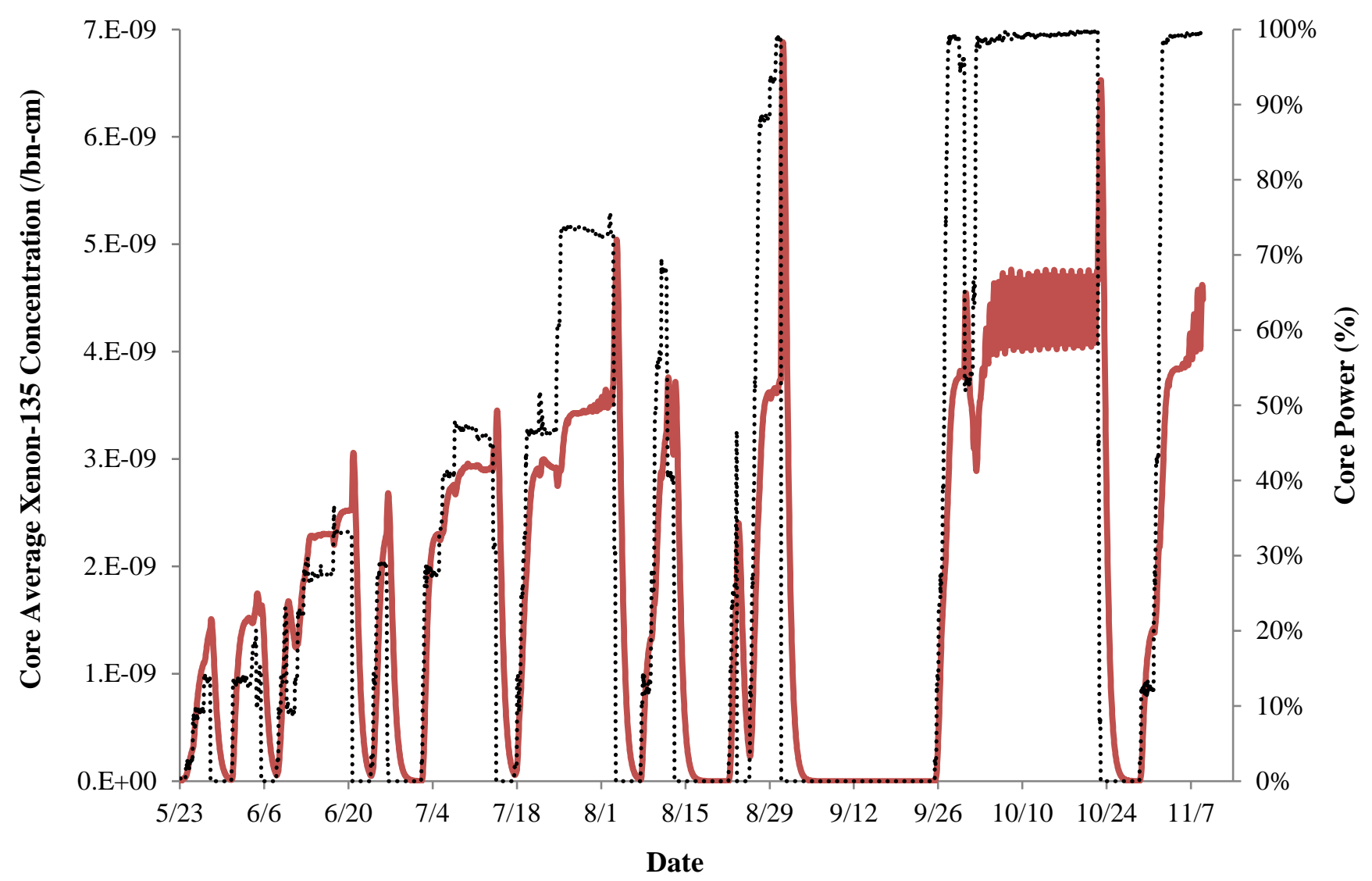

Figure 4-13. Calculated Core Average Xenon-135 Concentration.

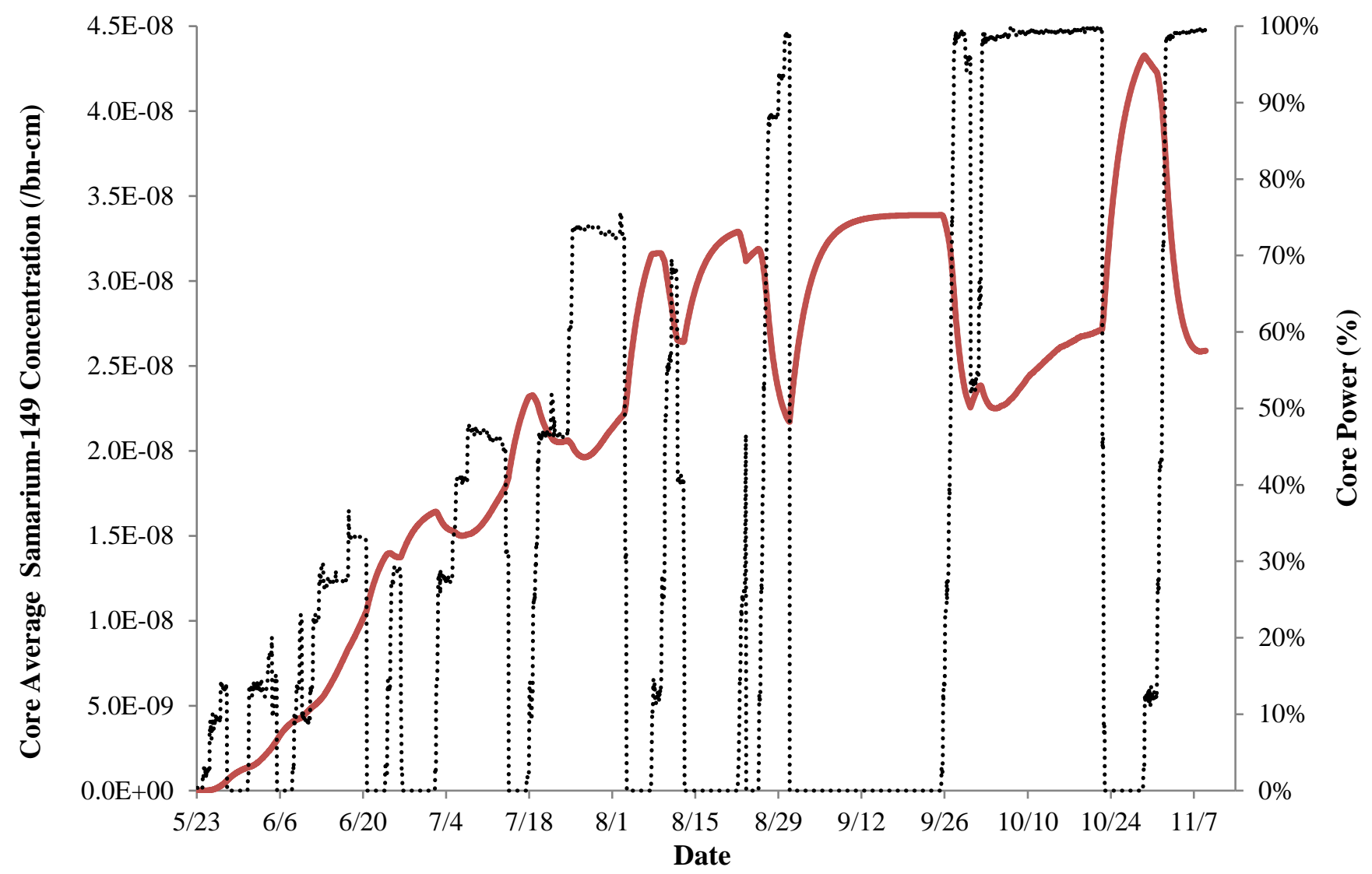

Figure 4-14. Calculated Core Average Samarium-149 Concentration. 


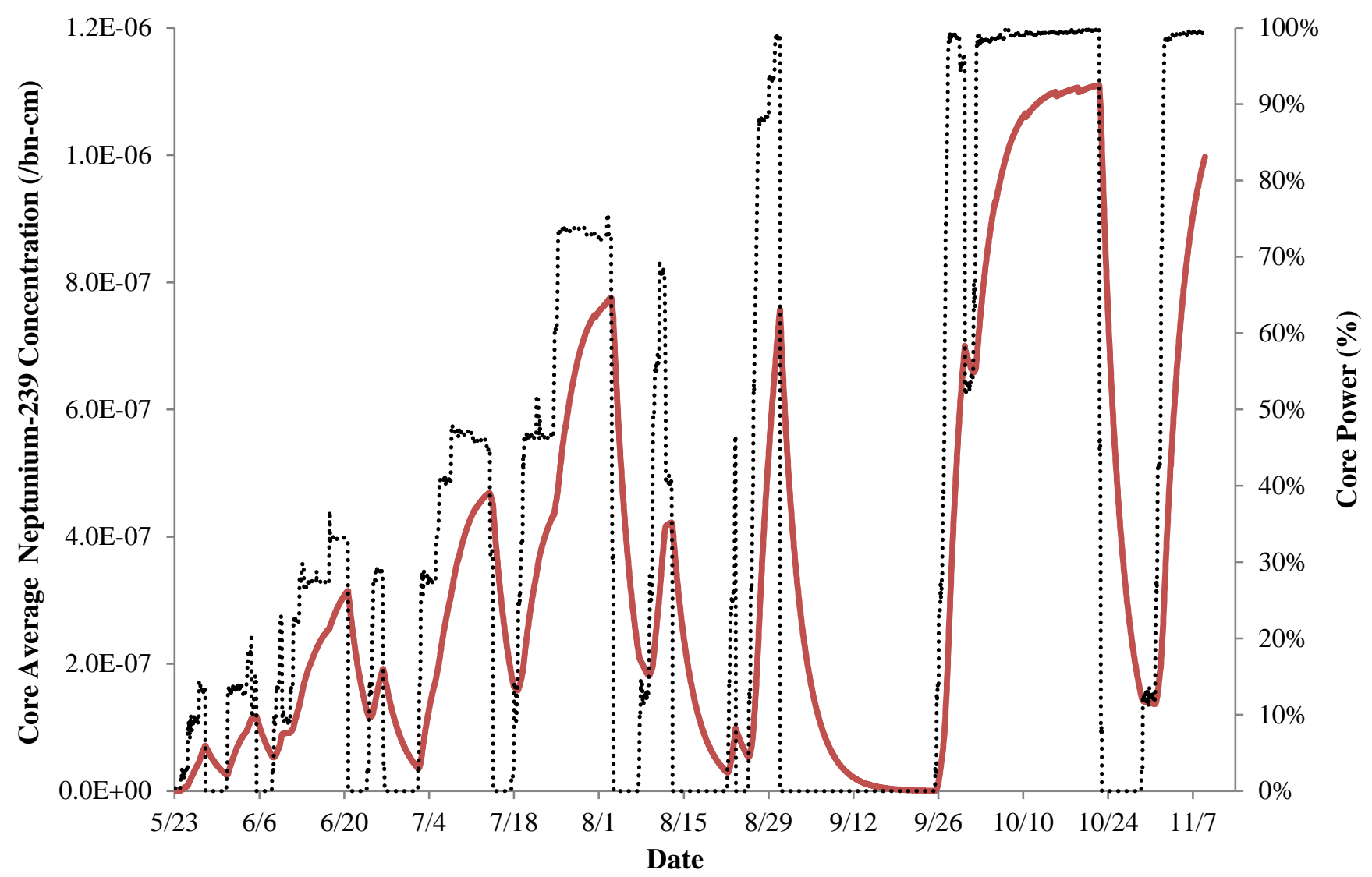

Figure 4-15. Calculated Core Average Neptunium-239 Concentration.

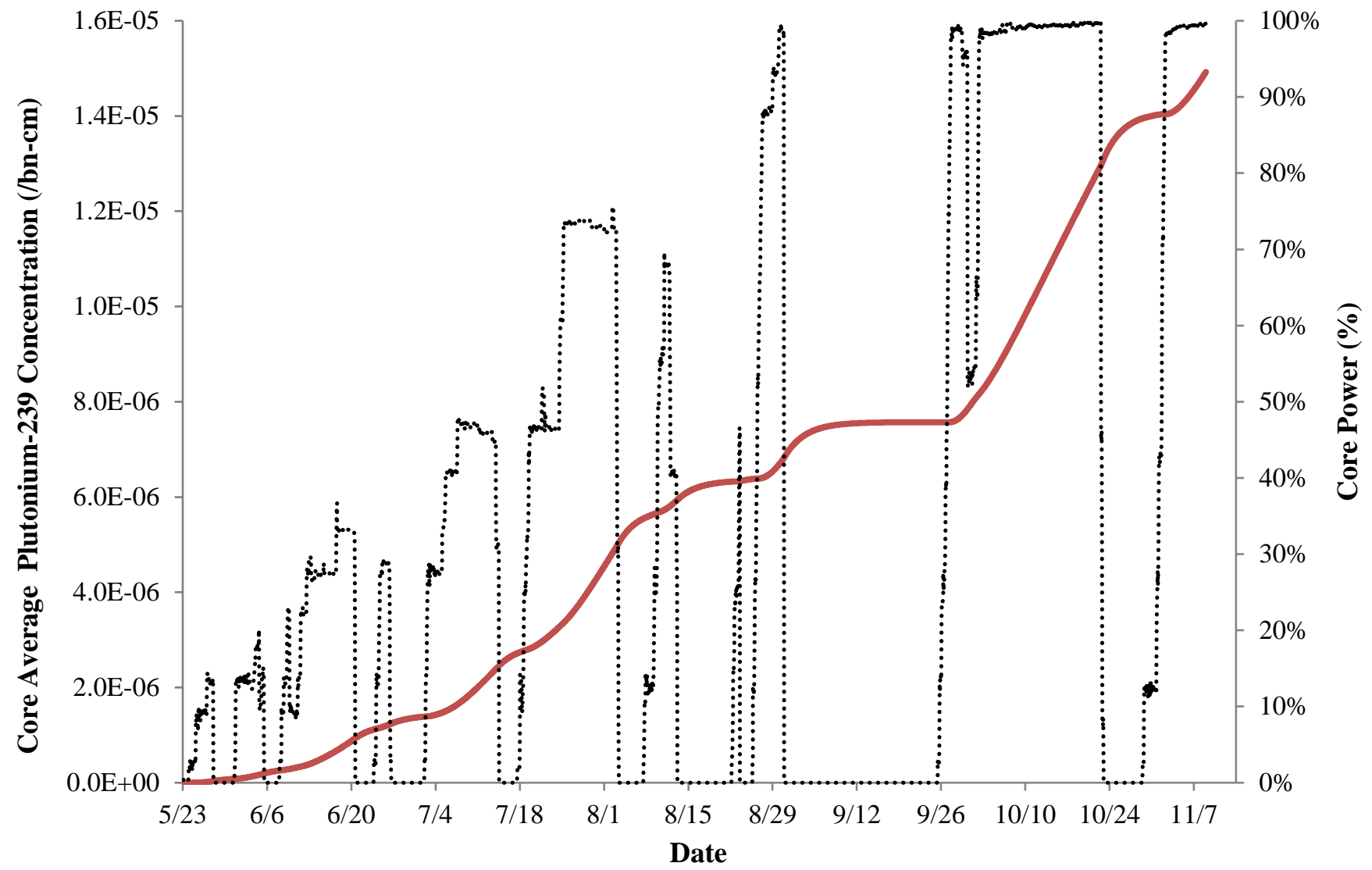

Figure 4-16. Calculated Core Average Plutonium-239 Concentration. 


\subsubsection{Axial Flux Difference}

The WBN2 reactor axial power shape is measured as a function of time using ex-core neutron detectors placed outside of the reactor vessel. Each power-range detector consists of a top and bottom sensor, with detectors outside of each quadrant of the reactor core. The ex-core axial flux difference (AFD) is calculated as the following:

$$
A F D=\frac{P_{\text {Top }}-P_{\text {Bottom }}}{P_{\text {Top }}+P_{\text {Bottom }}} \times \% F P
$$

where $P_{\text {Top }}$ and $P_{\text {Bottom }}$ are the signals in the top and bottom sensors, respectively, and $\% F P$ is the percent of rated thermal power of the core. TVA has provided the AFD for the entire power ascension sequence of WBN2.

The AFD calculated from VERA results has in principle the same definition, but is calculated with an integration by volume of the relative fission rate distribution in the fuel. The core midplane is used to differentiate between top and bottom powers, using volume weighting as necessary. Because VERA cannot directly calculate the ex-core detector response (this capability is still under development), the comparison of measured ex-core AFD to calculated in-core AFD is inconsistent, but does provide some insight and trends, especially given the very inaccurate axial power oscillations discussed earlier.

The figure below provides a comparison between the measured ex-core AFD and the corresponding in-core value calculated from the VERA power distribution. These results are using the modified BISON fuel temperatures which were chosen to damp the axial power oscillations (Fig. 4-10) and improve the AFD agreement with plant data. Compared to the original calculations, these results are much improved but still not as damped as what is observed from the plant data. More research will be required to understand why VERA is axially unstable with these problems with the original BISON fuel temperatures.

Visible in the results is also a consistent trend of under-predicting the core axial power shape, by several percent at times. A second plot is provided with a smaller timescale. It is not clear whether this is a real difference or simply an artifact of the comparison to ex-core data. A better comparison of axial power shape will be provided in Section 4.6 on comparison of in-core power distributions. 


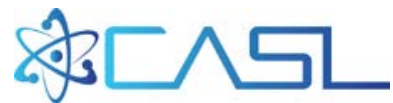

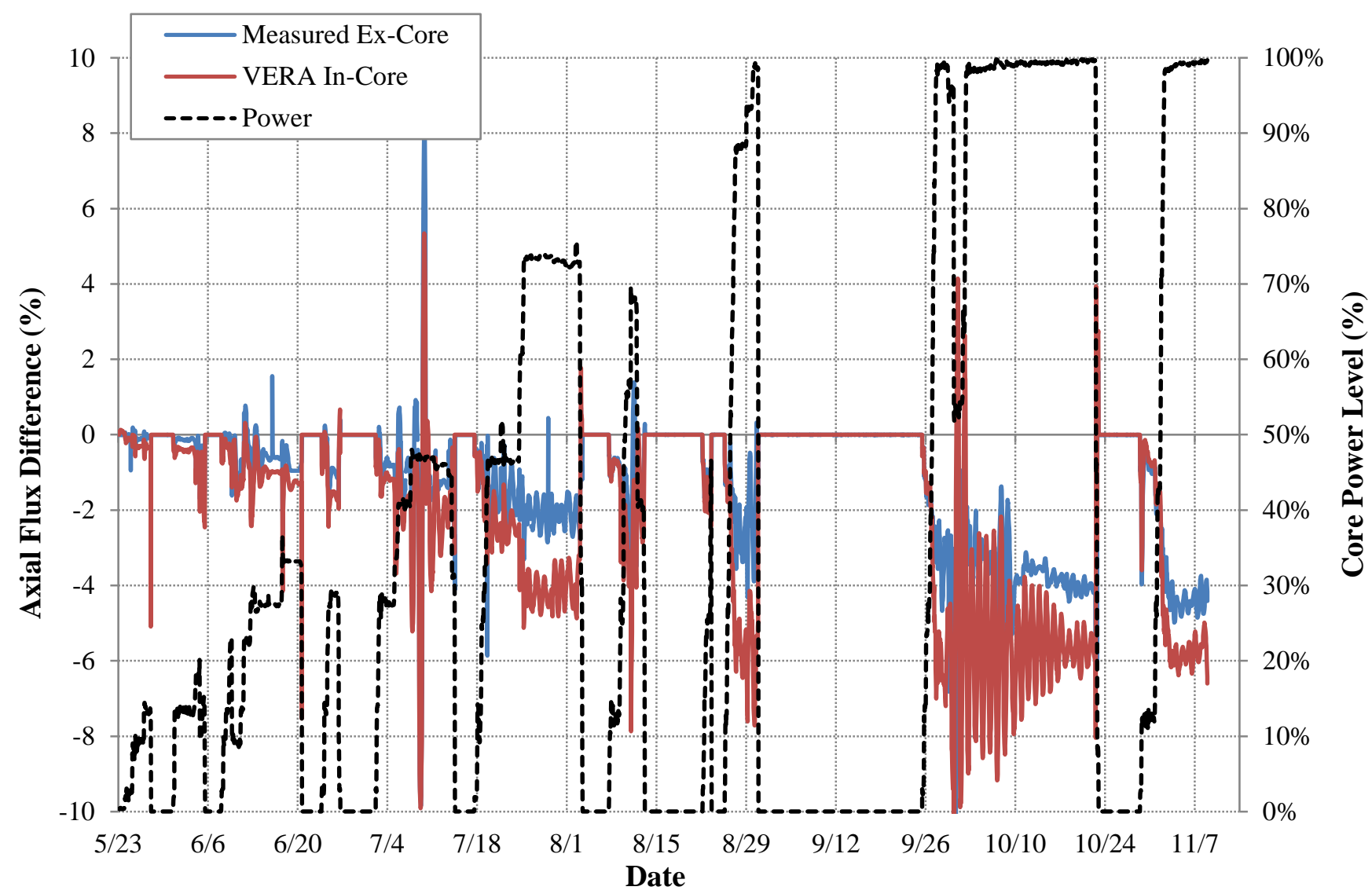

Figure 4-17. Calculated and Measured Axial Flux Difference Comparison.

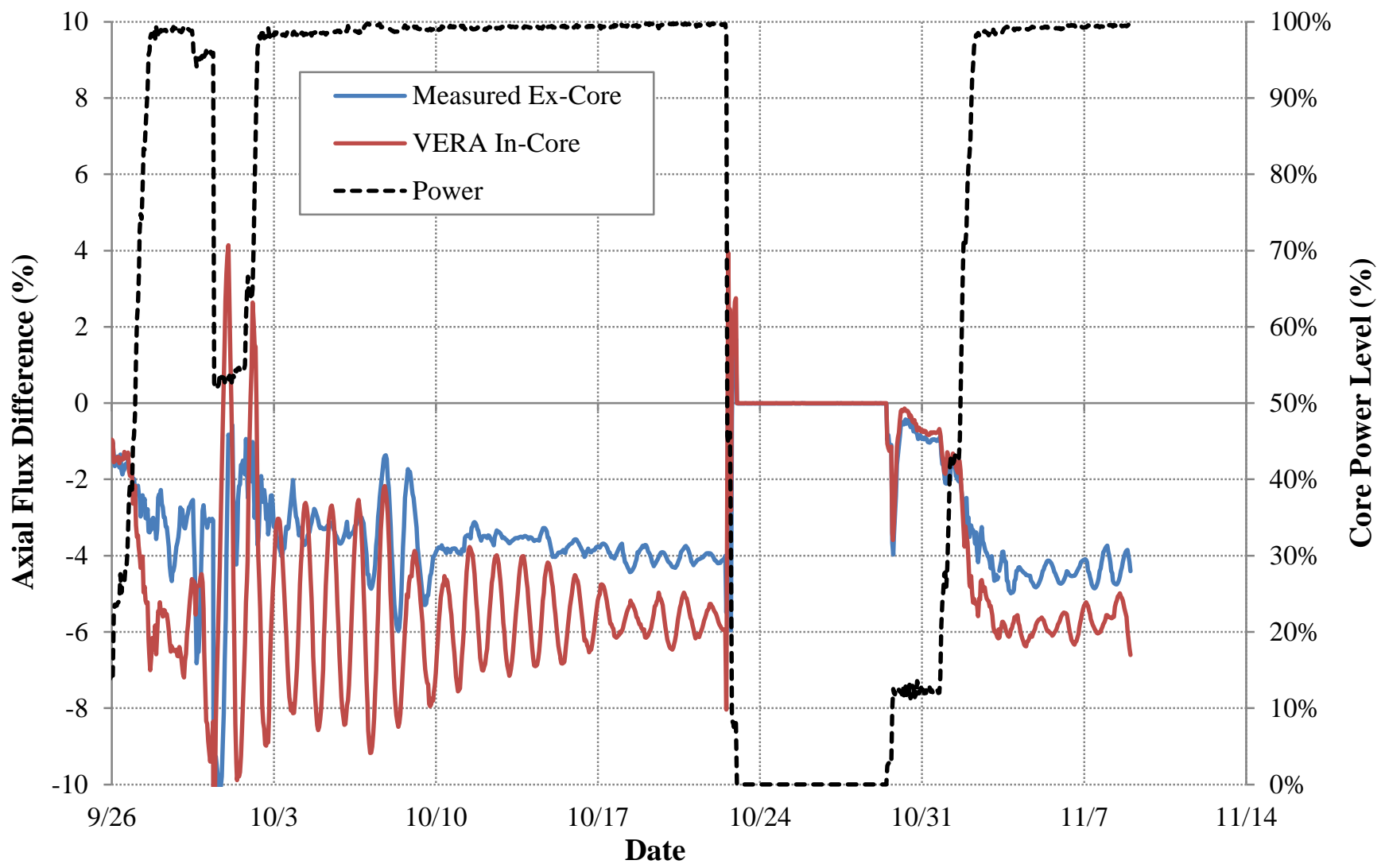

Figure 4-18. Calculated and Measured Axial Flux Difference Comparison near HFP. 


\subsubsection{Critical Boron Concentration}

Throughout the power ascension period of the WBN2 startup, encompassing nearly six months, over 350 soluble boron concentrations (greater than daily) were measured in the primary coolant system. Of these, over 200 are considered to be critical values, meaning the reactor was critical and likely generating power when the sample was taken. Comparison to these measured boron concentrations is vital to understanding if there is a reactivity bias in the values calculated by VERA associated with increasing power levels. Up to this point, all reactivity comparisons have been performed at HZP conditions. As power increases, the effects of thermal-hydraulics, fission product poisons, and fuel temperature models are very important to being able to consistently and accurately calculate reactivity at all operating conditions.

There is also some additional complexity in comparing to these values. The reactor conditions are not exactly known for each measurement, and the time of each sample does not necessarily coincide with the hourly data provided. Therefore, closest conditions to the time of the sample are used for comparison, which is a reasonable assumption if the reactor is operating at near equilibrium, but not if it is changing power or control rod positions. This increases the uncertainty in these results.

Furthermore, since the power escalation required several months and involved ten shutdowns, there is the potential for depletion of ${ }^{10} \mathrm{~B}$ in the coolant that needs to be accounted for in the comparisons. During this time, there were seven ${ }^{10} \mathrm{~B}$ measurements (approximately monthly). Additionally, since commercial operation began there have been four additional measurements made. A model was developed taking into account these measurements and the data from the outages in the following way:

1. A constant rate of depletion is assumed between each boric acid addition, which occurred during each shutdown period (i.e. soluble boron was increased to ensure sub-criticality). This depletion rate is assumed to be linear with burnup and is established by the last four measurements. The estimated depletion rate is -0.009 at\%/EFPD.

2. Replenishment of the depleted soluble boron is accomplished by either use of a measured data point, if available, or by estimating with a simple numerical model. This model approximates the mixing of depleted and fresh boron by assuming properties of the boric acid source and by knowing the minimum and maximum boron concentration between each outage. In this model, the largest ${ }^{10} \mathrm{~B}$ replenishment is assumed to be $<0.1$ at $\%$.

3. Two of the ten measured ${ }^{10} \mathrm{~B}$ abundances were not used because they were deemed to be untrustworthy because they are excessively low for the given point in the cycle.

The final ${ }^{10} \mathrm{~B}$ depletion model assumed for the WBN2 critical boron comparisons is shown below. The hourly data and simulation goes up to about 58 EFPD, and then from that point forward there is only monthly data. However, this data is important for establishing the rate of depletion for this core, which is used for the entire scenario. The model ${ }^{10} \mathrm{~B}$ abundance is shown as the red line, while the actual measured points are shown as blue circles. 


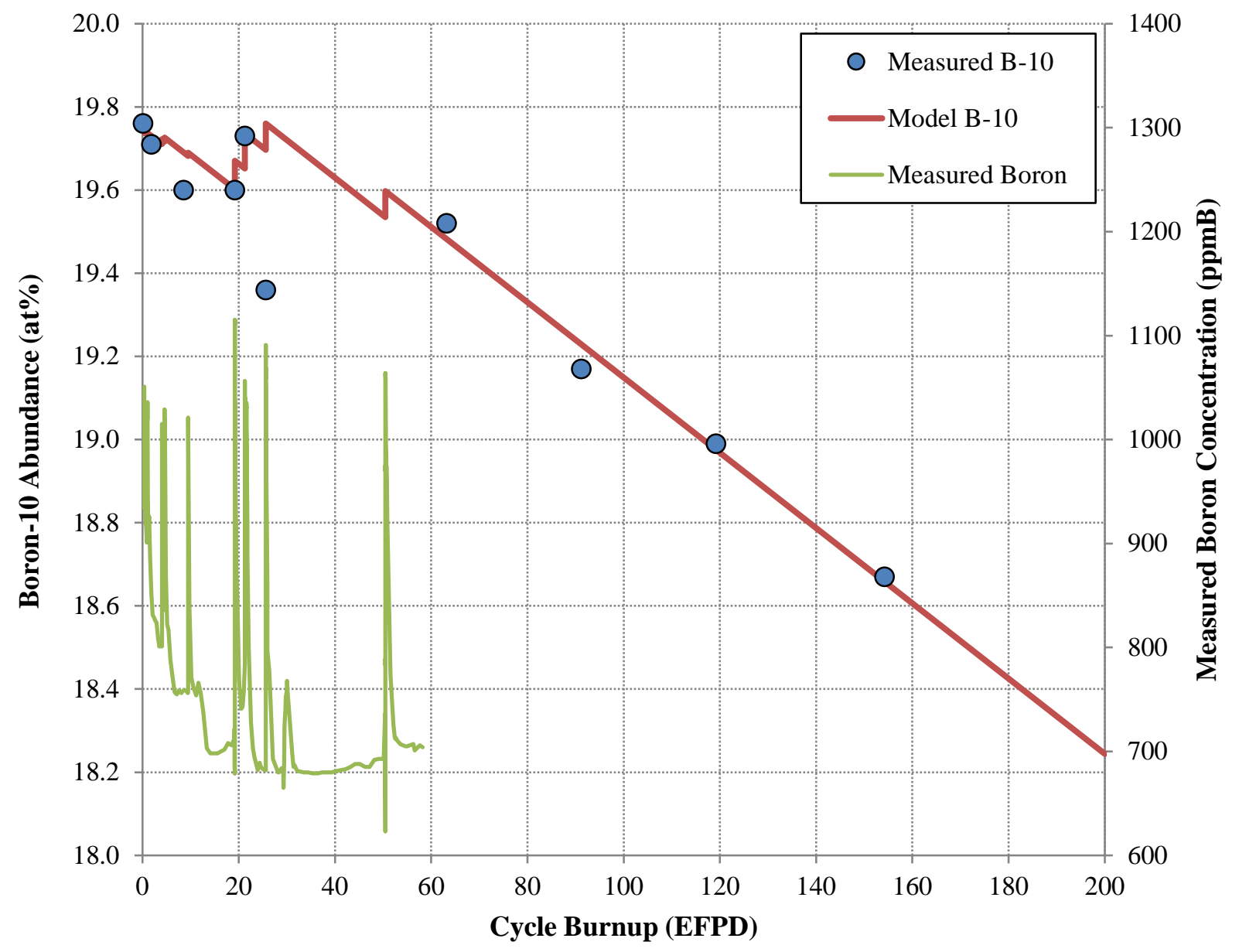

Figure 4-19. Boron-10 Depletion Model used for WBN2 Critical Boron Comparisons.

Using this linear model for approximating the ${ }^{10} \mathrm{~B}$ isotopic abundance in the soluble boron, the calculated critical boron concentrations from VERA can be easily adjusted for consistency with measured values. For first comparison, all measured concentrations are adjusted to 19.9 at\% equivalence and plotted along with the raw VERA output critical concentrations for the entire power ascension procedure. Since VERA used critical boron search, the results assume all cases are critical (k-effective $=1.0$ ) and the soluble boron concentration is changed to ensure criticality. During the ten shutdown periods, when the reactor was actually subcritical, the VERA model maintains the inlet temperature and rod positions at the last known critical condition, and the boron concentration is modified to offset the decay of ${ }^{135} \mathrm{Xe}$ and the other transient isotopes. In these intervals, the boron concentrations cannot be compared. 


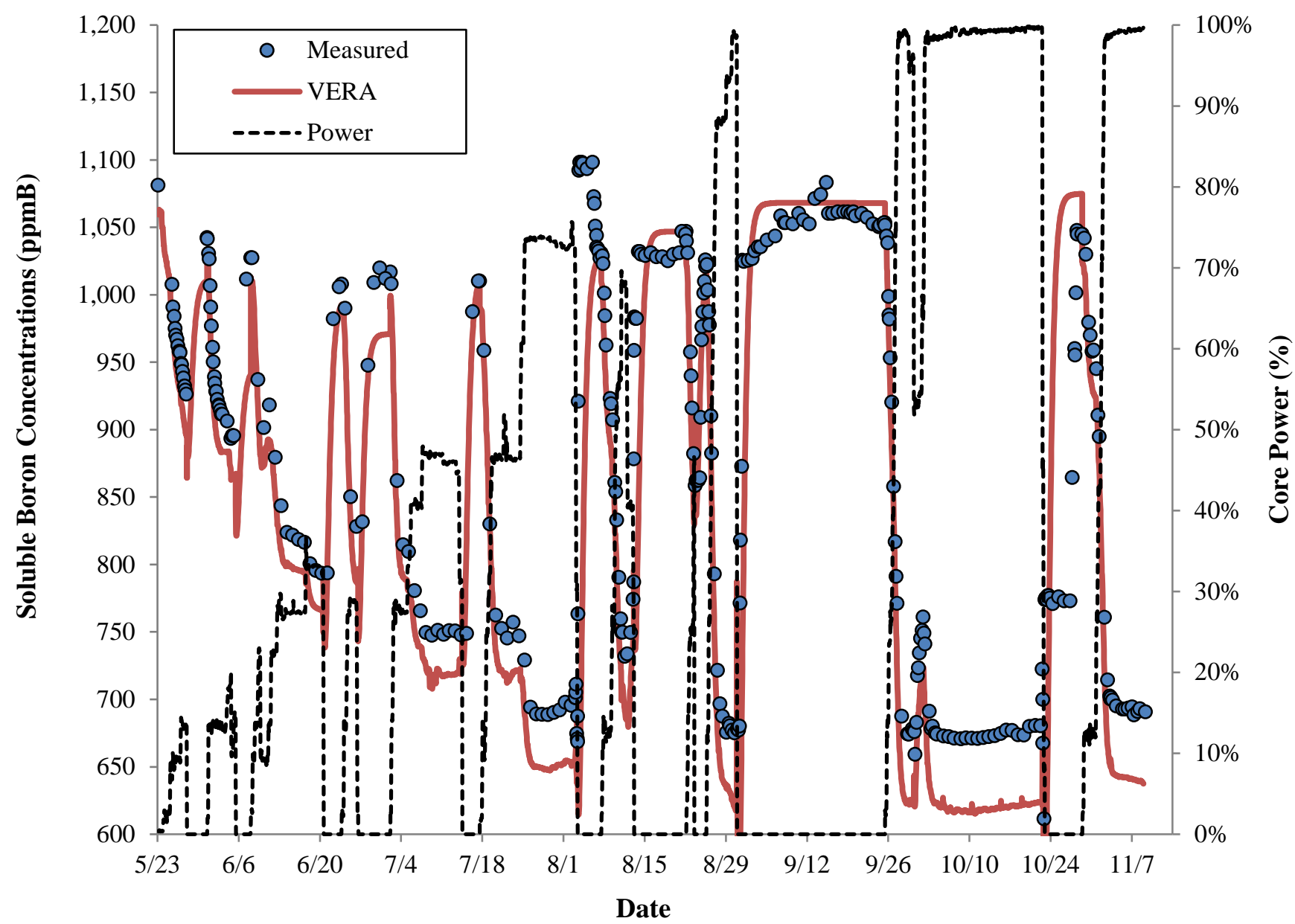

Figure 4-20. Soluble Boron Concentrations during Power Ascension Testing.

The following two figures provide the boron differences between the measured critical concentrations and the nearest corresponding values from VERA, corrected to the estimated ${ }^{10} \mathrm{~B}$ abundance for the measurement. The first figure provides the differences as a function of time (along with the core relative power level), and the second provides the differences as a function of relative core power. It is clear that there is a strong trend of under-predicting the core reactivity that significantly worsens as power increases. This is attributable to the modified BISON fuel temperature tables shown previously that were adopted in order to provide a more realistic (damped) axial power shape. These results can be significantly improved once CASL better understands the source of the axial oscillations and can use more realistic average fuel temperatures. 


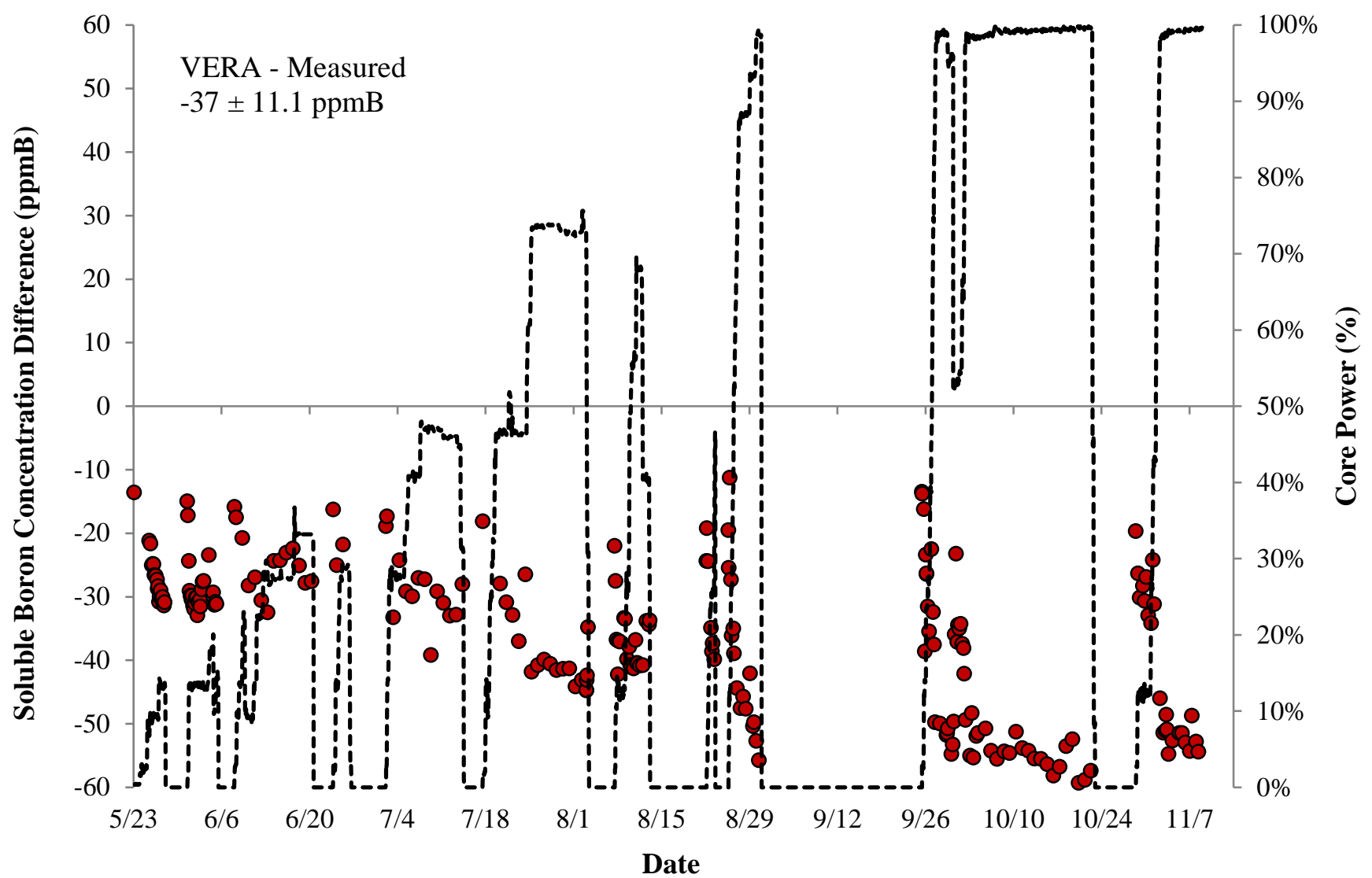

Figure 4-21. Critical Boron Concentration Differences during Power Ascension Testing.

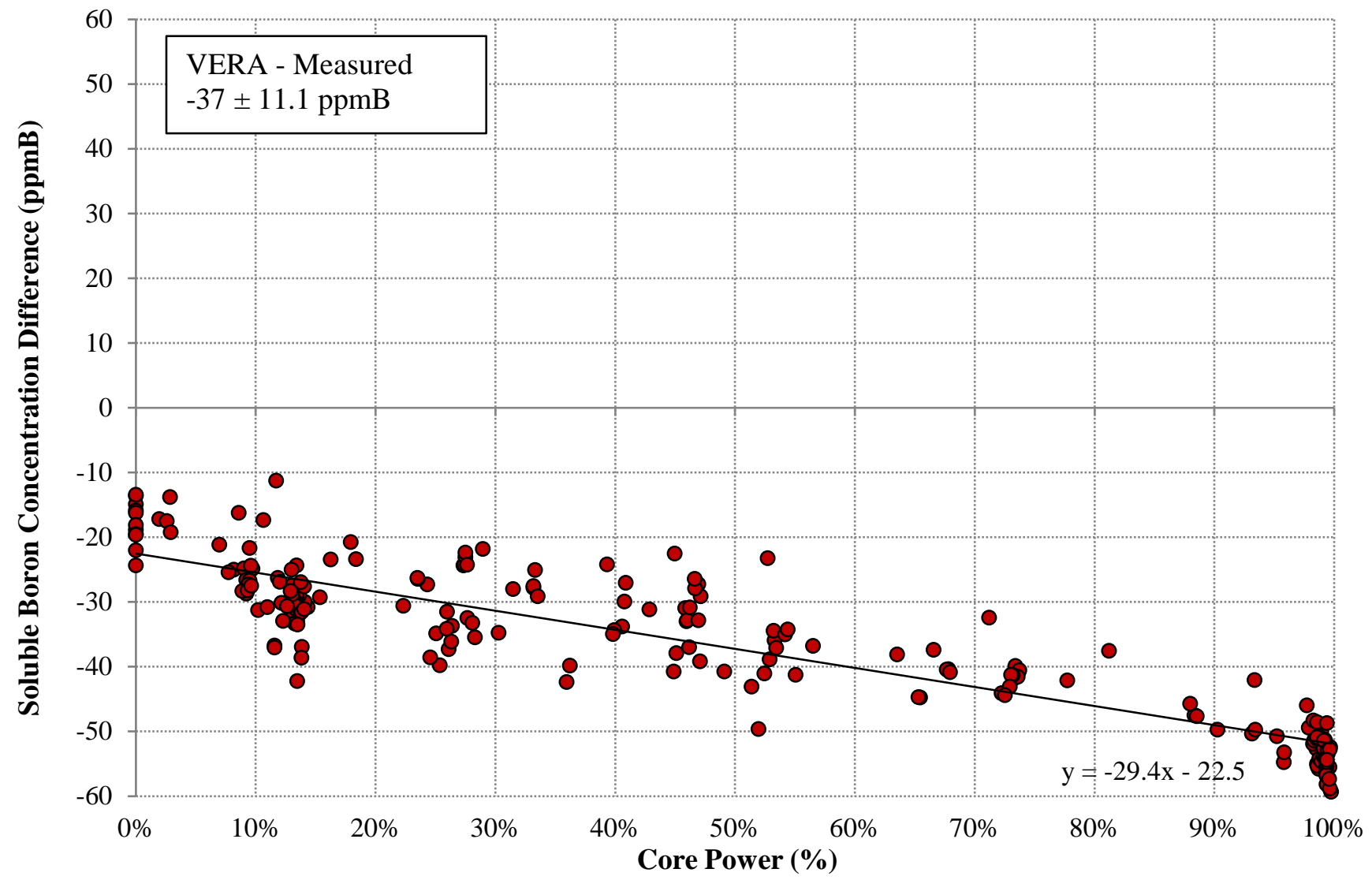

Figure 4-22. Critical Boron Concentration Differences as a Function of Core Power. 


\subsection{Power Distribution Comparisons}

Neutron flux measurements are taken inside the WBN2 reactor core using a fixed self-powered incore detector system. Unlike WBN1 [5], the in-core detectors are not moveable but are installed at fixed positions in the core for the entirety of the fuel cycle. These detectors consist of vanadium wire emitters which generate an electrical current from beta decay following a neutron absorption by ${ }^{51} \mathrm{~V}$. The response is slightly slower with vanadium compared to other self-powered systems because of a larger half-life (226 s), but demonstrations of this type of detector at other plants have had very good results. The major advantage gained by vanadium systems are longevity and mechanical robustness. The vanadium depletion rate is approximately $1 / 20^{\text {th }}$ of the corresponding rate for rhodium detectors, which will result in much fewer replacements in the lifetime of the power plant [36].

Each of the 58 core locations contains a detector, inserted from the bottom of the core into the assembly instrument tube, which consists of five wires of different lengths proportional to the active fuel height. The sensitive region of the longest wire essentially corresponds to the entire fuel stack, while the shortest wire is only sensitive to the bottom $20 \%$ of the core. Each wire length in a single detector location increases by approximately one fifth of the fuel height from one wire to the next, providing nearly equidistant coverage of the axial flux distribution in each core location. Because there are only five wires, the amount of axial information that can be inferred from these signals is limited compared to the moveable fission chambers used in WBN1. Additionally, like all selfpowered detection systems, the strength of the signals at low power levels is limited and may contain more measurement variability than at nominal operating conditions. Furthermore, due to differences in wire length and natural variation in diameter and density, the shorter wires may have more measurement uncertainty than the longer wires. Each of these items may lead to increased discrepancies when compared to software calculations which do not account for the variations.

In MPACT, the 3D detector response distribution is calculated from the neutron absorption reaction rate of vanadium at the pin-wise local conditions and 51-group neutron flux levels at any userspecified core location. The user may choose to model the detector thimble and structure explicitly, or MPACT can create a response from a 'virtual' detector at the center of the instrument tube. The physical detector geometry does slightly impact the radial core power distribution so this capability becomes relevant when deciding between full and quarter-core calculations. MPACT does not explicitly model the five vanadium wires and their currents, nor does it account for the timedependence in the instrument response due to the delayed beta decay. Therefore, comparisons need to be made when the reactor is relatively at steady state conditions for a short time (for at least ten minutes).

The relative vanadium emitter currents are reconstructed from VERA output by post-processing the detailed 3D detector response edits from MPACT. By default, the normalized detector responses are edited on the same axial mesh as used by the neutron transport and thermal-hydraulics solvers. In the WBN2 model, this results a 50-level detector response for each core location, with enough axial fidelity to observe geometric features such as spacer grids, axial blankets, and WABA material transitions in the calculated vanadium reaction rate. Figure 4-23 below provides a VERAView screenshot of the default detector response distribution from MPACT. The 3D distribution is represented by a $1 \mathrm{D}$ axial plot of the response in each core location containing an instrument. 


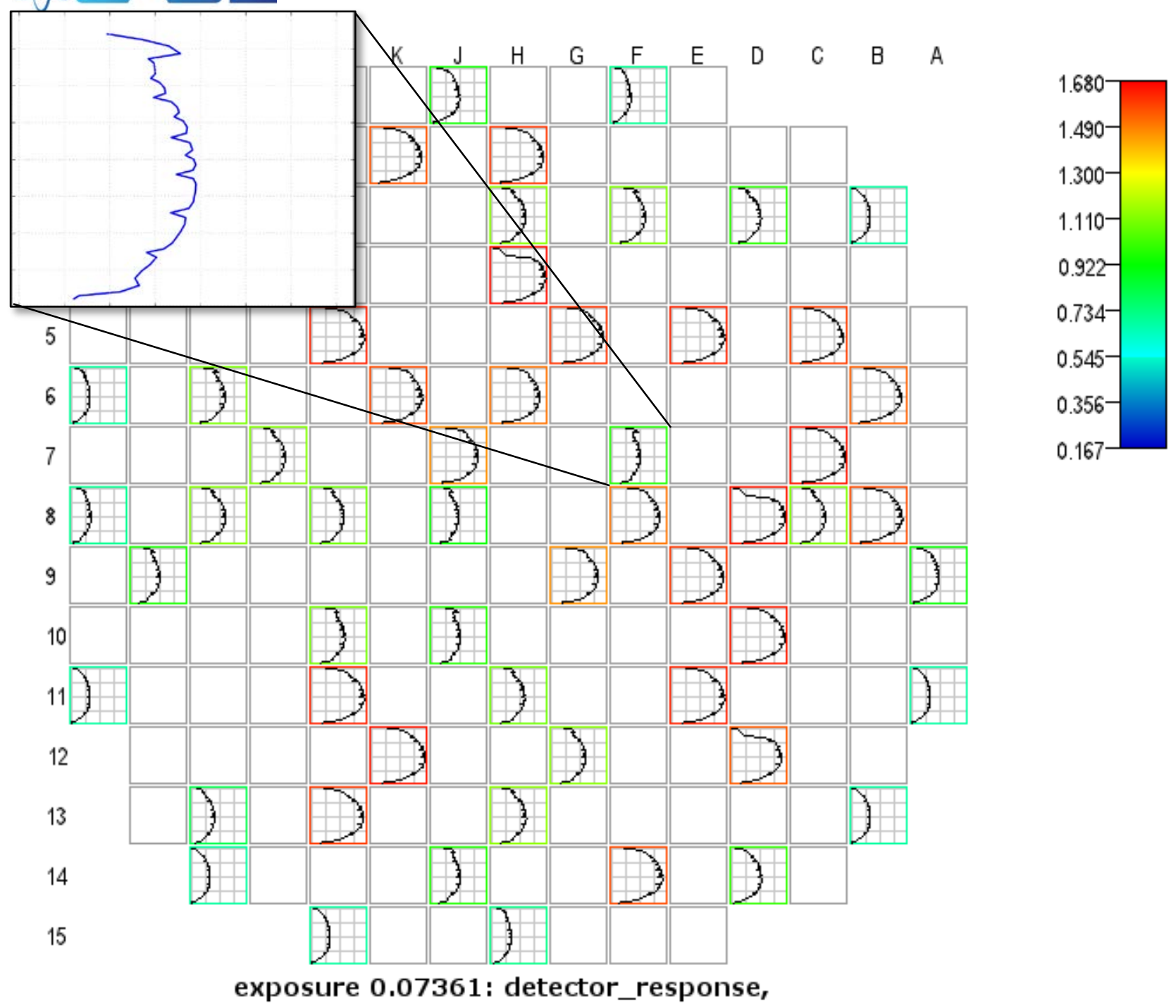

Figure 4-23. Raw Detector Response Output from VERA for the first WBN2 Flux Map.

In order to estimate the relative current of the vanadium wires, which have different lengths and axial positions than the MPACT axial mesh, a cubic spline (piece-wise third order polynomial) is used to fit the 50 level detector response and extend the calculated distribution above and below the active fuel column. For reliability, the highest and lowest extents of the spline are replaced with linear extrapolation. An example of this calculation is shown below in Figure 4-24, using core location F-7 (shown in the previous figure) for demonstration. The blue circles are the meshcentered volume-average vanadium detector response values from MPACT, and the red curve is the cubic spline representation with extrapolation. Agreement between the two is very good, with only $0.25 \%$ error in the total integrated response within the active fuel region. 


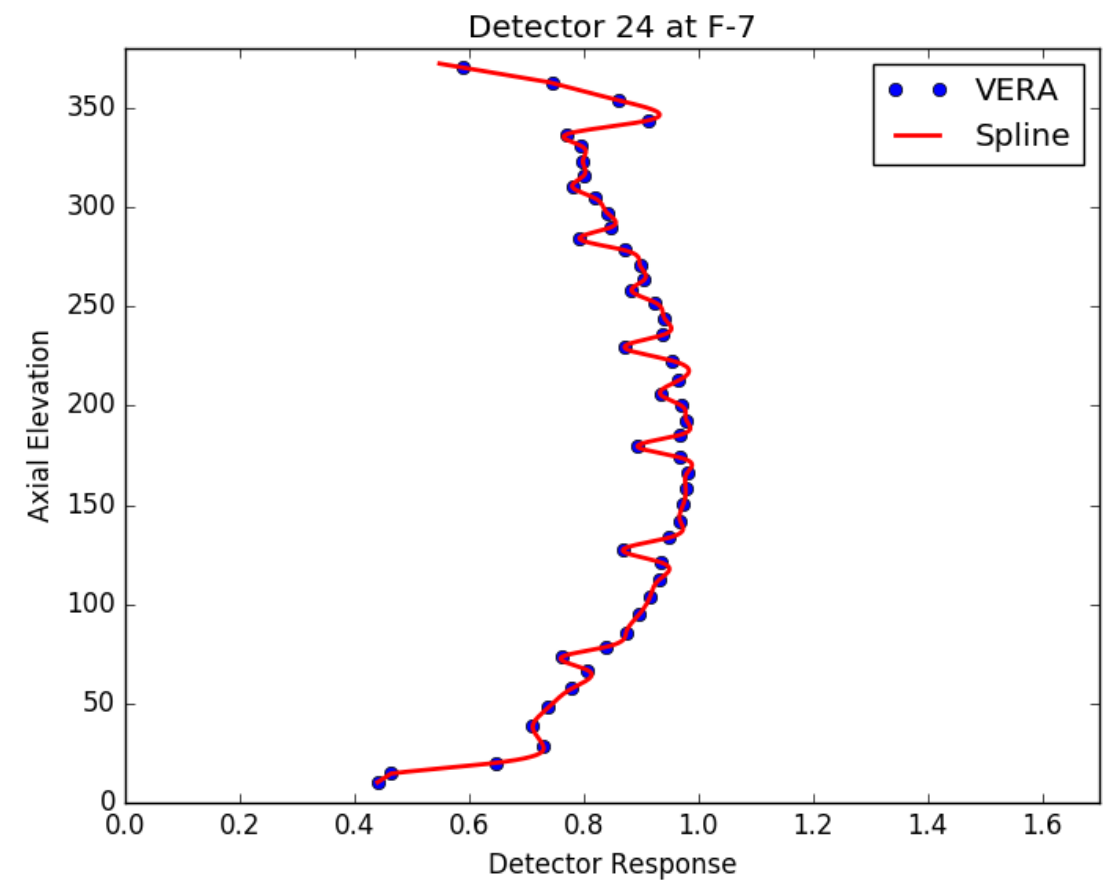

Figure 4-24. Example Cubic Spline Fit of Raw Detector Response Output from VERA.

Finally, the calculated relative current in each wire is calculated by integration of the cubic spline using elevations corresponding to the as-built emitter lengths and installed axial locations. This means that the calculated relative current is impacted by extrapolation of the MPACT results if the longest vanadium wire extends above the active fuel column (and vice versa). Using the example location F-7, the integrated currents for each of the five wires is shown in Figure 4-25 along with the measured currents from the same five wires. For comparison sake, each set of currents is normalized to the total current from all operable wires and then divided by the average of the measured currents in the shortest wires for scale. The relative error between calculated and measured currents in each wire is shown as a percentage of the measurement, and in this case the largest error is in the next-tolongest wire and is $2.5 \%$. 


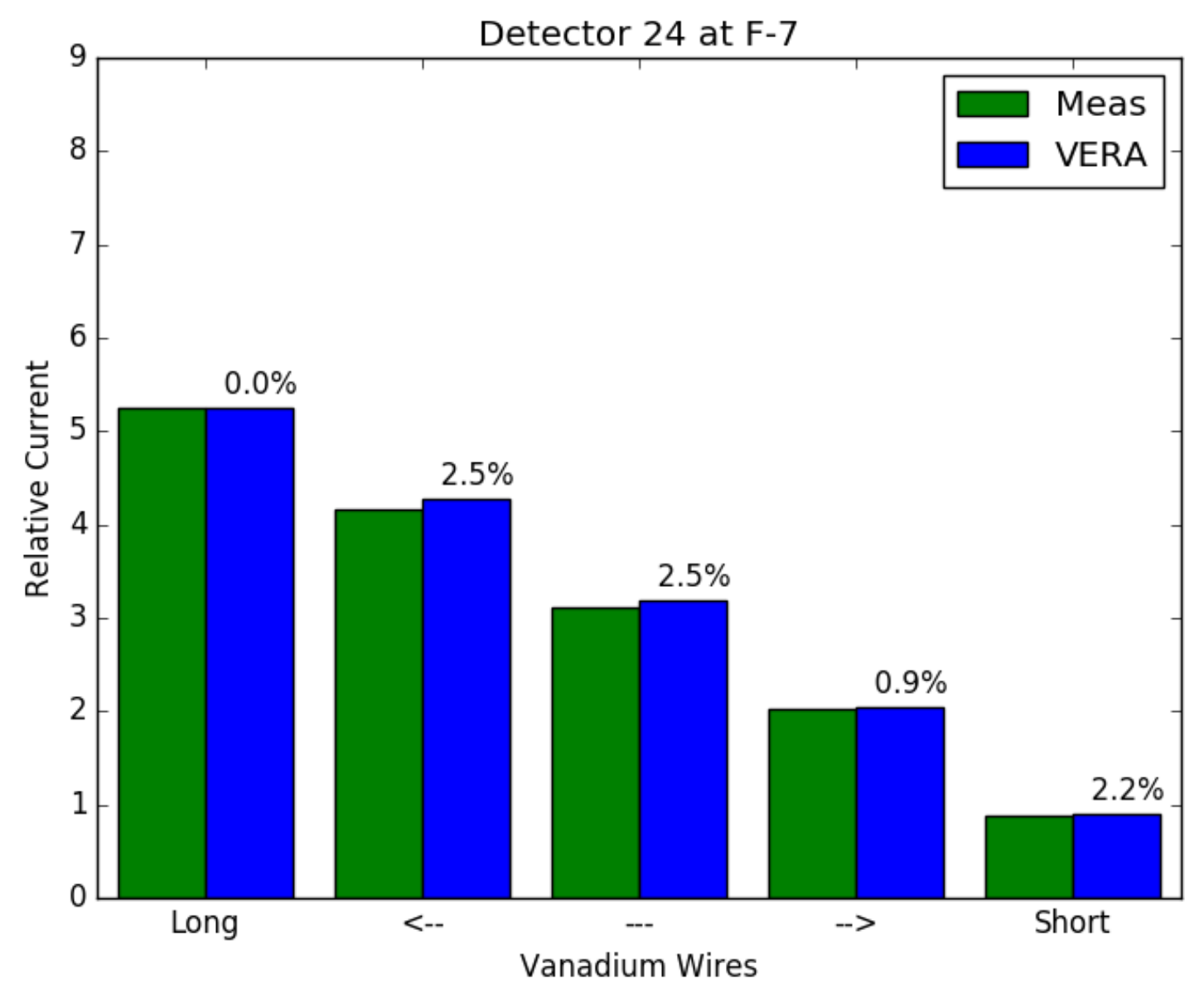

Figure 4-25. Comparison Calculated Detector Currents in F-7 of Flux Map 1.

In addition to the comparisons of vanadium wire currents, a more traditional response distribution comparison is possible by subtracting the currents between wires and using the current differences, also referred to as segments, to infer a five level power distribution. For instance, if the current differences are each divided be the segment heights, the linear segment response is directly comparable to the original MPACT detector response in 50 axial planes. This is shown in Figure 426 below. Here the same calculation is done for the measured and calculated currents, and the measured value for each segment is shown as a green box, with the absolute difference shown in percent to the left. For comparison sake, each distribution of segments is normalized to the average segment response.

It is important to note that the measurement segments are influenced by the variability in BOTH wires used to calculate them, and therefore may be subject to larger uncertainties themselves. Likewise, an inoperable wire results in TWO 'inoperable' segments, and both are removed from the population for statistics. It is also notable that a comparison of the axially integrated segments is essentially the same as the comparison of longest wires, which are fundamentally representative of the radial power distribution in the core. 

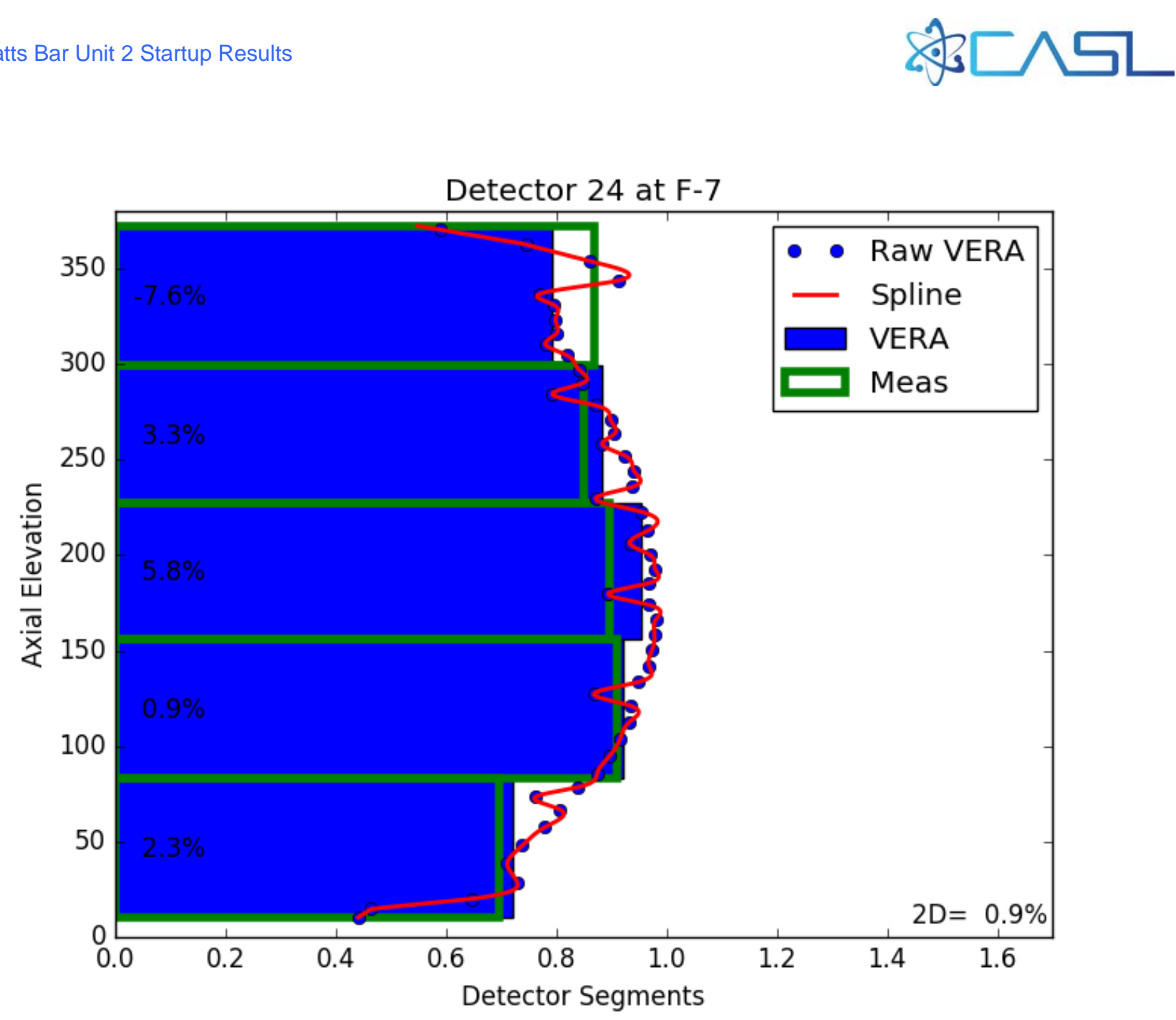

Figure 4-26. Comparison of Detector Segments F-7 of Flux Map 1.

Despite the very good comparisons of the individual wire currents in Figure 4-26, the traditional power distribution comparison methodology indicates less favorable agreement. For the detector in the example, the segment at the top of the assembly (the top 20\%) is under-predicted by $7.6 \%$, while the center of the core is over-predicted by 5.8\%, and the axially integrated segment responses are $0.9 \%$ different. This is partially explained by recognition that the current comparison is a relative error of values that are essentially four times larger than their difference. Furthermore, because the agreement is better between the longest wires than the next longest wires, the top predicted segment is smaller and therefore under-predicted. Because there are merits to looking at the comparisons in both ways, both the analysis of wire currents and segments will be continued through this report.

Since the startup of WBN2, twelve sets of measured in-core detector signals have been analyzed and compared to VERA calculations. These "flux maps" were provided by TVA from the WBN2 online monitoring system at various burnups and power levels throughout the power ascension testing and beyond. Though commercial operation was reached at the end of October, 2016, CASL has continued to make comparisons to measured detector signals in an effort to further understand the differences. In fact, the best comparisons are the most recent ones, which help to increase confidence in this analysis technique. A summary of all of the measured maps and their conditions is provided in Table 4-6. Also, Figure 4-27 is provided to demonstrate how the maps correspond to the startup history. 
Table 4-6. Summary of Measured Flux Map Cases and Conditions

\begin{tabular}{cccccc}
\hline Map & Date/Time & Power & Bank D & Exposure & EFPD \\
\hline 1 & $6 / 13 / 201615: 45$ & 26.7 & 185 & 0.068 & 1.9 \\
2 & $6 / 14 / 201615: 48$ & 27.6 & 185 & 0.079 & 2.2 \\
3 & $7 / 6 / 201620: 31$ & 40.2 & 189 & 0.223 & 6.0 \\
4 & $7 / 8 / 201617: 18$ & 46.9 & 191 & 0.254 & 6.8 \\
5 & $7 / 26 / 201610: 25$ & 73.8 & 202 & 0.506 & 13.5 \\
6 & $8 / 27 / 201618: 37$ & 88.1 & 210 & 0.86 & 22.7 \\
7 & $8 / 30 / 201620: 42$ & 98.6 & 219 & 0.968 & 25.5 \\
8 & $11 / 3 / 20167: 14$ & 98.6 & 221 & 1.994 & 52.5 \\
9 & $12 / 19 / 20168: 14$ & 99.7 & 220 & 3.732 & 97.9 \\
10 & $1 / 17 / 20177: 04$ & 99.6 & 220 & 4.830 & 126.7 \\
11 & $2 / 13 / 20177: 50$ & 99.9 & 220 & 5.856 & 153.6 \\
12 & $3 / 13 / 201713: 28$ & 99.6 & 220 & 6.928 & 181.7 \\
\hline
\end{tabular}

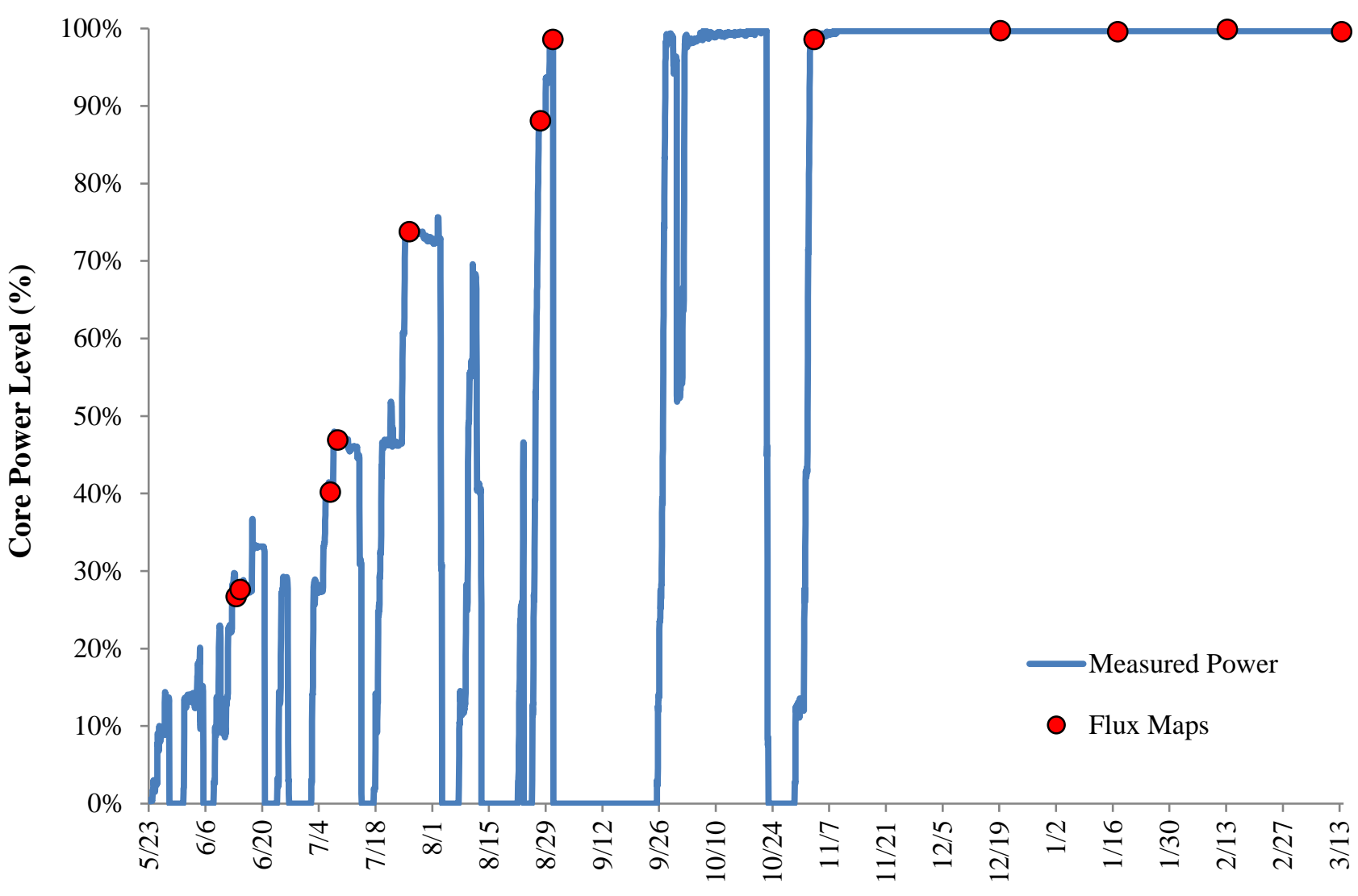

Date

Figure 4-27. WBN2 Power History Showing Dates of Measured Flux Maps. 


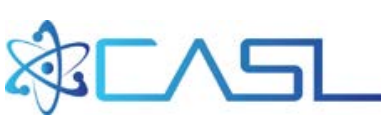

For each of the flux map comparison cases, a restart file was written as part of the quarter-core hourly power ascension cases. Then the flux map was re-executed from the restart file with the following changes:

1. The geometry was expanded to full core symmetry and executed on 3,712 cores.

2. The exact power, inlet temperature, Bank D position, and pressure were input as statepoint conditions.

3. The stainless steel instrument thimbles were inserted into the instrumented locations.

4. The WABAs located in the two locations of the primary sources were removed.

5. The secondary source rodlets were added (for moderator displacement).

6. For the last five maps which were recorded at steady-state conditions after the power escalation, the equilibrium xenon option was applied (for consistency with the full core symmetry).

7. For the last five maps which were recorded at steady-state conditions after the power escalation, and didn't require axial power dampening, the original BISON fuel temperature tables were used (consistent with the VERA 3.6 defaults).

Following is a detailed comparison of the most recent flux map on March 13, 2017. Then summary results will be provided for all maps, leaving the detailed distributions for the other eleven maps in Appendix B, to be studied at the reader's interest level. In all cases, both the traditional power distribution comparisons are made between detector segments, and then a direct comparison of detector currents for each wire is also performed.

The summary statistics for the comparison of detector segments for Case 12 are shown in Table 4-7. As described earlier, the measured and calculated detector segments are each normalized to the core average value. The comparisons are made in terms of absolute differences, and the population statistics are expressed in terms of a root mean square (RMS) difference, each multiplied by 100 (\%). Also the maximum absolute difference is provided. Statistics are provided for the total population of differences (3-D), the differences in radial response distributions (axially integrated), and the differences in the five level axial average distributions (radially integrated).

Table 4-7. Segment Comparison Statistics for Case 12

\begin{tabular}{llll}
\hline & Total & Radial & Axial \\
\hline RMS & $3.19 \%$ & $1.91 \%$ & $1.50 \%$ \\
Maximum & $10.53 \%$ & $4.22 \%$ & $2.68 \%$ \\
\hline
\end{tabular}

For Case 12, VERA shows excellent agreement with the measured vanadium segments with a total RMS difference in all detector segments of only 3.2\%. The differences in radial segment responses are shown below in Figure 4-28 from VERAView, and the core average axial shape differences are shown in Figure 4-29. Despite the significant differences in in-core detector systems between WBN1 and WBN2, these detector response comparisons are approximately as good (or slightly better) than VERA's agreement with WBN1 Cycle 1 data at about the same burnup (3.5\% total, $1.2 \%$ radial, $2.8 \%$ axial) [5]. 


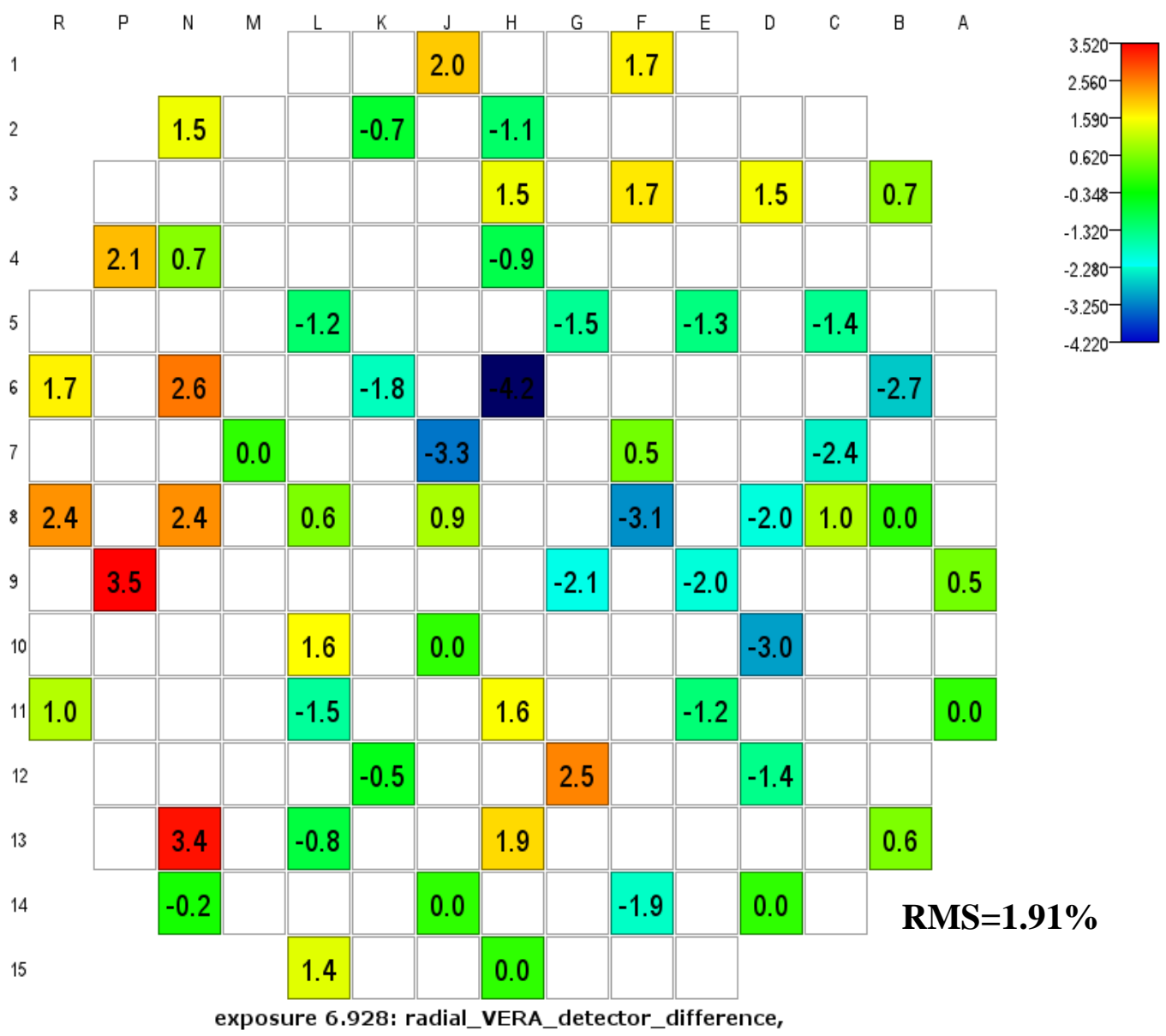

Figure 4-28. Radial Detector Segment Response Differences (C-M,\%) for Map 12.

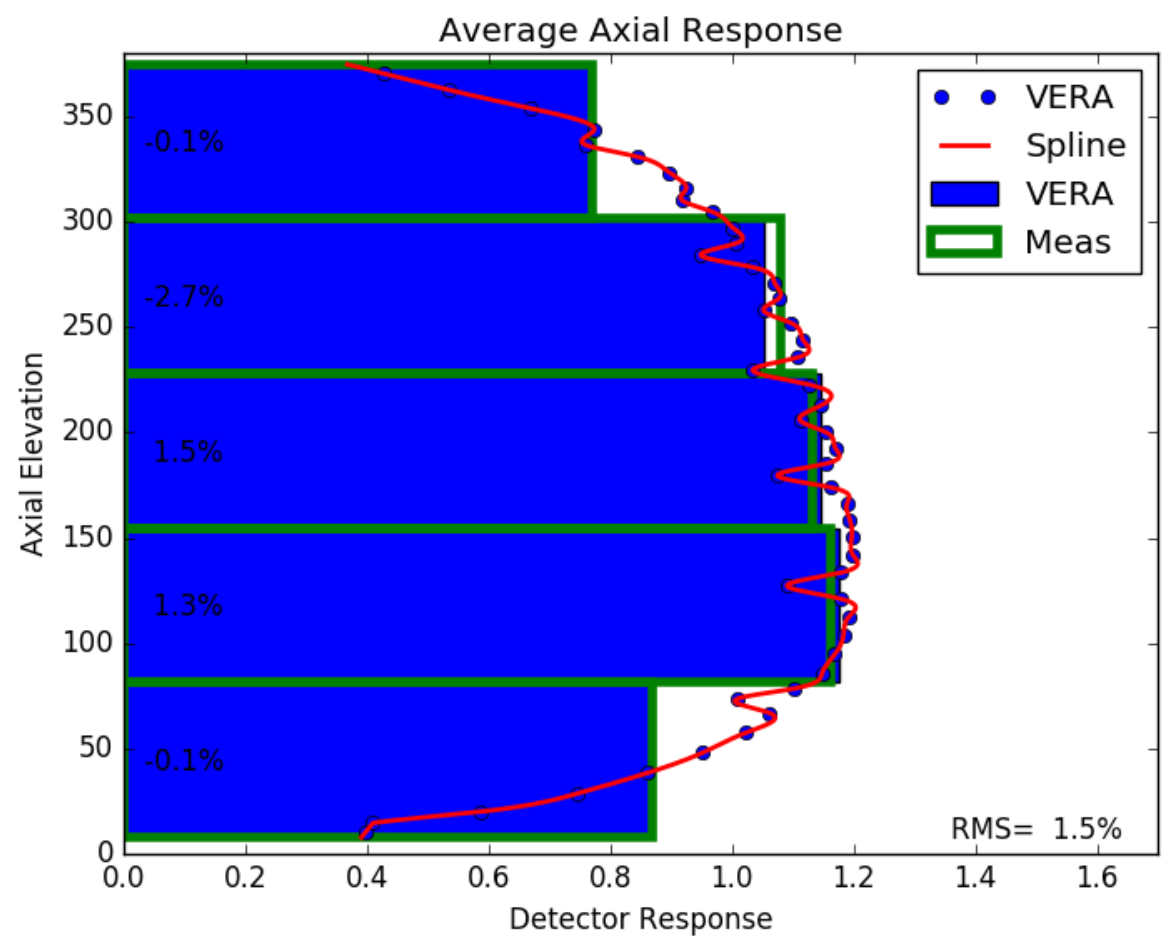

Figure 4-29. Axial Detector Segment Response Differences (C-M,\%) for Map 12. 


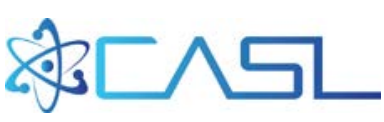

The results of the direct current analysis appear to be even better, demonstrating more agreement between measured and predicted wire currents. The statistics are provided for relative currents in all wires, just the long wires, and the average of each length of wire (pseudo -“axial”). The currents are referred to as "relative" because each population of currents is normalized to the total current for the entire reactor, then rescaled such that average measured current for all short wires is 1.0. Each of the currents are compared by relative error (calculated minus measured, divided by measured), and each population of errors is summarized by average, standard deviation, RMS, and maximum absolute error.

Table 4-8. Wire-based Relative Current Comparison Statistics for Case 12

\begin{tabular}{llll}
\hline & All Wires & Long Wires & $\begin{array}{l}\text { Five } \\
\text { Averages }\end{array}$ \\
\hline Average & $0.49 \%$ & $0.25 \%$ & $0.01 \%$ \\
Standard Deviation & $2.21 \%$ & $2.08 \%$ & $0.37 \%$ \\
RMS & $2.26 \%$ & $2.09 \%$ & $0.37 \%$ \\
Maximum & $5.83 \%$ & $4.79 \%$ & $0.58 \%$ \\
\hline
\end{tabular}

Table 4-8 shows that in this map, the error in all operable vanadium wires is only $0.5 \pm 2.2 \%$, and this error distribution is similarly reflected in the long wires. The distribution of errors in the long wires is shown below in Figure 4-30, and the statistics for each length of wire is shown in Figure 431. The distribution of errors in each wire length is similar, with standard deviations between 2.0 and $2.5 \%$, and average errors of $<1.0 \%$. 


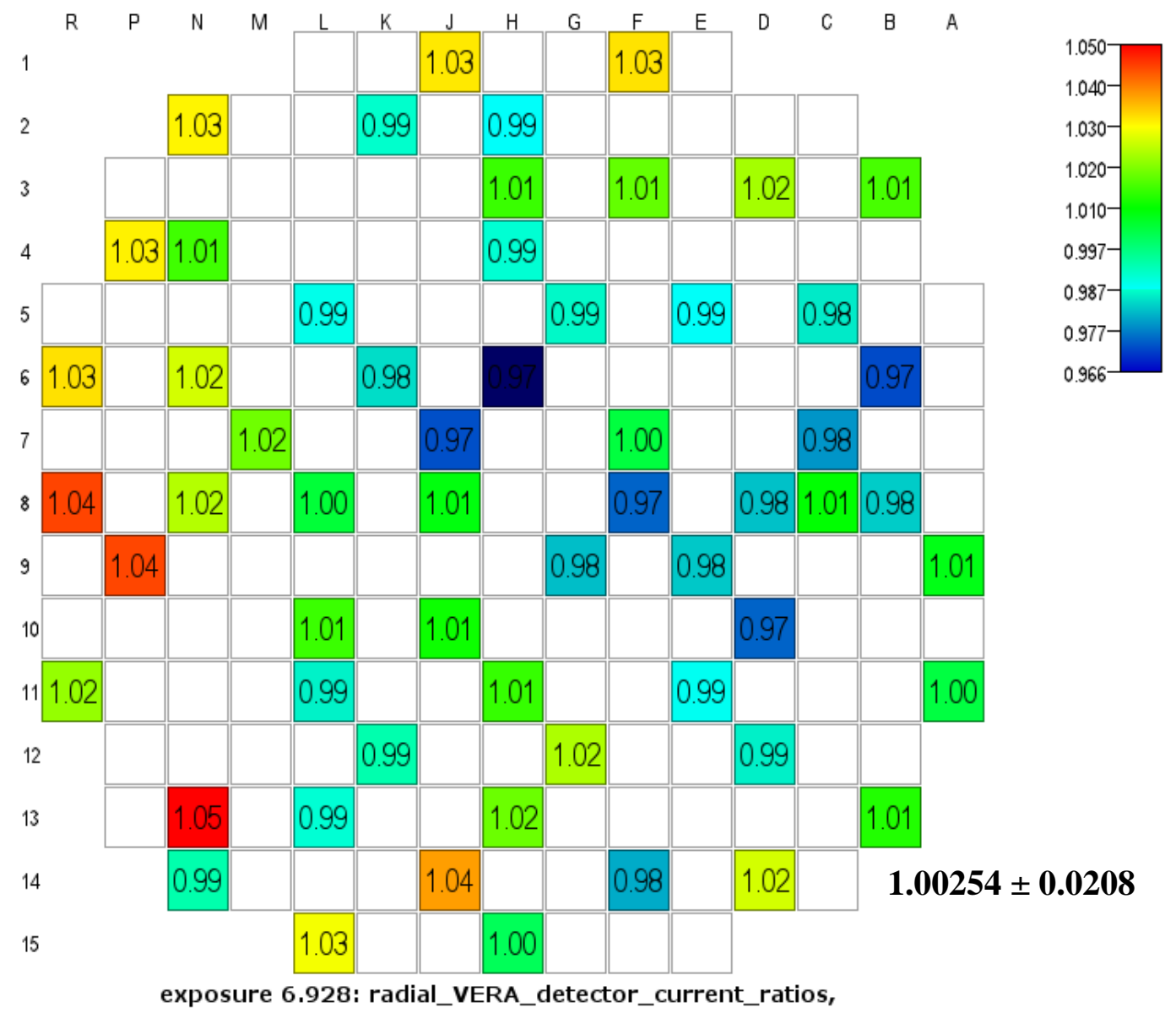

Figure 4-30. Long Wire Relative Current Ratios (C/M) for Map 12.

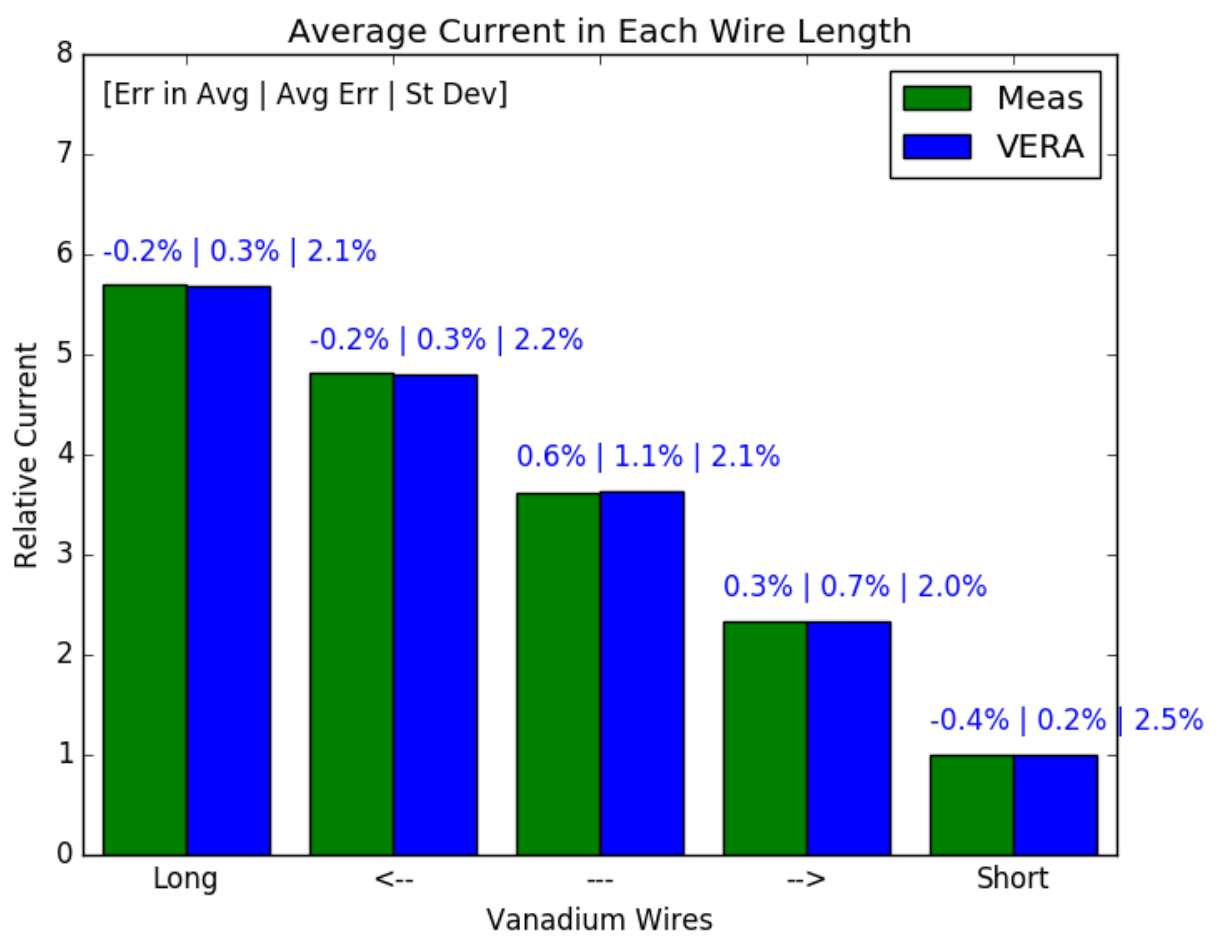

Figure 4-31. Relative Current Comparison in Each Wire Length for Map 12. 
Figure 4-31 displays excellent agreement in the average relative current for each length of wire, with the error in average currents being less than $0.6 \%$. The average error in each length of wire is also less than $1.1 \%$, and the standard deviation in each set of wires is between 2.0 and $2.5 \%$.

It is clear from the results of Map 12 that VERA is capable of accurately predicting the vanadium emitter currents and that the analysis methodology being employed is acceptable. However, Map 12 shows the best in-core detector response results, which over the course of the startup appeared to continually improve with time. This could be due to power increasing or due to the effects of core burnup. The RMS differences of the detector segments over the twelve maps are shown in Figure 432 below. The total, radial, and axial RMS's over all cases are $4.4 \%, \mathbf{2 . 6 \%}$, and $\mathbf{2 . 5 \%}$, respectively.

Likewise, the RMS errors of the integrated wire relative currents are shown in Figure 4-33. The values for the RMS in all wire errors, as well as the RMS values for each length of wire, are shown as a function of case number. The RMS of all the currents is $\mathbf{3 . 3 \%}$ and the RMS of all the long wires in all cases is $\mathbf{2 . 7 \%}$. 


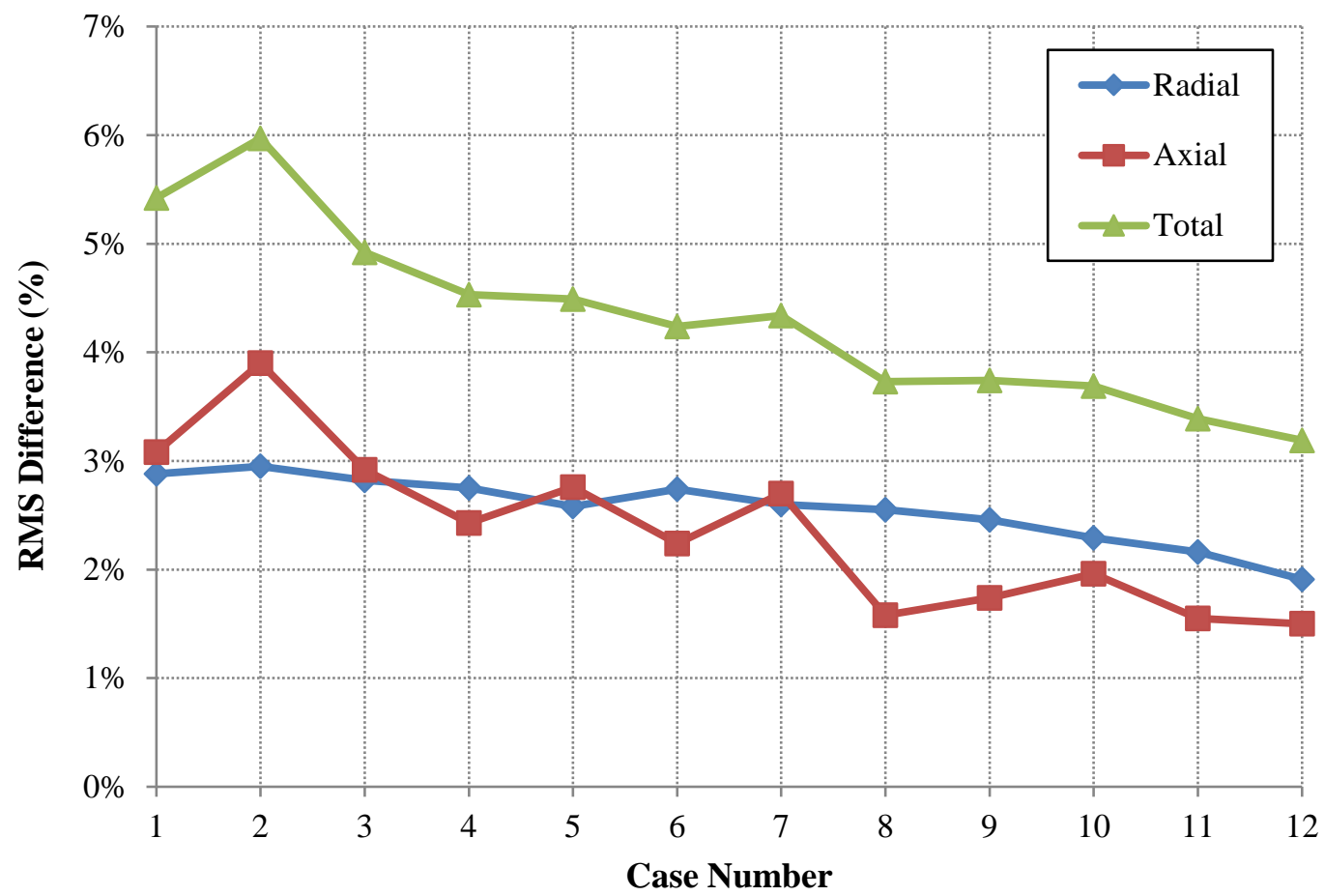

Figure 4-32. Statistical Summary of the Detector Segment Comparisons for All Cases.

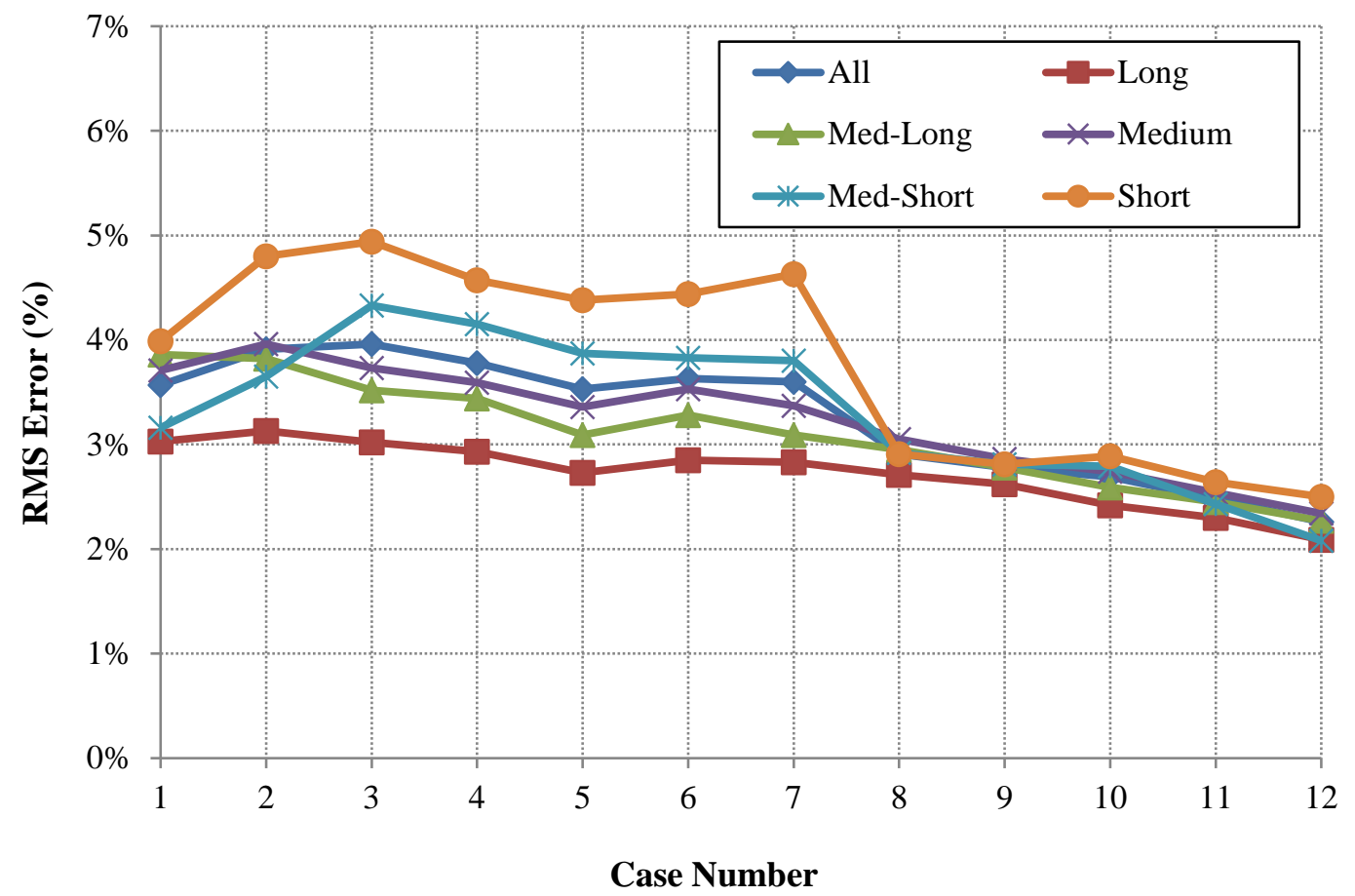

Figure 4-33. Statistical Summary of the Relative Detector Current Comparisons for All Cases. 


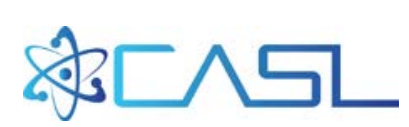

\subsubsection{Flux Map Critical Boron Concentrations}

There are no exact measured soluble boron concentrations for the flux map conditions. However, with measurements every day, the conditions are likely similar and still may allow for reasonable comparisons to predicted values. Table 4.9 provides the measured boron concentration for the closest time to the flux map, along with the predicted concentration for the map from VERA. Results are included for both the original BISON fuel temperature table and the modified table described in Section 4.5.5. The predictions are adjusted to estimated ${ }^{10} \mathrm{~B}$ values using the model described in Section 4.5.9. Note that not all calculations were performed with both temperature sets.

Table 4-9. Approximate Critical Boron Comparisons for Each Flux Map

\begin{tabular}{|c|c|c|c|c|c|c|c|}
\hline Map & Power & EFPD & $\begin{array}{c}\text { Measured } \\
(\mathrm{ppmB})\end{array}$ & $\begin{array}{c}\text { Calculated } \\
\text { (original) } \\
\text { (ppmB) }\end{array}$ & $\begin{array}{c}\text { Calculated } \\
\text { (modified) } \\
\text { (ppmB) }\end{array}$ & $\begin{array}{c}\text { Difference } \\
\text { (original) } \\
\text { (ppmB) }\end{array}$ & $\begin{array}{r}\text { Difference } \\
\text { (modified) } \\
\text { (ppmB) }\end{array}$ \\
\hline 1 & 26.7 & 1.9 & 851 & -- & 808 & -- & -43 \\
\hline 2 & 27.6 & 2.2 & 831 & -- & 804 & -- & -27 \\
\hline 3 & 40.2 & 6.0 & 788 & -- & 747 & -- & -41 \\
\hline 4 & 46.9 & 6.8 & 757 & -- & 725 & -- & -32 \\
\hline 5 & 73.8 & 13.5 & 703 & 688 & 660 & -15 & -43 \\
\hline 6 & 88.1 & 22.7 & 728 & 704 & 665 & -24 & -63 \\
\hline 7 & 98.6 & 25.5 & 682 & 666 & 622 & -16 & -60 \\
\hline 8 & 98.6 & 52.5 & 712 & 705 & 662 & -7 & -50 \\
\hline 9 & 99.7 & 97.9 & 713 & 698 & 653 & -15 & -60 \\
\hline 10 & 99.6 & 126.7 & 708 & 689 & 643 & -19 & -65 \\
\hline 11 & 99.9 & 153.6 & 687 & 668 & -- & -19 & -- \\
\hline 12 & 99.6 & 181.7 & 656 & 638 & -- & -18 & -- \\
\hline \multicolumn{3}{|c|}{ Average } & & & & -17 & -48 \\
\hline \multicolumn{3}{|c|}{ St. Deviation } & & & & 5 & 13 \\
\hline
\end{tabular}

The uncertainty in these measured values is expected to be between 5 and $15 \mathrm{ppmB}$. The components include the uncertainty in the measurement of the boron concentration, the uncertainty in the assumed ${ }^{10} \mathrm{~B}$ abundance, and the uncertainty in the consistency of conditions between the measured value and the flux map conditions. The results for the original BISON fuel temperature table are good with a low variation, but the new table results in an increase in error of 31 ppmB less and nearly a tripling in variance. The trend in the boron differences for the modified fuel temperature tables matches that of Figure 4-22, in that it shows that VERA is overestimating the power defect. 


\section{CONCLUSIONS}

The WBN2 startup simulations and subsequent analyses have demonstrated the value of VERA as a high-fidelity, easy-to-use predictive tool for new reactor startups and first-of-a-kind evolutions. The predictions made by CASL for physics testing were made three months in advance of the reactor startup and were proven very accurate. Subsequent calculations with the most recent version VERA 3.6 shows near perfect agreement with the initial critical boron measurements of $-2 \mathrm{ppm}$, and total control bank worth errors of less than $1 \%$.

The five month power escalation procedure was simulated by the hour, requiring 900,000 corehours on 2,784 processors and two weeks of total runtime. This was first performed on-the-fly during the power ascension with frequent interaction between CASL and TVA staff. However, the initial results were quite poor at the higher power plateaus, with large undamped axial power oscillations resulting from axial transient ${ }^{135}$ Xe swings. Though this issue has not been resolved, it was found (as has been true with other methods) that increasing the fuel temperature response to power increases would dampen the oscillations and result in better axial power shape agreement with measurements. The startup scenario was recalculated in its entirety and the improvements in AFD were dramatic, but the agreement in critical boron concentrations and radial power distributions both worsened with the modified fuel temperatures. Improvements are needed in the area of fuel temperature inputs to either get better best-estimate Doppler feedback, or to eliminate temperature and possibly lead to some other related problem.

Despite the axial power shape problems, VERA was able to successful execute over 4,000 hourly timesteps including over 16,600 fully-coupled neutrons/thermal-hydraulic iterations. This impressive performance provides additional confidence as CASL increases its focus on PCI related simulations performing load following maneuvers. The recent performance improvements in VERA have led to significantly reduced runtimes, and in this case the average statepoint runtime was less than five minutes. CASL continues to demonstrate that the methods in VERA can be used for realistic reactor simulations and that the computational requirements for these calculations are not beyond the attainability of industrial organizations.

Finally, the in-core power distribution comparisons started with larger than desired differences in both the radial and axial directions. However, these comparisons have significantly improved as power increased and the cycle has progressed, and the latest results are excellent. It is unclear if the larger errors early in the startup were related to errors in axial power shape prediction, the inaccurate modified fuel temperatures utilized for dampening the aforementioned axial power oscillations, or if the uncertainty in the self-powered detector system was significantly larger at those lower power levels. Because the last several flux maps look very good, it is assumed that the approximations made for calculating the five wire relative currents in VERA are not a significant contributor to the differences.

This activity has demonstrated again the immense value in the direct collaboration between the power plant operator, fuel vendor, and national laboratory. The original goals of the CASL program continue to be proven successful, and as the code capabilities and accuracy improves, the value brought to the nuclear industry by CASL will continue to increase. But this success has occurred and will only continue as long as the participants continue to share data, expertise, and computational resources for the mutual benefit of the entire nuclear industry. 


\section{ACKNOWLEDGEMENTS}

The authors acknowledge the many contributors from CASL partner organizations that contributed to the success of these simulations, including Steven Halcomb and Christine Setter of TVA, and Fausto Franceschini, David Salazar, Vefa Kucukboyaci, and Jeffrey Secker of Westinghouse. Additionally the support of Don Maxwell of OLCF was essential to this activity. Significant contributions were also made by Kathleen Cunningham, now retired from TVA. The authors wish to acknowledge the many methods and software developers working to improve the accuracy, performance, and usability of VERA, including Scott Palmtag, Bob Salko, Brendan Kochunas, Dan Jabaay, Tom Downar, Kevin Clarno, Tom Evans, and Tara Pandya, as well as ORNL's Ron Lee for his development of VERAView. Finally, the success of the WBN2 startup simulations along with the VERA development and the CASL program is substantially due to the excellent leadership and mentoring provided by Jess Gehin.

This research also made use of the Oak Ridge Leadership Computing Facility at the Oak Ridge National Laboratory (ORNL), which is supported by the Office of Science of the U.S. Department of Energy under Contract No. DE-AC05-00OR22725, as well as the High Performance Computing Center at INL, supported by the Office of Nuclear Energy of the U.S. Department of Energy under Contract No. DE-AC07-05ID14517. 


\section{REFERENCES}

1. “TVA - Watts Bar 2 Project”. Tennessee Valley Authority. Dec. 2016. https://www.tva.com/Newsroom/Watts-Bar-2-Project

2. “Watts Bar Unit 2 Reactivation”, U.S. Nuclear Regulatory Commission. October, 2015. https://www.nrc.gov/info-finder/reactors/wb/watts-bar/history.html

3. "Watts Bar Nuclear Plant Unit 2 Completion Project - Estimate to Complete - Executive Final Report, Tennessee Valley Authority, April 2012. https://www.tva.gov/file_source/TVA/Site\%20Content/News/wb2/wattsbar2_executive_etc.pdf

4. “TVA’s Watts Bar 2 Officially Begins Operating”, Nuclear Energy Institute (NEI), October, 2016. https://www.nei.org/News-Media/News/News-Archives/TVA-s-Watts-Bar-2-OfficiallyBegins-Operating

5. A. Godfrey, et. al., "VERA Benchmarking Results for Watts Bar Nuclear Plant Unit 1 Cycles 112", CASL-U-2015-0206-000, CASL, June 2016. http://www.casl.gov/docs/CASL-U-2015-0206-000.pdf

6. A. Godfrey, "VERA Core Physics Benchmark Progression Problem Specifications”, CASL-U2012-0131-004, Revision 4, CASL, August, 2014. http://www.casl.gov/docs/CASL-U-2012-0131-004.pdf

7. S. Palmtag and A. Godfrey, "VERA Common Input User Manual”, CASL-U-2014-0014-002, Revision 2, CASL, February, 2015. http://www.casl.gov/docs/CASL-U-2014-0014-002.pdf

8. B. Collins, et. al., "Stability and Accuracy of 3D Neutron Transport Simulations Using the 2D/1D Method in MPACT,” Journal of Computational Physics, 326, 612, 2016

9. K. Kim, M. Williams, D. Wiarda, and A. Godfrey, "Development of a New 47-group Library for the CASL Neutronics Simulator,” Proc. ANS MC2015-Joint International Conference on Mathematics and Computation (M\&C), Supercomputing in Nuclear Applications (SNA) and the Monte Carlo (MC) Method, Nashville, Tennessee, April 19-23, 2015. http://www.casl.gov/docs/CASL-U-2015-0180-000.pdf

10. D. Wiarda, S. Goluoglu, M.E. Dunn, N.M. Green and L. M. Petrie, “AMPX-6: A Modular Code System for Processing ENDF/B Evaluations,” in preparation, 2014.

11. R. J. J. Stamm’ler et al., “The HELIOS Methods,” Studsvik Scandpower , 1998.

12. K. Kim et al., "Monte Carlo Resonance Treatment for the Deterministic Transport Lattice Codes,” Journal of the Korean Nuclear Society, 35, No.6, 581-595, 2003.

13. B. Herman, B. Forget, K. Smith, "Improved Diffusion Coefficients Generated From Monte Carlo Codes,” M\&C 2013, Sun Valley, Idaho, May 5-9, 2013.

14. S. Palmtag, "MPACT Library Verification by Comparison of Assembly Calculations Monte Carlo Results”, CASL-U-2016-1052-000, CASL, March 2016. http://www.casl.gov/docs/CASLU-2016-1052-000.pdf

15. C. Gentry, A. Godfrey, and F. Franceschini, “AP1000 ${ }^{\circledR}$ Benchmarking of VERA Neutronics Toolset”, Proc. M\&C 2017 - International Conference on Mathematics \& Computational Methods Applied to Nuclear Science \& Engineering, Jeju, Korea, April 16-20, 2017.

16. R. Salko, et. al., "Development of COBRA-TF for Modeling Full-Core, Reactor Operating Cycles,” Advances in Nuclear Fuel Management V (ANFM 2015), March 29-April 1, Hilton Head, South Carolina, 2015. http://www.casl.gov/docs/CASL-U-2015-0133-000.pdf 
17. V. Kucukboyaci, Y. Sung, and R. Salko, "COBRA-TF Parallelization and Application to PWR Reactor Core Subchannel DNB Analysis," Proceedings of the ANS MC2015 - Joint International Conference on Mathematics and Computation (M\&C), Supercomputing in Nuclear Applications (SNA) and the Monte Carlo (MC) Method, Volume (ANS paper_176_1), April 19, 2015, Nashville, Tennessee, 2015. http://www.casl.gov/docs/CASL-U-2015-0167-000.pdf

18. C. Frepoli, et al., "Modeling of annular film dry out with COBRA-TF". Proceedings of the 9th International Conference on Nuclear Engineering, 2001.

19. M. Avramova, K. Ivanov, L. Hochreiter, S. Balzus, and R. Mueller. "Comparitive analysis of PWR core wide and hot channel calculations”. Transactions from 2002 ANS Winter Meeting, 2002.

20. M. Avramova and D. Cuervo. "Assessment of CTF boiling transition and critical heat flux modeling capabilities using the OECD/NRC BFBT and PSBT benchmarks database”. Proceedings of the 14th International Topical Meeting on Nuclear Reactor Thermal Hydraulics, 2011.

21. R. Salko, A. Wysocki, B. Collins,A. Godfrey, C. Gosdin, M. Avramova, “Development and Testing of CTF to Support Modeling of BWR Operating Conditions”, CASL-U-2016-1030-000, CASL, January, 2016. http://www.casl.gov/docs/CASL-U-2016-1030-000.pdf

22. M. Avramova, K. Ivanov, B. Krzykacz-Hausmann, K. Velkov, A. Pautz, and Y. Perin. "Uncertainty analysis of COBRA-TF void distribution predictions for the OECD/NRC BFBT benchmark”. Proceedings of the 2009 International Conference on Advances in Mathematics, Computational Methods and Reactor Physics, number 202600, 2009.

23. M. Avramova, A. Velazquez-Lozada, and A. Rubin. "Comparative analysis of CTF and TRACE thermal-hydraulic codes using OECD/NRC PSBT benchmark void distribution database”. Proceedings of the 14th International Topical Meeting on Nuclear Reactor Thermal Hydraulics, 2011.

24. B. Rearden and M. Jessee, Eds., “SCALE Code System,” ORNL/TM-2005/39, Version 6.2, Oak Ridge National Laboratory, Oak Ridge, Tennessee, 2016. Available from Radiation Safety Information Computational Center as CCC-834.

25. I. Gauld G. Radulescu, G. Ilas, B. Murphy, M. Williams, and D. Wiarda, “Isotopic Depletion and Decay Methods and Analysis Capabilities in SCALE,” Nuclear Technology, 174(2), 169, 2011.

26. G. Ilas, I. C. Gauld, and H. Liljenfeldt, "Validation of ORIGEN for LWR used fuel decay heat analysis with SCALE," Nuclear Engineering and Design, vol.273, p. 58-67 (2014).

27. G. Ilas, I. C. Gauld, and G. Radulescu, "Validation of new depletion capabilities and ENDF/BVII data libraries in SCALE," Annals of Nuclear Energy, vol. 46, p.43-55, 2012.

28. W. Wieselquist, "The SCALE 6.2 ORIGEN API for High Performance Depletion," Proc. M\&C \& SNA 2014, Nashville, TN, USA. April 19-23 (2015).

29. A. Isotalo and W. Wieselquist, "Implementation of CRAM Depletion Solver with External Feed and Improved Accuracy into ORIGEN," Proc. M\&C \& SNA 2014, Nashville, TN, USA. April 19-23, 2015.

30. R. Williamson, et al., "Multidimensional Multiphysics Simulation of Nuclear Fuel Behavior," Journal of Nuclear Materials, 423, 149-163, 2012.

31. D. Gaston, et al., "Moose: A Parallel Computational Framework for Coupled Systems of Nonlinear Equations,” Nuclear Engineering Design, 239, 1768-1778, 2009.

32. T. Pandya, S. Johnson, G. Davidson, T. Evans, and S. Hamilton, "SHIFT: A Massively Parallel Monte Carlo Radiation Transport Package,” Proc. ANS MC2015-Joint International Conference on Mathematics and Computation (M\&C), Supercomputing in Nuclear Applications 
(SNA) and the Monte Carlo (MC) Method, April 19-23, 2015, Nashville, Tennessee, 2015. http://www.casl.gov/docs/CASL-U-2015-0170-000.pdf

33. "Oak Ridge Leadership Computing Facility - Titan System Users Guide”, OLCF, March, 2017. https://www.olcf.ornl.gov/support/system-user-guides/titan-user-guide/\#29

34. T. Pandya, T. Evans, G. Davidson, S. Johnson, A. Godfrey, "Shift Verification and Validation", CASL-U-2016-1186-000, CASL, September, 2016.

35. T. Pandya, S. Johnson, T. Evans, G. Davidson, S. Hamilton, A. Godfrey, "Implementation, capabilities, and benchmarking of Shift, a massively parallel Monte Carlo radiation transport code, ” Journal of Computational Physics, 308, 239-272, March, 2016.

36. "Vanadium detectors offer accuracy and long life", Nuclear Engineering International, March 2002.

http://www.neimagazine.com/features/featurevanadium-detectors-offer-accuracy-and-long-life/ 


\section{APPENDIX A: LETTER TO TVA WITH PREDICTIONS}


Kathleen A. Cunningham

March 1,2016

PWR Fuels Engineering Manager

Reactor Engineering and Fuels

Tennessee Valley Authority

Dear Kathleen,

CASL has successfully completed predictions for the HZP testing phase of the WBN2 initial startup. Through collaboration with Westinghouse, ORNL has prepared a highly detailed model of the reactor core and performed the physics parameter calculations with the high-fidelity $3 \mathrm{D}$ reactor simulator VERA-CS on 4526 parallel processors at INL. We believe that the VERA-CS platform provides the most advanced reactor core simulation capability available. The ZPPT test results for WBN2C1 predicted by VERA are the following:

BOC HZP Critical Boron Concentrations (19.9 at \% B-10):

- $\quad A R O=1064 \mathrm{ppmB}$

- Bank D inserted $=938$ ppmB

BOC HZP Control Bank Worths: See Table 1.

BOC HZP Isothermal Temperature Coefficients:

- $\mathrm{ARO}=-6.1 \mathrm{pcm} /{ }^{\circ} \mathrm{F}$

- Bank D inserted $=-\mathbf{1 0 . 5} \mathbf{~ p c m} /{ }^{\circ} \mathbf{F}$

$>$ BOC HZP Differential Boron Worth: $-10.5 \mathrm{pcm} / \mathrm{ppmB}$

Table 1: Bank Worths (pcm)

\begin{tabular}{ccc}
\hline Bank & Rod Swap & DRWM \\
\hline D & 1325 & 1320 \\
C & 1086 & 1078 \\
B & 793 & 821 \\
\hline A & 934 & 912 \\
SD & 442 & 452 \\
\hline SC & 441 & 452 \\
\hline SB & 1061 & 1072 \\
\hline SA & 399 & 420 \\
\hline
\end{tabular}

We, in continued collaboration with Westinghouse, would like to present these results to you, with the intent to provide TVA with additional insight and confidence in support of this important milestone. Westinghouse has reviewed these results and found that they are consistent with those in the Electronic Nuclear Parameters and Operations Package (eNuPOP) for WBN2 Cycle 1, with all differences being less than the typical acceptance criteria for each of the startup tests.

Please feel free to contact me for questions about these results or if you are interested in any additional VERA calculations. Our future plans include simulations of the power escalation testing and the nominal depletion of Cycle 1 .

Sincerely,

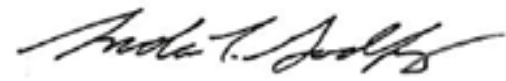

Andrew T. Godfrey

Senior R\&D Staff, Reactor Physics

Oak Ridge National Laboratory

godfreyat@oml.gov

c: J.C. Gehin, C.A Gentry, S.M. Halcomb, J. Hoagland, R.L. Oelrich, Jr., F. Franceschini 


\section{APPENDIX B: POWER DISTRIBUTION COMPARISONS}

\section{Case 1:}

$\begin{array}{ll}\text { Date/Time: } & \text { 6/13/2016 15:45 } \\ \text { Power: } & 26.7 \% \text { FP } \\ \text { Bank D Position: } & 185 \text { Steps withdrawn } \\ \text { VERA Burnup: } & 0.074 \text { GWd/MTU }\end{array}$

Typical Power Distribution Analysis of Segment Differences

\begin{tabular}{lccc} 
& TOTAL & RADIAL & AXIAL \\
\hline Average & $-0.0 \odot \%$ & $-0.0 \odot \%$ & $-0.0 \odot \%$ \\
RMS & $5.42 \%$ & $2.88 \%$ & $3.08 \%$ \\
Maximum & $25.26 \%$ & $7.04 \%$ & $6.01 \%$
\end{tabular}

By-Wire Statistics of Total Current Ratios

\begin{tabular}{lrrr} 
& \multicolumn{1}{c}{ ALL } & \multicolumn{1}{c}{ LONG } & AVERAGES \\
\hline Average & $1.14 \%$ & $-0.07 \%$ & $0.24 \%$ \\
Stdev & $3.38 \%$ & $3.03 \%$ & $0.63 \%$ \\
RMS & $3.57 \%$ & $3.03 \%$ & $0.67 \%$ \\
Maximum & $10.19 \%$ & $6.66 \%$ & $0.92 \%$
\end{tabular}

Statistics for Each Set of Wire Lengths

$\begin{array}{cccc}\text { Wires } & \text { Average } & \text { StDev } & \text { RMS } \\ \text { Long } & -0.07 \% & 3.03 \% & 3.03 \% \\ & 1.41 \% & 3.59 \% & 3.86 \% \\ & 1.63 \% & 3.34 \% & 3.71 \% \\ \text { Short } & 0.91 \% & 3.02 \% & 3.16 \% \\ & 1.84 \% & 3.54 \% & 3.99 \%\end{array}$




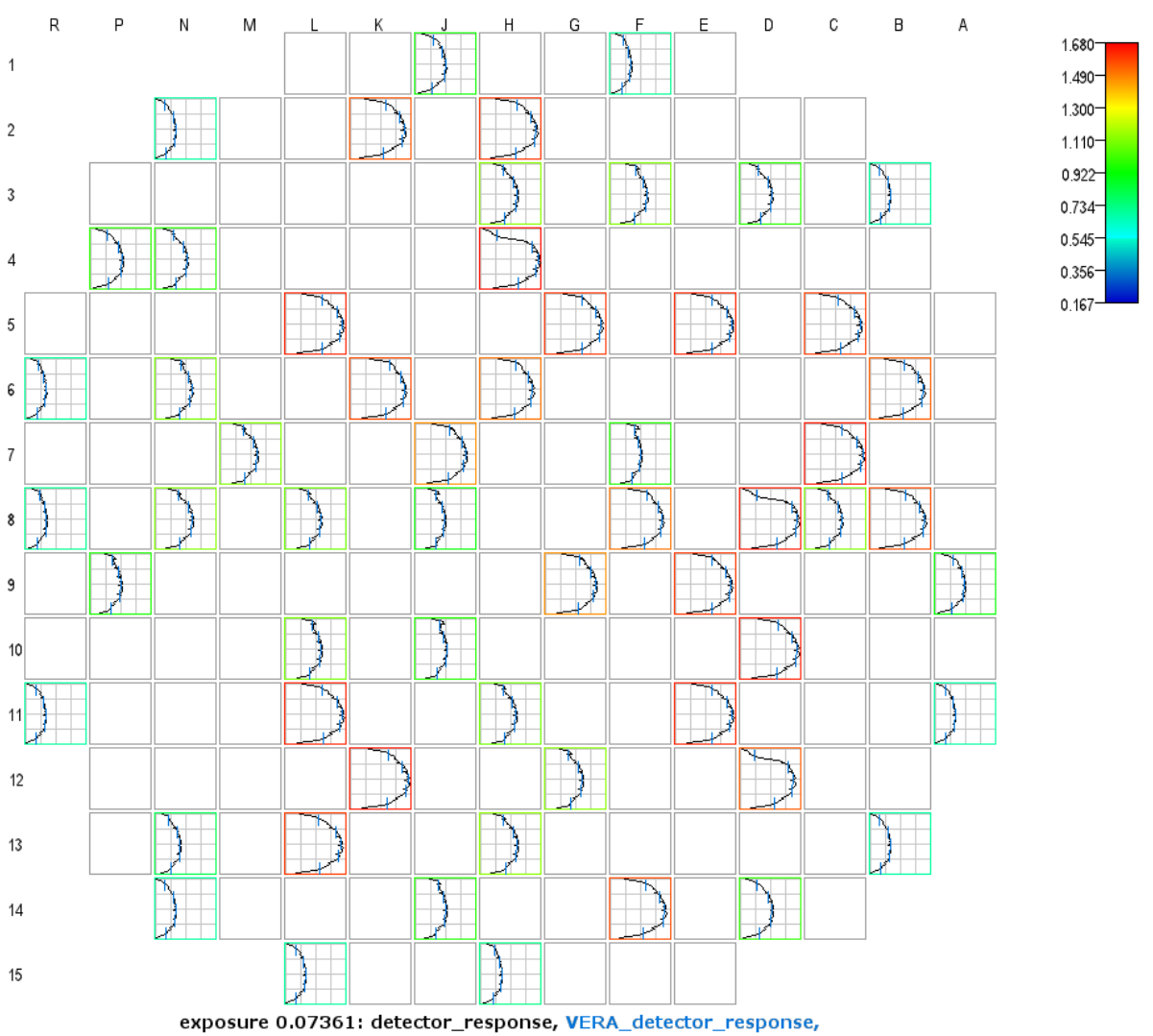

Figure B-1. Raw and Vanadium Detector Response Results from VERA for Case 1.

\begin{tabular}{|c|c|c|c|c|c|c|c|c|c|c|c|c|c|c|c|}
\hline \multirow{2}{*}{\multicolumn{2}{|c|}{$\mathrm{R}$}} & P & $\mathrm{N}$ & M & $L$ & K & J & $\mathrm{H}$ & G & $F$ & $E$ & \multirow[t]{2}{*}{ D } & \multirow[t]{2}{*}{ c } & \multirow[t]{2}{*}{ B } & \multirow[t]{2}{*}{ A } \\
\hline & & & & & & & 2.7 & & & 2.2 & & & & & \\
\hline 2 & & & 2.3 & & & -1.1 & & -3.4 & & & & & & & \\
\hline 3 & & & & & & & & 1.7 & & 2.1 & & -0.0 & & 2.0 & \\
\hline 4 & & 3.4 & 0.2 & & & & & -1.1 & & & & & & & \\
\hline 5 & & & & & -2.9 & & & & -3.0 & & -1.8 & & -1.4 & & \\
\hline 6 & 2.7 & & 4.3 & & & -4.1 & & -3.6 & & & & & & -3.6 & \\
\hline 7 & & & & 2.2 & & & -3.0 & & & 0.9 & & & -4.3 & & \\
\hline 8 & 4.3 & & 2.9 & & 1.1 & & 2.5 & & & -4.0 & & -3.0 & 0.3 & -5.7 & \\
\hline 9 & & 5.2 & & & & & & & -1.2 & & -3.5 & & & & -0.1 \\
\hline 10 & & & & & -2.3 & & 2.5 & & & & & & & & \\
\hline 11 & 2.7 & & & & -2.0 & & & 1.1 & & & -3.7 & & & & 0.1 \\
\hline 12 & & & & & & -1.8 & & & 2.9 & & & -1.6 & & & \\
\hline 13 & & & 3.8 & & -1.0 & & & 1.5 & & & & & & 0.8 & \\
\hline 14 & & & 2.6 & & & & 3.2 & & & -1.4 & & 3.3 & & & \\
\hline 15 & & & & & 2.7 & & & 2.9 & & & & & & & \\
\hline
\end{tabular}

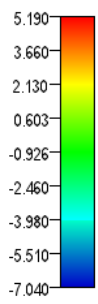

Figure B-2. Radial Detector Segment Differences (C-M,\%) for Case 1. 


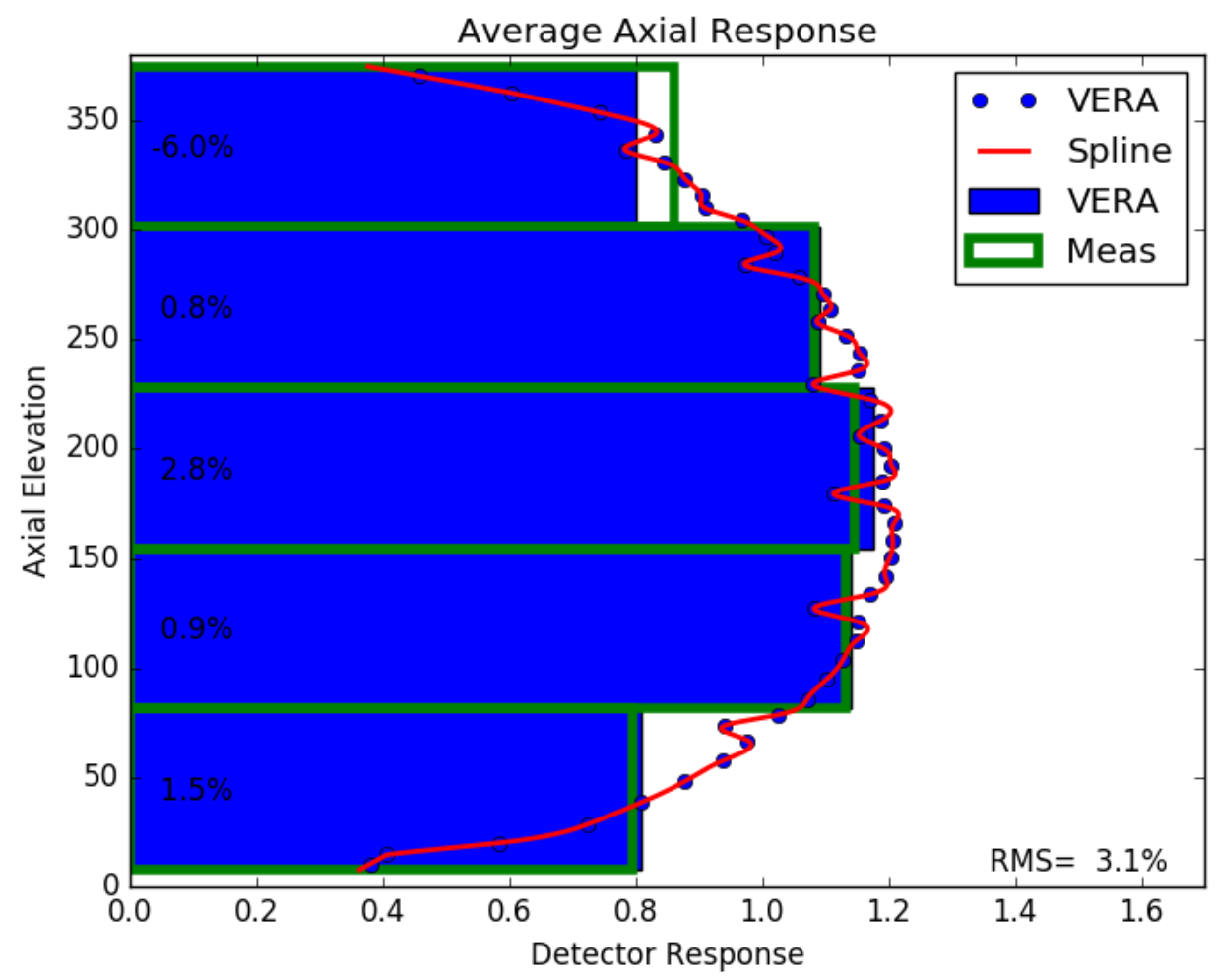

Figure B-3. Axial Detector Segment Differences (C-M,\%) for Case 1.

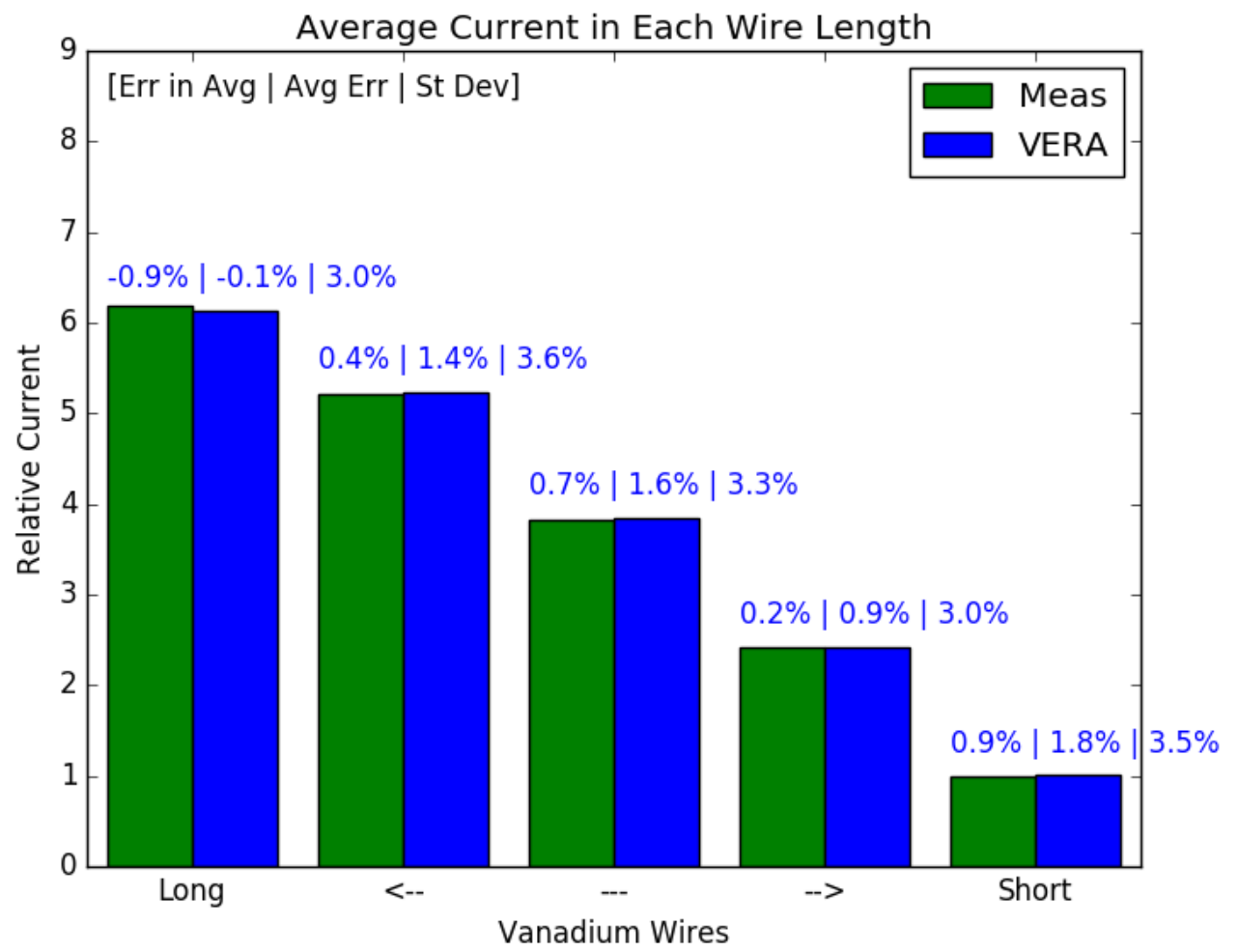

Figure B-4. Detector Relative Current Comparisons (C/M-1,\%) for Case 1. 


\section{Case 2:}

$\begin{array}{ll}\text { Date/Time: } & 6 / 14 / 201615: 48 \\ \text { Power: } & 27.6 \% F P \\ \text { Bank D Position : } 185 \text { Steps withdrawn } \\ \text { VERA Burnup: } & 0.084 \text { GWd/MTU }\end{array}$

Typical Power Distribution Analysis of Segment Differences

TOTAL RADIAL AXIAL

$\begin{array}{lrrr}\text { Average } & -0.00 \% & -0.00 \% & -0.00 \% \\ \text { RMS } & 5.97 \% & 2.95 \% & 3.90 \% \\ \text { Maximum } & 26.90 \% & 7.67 \% & 7.16 \%\end{array}$

By-Wire Statistics of Total Current Ratios

\begin{tabular}{|c|c|c|c|}
\hline & ALL & LONG & AVERAGES \\
\hline Average & $1.51 \%$ & $-0.64 \%$ & $0.59 \%$ \\
\hline Stdev & $3.61 \%$ & $3.06 \%$ & $1.22 \%$ \\
\hline RMS & $3.91 \%$ & $3.13 \%$ & $1.36 \%$ \\
\hline Maximum & $11.78 \%$ & $6.80 \%$ & $2.08 \%$ \\
\hline \multicolumn{4}{|c|}{ Statistics fol } \\
\hline Wires & Average & StDev & RMS \\
\hline \multirow{4}{*}{ Long } & $-0.64 \%$ & $3.06 \%$ & $3.13 \%$ \\
\hline & $1.10 \%$ & $3.65 \%$ & $3.82 \%$ \\
\hline & $2.05 \%$ & $3.39 \%$ & $3.96 \%$ \\
\hline & $1.96 \%$ & $3.08 \%$ & $3.65 \%$ \\
\hline Short & $3.08 \%$ & $3.69 \%$ & $4.80 \%$ \\
\hline
\end{tabular}




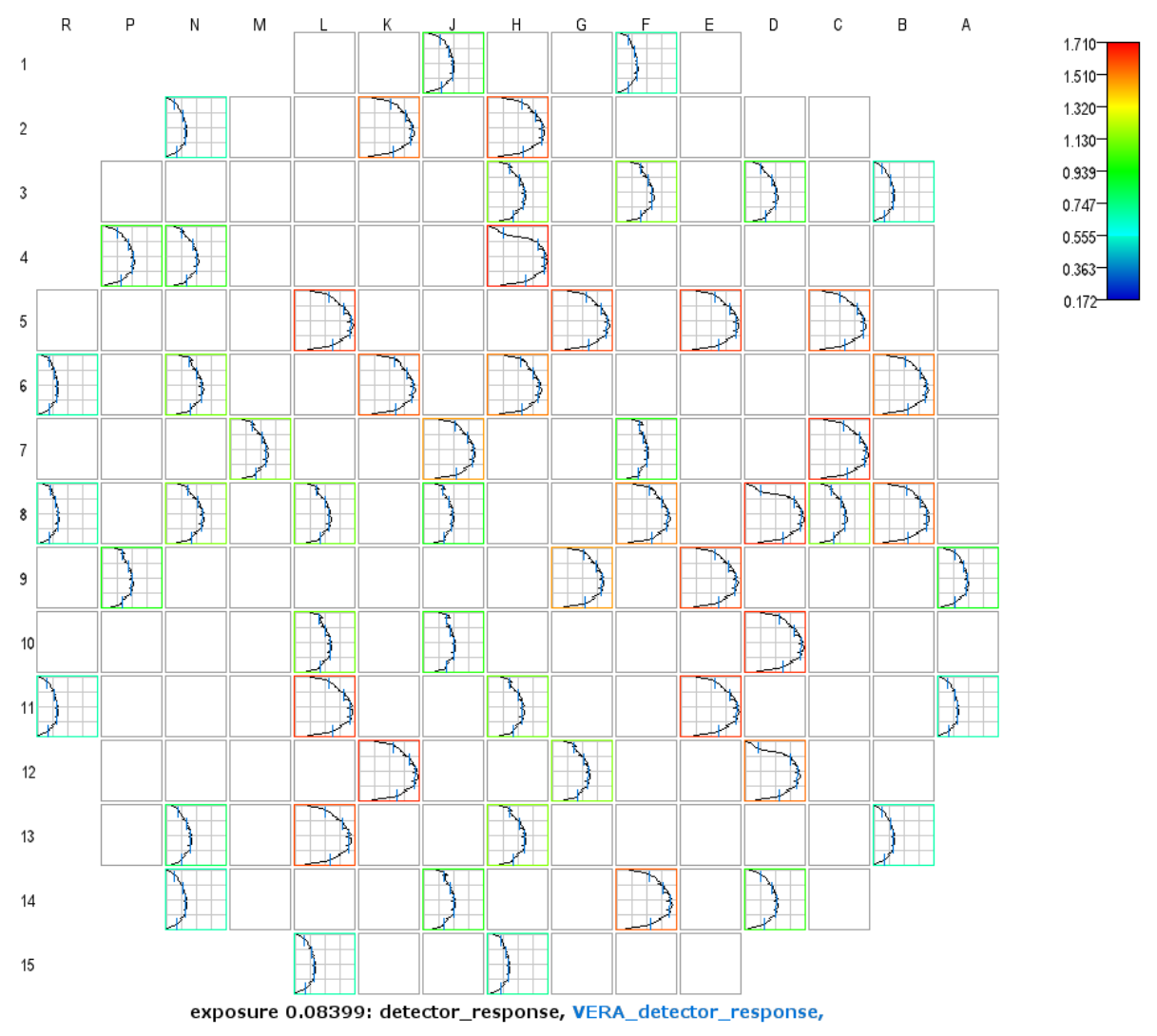

Figure B-5. Raw and Vanadium Detector Response Results from VERA for Case 2.

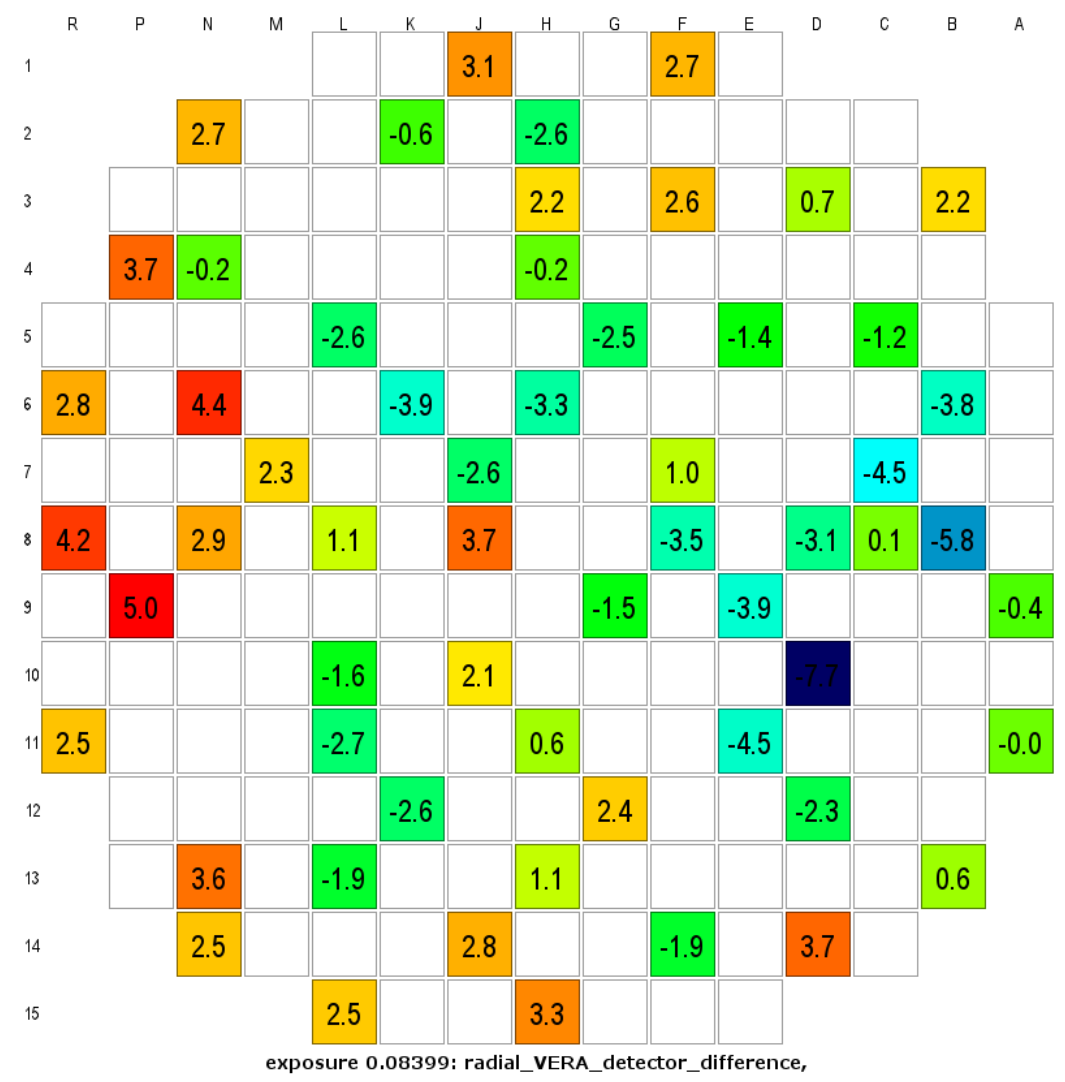

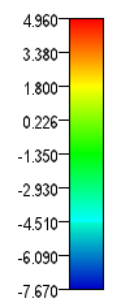

Figure B-6. Radial Detector Segment Differences (C-M,\%) for Case 2. 


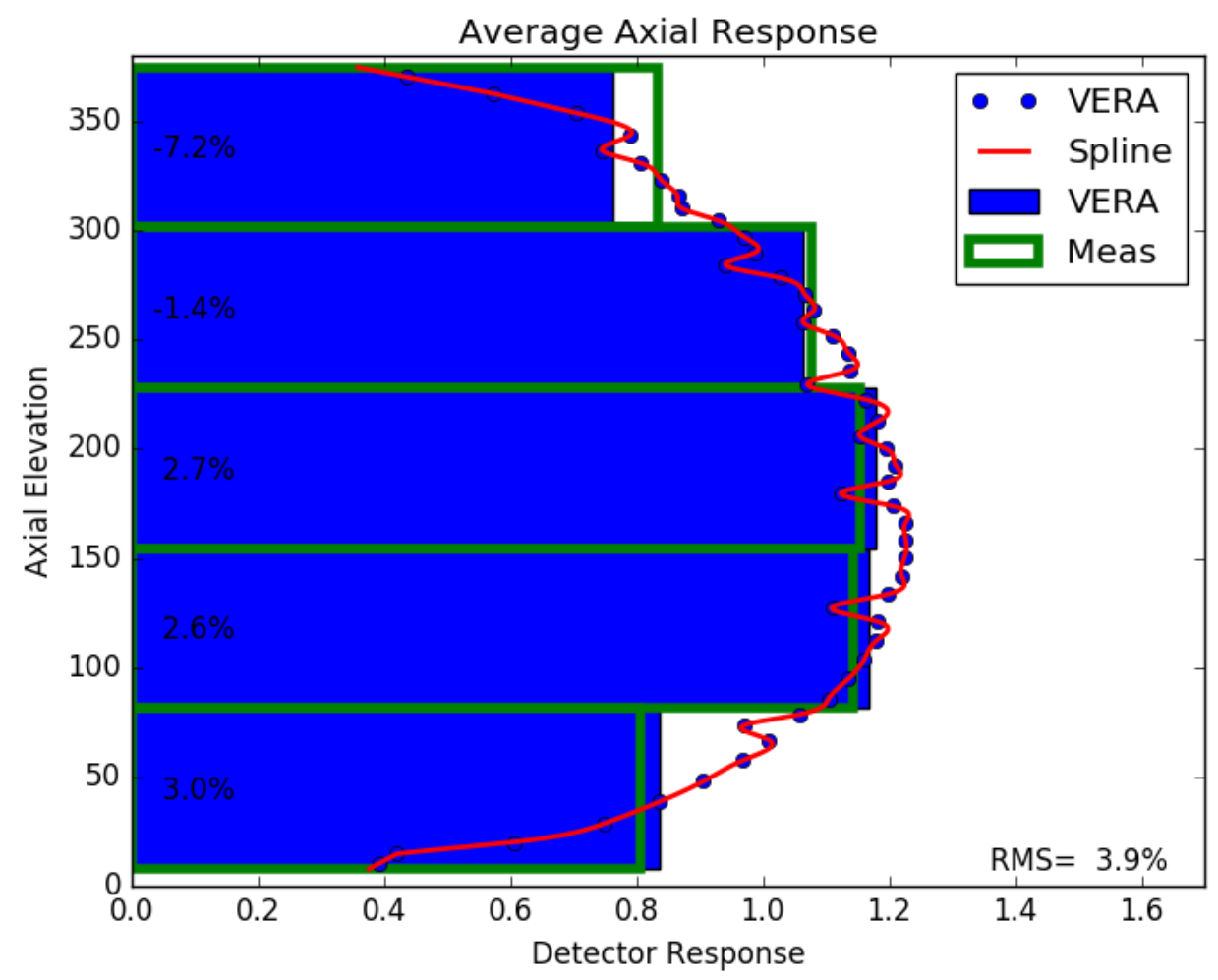

Figure B-7. Axial Detector Segment Differences (C-M,\%) for Case 2.

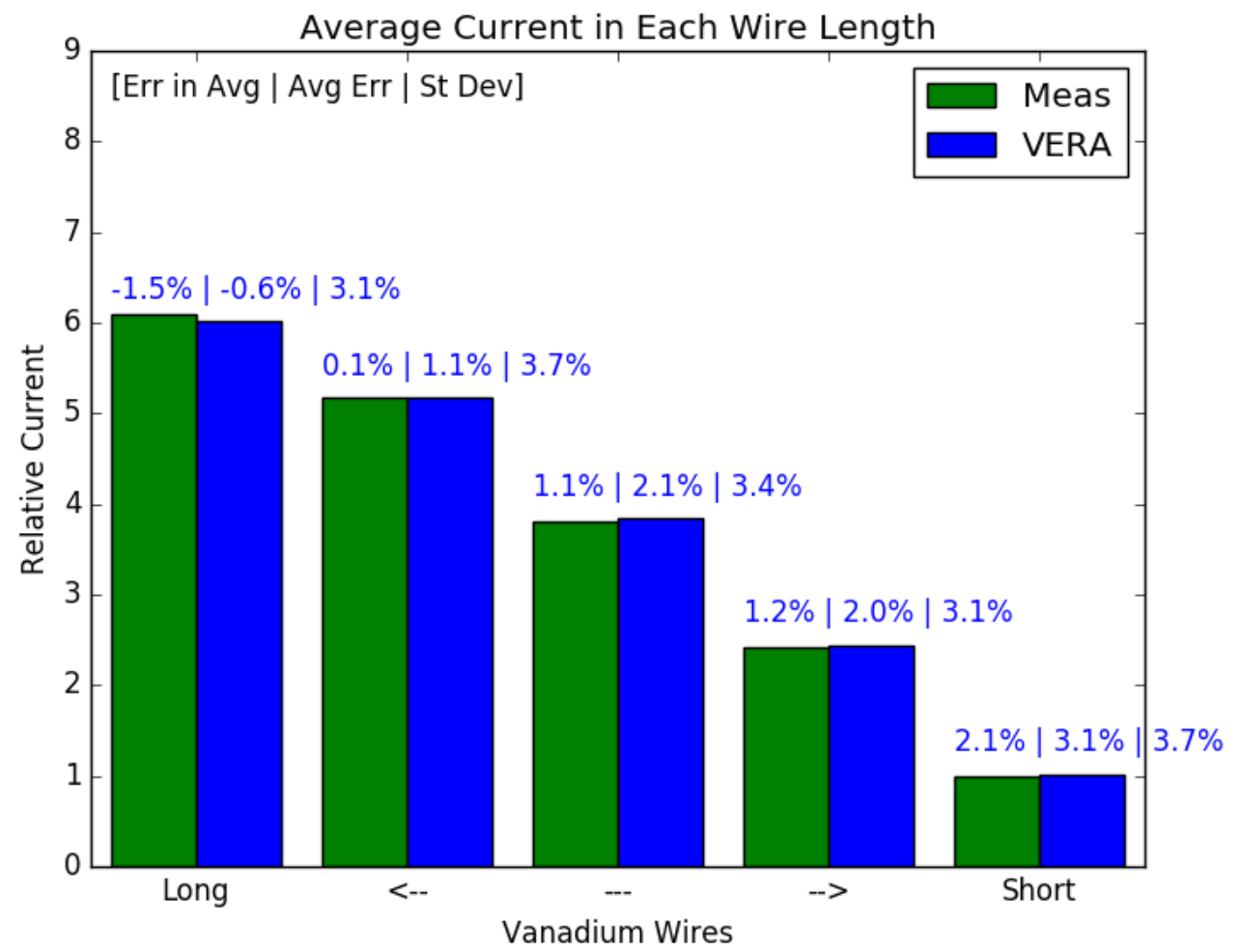

Figure B-8. Detector Relative Current Comparisons (C/M-1,\%) for Case 2. 


\section{Case 3:}

$\begin{array}{ll}\text { Date/Time: } & 7 / 6 / 2016 \quad 20: 31 \\ \text { Power: } & 40.2 \% F P\end{array}$

Bank D Position: 189 Steps withdrawn

VERA Burnup: $\quad 0.229 \mathrm{GWd} / \mathrm{MTU}$

Typical Power Distribution Analysis of Segment Differences

TOTAL RADIAL AXIAL

$\begin{array}{lrrr}\text { Average } & 0.0 \odot \% & 0.0 \odot \% & 0.0 \odot \% \\ \text { RMS } & 4.92 \% & 2.82 \% & 2.92 \% \\ \text { Maximum } & 18.64 \% & 6.81 \% & 4.08 \%\end{array}$

By-Wire Statistics of Total Current Ratios

\begin{tabular}{|c|c|c|c|}
\hline & ALL & LONG & AVERAGES \\
\hline Average & $1.63 \%$ & $-0.39 \%$ & $0.64 \%$ \\
\hline Stdev & $3.61 \%$ & $3.00 \%$ & $1.30 \%$ \\
\hline RMS & $3.96 \%$ & $3.02 \%$ & $1.45 \%$ \\
\hline Maximum & $11.91 \%$ & $5.96 \%$ & $2.37 \%$ \\
\hline \multicolumn{4}{|c|}{ Statistics for Each Set of Wire Leng } \\
\hline Wires & Average & StDev & RMS \\
\hline \multirow{4}{*}{ Long } & $-0.39 \%$ & $3 . \odot \odot \%$ & \\
\hline & $0.76 \%$ & $3.44 \%$ & $3.52 \%$ \\
\hline & $1.77 \%$ & $3.28 \%$ & $3.73 \%$ \\
\hline & $2.65 \%$ & $3.42 \%$ & $4.33 \%$ \\
\hline Short & $3.40 \%$ & $3.59 \%$ & $4.94 \%$ \\
\hline
\end{tabular}




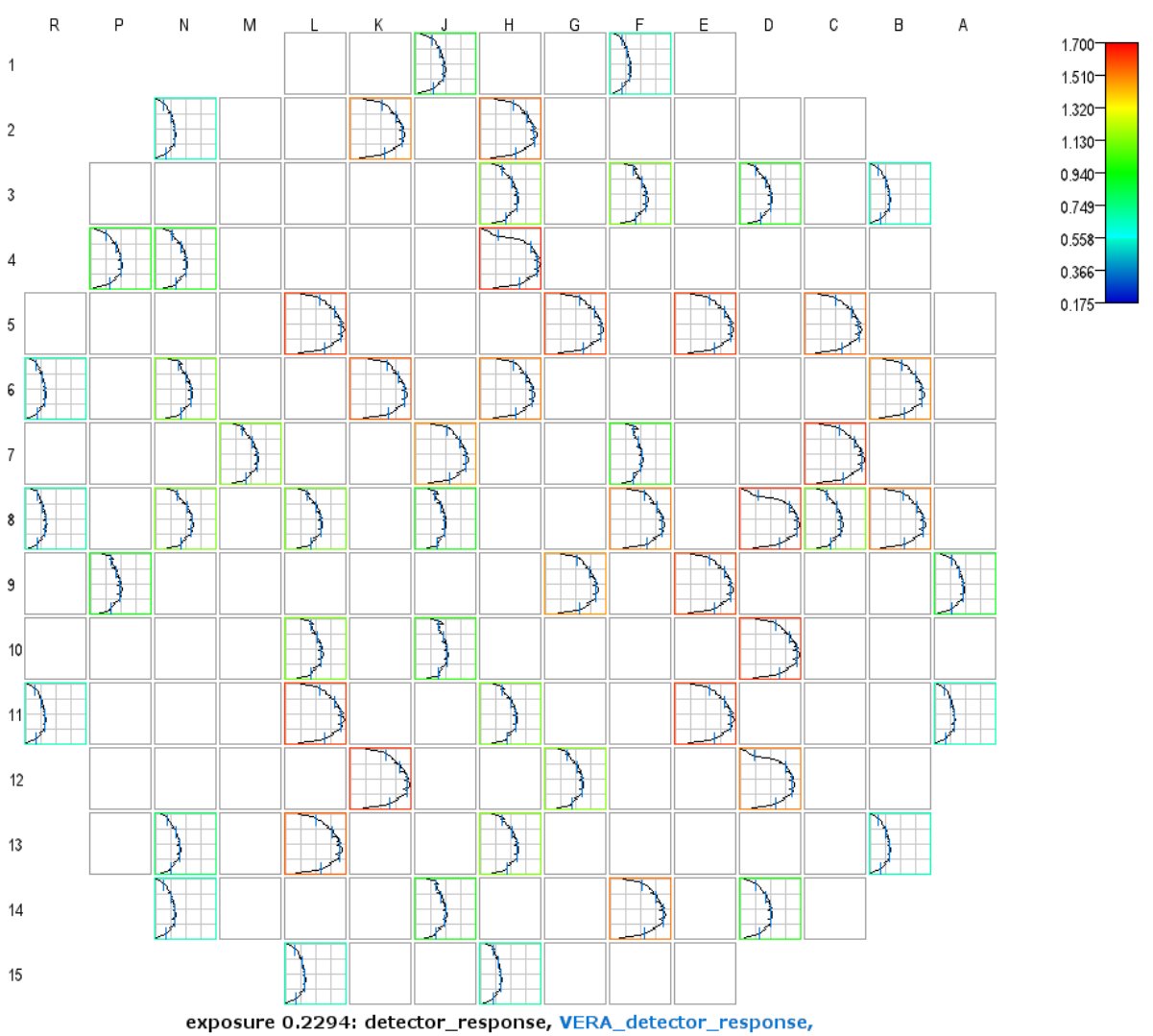

Figure B-9. Raw and Vanadium Detector Response Results from VERA for Case 3.

\begin{tabular}{|c|c|c|c|c|c|c|c|c|c|c|c|c|c|c|}
\hline$R$ & $P$ & $\mathrm{~N}$ & M & $L$ & K & J & H & G & $F$ & $E$ & \multirow[t]{2}{*}{ D } & \multirow[t]{2}{*}{ c } & \multirow[t]{2}{*}{ B } & \multirow[t]{2}{*}{ A } \\
\hline 1 & & & & & & 2.9 & & & 2.6 & & & & & \\
\hline 2 & & 3.0 & & & -0.5 & & -1.7 & & & & & & & \\
\hline 3 & & & & & & & 1.8 & & 2.3 & & 2.3 & & 2.6 & \\
\hline 4 & 3.5 & 0.7 & & & & & -0.6 & & & & & & & \\
\hline 5 & & & & -2.6 & & & & -2.2 & & -1.0 & & -1.1 & & \\
\hline $\begin{array}{ll}6 & 2.8\end{array}$ & & 3.7 & & & -4.2 & & -4.6 & & & & & & -3.5 & \\
\hline 7 & & & 2.1 & & & -4.3 & & & 0.4 & & & -3.8 & & \\
\hline $\begin{array}{ll}8 & 3.8\end{array}$ & & 2.8 & & 0.8 & & 3.8 & & & -4.3 & & -3.0 & 0.1 & -5.0 & \\
\hline 9 & 4.2 & & & & & & & -2.7 & & -4.4 & & & & -0.3 \\
\hline 10 & & & & 0.9 & & 1.3 & & & & & & & & \\
\hline 112.4 & & & & -2.6 & & & 0.7 & & & -4.1 & & & & 0.0 \\
\hline 12 & & & & & -1.8 & & & 1.9 & & & -2.2 & & & \\
\hline 13 & & 3.2 & & -1.6 & & & 1.1 & & & & & & 1.7 & \\
\hline 14 & & 2.6 & & & & 2.4 & & & -0.7 & & 2.1 & & & \\
\hline 15 & & & & 2.4 & & & 2.4 & & & & & & & \\
\hline
\end{tabular}

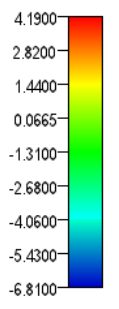

Figure B-10. Radial Detector Segment Differences (C-M,\%) for Case 3. 


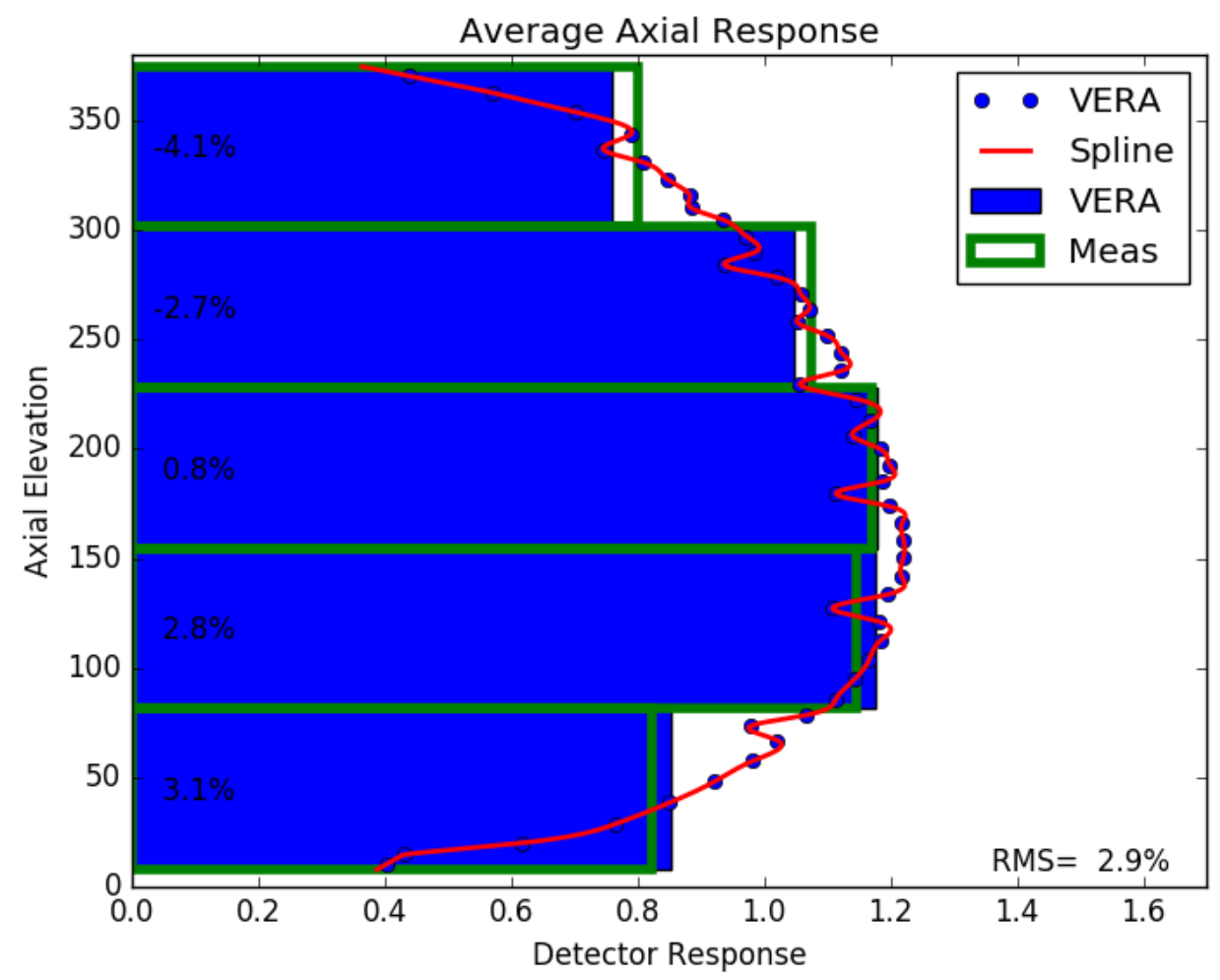

Figure B-11. Axial Detector Segment Differences (C-M,\%) for Case 3.

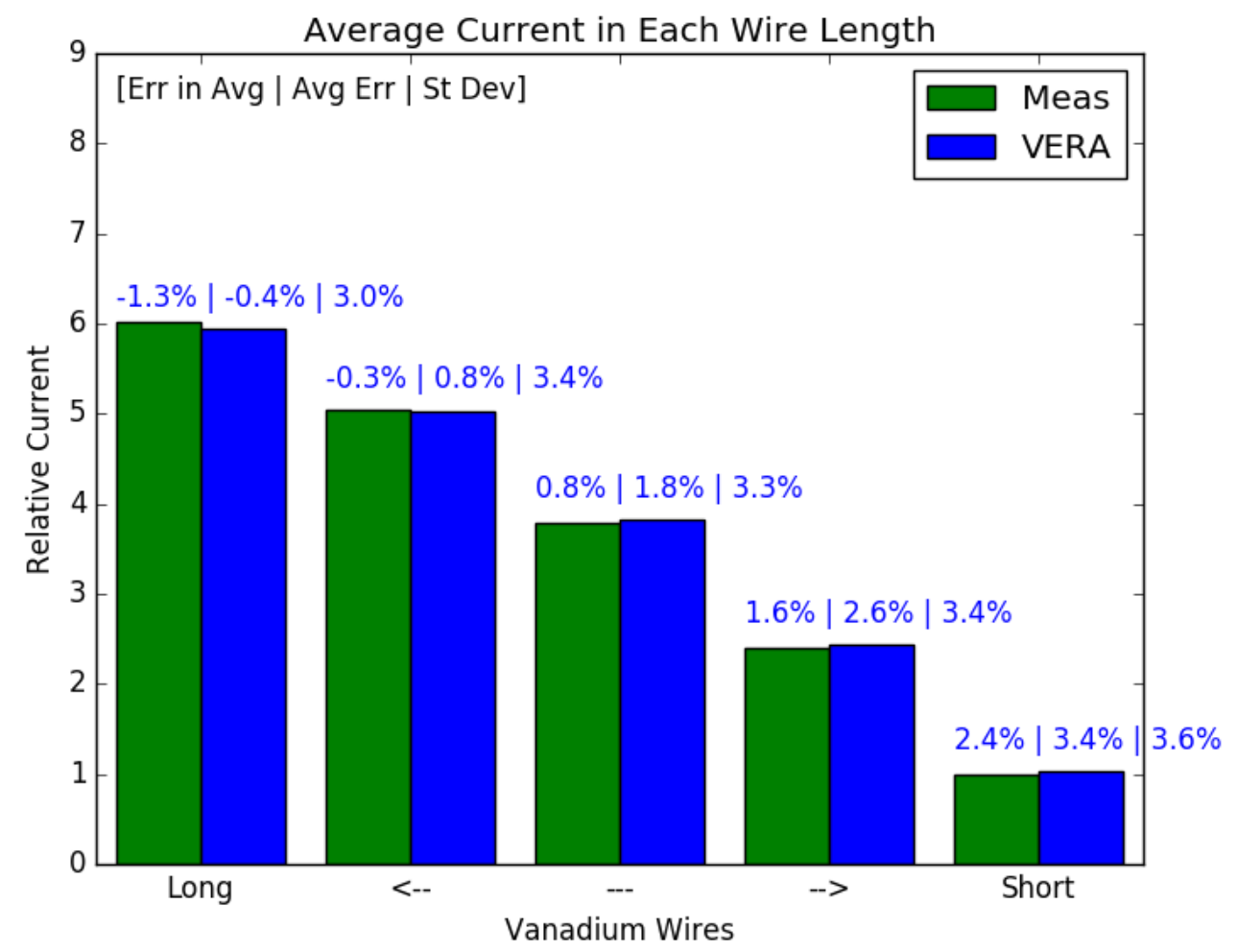

Figure B-12. Detector Relative Current Comparisons (C/M-1,\%) for Case 3. 


\section{Case 4:}

$\begin{array}{ll}\text { Date/Time: } & \text { 7/8/2016 17:18 } \\ \text { Power: } & 46.9 \% \mathrm{FP} \\ \text { Bank D Position: } 191 \text { Steps withdrawn } \\ \text { VERA Burnup: } & 0.261 \mathrm{GWd} / \text { MTU }\end{array}$

Typical Power Distribution Analysis of Segment Differences

TOTAL RADIAL AXIAL

$\begin{array}{lrrr}\text { Average } & -0.0 \odot \% & -0.0 \odot \% & -0.0 \odot \% \\ \text { RMS } & 4.53 \% & 2.75 \% & 2.43 \% \\ \text { Maximum } & 17.26 \% & 6.56 \% & 3.33 \%\end{array}$

By-Wire Statistics of Total Current Ratios

\begin{tabular}{|c|c|c|c|}
\hline & ALL & LONG & AVERAGES \\
\hline Average & $1.52 \%$ & $-0.21 \%$ & $0.56 \%$ \\
\hline Stdev & $3.46 \%$ & $2.92 \%$ & $1.12 \%$ \\
\hline RMS & $3.78 \%$ & $2.93 \%$ & $1.25 \%$ \\
\hline Maximum & $10.82 \%$ & $5.59 \%$ & $2.06 \%$ \\
\hline \multicolumn{4}{|c|}{ Statistics for Each Set of Wire Leng } \\
\hline Wires & Average & StDev & RMS \\
\hline \multirow{4}{*}{ Long } & & & \\
\hline & $\begin{array}{r}-0.21 \% \\
0.76 \%\end{array}$ & $\begin{array}{l}2.92 \% \\
3.36 \%\end{array}$ & \\
\hline & $1.64 \%$ & 3.1 & $3.59 \%$ \\
\hline & $2.40 \%$ & 3.3 & $4.15 \%$ \\
\hline Short & $3.05 \%$ & $3.40 \%$ & $4.57 \%$ \\
\hline
\end{tabular}




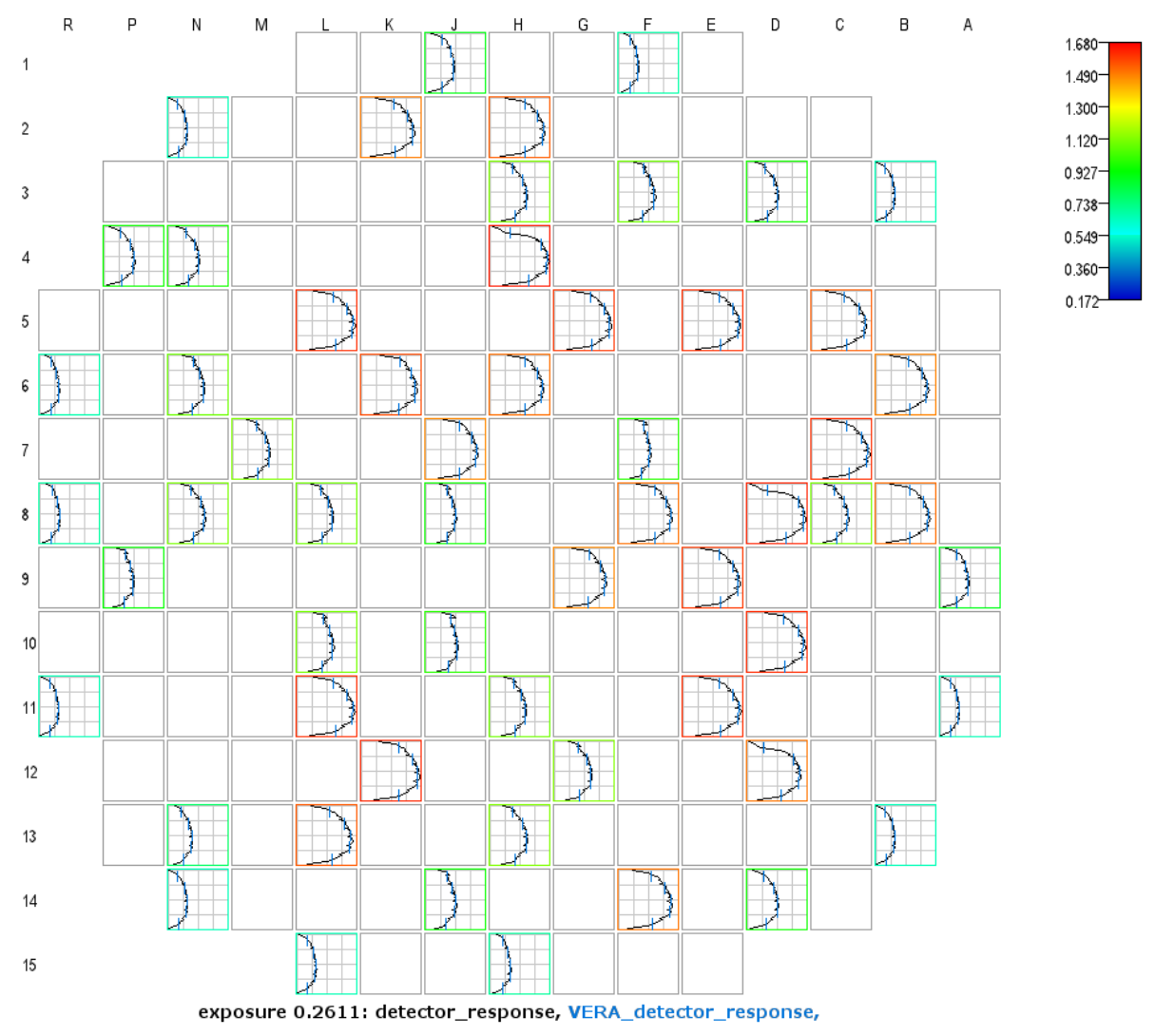

Figure B-13. Raw and Vanadium Detector Response Results from VERA for Case 4.

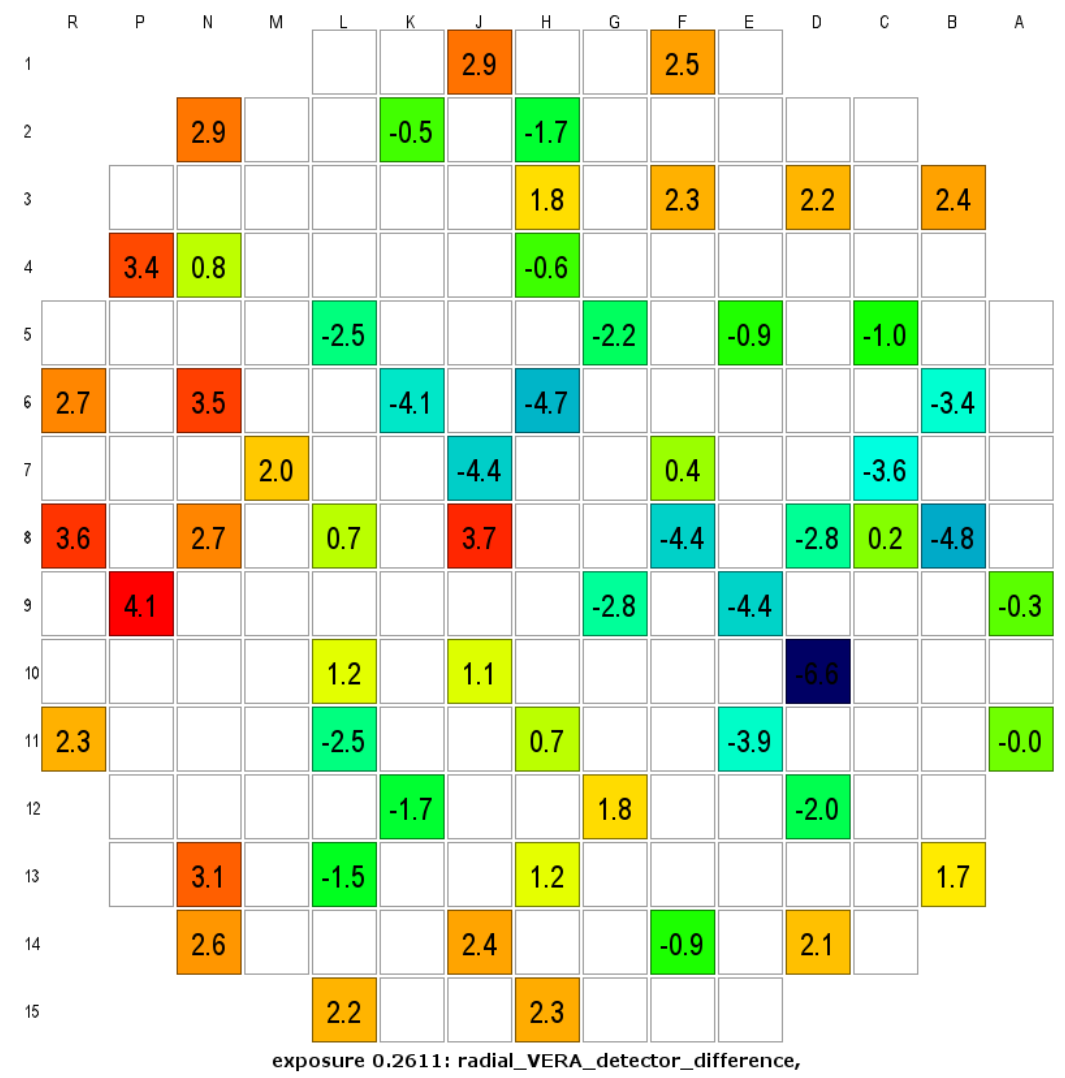

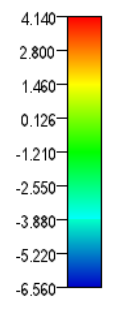

Figure B-14. Radial Detector Segment Differences (C-M,\%) for Case 4. 


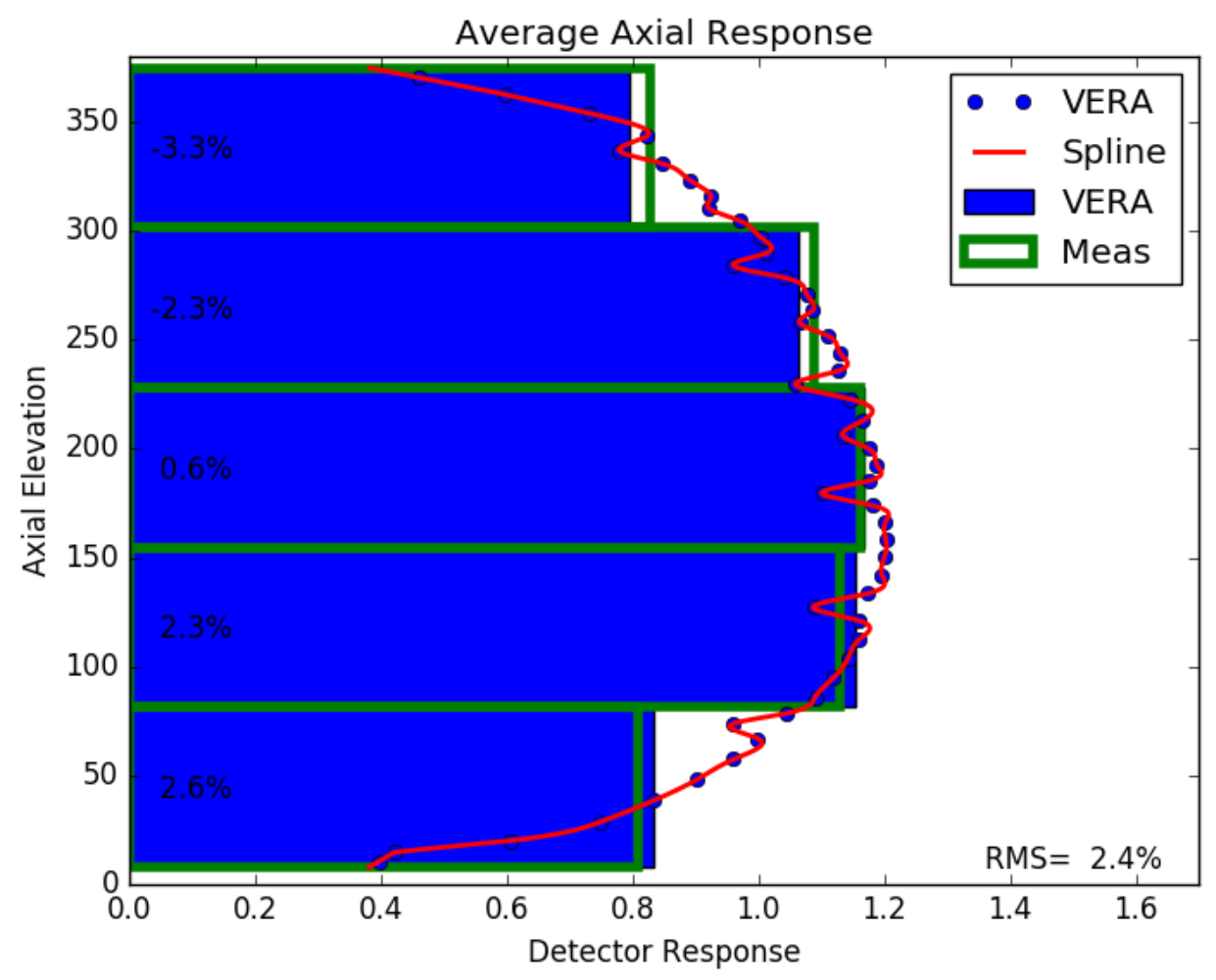

Figure B-15. Axial Detector Segment Differences (C-M,\%) for Case 4.

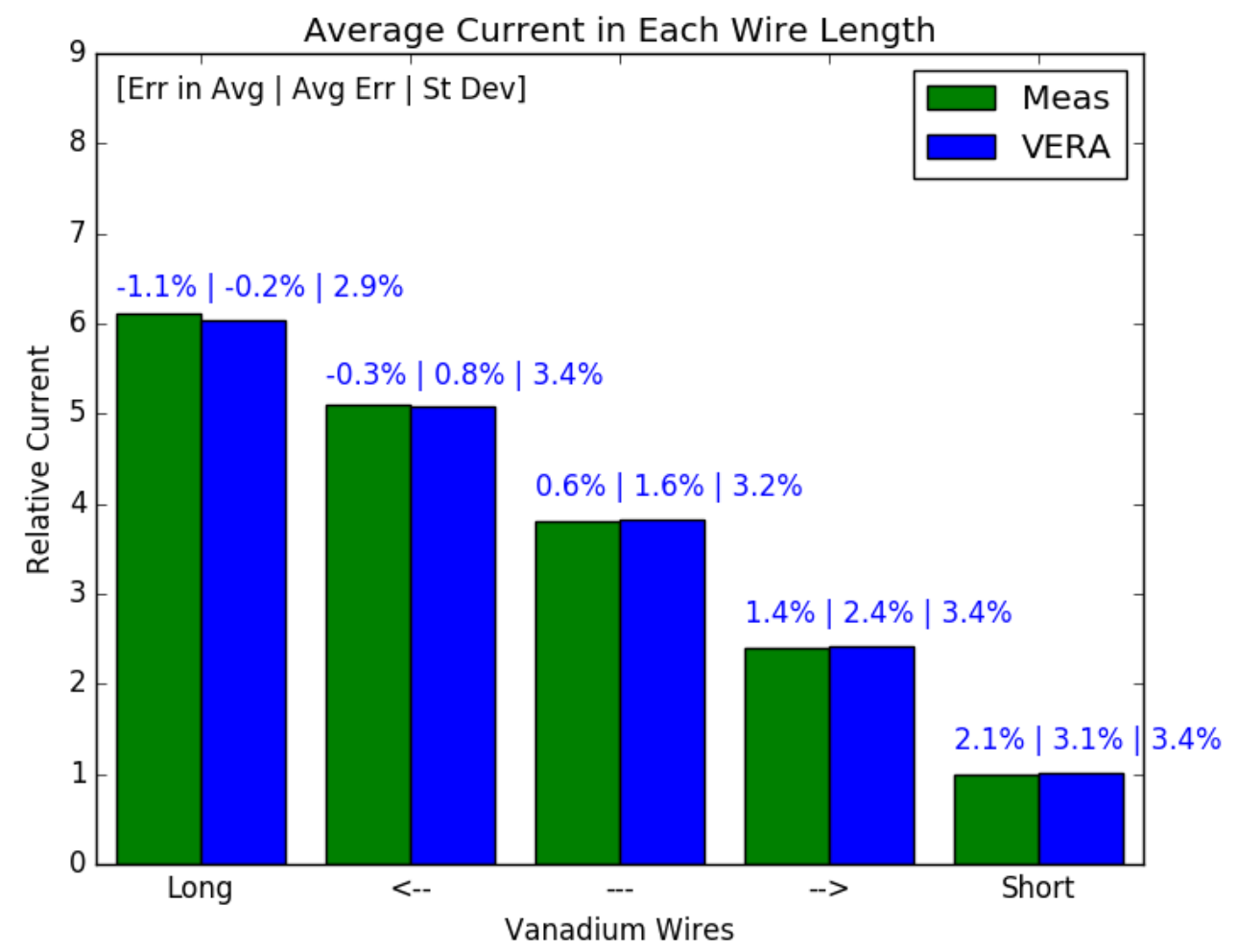

Figure B-16. Detector Relative Current Comparisons (C/M-1,\%) for Case 4. 


\section{Case 5:}

$\begin{array}{ll}\text { Date/Time: } & 7 / 26 / 2016 \quad 10: 25 \\ \text { Power: } & 73.8 \% \mathrm{FP}\end{array}$

Bank D Position: 202 Steps withdrawn

VERA Burnup: $\quad 0.513 \mathrm{GWd} / \mathrm{MTU}$

Typical Power Distribution Analysis of Segment Differences

TOTAL RADIAL AXIAL

$\begin{array}{lrrr}\text { Average } & 0 . \odot \odot \% & 0.0 \odot \% & 0.0 \odot \% \\ \text { RMS } & 4.49 \% & 2.58 \% & 2.76 \% \\ \text { Maximum } & 15.96 \% & 5.75 \% & 3.30 \%\end{array}$

By-Wire Statistics of Total Current Ratios

\begin{tabular}{|c|c|c|c|}
\hline & ALL & LONG & AVERAGES \\
\hline Average & $1.48 \%$ & $-0.35 \%$ & $0.62 \%$ \\
\hline Stdev & $3.21 \%$ & $2.71 \%$ & $1.27 \%$ \\
\hline RMS & $3.53 \%$ & $2.73 \%$ & $1.41 \%$ \\
\hline Maximum & $9.87 \%$ & $5.15 \%$ & $2.31 \%$ \\
\hline \multicolumn{4}{|c|}{ Statistics for Each set of Wire Leng } \\
\hline Wires & Average & StDev & RMS \\
\hline \multirow{4}{*}{ Long } & $-0.35 \%$ & $2.71 \%$ & \\
\hline & $0.52 \%$ & $3.04 \%$ & $3.09 \%$ \\
\hline & $1.64 \%$ & $2.93 \%$ & $3.36 \%$ \\
\hline & $2.47 \%$ & $2.98 \%$ & $3.87 \%$ \\
\hline Short & $3.17 \%$ & $3.02 \%$ & $4.38 \%$ \\
\hline
\end{tabular}




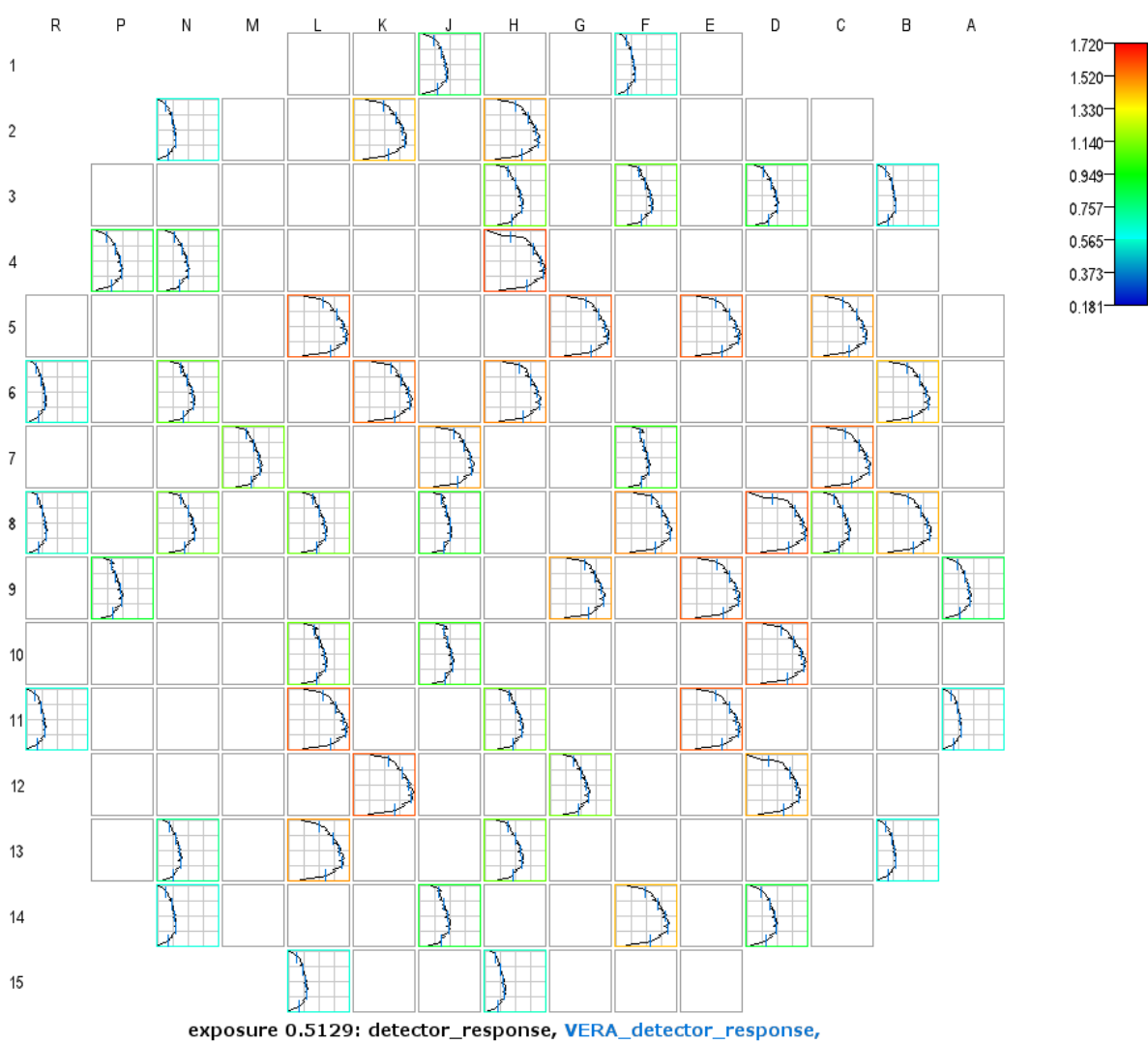

Figure B-17. Raw and Vanadium Detector Response Results from VERA for Case 5.

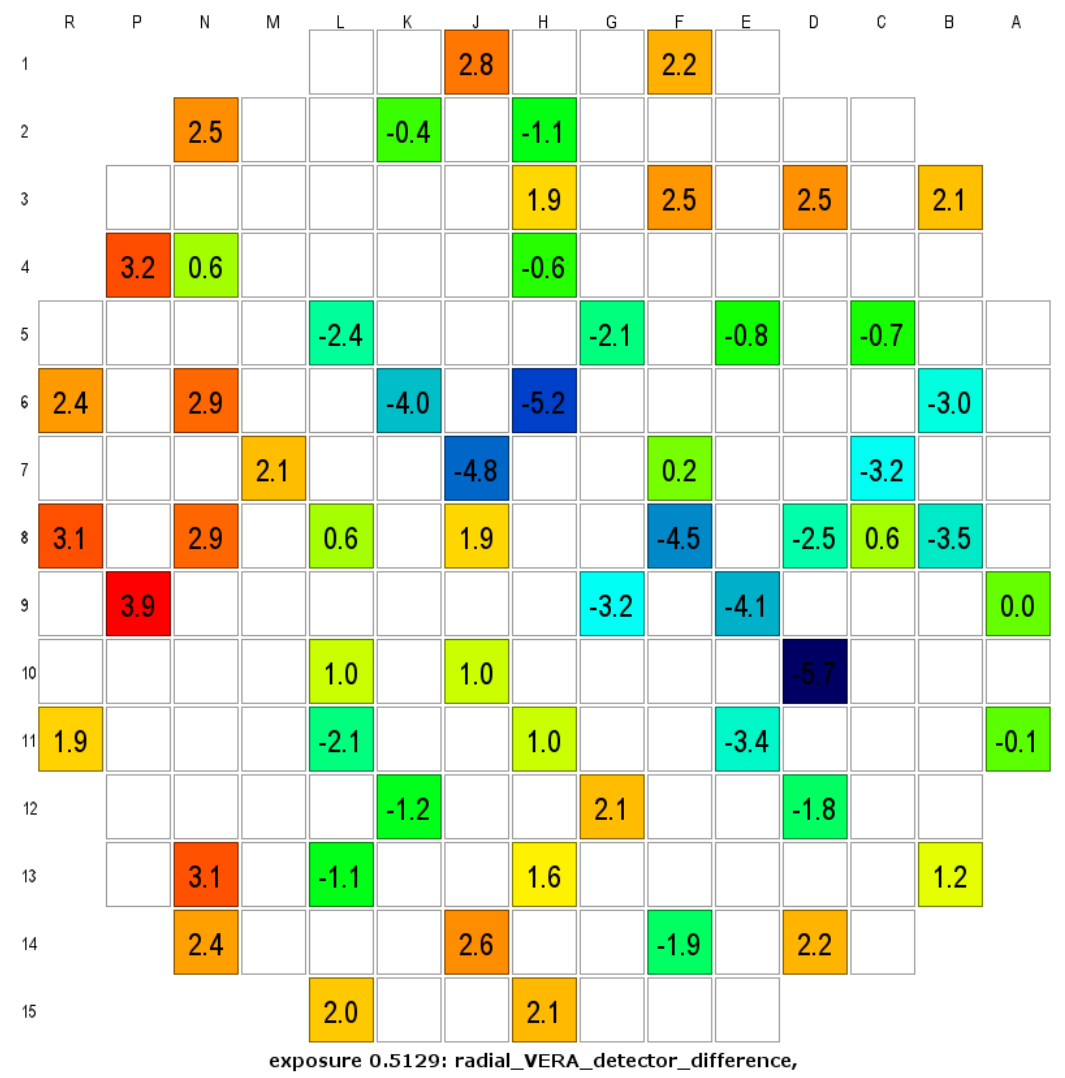

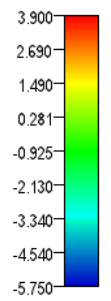

Figure B-18. Radial Detector Segment Differences (C-M,\%) for Case 5. 


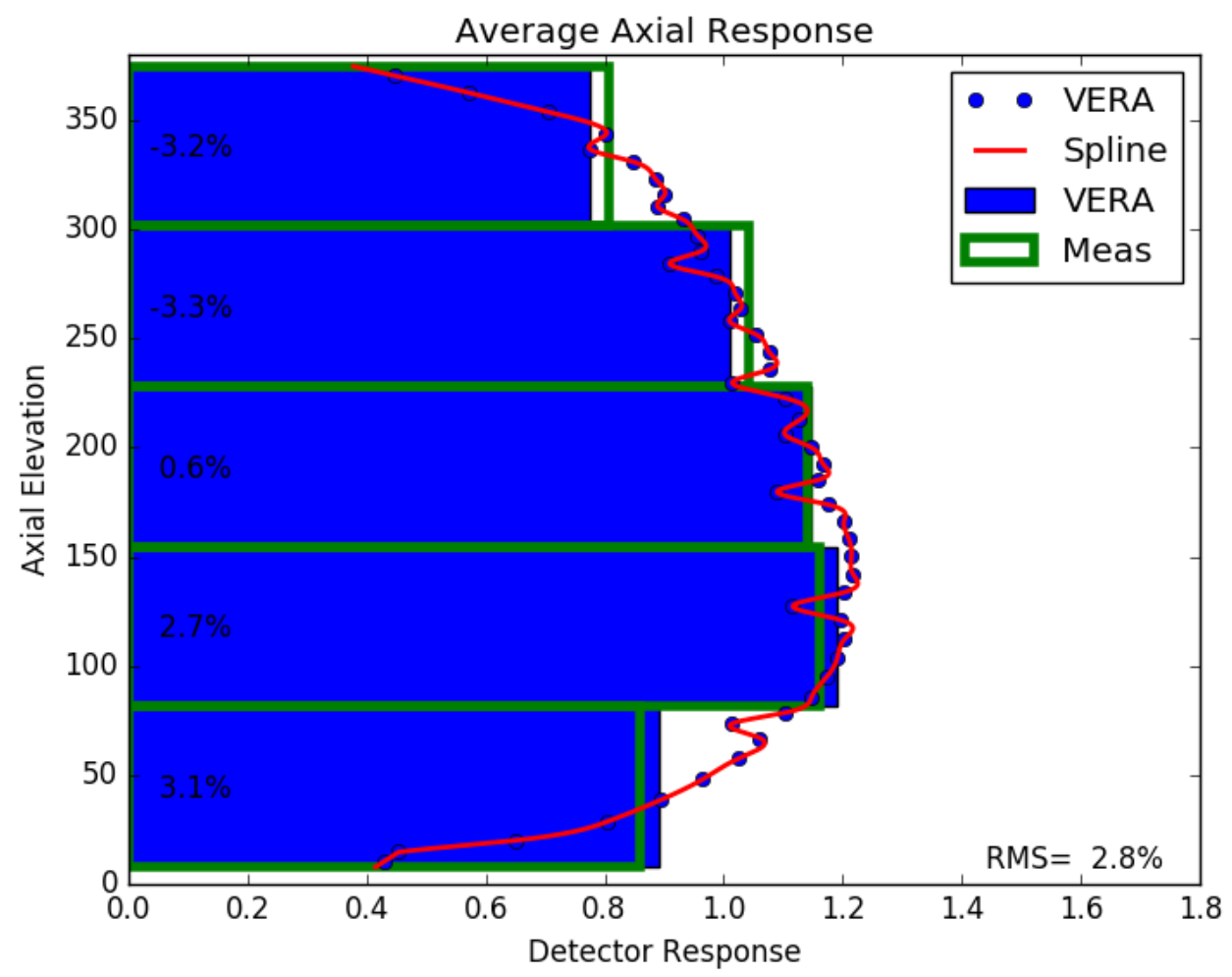

Figure B-19. Axial Detector Segment Differences (C-M,\%) for Case 5.

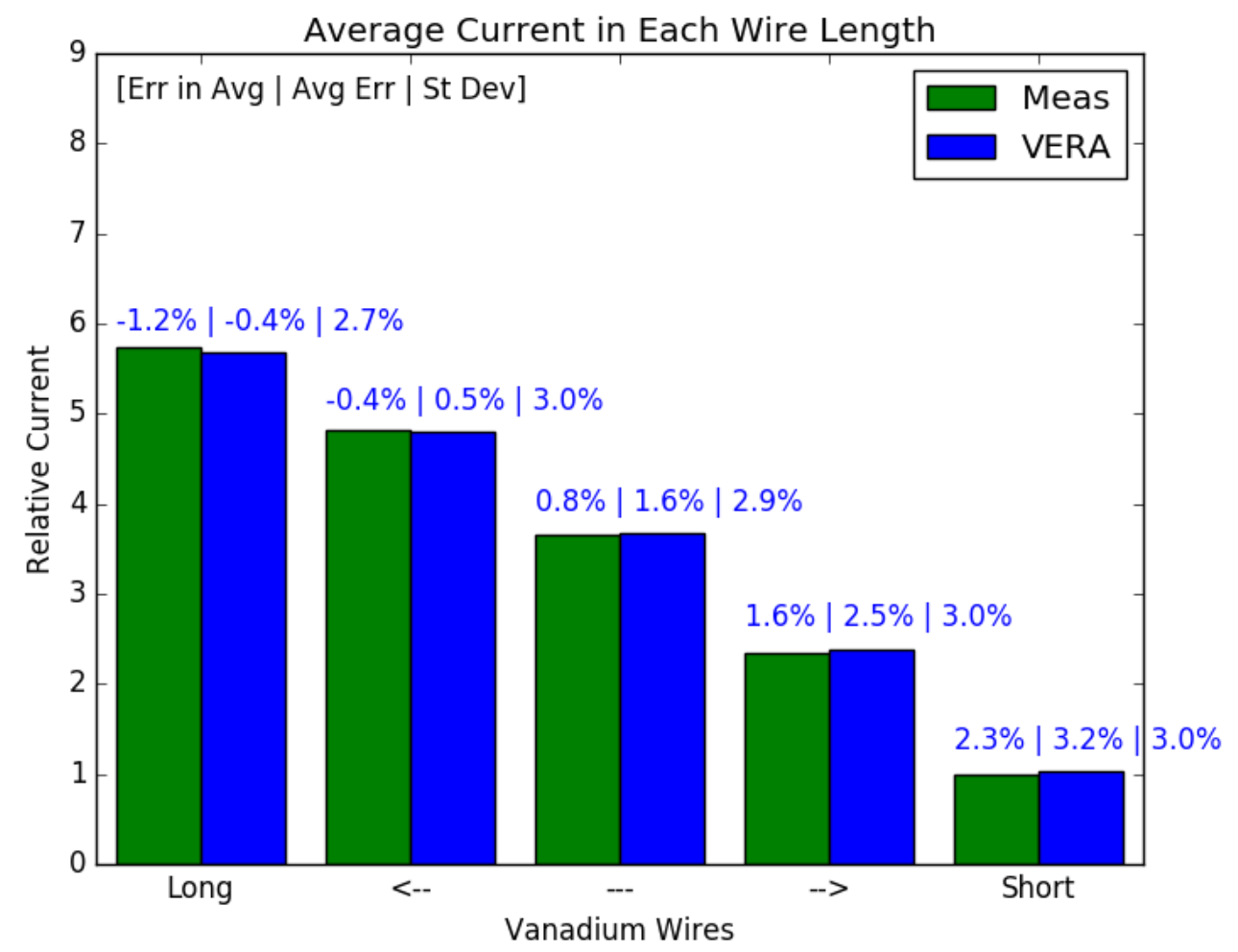

Figure B-20. Detector Relative Current Comparisons (C/M-1,\%) for Case 5. 


\section{Case 6:}

Date/Time: $\quad 8 / 27 / 2016$ 18:37
Power: $\quad 88.1 \% F P$
Bank D Position: 210 Steps withdrawn
VERA Burnup: $\quad 0.865$ GWd/MTU
Typical Power Distribution Analysis of Segment Differences

TOTAL RADIAL AXIAL

$\begin{array}{lrrr}\text { Average } & -0.0 \odot \% & -0.0 \odot \% & -0.0 \odot \% \\ \text { RMS } & 4.24 \% & 2.74 \% & 2.24 \% \\ \text { Maximum } & 13.78 \% & 7.47 \% & 2.95 \%\end{array}$

By-Wire Statistics of Total Current Ratios

\begin{tabular}{|c|c|c|c|}
\hline & ALL & LONG & AVERAGES \\
\hline Average & $1.42 \%$ & $-\odot . \odot \odot \%$ & $0.55 \%$ \\
\hline Stdev & $3.34 \%$ & $2.85 \%$ & $1.15 \%$ \\
\hline RMS & $3.63 \%$ & $2.85 \%$ & $1.28 \%$ \\
\hline Maximum & $8.88 \%$ & $12.18 \%$ & $2.27 \%$ \\
\hline \multicolumn{4}{|c|}{ Statistics } \\
\hline Wires & Average & StDev & RMS \\
\hline \multirow{4}{*}{ Long } & $-\odot . \odot \odot \%$ & $2.85 \%$ & $2.85 \%$ \\
\hline & $0.44 \%$ & $3.25 \%$ & $3.28 \%$ \\
\hline & $1.41 \%$ & $3.24 \%$ & $3.53 \%$ \\
\hline & $2.16 \%$ & $3.16 \%$ & $3.83 \%$ \\
\hline Short & $3.07 \%$ & $3.20 \%$ & $4.44 \%$ \\
\hline
\end{tabular}



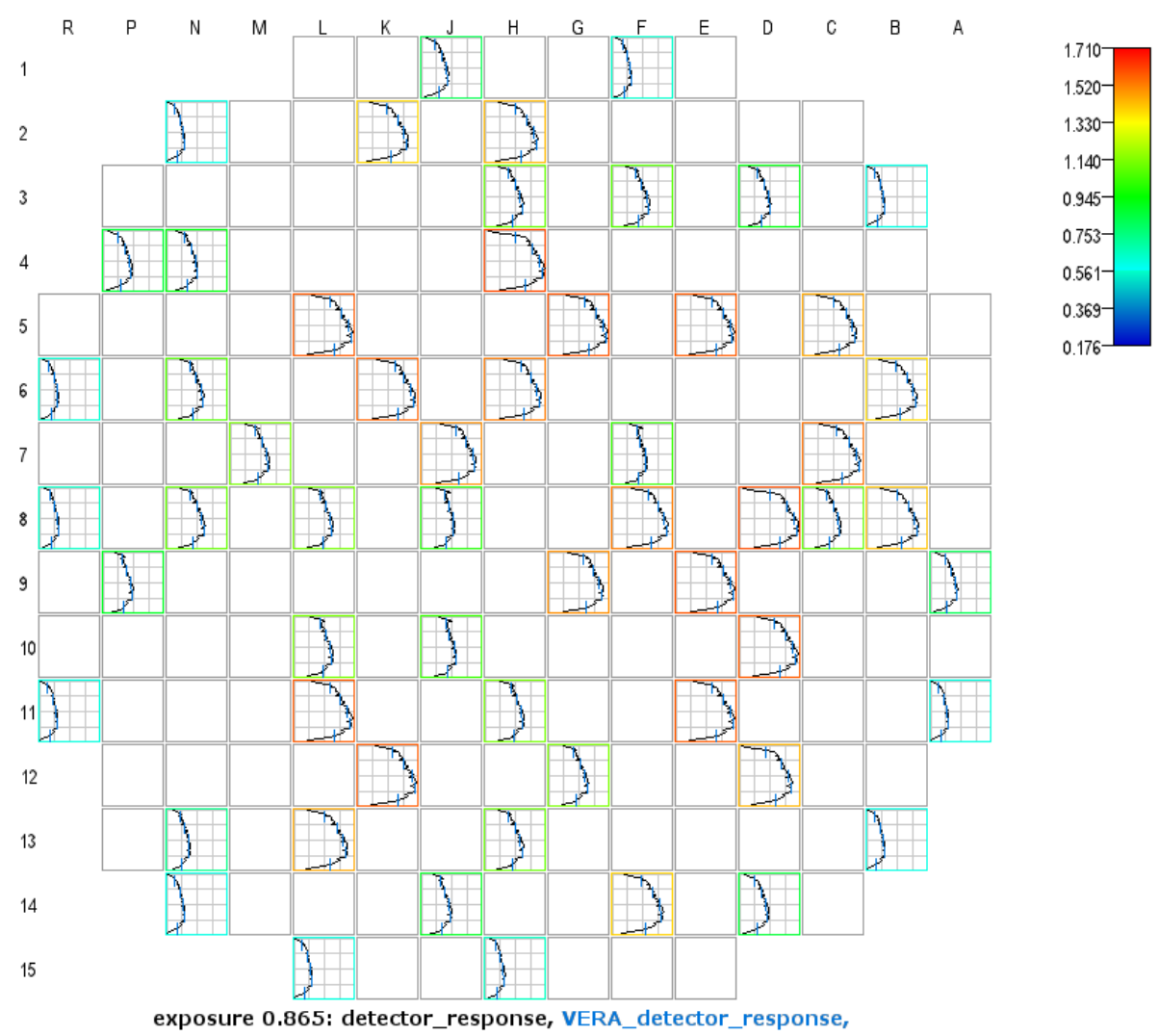

Figure B-21. Raw and Vanadium Detector Response Results from VERA for Case 6.

\begin{tabular}{|c|c|c|c|c|c|c|c|c|c|c|c|c|c|c|c|c|}
\hline \multicolumn{2}{|r|}{$\mathrm{R}$} & $P$ & $\mathrm{~N}$ & M & L & K & J & H & G & $F$ & $E$ & \multirow[t]{2}{*}{$D$} & \multirow[t]{2}{*}{$c$} & B & A & \multirow{3}{*}{$\begin{array}{l}4.320 \\
2.840- \\
1.370-\end{array}$} \\
\hline 1 & & & & & & & 3.1 & & & 2.5 & & & & & & \\
\hline 2 & & & 2.4 & & & 0.1 & & -0.5 & & & & & & & & \\
\hline 3 & & & & & & & & & & 2.7 & & 2.6 & & 2.0 & & $-1.570-$ \\
\hline 4 & & 3.4 & 1.3 & & & & & -1.2 & & & & & & & & $\begin{array}{l}-3.050- \\
-4.520-\end{array}$ \\
\hline 5 & & & & & -2.3 & & & & -2.0 & & -0.8 & & -0.3 & & & _- \\
\hline 6 & 2.6 & & 3.1 & & & -4.0 & & -5.5 & & & & & & -2.1 & & \\
\hline 7 & & & & 2.2 & & & -5.1 & & & 0.1 & & & -2.7 & & & \\
\hline 8 & 3.3 & & 3.1 & & 0.4 & & 0.4 & & & -4.7 & & -2.9 & 0.7 & -2.5 & & \\
\hline 9 & & 4.3 & & & & & & & -3.6 & & -4.1 & & & & 0.5 & \\
\hline 10 & & & & & 1.5 & & 1.0 & & & & & -5.2 & & & & \\
\hline 11 & 2.1 & & & & -1.9 & & & 0.9 & & & -3.3 & & & & 0.2 & \\
\hline 12 & & & & & & -1.0 & & & 2.0 & & & -1.9 & & & & \\
\hline 13 & & & 3.5 & & -0.7 & & & 1.8 & & & & & & 1.0 & & \\
\hline 14 & & & 2.4 & & & & 3.1 & & & -1.6 & & 2.4 & & & & \\
\hline 15 & & & & & 2.2 & & & 2.4 & & & & & & & & \\
\hline
\end{tabular}

Figure B-22. Radial Detector Segment Differences (C-M,\%) for Case 6. 


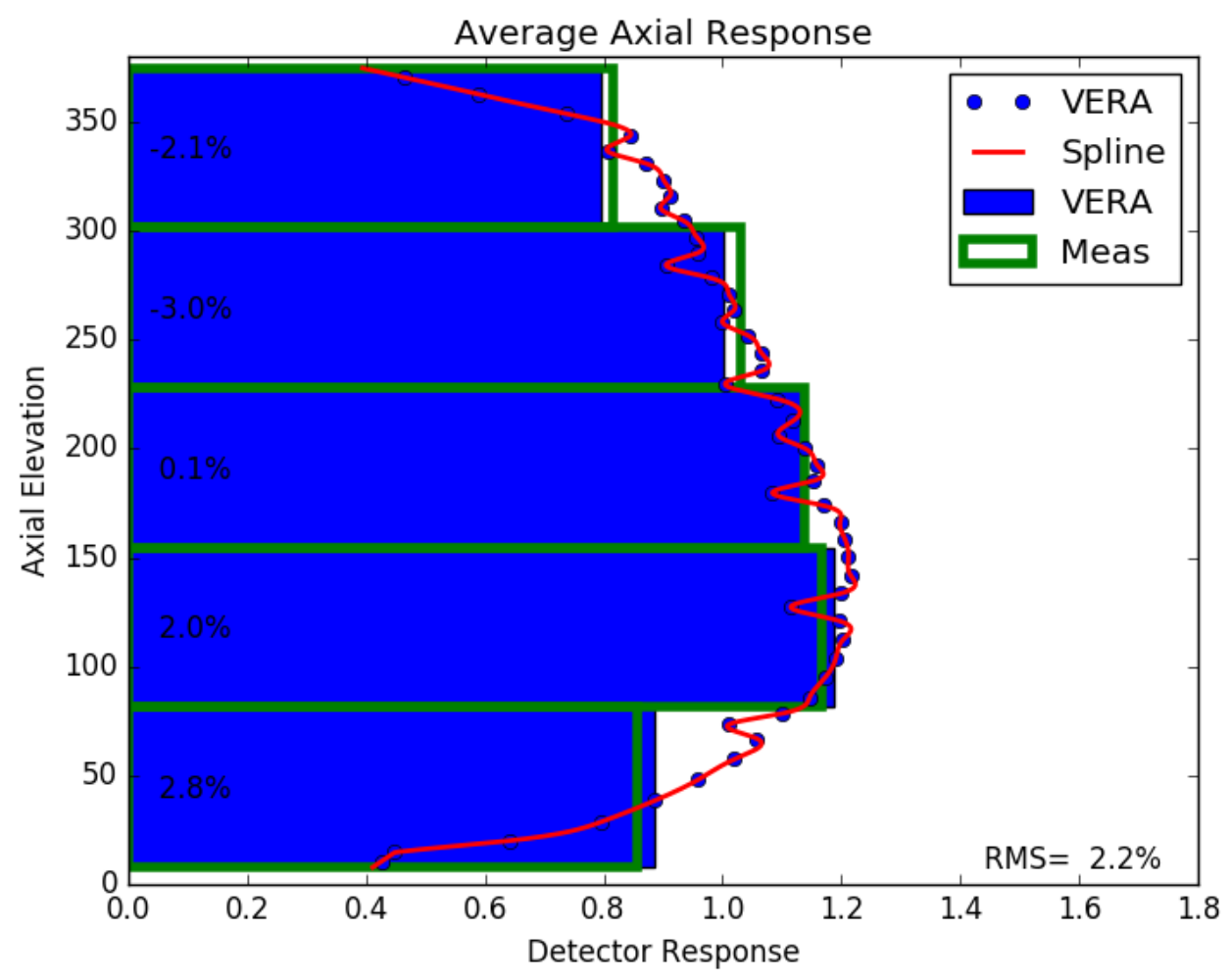

Figure B-23. Axial Detector Segment Differences (C-M,\%) for Case 6.

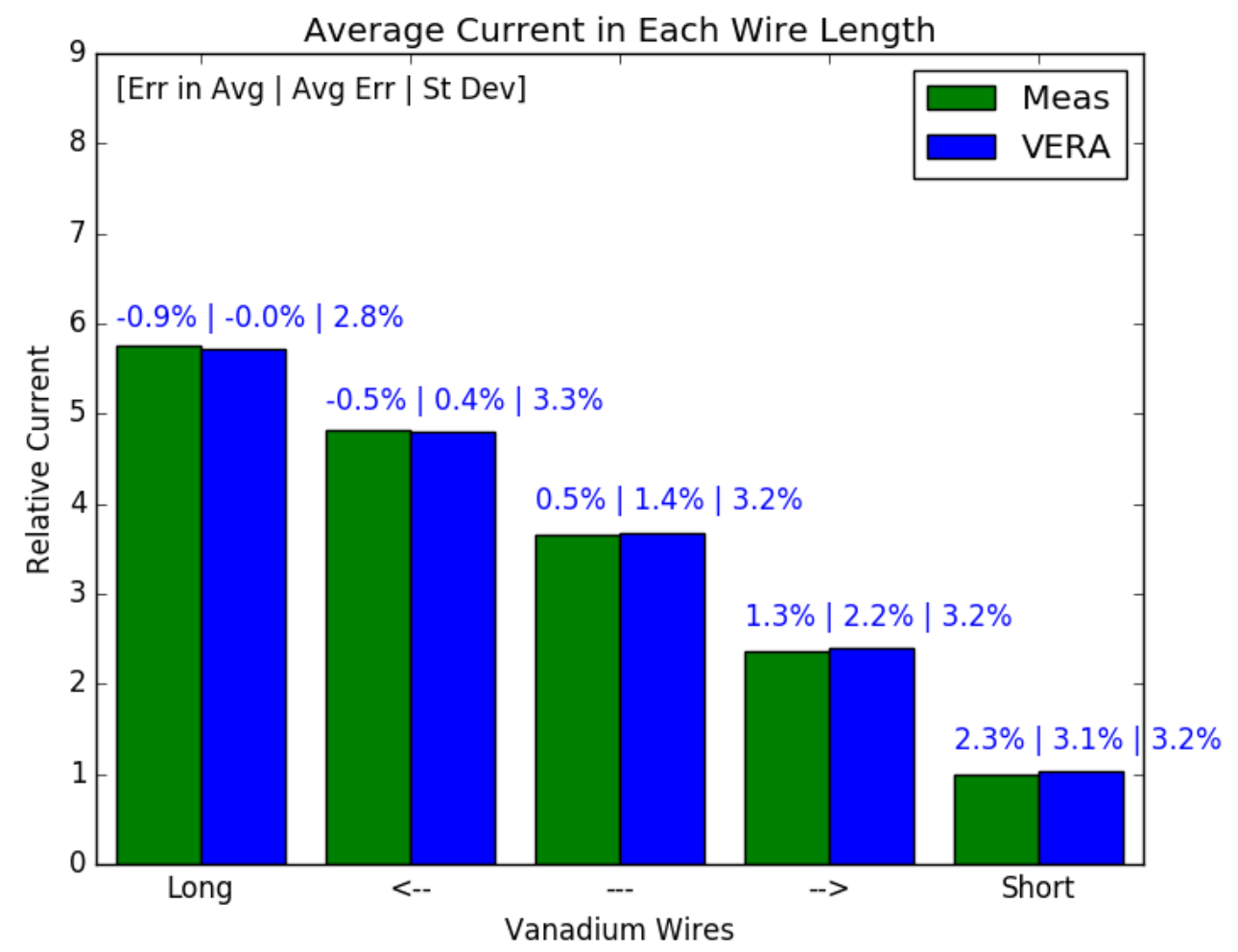

Figure B-24. Detector Relative Current Comparisons (C/M-1,\%) for Case 6. 


\section{Case 7:}

$\begin{array}{ll}\text { Date/Time: } & \text { 8/30/2016 20:42 } \\ \text { Power: } & 98.6 \% \mathrm{FP} \\ \text { Bank D Position: } 219 \text { Steps withdrawn } \\ \text { VERA Burnup: } & 0.974 \mathrm{GWd} / \text { MTU }\end{array}$

Typical Power Distribution Analysis of Segment Differences

TOTAL RADIAL AXIAL

$\begin{array}{lrrr}\text { Average } & -0.00 \% & -0.00 \% & 0.00 \% \\ \text { RMS } & 4.34 \% & 2.60 \% & 2.70 \% \\ \text { Maximum } & 14.76 \% & 5.57 \% & 3.35 \%\end{array}$

By-Wire Statistics of Total Current Ratios

\begin{tabular}{|c|c|c|c|}
\hline & ALL & LONG & AVERAGES \\
\hline Average & $1.54 \%$ & $-0.31 \%$ & $0.67 \%$ \\
\hline Stdev & $3.26 \%$ & $2.82 \%$ & $1.38 \%$ \\
\hline RMS & $3.60 \%$ & $2.83 \%$ & $1.54 \%$ \\
\hline Maximum & $9.48 \%$ & $5.13 \%$ & $2.67 \%$ \\
\hline \multicolumn{4}{|c|}{ Statistics } \\
\hline Wires & Average & StDev & RMS \\
\hline \multirow[t]{4}{*}{ Long } & $-0.31 \%$ & $2.82 \%$ & $2.83 \%$ \\
\hline & $0.46 \%$ & $3.06 \%$ & $3.09 \%$ \\
\hline & $1.58 \%$ & $2.98 \%$ & $3.37 \%$ \\
\hline & $2.44 \%$ & $2.91 \%$ & $3.80 \%$ \\
\hline Short & $3.50 \%$ & $3.03 \%$ & $4.63 \%$ \\
\hline
\end{tabular}



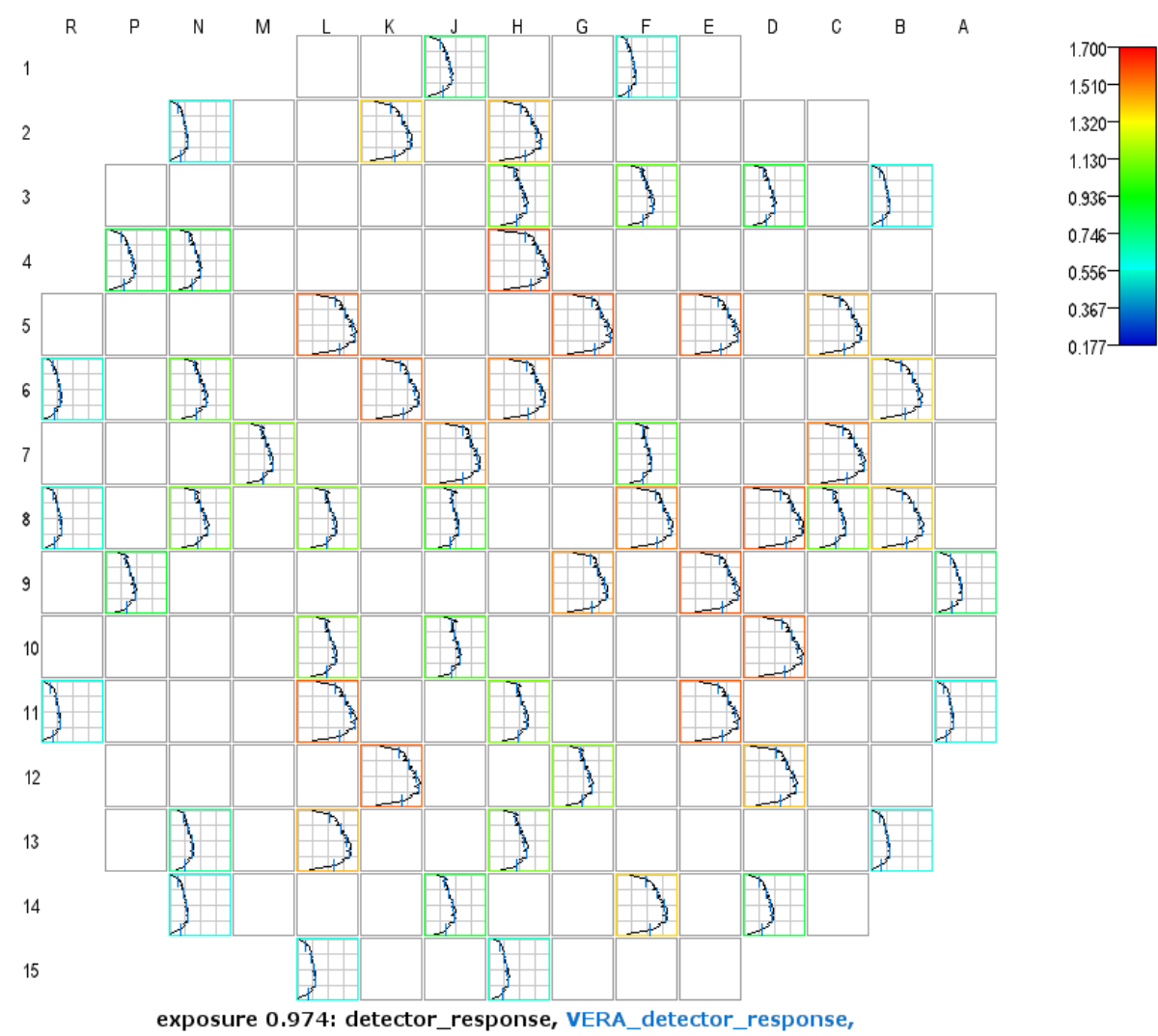

Figure B-25. Raw and Vanadium Detector Response Results from VERA for Case 7.

\begin{tabular}{|c|c|c|c|c|c|c|c|c|c|c|c|c|c|c|c|}
\hline \multicolumn{2}{|r|}{$\mathrm{R}$} & P & $\mathrm{N}$ & M & $L$ & K & J & $\mathrm{H}$ & G & $F$ & $E$ & \multirow[t]{2}{*}{ D } & \multirow[t]{2}{*}{$c$} & \multirow[t]{2}{*}{ B } & \multirow[t]{2}{*}{ A } \\
\hline 1 & & & & & & & 3.0 & & & 2.4 & & & & & \\
\hline 2 & & & 2.3 & & & 0.1 & & -0.5 & & & & & & & \\
\hline 3 & & & & & & & & -0.1 & & 2.7 & & 2.6 & & 2.0 & \\
\hline 4 & & 3.1 & 0.9 & & & & & -1.6 & & & & & & & \\
\hline 5 & & & & & -2.4 & & & & -2.0 & & -0.9 & & -0.4 & & \\
\hline 6 & 2.6 & & 3.0 & & & -4.0 & & & & & & & & -2.2 & \\
\hline 7 & & & & 2.1 & & & -5.2 & & & 0.1 & & & -2.9 & & \\
\hline 8 & 3.1 & & 2.9 & & 0.3 & & 0.1 & & & -4.9 & & -3.4 & 0.6 & -2.6 & \\
\hline 9 & & 4.1 & & & & & & & -3.8 & & -4.2 & & & & 0.5 \\
\hline 10 & & & & & 1.5 & & 0.8 & & & & & -5.2 & & & \\
\hline 11 & 2.0 & & & & -2.0 & & & 0.8 & & & -3.2 & & & & 0.1 \\
\hline 12 & & & & & & -1.0 & & & 1.9 & & & -2.2 & & & \\
\hline 13 & & & 3.4 & & -0.7 & & & 1.8 & & & & & & 1.0 & \\
\hline 14 & & & 2.4 & & & & 2.9 & & & -1.7 & & 2.4 & & & \\
\hline 15 & & & & & 2.1 & & & 2.4 & & & & & & & \\
\hline
\end{tabular}

Figure B-26. Radial Detector Segment Differences (C-M,\%) for Case 7. 


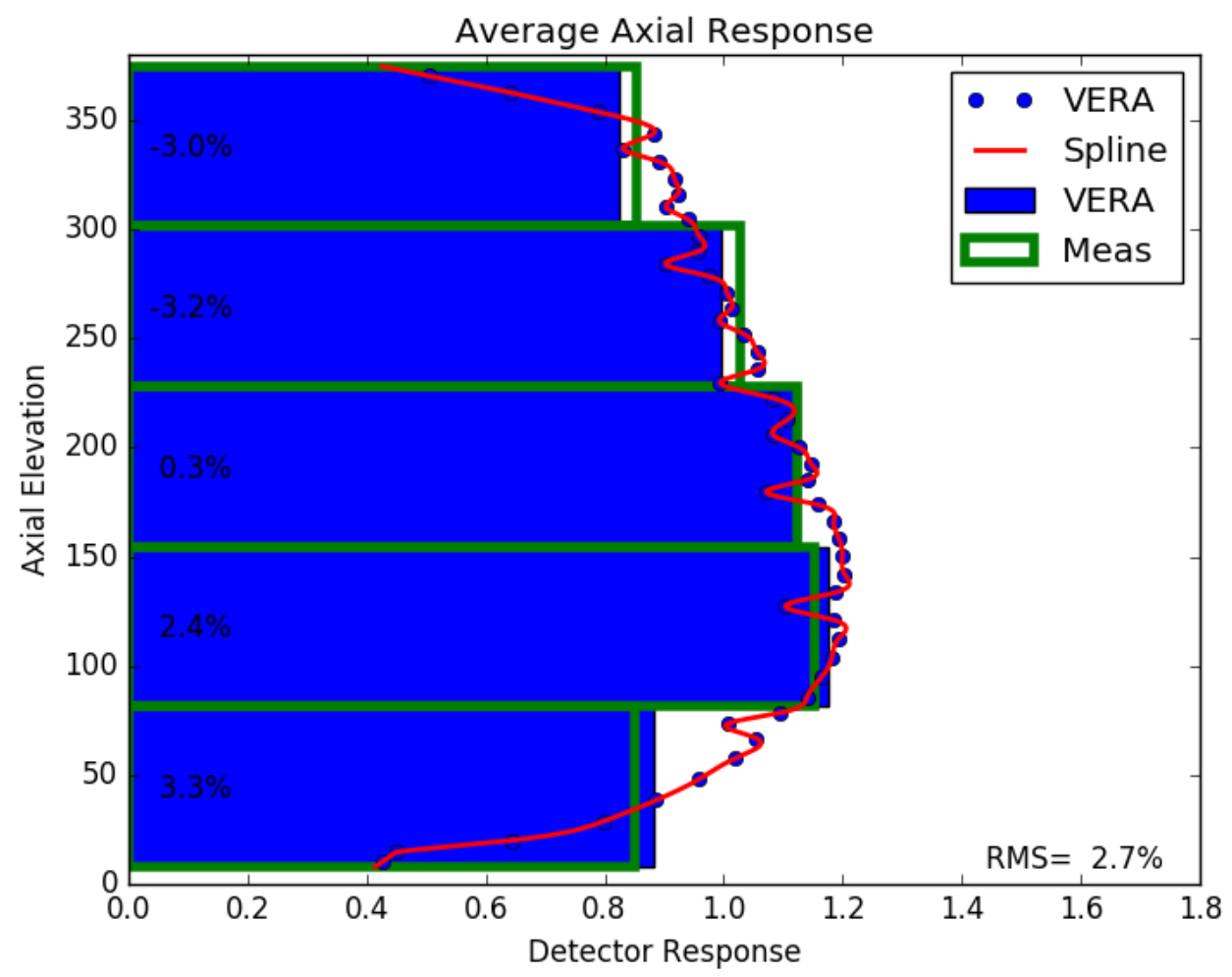

Figure B-27. Axial Detector Segment Differences (C-M,\%) for Case 7.

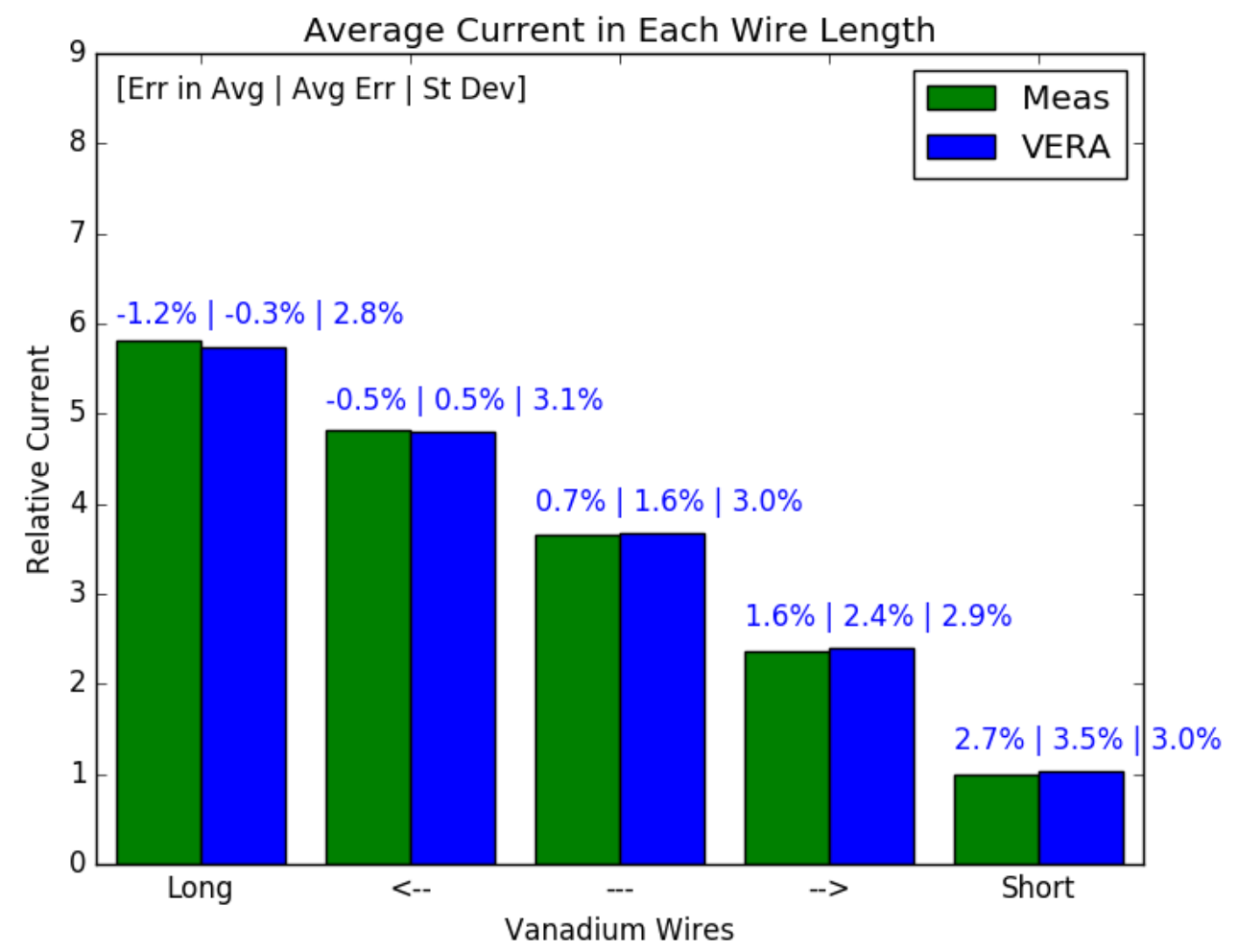

Figure B-28. Detector Relative Current Comparisons (C/M-1,\%) for Case 7. 


\section{Case 8:}

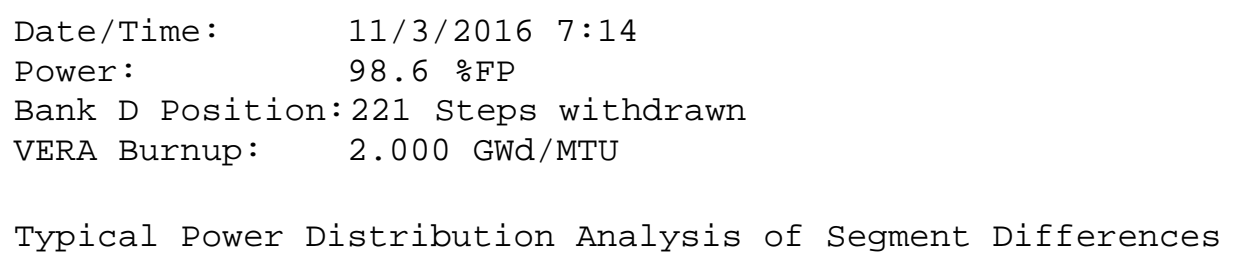

TOTAL RADIAL AXIAL

$\begin{array}{lrrr}\text { Average } & \odot .0 \odot \% & 0.0 \odot \% & 0.0 \odot \% \\ \text { RMS } & 3.73 \% & 2.55 \% & 1.58 \% \\ \text { Maximum } & 13.39 \% & 5.52 \% & 2.94 \%\end{array}$

By-Wire Statistics of Total Current Ratios

\begin{tabular}{|c|c|c|c|}
\hline & ALL & LONG & AVERAGES \\
\hline Average & $0.88 \%$ & ๑.4०\% & $0.15 \%$ \\
\hline Stdev & $2.77 \%$ & $2.68 \%$ & $0.44 \%$ \\
\hline RMS & $2.91 \%$ & $2.71 \%$ & $0.47 \%$ \\
\hline Maximum & $7.71 \%$ & $5.40 \%$ & $\odot .75 \%$ \\
\hline \multicolumn{4}{|c|}{ Statistics for Each Set of Wire Leng } \\
\hline Wires & Average & StDev & RMS \\
\hline \multirow{4}{*}{ Long } & $\odot .40 \%$ & $2.68 \%$ & $2.71 \%$ \\
\hline & $0.46 \%$ & $2.92 \%$ & $2.95 \%$ \\
\hline & $1.25 \%$ & $2.78 \%$ & $3.05 \%$ \\
\hline & $1.42 \%$ & $2.56 \%$ & $2.92 \%$ \\
\hline Short & $0.91 \%$ & $2.76 \%$ & $2.91 \%$ \\
\hline
\end{tabular}



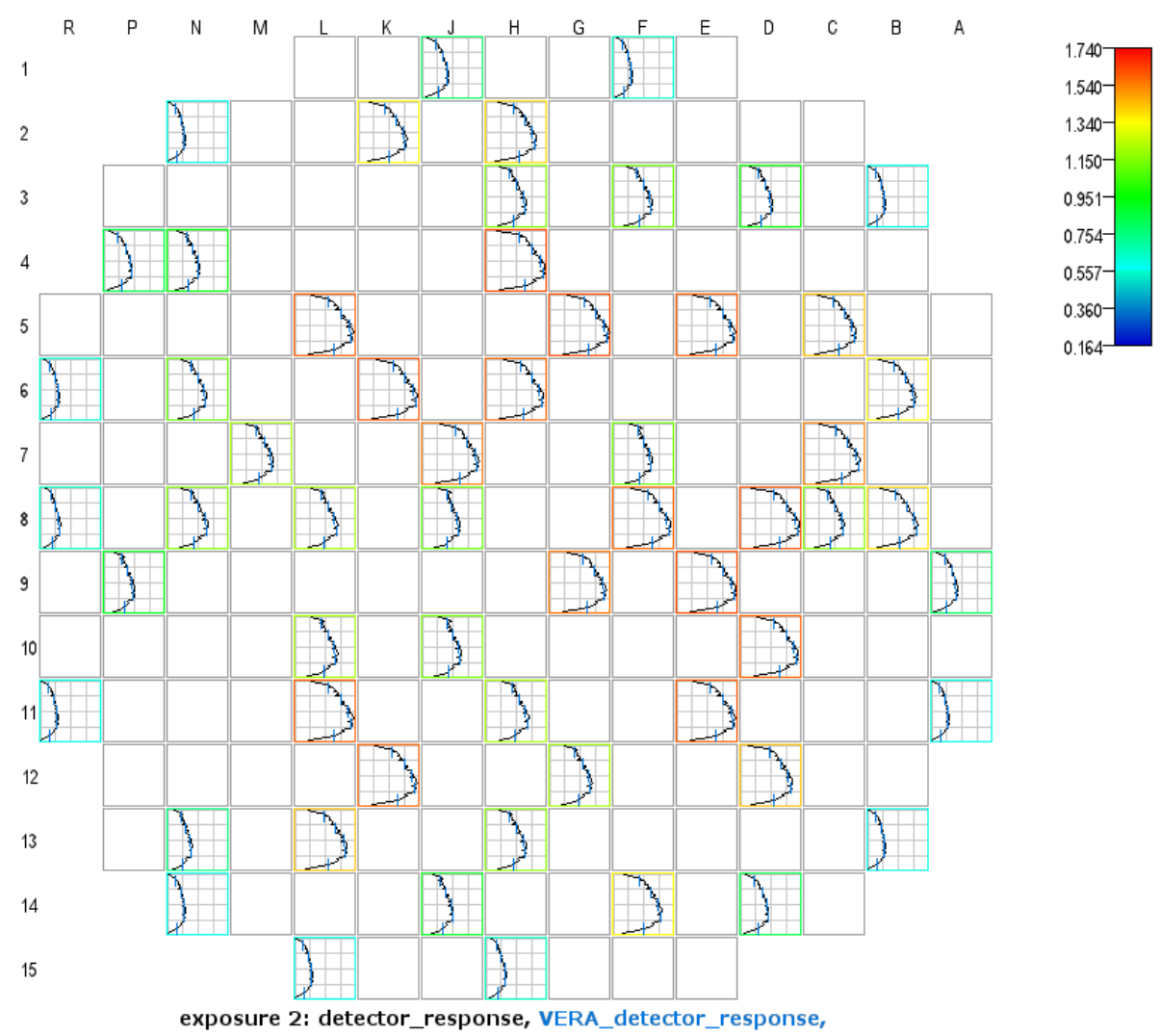

Figure B-29. Raw and Vanadium Detector Response Results from VERA for Case 8.

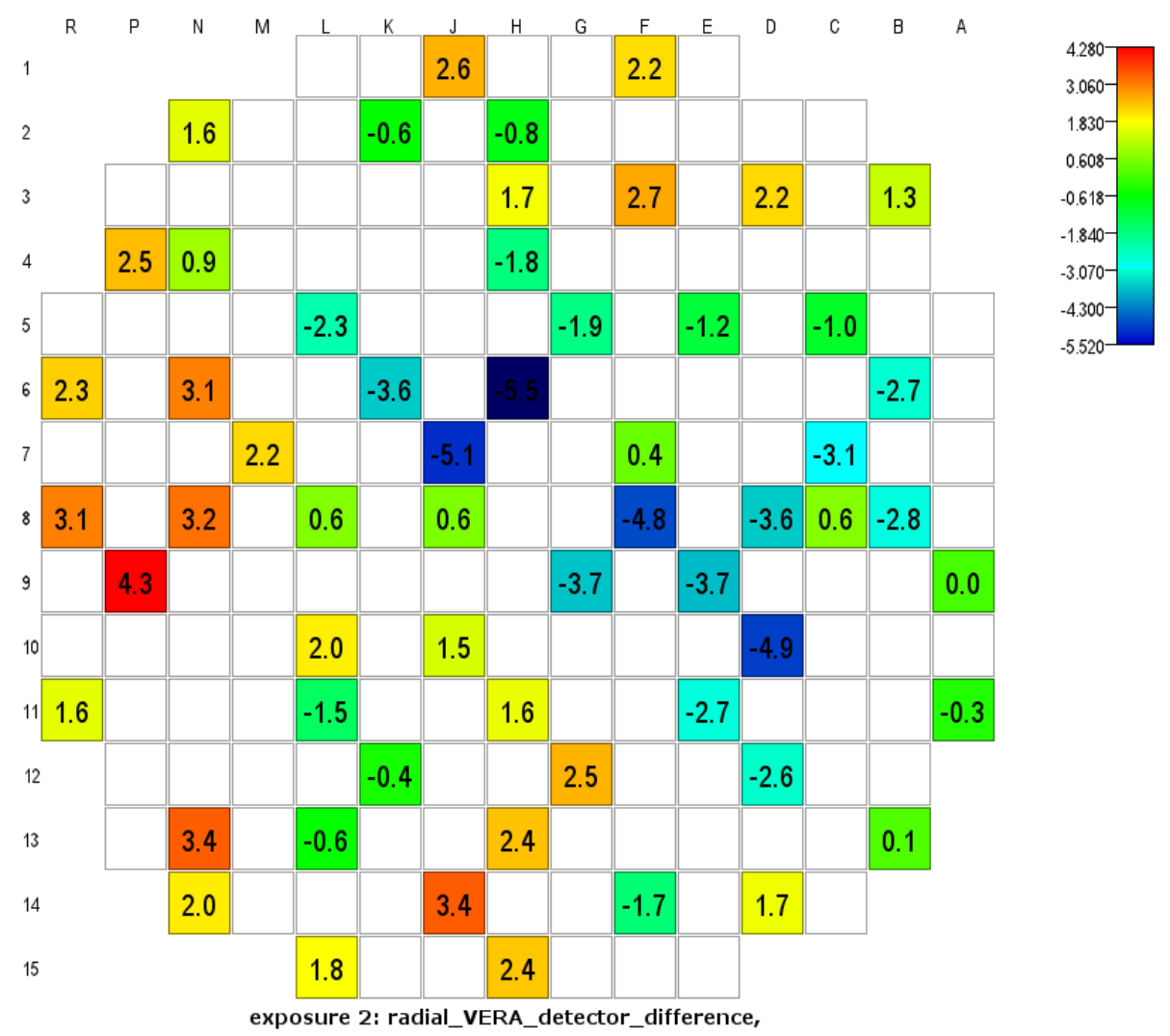

Figure B-30. Radial Detector Segment Differences (C-M,\%) for Case 8. 


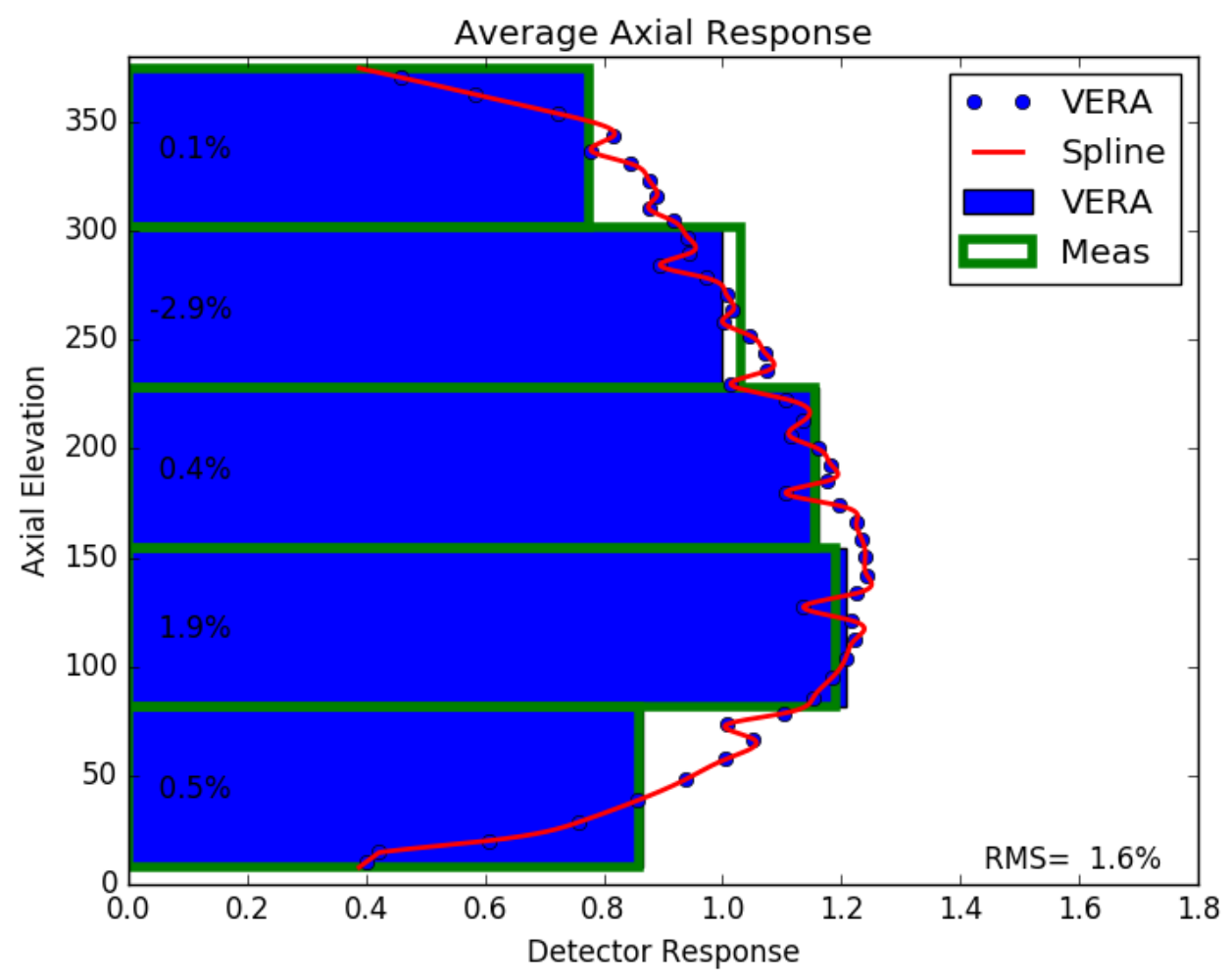

Figure B-31. Axial Detector Segment Differences (C-M,\%) for Case 8.

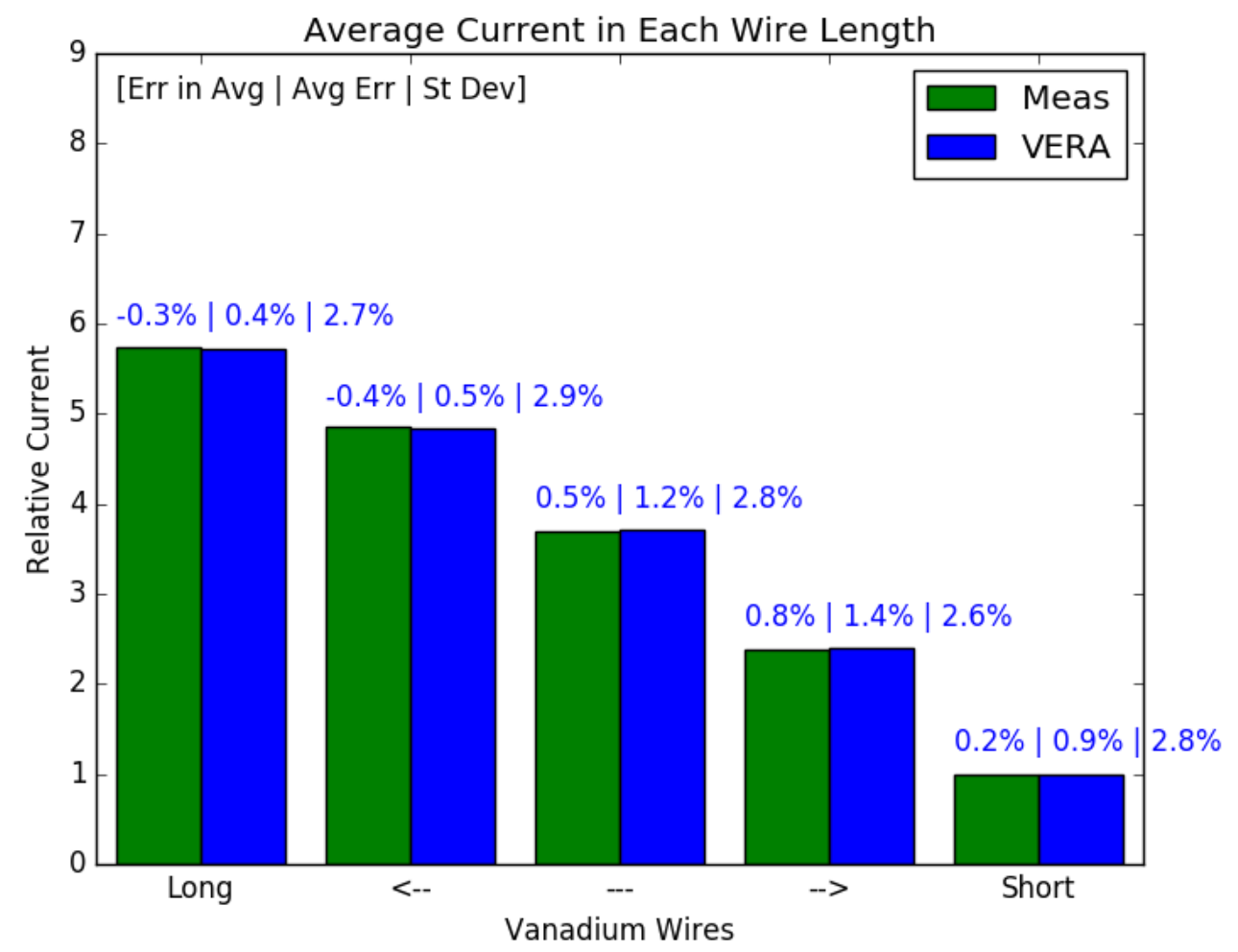

Figure B-32. Detector Relative Current Comparisons (C/M-1,\%) for Case 8. 


\section{Case 9:}

$\begin{array}{ll}\text { Date/Time: } & \text { 12/19/2016 } 8: 14 \\ \text { Power: } & 99.7 \% \text { FP } \\ \text { Bank D Position: } 220 \text { Steps withdrawn } \\ \text { VERA Burnup: } \quad 3.732 \text { GWd/MTU }\end{array}$

Typical Power Distribution Analysis of Segment Differences

TOTAL RADIAL AXIAL

$\begin{array}{lrrr}\text { Average } & 0.0 \odot \% & 0.00 \% & 0.00 \% \\ \text { RMS } & 3.74 \% & 2.46 \% & 1.74 \% \\ \text { Maximum } & 13.47 \% & 5.32 \% & 3.37 \%\end{array}$

By-Wire Statistics of Total Current Ratios

\begin{tabular}{|c|c|c|c|}
\hline & ALL & LONG & AVERAGES \\
\hline Average & $0.83 \%$ & $0.37 \%$ & $0.17 \%$ \\
\hline Stdev & $2.65 \%$ & $2.60 \%$ & $0.48 \%$ \\
\hline RMS & $2.78 \%$ & $2.62 \%$ & $0.51 \%$ \\
\hline Maximum & $7.48 \%$ & $5.33 \%$ & $0.79 \%$ \\
\hline \multicolumn{4}{|c|}{ Statistics } \\
\hline Wires & Average & StDev & RMS \\
\hline \multirow[t]{4}{*}{ Long } & $0.37 \%$ & $2.60 \%$ & $2.62 \%$ \\
\hline & $0.28 \%$ & $2.76 \%$ & $2.78 \%$ \\
\hline & $1.16 \%$ & $2.62 \%$ & $2.86 \%$ \\
\hline & $1.38 \%$ & $2.44 \%$ & $2.81 \%$ \\
\hline Short & $0.97 \%$ & $2.64 \%$ & $2.81 \%$ \\
\hline
\end{tabular}



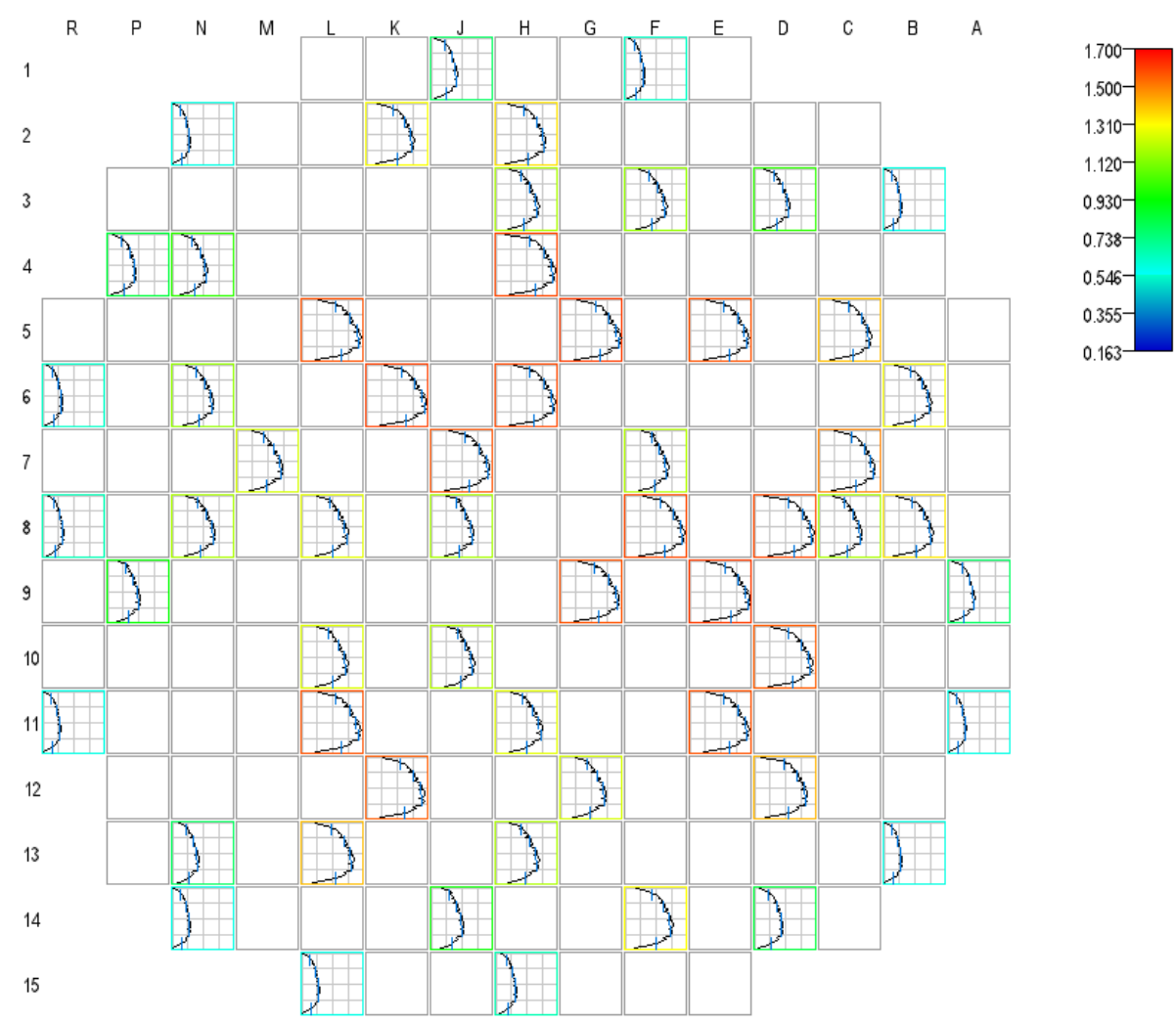

exposure 3.732: detector_response, VERA_detector_response,

Figure B-33. Raw and Vanadium Detector Response Results from VERA for Case 9.

\begin{tabular}{|c|c|c|c|c|c|c|c|c|c|c|c|c|c|c|c|c|}
\hline \multicolumn{2}{|r|}{$\mathrm{R}$} & $P$ & $\mathrm{~N}$ & M & L & K & J & $\mathrm{H}$ & G & $F$ & $E$ & \multirow[t]{2}{*}{ D } & \multirow[t]{2}{*}{ c } & \multirow[t]{2}{*}{ B } & A & \multirow{3}{*}{$\begin{array}{l}4.300- \\
3.100- \\
1.900-\end{array}$} \\
\hline 1 & & & & & & & 2.4 & & & 2.1 & & & & & & \\
\hline 2 & & & 1.6 & & & -0.6 & & -0.8 & & & & & & & & \\
\hline 3 & & & & & & & & 1.7 & & 2.4 & & 2.3 & & 1.2 & & $-0.508-$ \\
\hline 4 & & 2.5 & 1.1 & & & & & -1.5 & & & & & & & & $-2.910-$ \\
\hline 5 & & & & & -2.1 & & & & -2.1 & & -1.3 & & -1.2 & & & $\begin{array}{l}-4.120- \\
-5320\end{array}$ \\
\hline 6 & 0.0 & & 3.1 & & & -3.2 & & & & & & & & -2.7 & & \\
\hline 7 & & & & 2.2 & & & -4.8 & & & 0.2 & & & -2.9 & & & \\
\hline 8 & 2.9 & & 3.1 & & 0.6 & & 0.6 & & & -4.7 & & -3.4 & 0.6 & -2.5 & & \\
\hline 9 & & 4.3 & & & & & & & -3.4 & & -3.4 & & & & 0.2 & \\
\hline 10 & & & & & 1.8 & & 1.2 & & & & & -4.6 & & & & \\
\hline 11 & 1.6 & & & & -1.5 & & & 1.4 & & & -2.5 & & & & -0.1 & \\
\hline 12 & & & & & & -0.5 & & & 2.5 & & & -2.3 & & & & \\
\hline 13 & & & 3.6 & & -0.4 & & & 2.2 & & & & & & 0.4 & & \\
\hline 14 & & & 2.0 & & & & 3.3 & & & -1.7 & & 1.8 & & & & \\
\hline 15 & & & & & 1.7 & & & 2.4 & & & & & & & & \\
\hline
\end{tabular}

Figure B-34. Radial Detector Segment Differences (C-M,\%) for Case 9. 


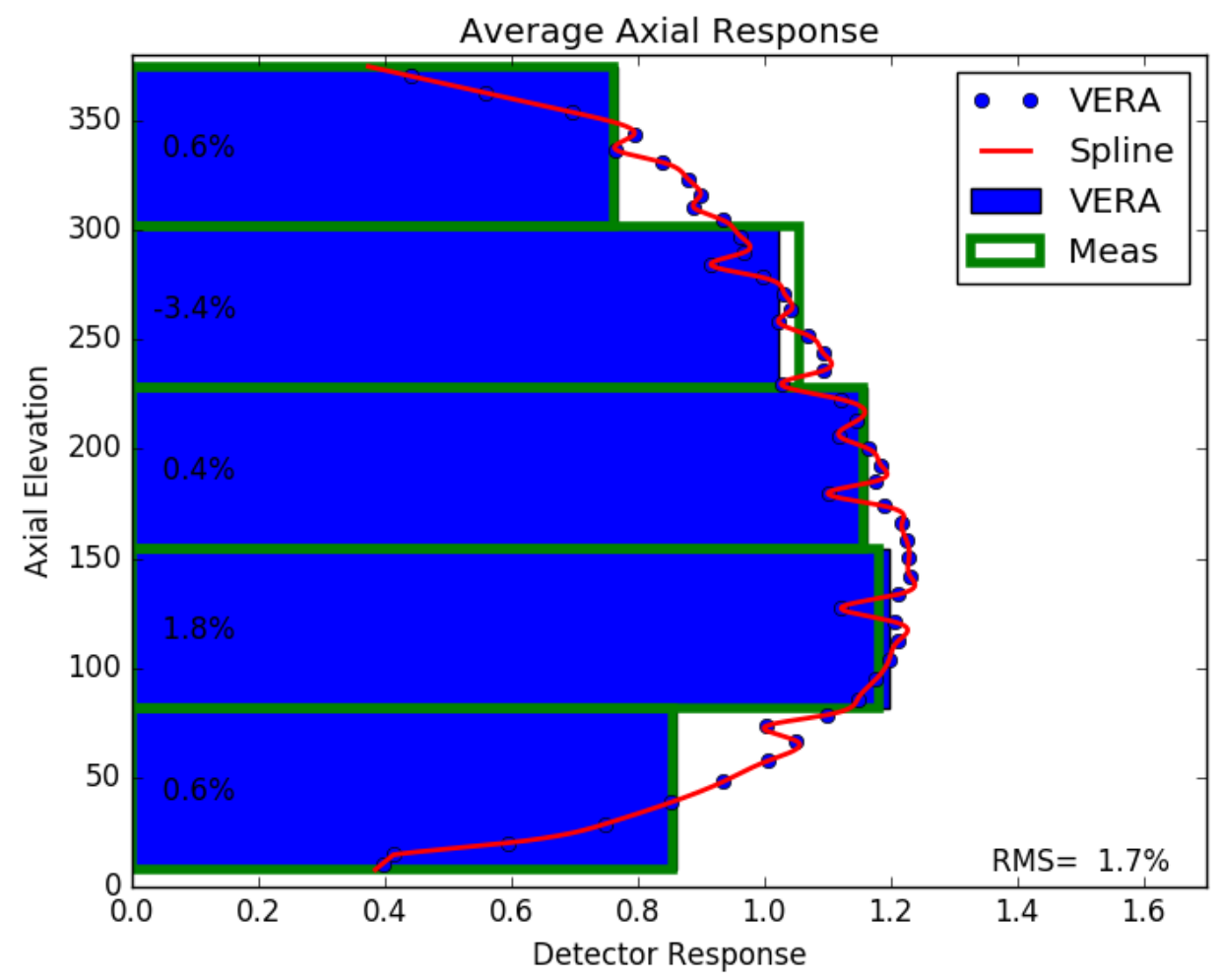

Figure B-35. Axial Detector Segment Differences (C-M,\%) for Case 9.

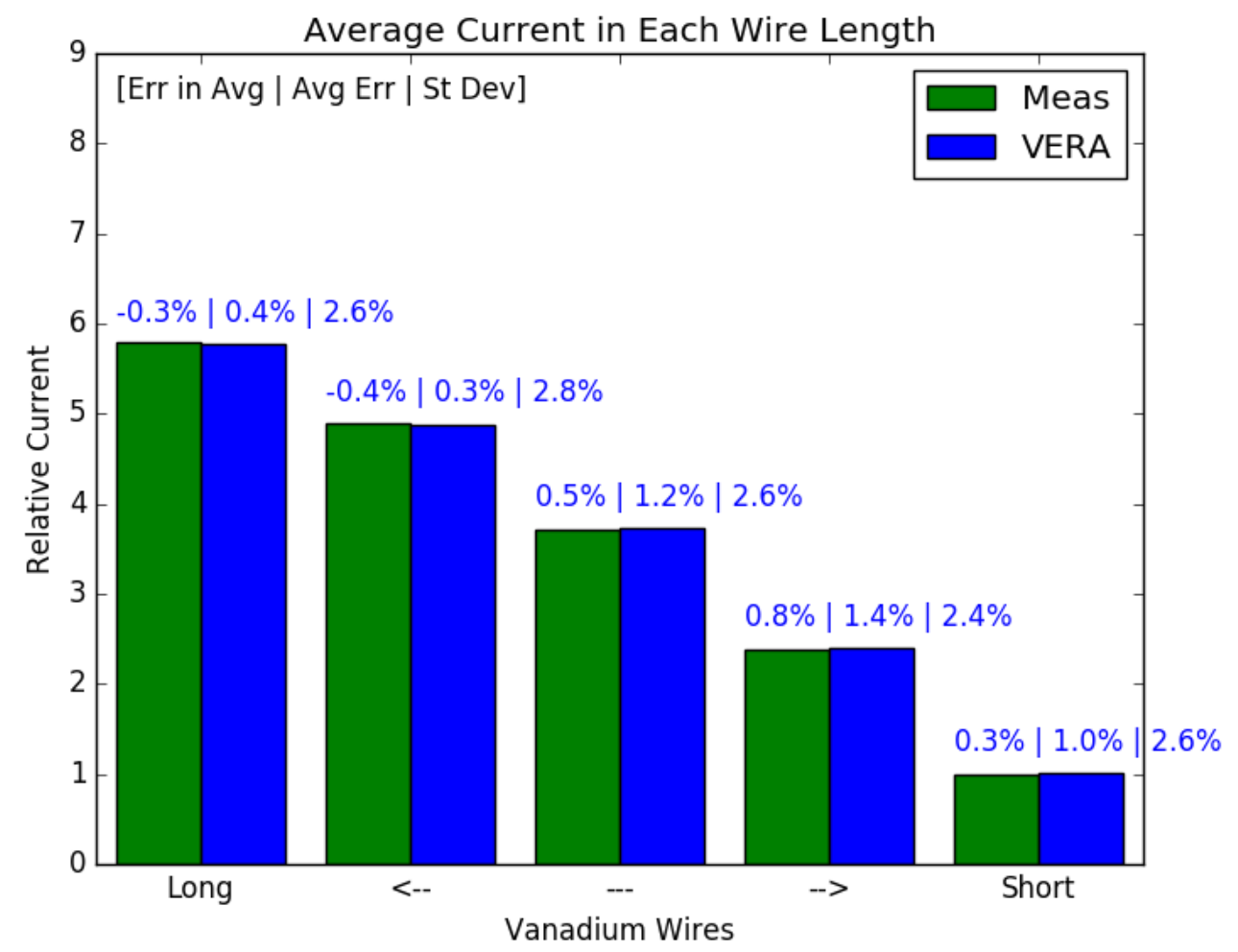

Figure B-36. Detector Relative Current Comparisons (C/M-1,\%) for Case 9. 


\section{Case 10:}

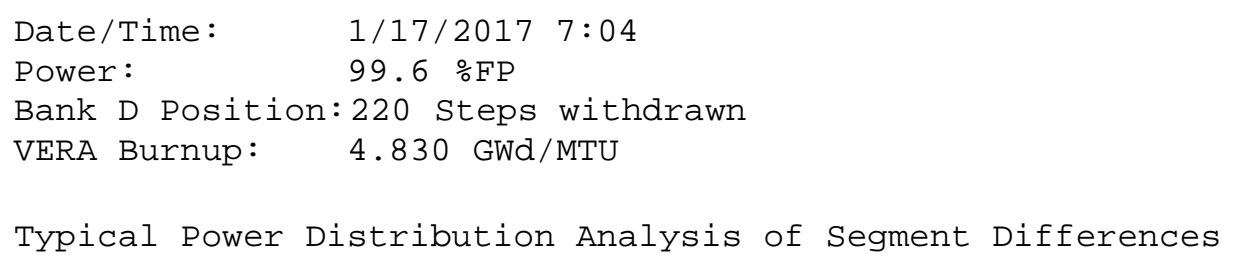

TOTAL RADIAL AXIAL

$\begin{array}{lrrr}\text { Average } & -0.0 \odot \% & -0.0 \odot \% & -0.0 \odot \% \\ \text { RMS } & 3.69 \% & 2.29 \% & 1.96 \% \\ \text { Maximum } & 13.0 \odot \% & 4.94 \% & 3.61 \%\end{array}$

By-Wire Statistics of Total Current Ratios

\begin{tabular}{|c|c|c|c|}
\hline & ALL & LONG & AVERAGES \\
\hline Average & $0.85 \%$ & $\odot .07 \%$ & $0.26 \%$ \\
\hline Stdev & $2.55 \%$ & $2.42 \%$ & $0.62 \%$ \\
\hline RMS & $2.69 \%$ & $2.42 \%$ & $0.67 \%$ \\
\hline Maximum & $7.13 \%$ & $5.01 \%$ & $\odot .99 \%$ \\
\hline \multicolumn{4}{|c|}{ Statistics for Each Set of Wire Leng } \\
\hline Wires & Average & StDev & RMS \\
\hline \multirow{4}{*}{ Long } & $0.07 \%$ & $2.42 \%$ & $2.42 \%$ \\
\hline & $0.19 \%$ & $2.58 \%$ & $2.59 \%$ \\
\hline & $1.22 \%$ & $2.46 \%$ & $2.74 \%$ \\
\hline & $1.53 \%$ & $2.33 \%$ & $2.79 \%$ \\
\hline Short & $1.25 \%$ & $2.60 \%$ & $2.89 \%$ \\
\hline
\end{tabular}



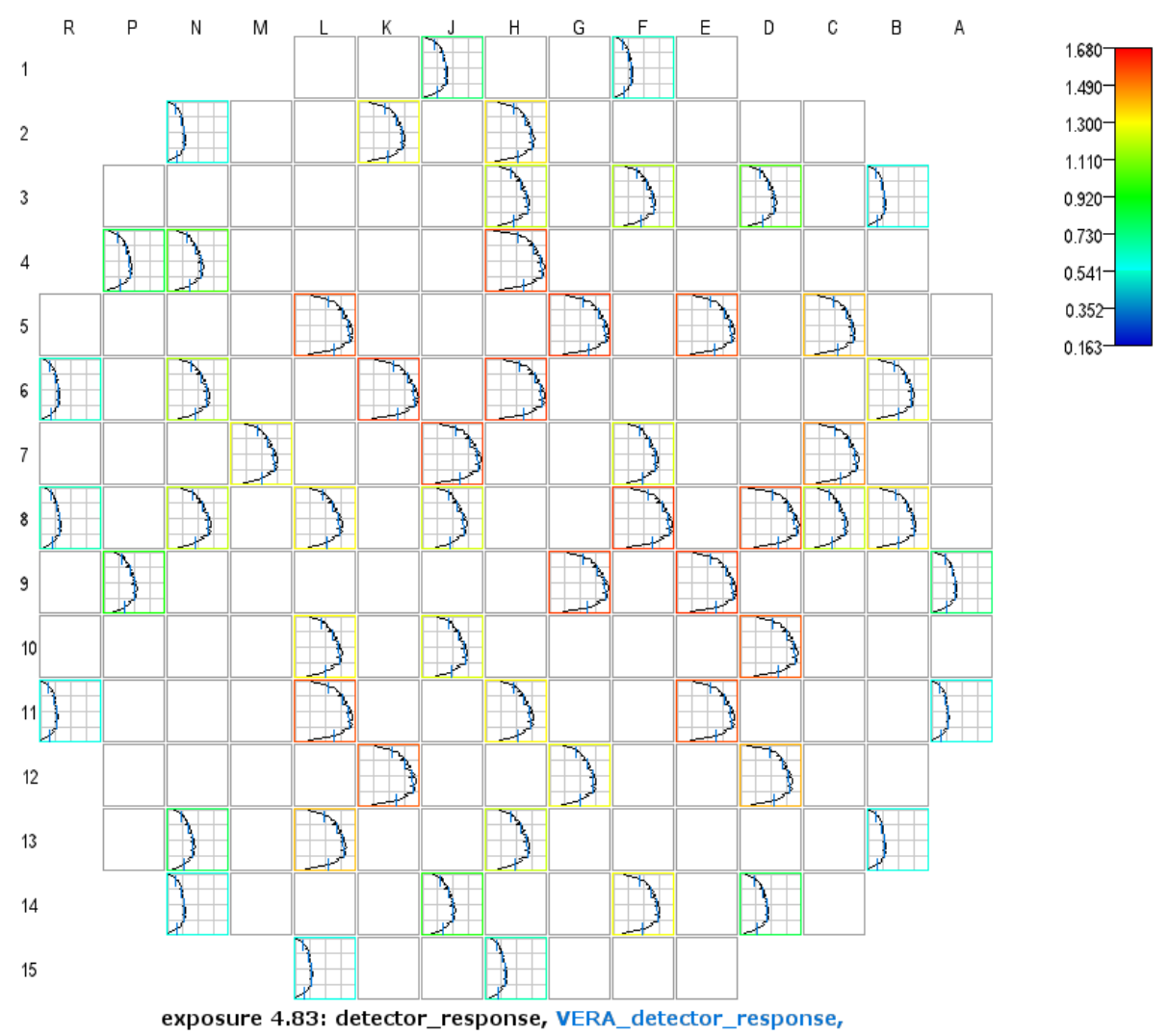

Figure B-37. Raw and Vanadium Detector Response Results from VERA for Case 10.

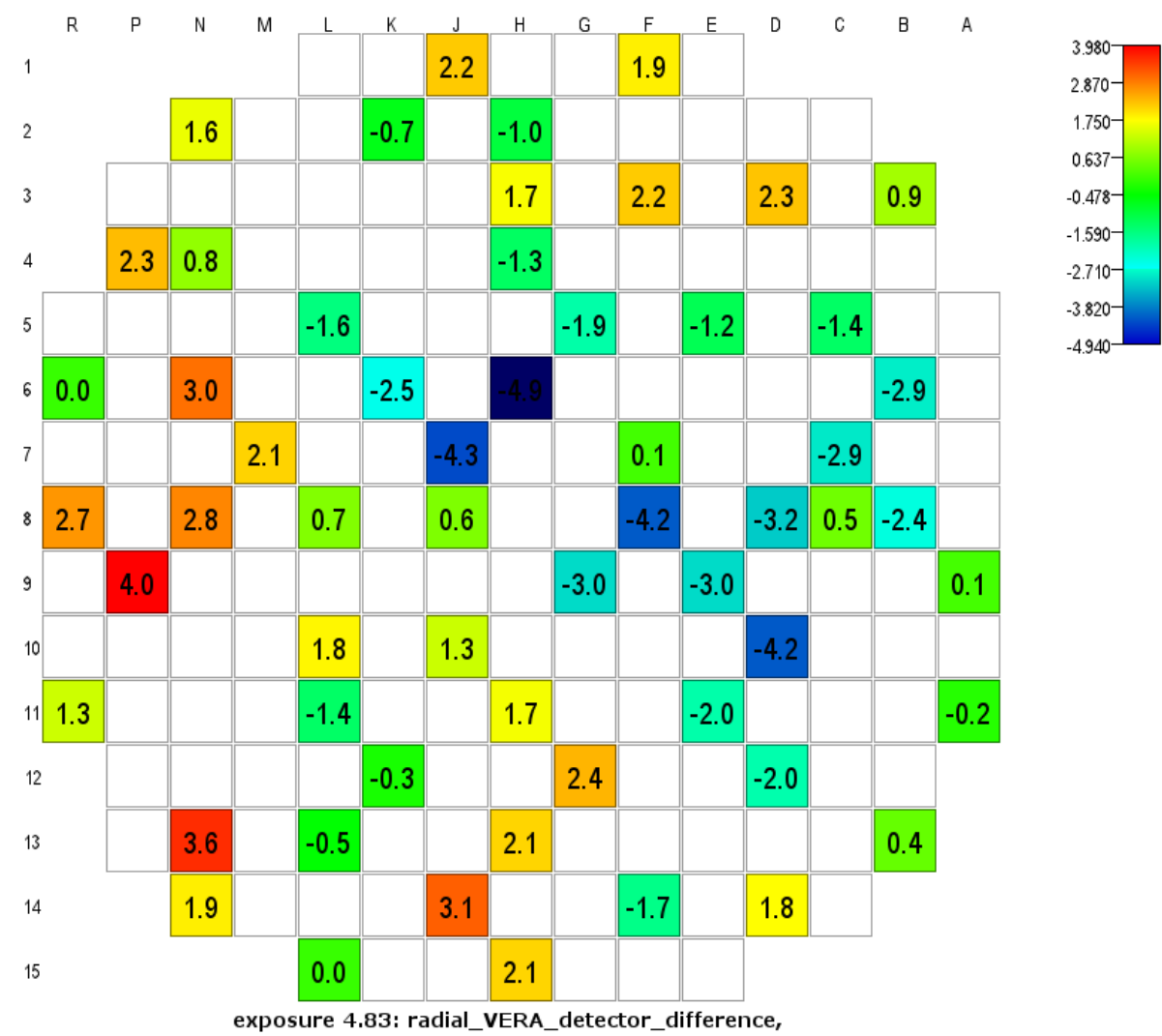

Figure B-38. Radial Detector Segment Differences (C-M,\%) for Case 10. 


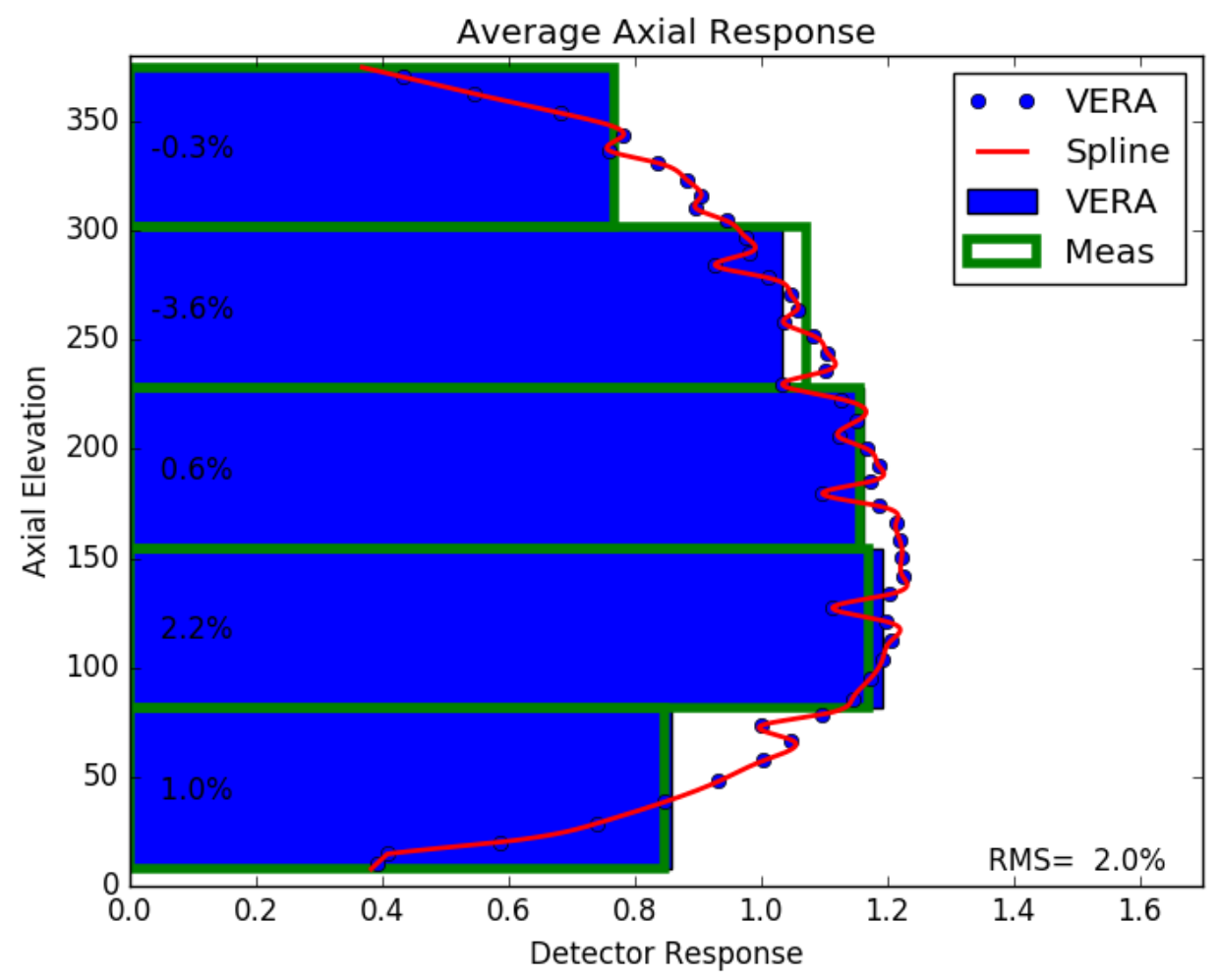

Figure B-39. Axial Detector Segment Differences (C-M,\%) for Case 10.

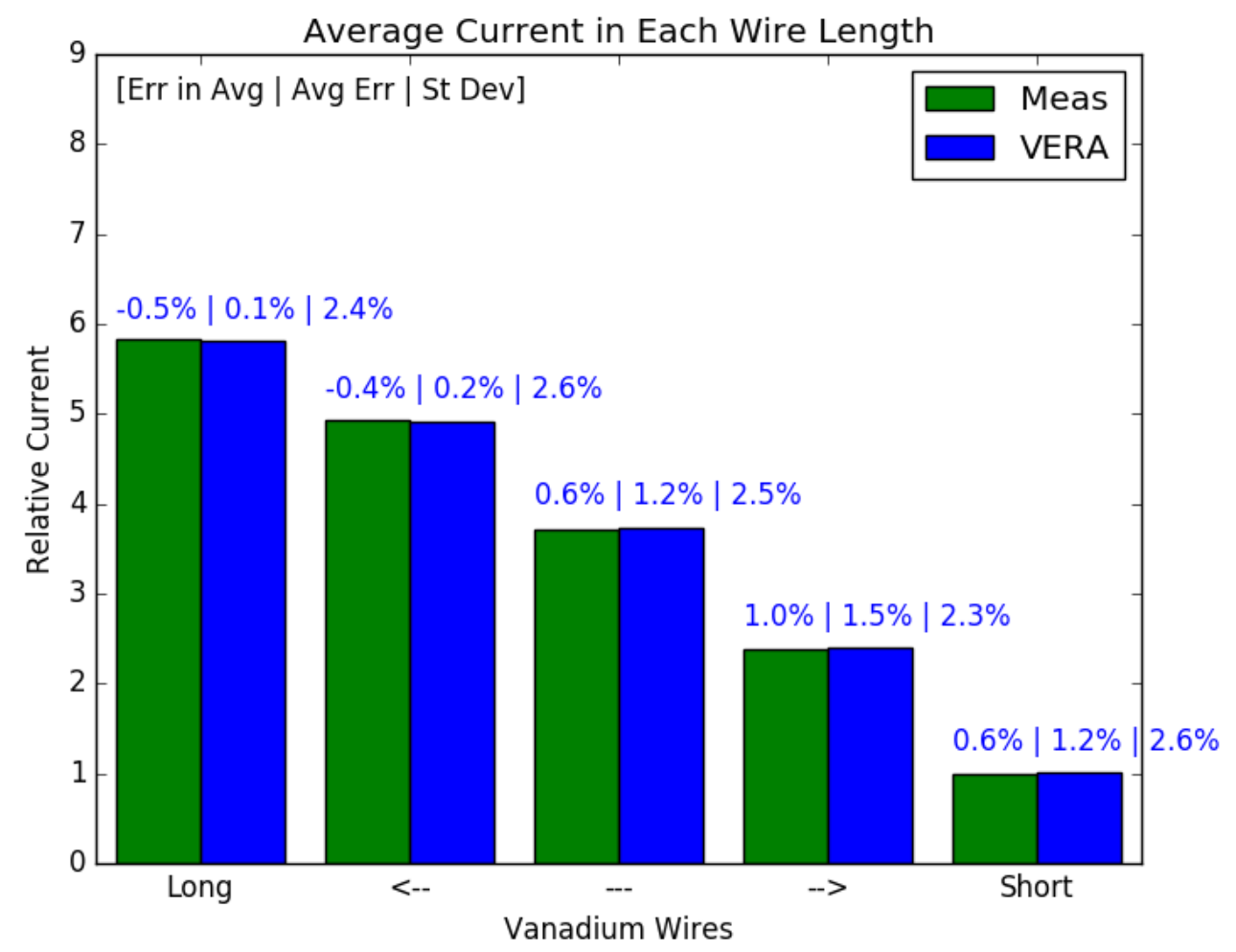

Figure B-40. Detector Relative Current Comparisons (C/M-1,\%) for Case 10. 


\section{Case 11:}

$\begin{array}{ll}\text { Date/Time: } & \text { 2/13/2017 } 7: 50 \\ \text { Power: } & 99.9 \% \text { FP } \\ \text { Bank D Position: } 220 \text { Steps withdrawn } \\ \text { VERA Burnup: } \quad 5.856 \text { GWd/MTU }\end{array}$

Typical Power Distribution Analysis of Segment Differences

TOTAL RADIAL AXIAL

$\begin{array}{lrrr}\text { Average } & 0.0 \odot \% & 0.0 \odot \% & 0.0 \odot \% \\ \text { RMS } & 3.39 \% & 2.16 \% & 1.55 \% \\ \text { Maximum } & 11.75 \% & 4.83 \% & 3.00 \%\end{array}$

By-Wire Statistics of Total Current Ratios

\begin{tabular}{|c|c|c|c|}
\hline & ALL & LONG & AVERAGES \\
\hline Average & $0.68 \%$ & ๑. $29 \%$ & $0.11 \%$ \\
\hline Stdev & $2.38 \%$ & $2.28 \%$ & $\odot .39 \%$ \\
\hline RMS & $2.48 \%$ & $2.30 \%$ & $0.40 \%$ \\
\hline Maximum & $6.16 \%$ & $4.93 \%$ & $0.59 \%$ \\
\hline \multicolumn{4}{|c|}{ Statistics } \\
\hline Wires & Average & StDev & RMS \\
\hline \multirow{4}{*}{ Long } & $0.29 \%$ & $2.28 \%$ & $2.30 \%$ \\
\hline & $0.26 \%$ & $2.44 \%$ & $2.45 \%$ \\
\hline & $1.06 \%$ & $2.31 \%$ & $2.54 \%$ \\
\hline & $1.10 \%$ & $2.17 \%$ & $2.43 \%$ \\
\hline Short & $0.72 \%$ & $2.54 \%$ & $2.64 \%$ \\
\hline
\end{tabular}




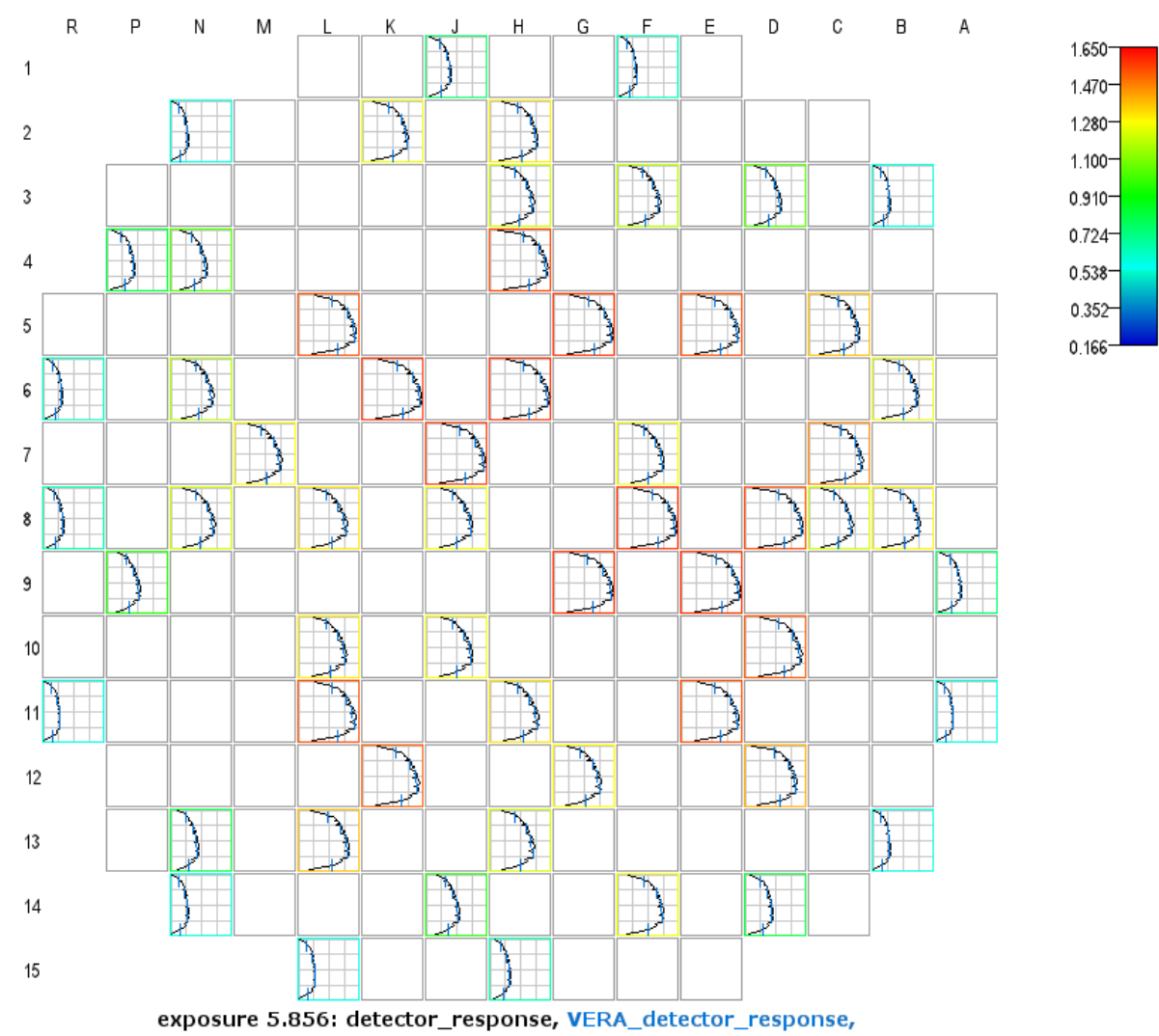

Figure B-41. Raw and Vanadium Detector Response Results from VERA for Case 11.

\begin{tabular}{|c|c|c|c|c|c|c|c|c|c|c|c|c|c|c|c|}
\hline \multicolumn{2}{|r|}{$\mathrm{R}$} & $P$ & $\mathrm{~N}$ & M & & K & & $\mathrm{H}$ & G & $F$ & $E$ & \multirow[t]{2}{*}{$D$} & c & B & \multirow[t]{2}{*}{ A } \\
\hline 1 & & & & & & & 2.1 & & & 1.8 & & & & & \\
\hline 2 & & & 1.5 & & & -0.8 & & -1.2 & & & & & & & \\
\hline 3 & & & & & & & & 1.4 & & 1.9 & & 1.8 & & 0.8 & \\
\hline 4 & & 2.2 & 0.8 & & & & & -1.2 & & & & & & & \\
\hline 5 & & & & & -1.5 & & & & -2.0 & & -1.6 & & -1.4 & & \\
\hline 6 & 1.9 & & 2.7 & & & -2.2 & & & & & & & & -3.0 & \\
\hline 7 & & & & 2.0 & & & -4.0 & & & 0.1 & & & -2.8 & & \\
\hline 8 & 2.5 & & 2.6 & & 0.6 & & 0.7 & & & -4.0 & & -2.9 & 0.6 & -2.2 & \\
\hline 9 & & 3.7 & & & & & & & -2.8 & & -2.7 & & & & 0.3 \\
\hline 10 & & & & & 1.8 & & 1.2 & & & & & -3.8 & & & \\
\hline 11 & 1.1 & & & & -1.5 & & & 1.6 & & & -1.8 & & & & 0.0 \\
\hline 12 & & & & & & -0.5 & & & 2.4 & & & -1.9 & & & \\
\hline 13 & & & 3.5 & & -0.8 & & & 2.0 & & & & & & 0.5 & \\
\hline 14 & & & 1.7 & & & & 3.1 & & & -1.8 & & 1.6 & & & \\
\hline 15 & & & & & 0.0 & & & 2.0 & & & & & & & \\
\hline
\end{tabular}

Figure B-42. Radial Detector Segment Differences (C-M,\%) for Case 11. 


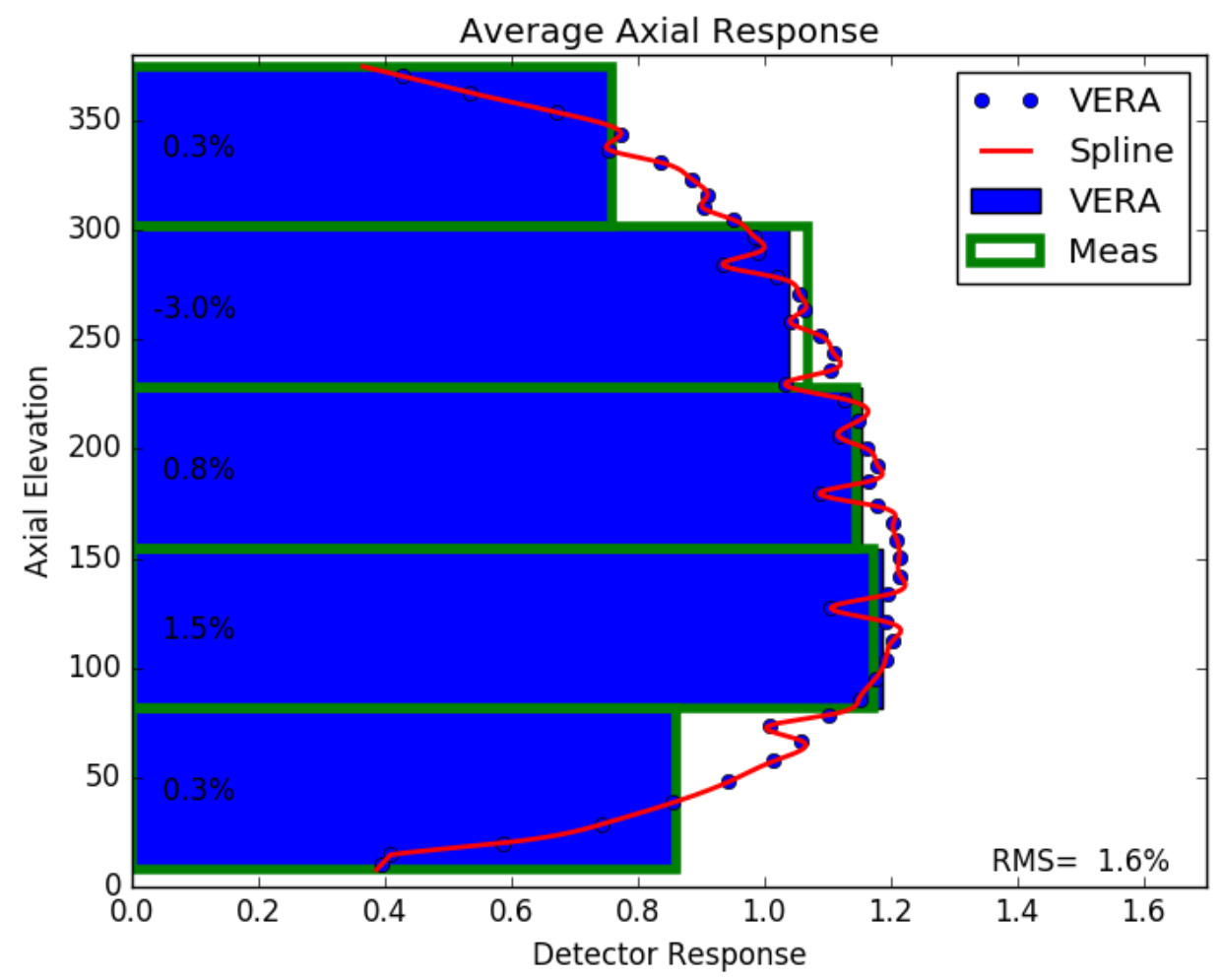

Figure B-43. Axial Detector Segment Differences (C-M,\%) for Case 11.

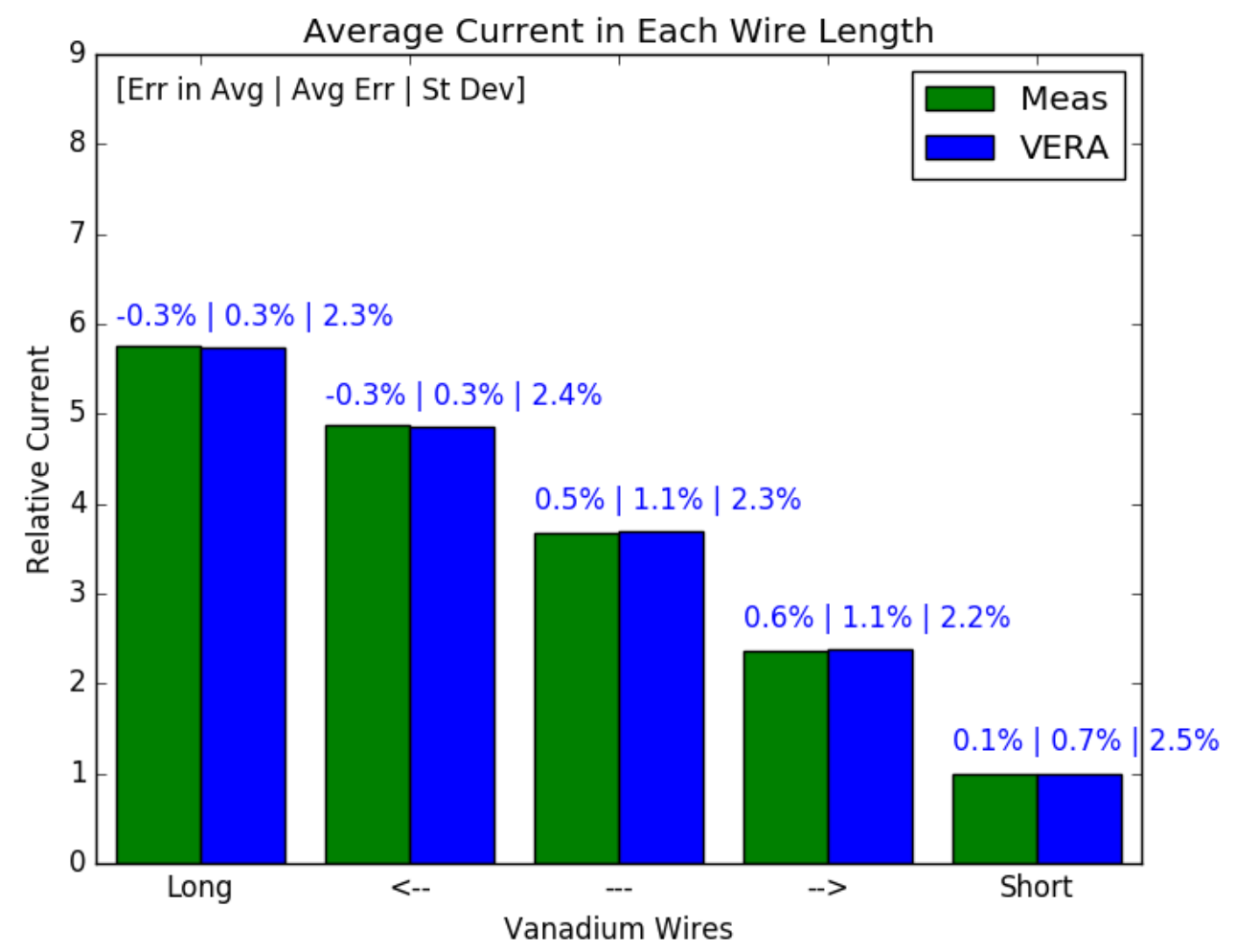

Figure B-44. Detector Relative Current Comparisons (C/M-1,\%) for Case 11. 


\section{Case 12:}

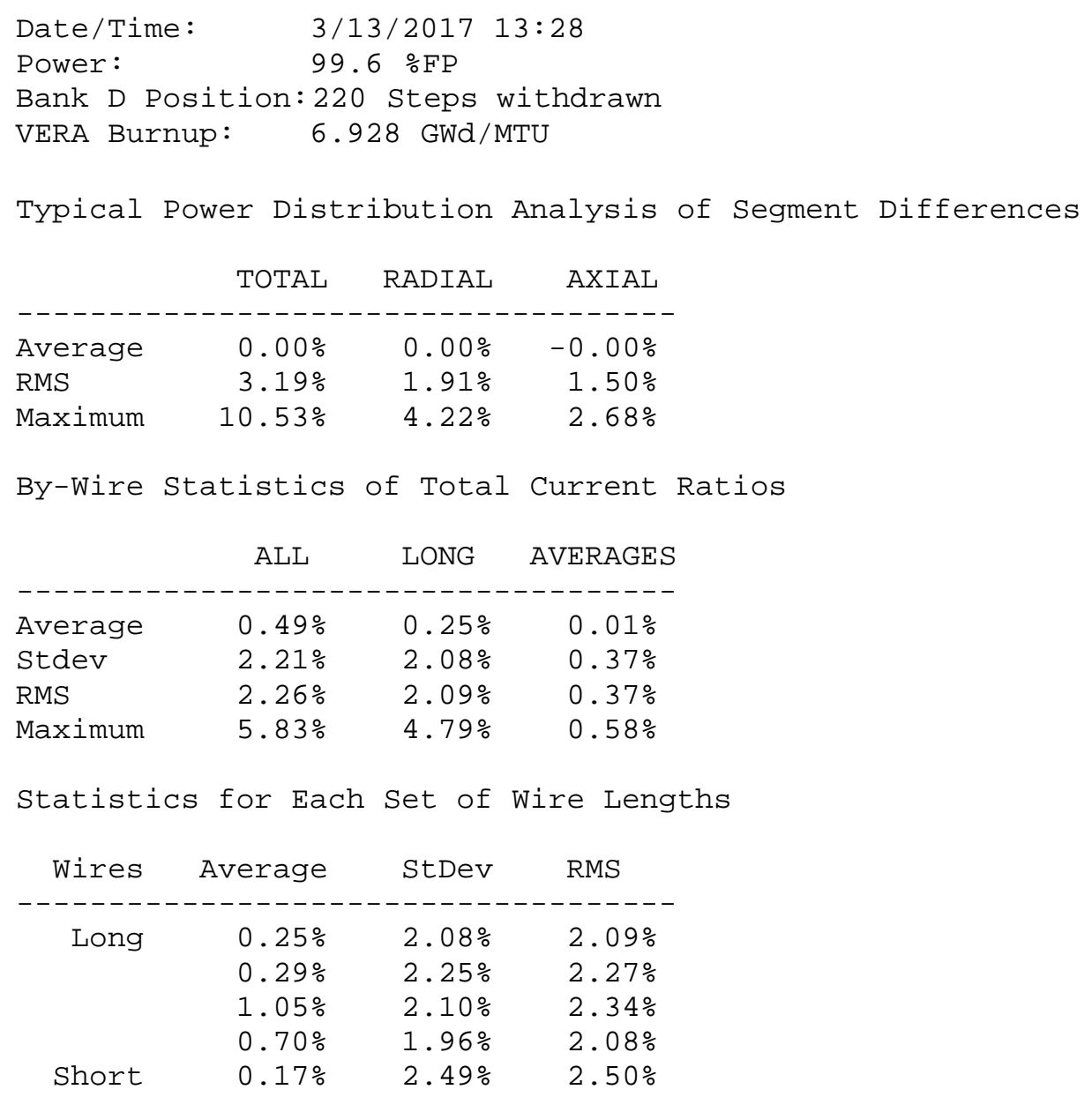



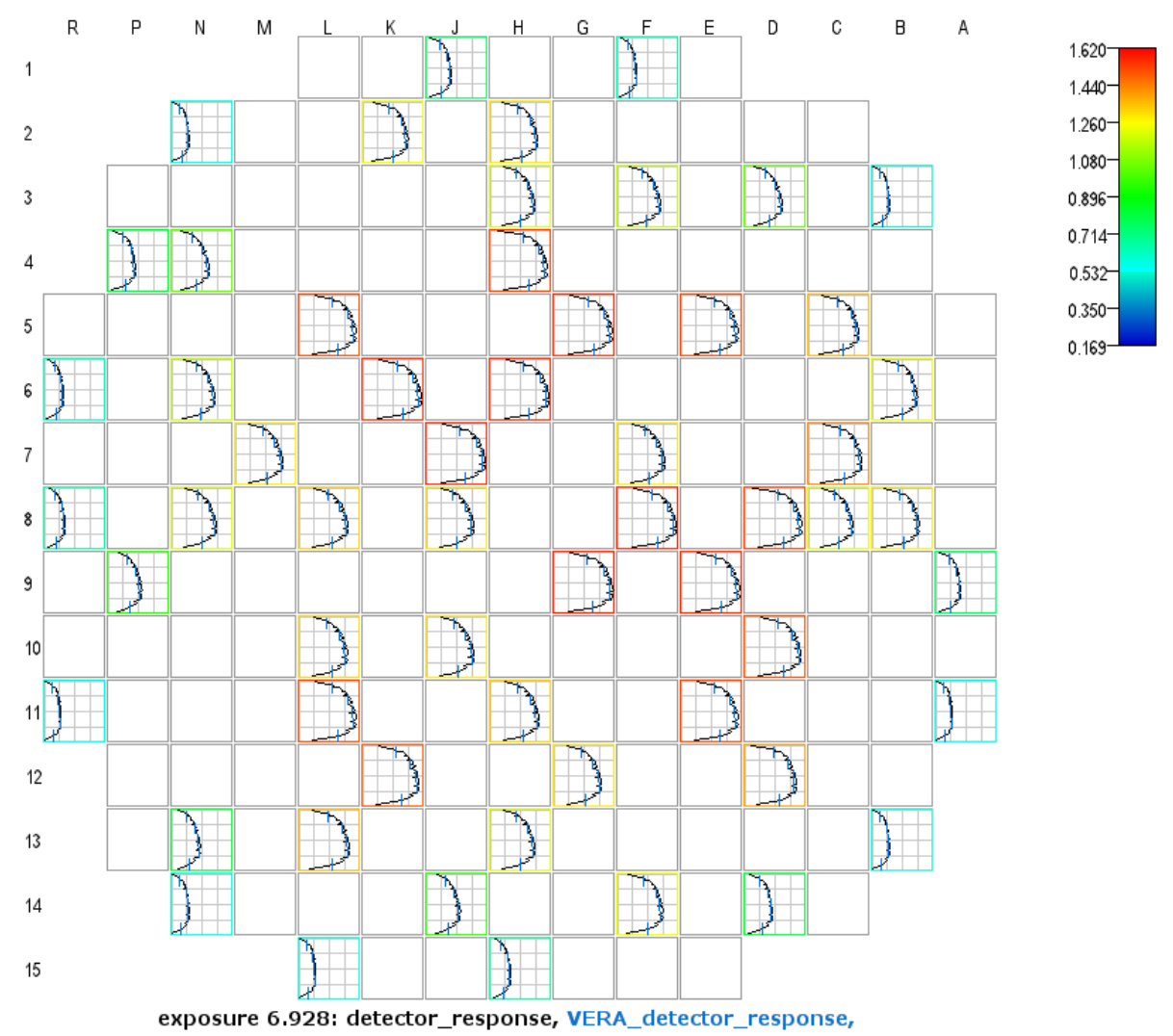

Figure B-45. Raw and Vanadium Detector Response Results from VERA for Case 12.

\begin{tabular}{|c|c|c|c|c|c|c|c|c|c|c|c|c|c|c|c|c|}
\hline \multicolumn{2}{|r|}{$\mathrm{R}$} & $\mathrm{P}$ & $\mathrm{N}$ & M & L & K & J & $\mathrm{H}$ & G & $F$ & $E$ & \multirow[t]{2}{*}{ D } & \multirow[t]{2}{*}{$c$} & \multirow[t]{2}{*}{ B } & A & \\
\hline 1 & & & & & & & 2.0 & & & 1.7 & & & & & & \\
\hline 2 & & & 1.5 & & & -0.7 & & -1.1 & & & & & & & & $1.590-$ \\
\hline 3 & & & & & & & & 1.5 & & 1.7 & & 1.5 & & 0.7 & & $-0.348-$ \\
\hline 4 & & 2.1 & 0.7 & & & & & -0.9 & & & & & & & & -2.280 \\
\hline 5 & & & & & -1.2 & & & & -1.5 & & -1.3 & & -1.4 & & & $\begin{array}{r}-3.250- \\
-4220-\end{array}$ \\
\hline 6 & 1.7 & & 2.6 & & & -1.8 & & & & & & & & -2.7 & & \\
\hline 7 & & & & 0.0 & & & -3.3 & & & 0.5 & & & -2.4 & & & \\
\hline 8 & 2.4 & & 2.4 & & 0.6 & & 0.9 & & & -3.1 & & -2.0 & 1.0 & 0.0 & & \\
\hline 9 & & 3.5 & & & & & & & -2.1 & & -2.0 & & & & 0.5 & \\
\hline 10 & & & & & 1.6 & & 0.0 & & & & & -3.0 & & & & \\
\hline 11 & 1.0 & & & & -1.5 & & & 1.6 & & & -1.2 & & & & 0.0 & \\
\hline 12 & & & & & & -0.5 & & & 2.5 & & & -1.4 & & & & \\
\hline 13 & & & 3.4 & & -0.8 & & & 1.9 & & & & & & 0.6 & & \\
\hline 14 & & & -0.2 & & & & 0.0 & & & -1.9 & & 0.0 & & & & \\
\hline 15 & & & & & 1.4 & & & 0.0 & & & & & & & & \\
\hline
\end{tabular}

Figure B-46. Radial Detector Segment Differences (C-M,\%) for Case 12. 


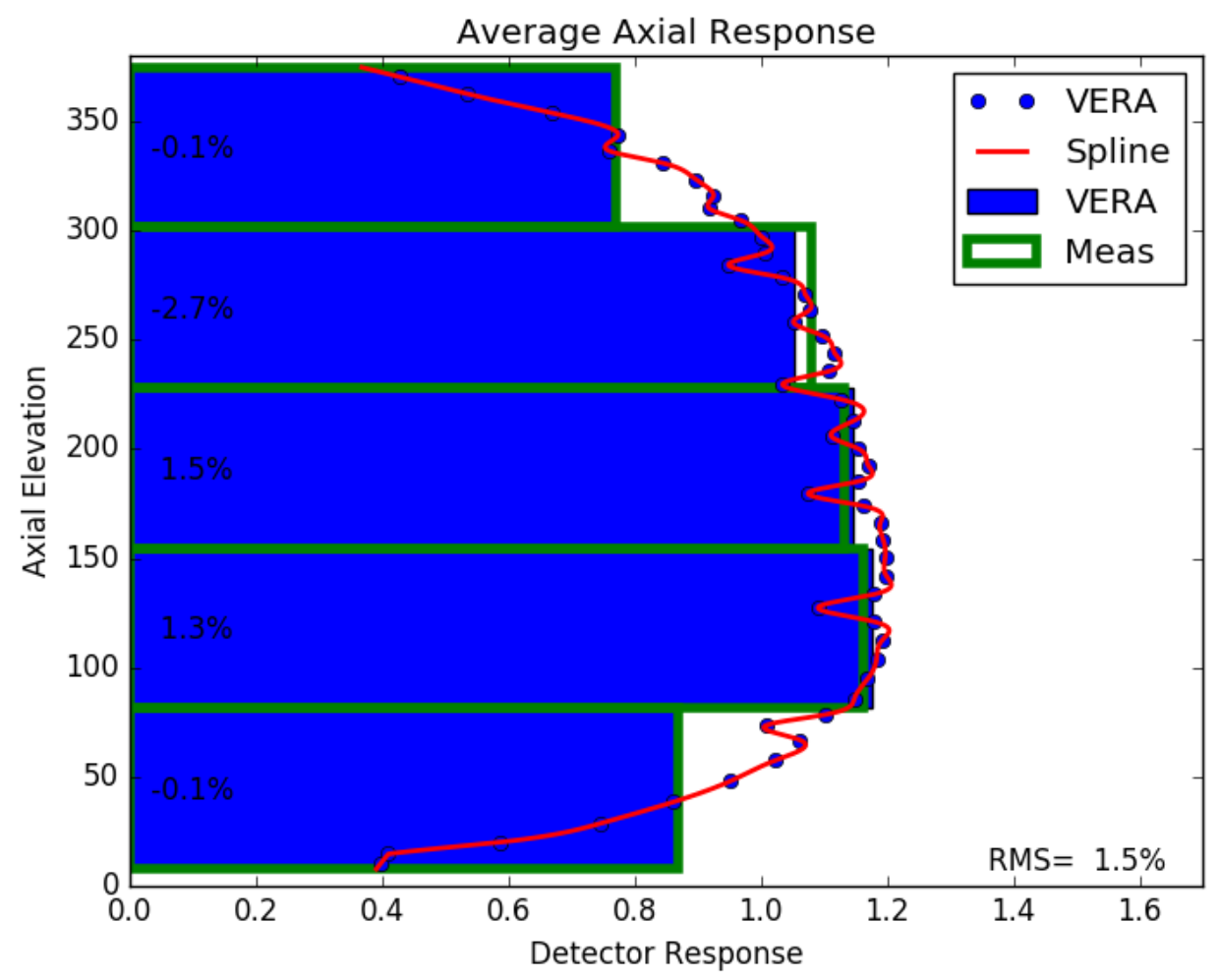

Figure B-47. Axial Detector Segment Differences (C-M,\%) for Case 12.

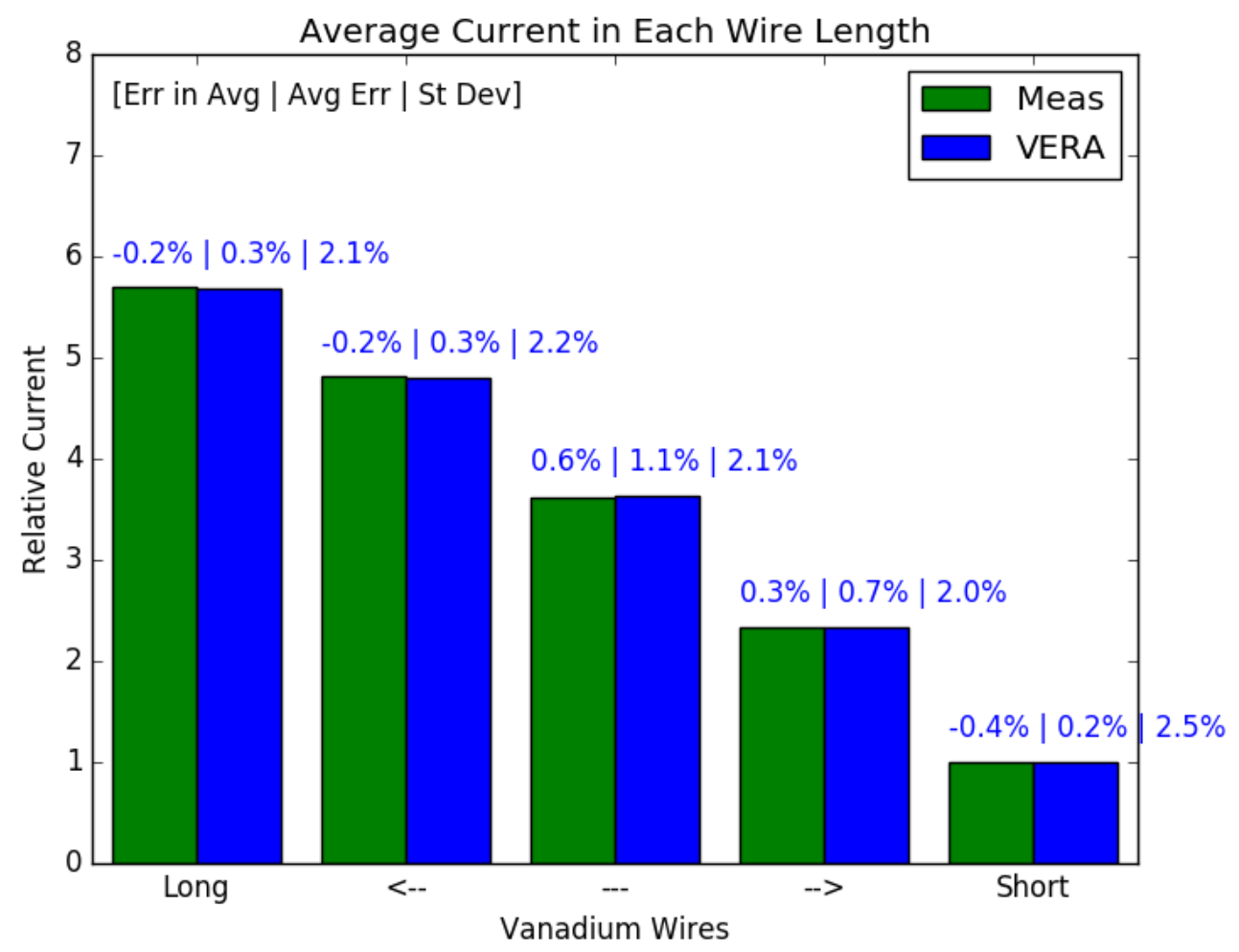

Figure B-48. Detector Relative Current Comparisons (C/M-1,\%) for Case 12. 


\section{APPENDIX C: ASSYMETRIC POWER DISTRIBUTION CALCULATIONS}

The primary and secondary neutron sources are installed in the WBN2 core in asymmetric locations. However, the majority of the VERA calculations are performed assuming quarter-core symmetry, so the neutron sources (and the instrument thimbles) are not included in the calculations. This appendix documents the effects of the sources on the steady state reactivity and power distribution.

It is noted that this is not a fixed source or kinetics solution. The effects calculated are merely due to replacing a WABA rod with a non-absorbing primary rod, and displacing moderator with a secondary rod. The sources are merely modelled as empty stainless steel tubes.

Calculations were performed with VERA in 2D to compare the power distribution and reactivity effects of the sources at HZP all-rods-out conditions. The eigenvalue difference between the two cases was $8 \mathrm{pcm}$ (higher when removing WABA), and the pin power difference is shown in the figure below.

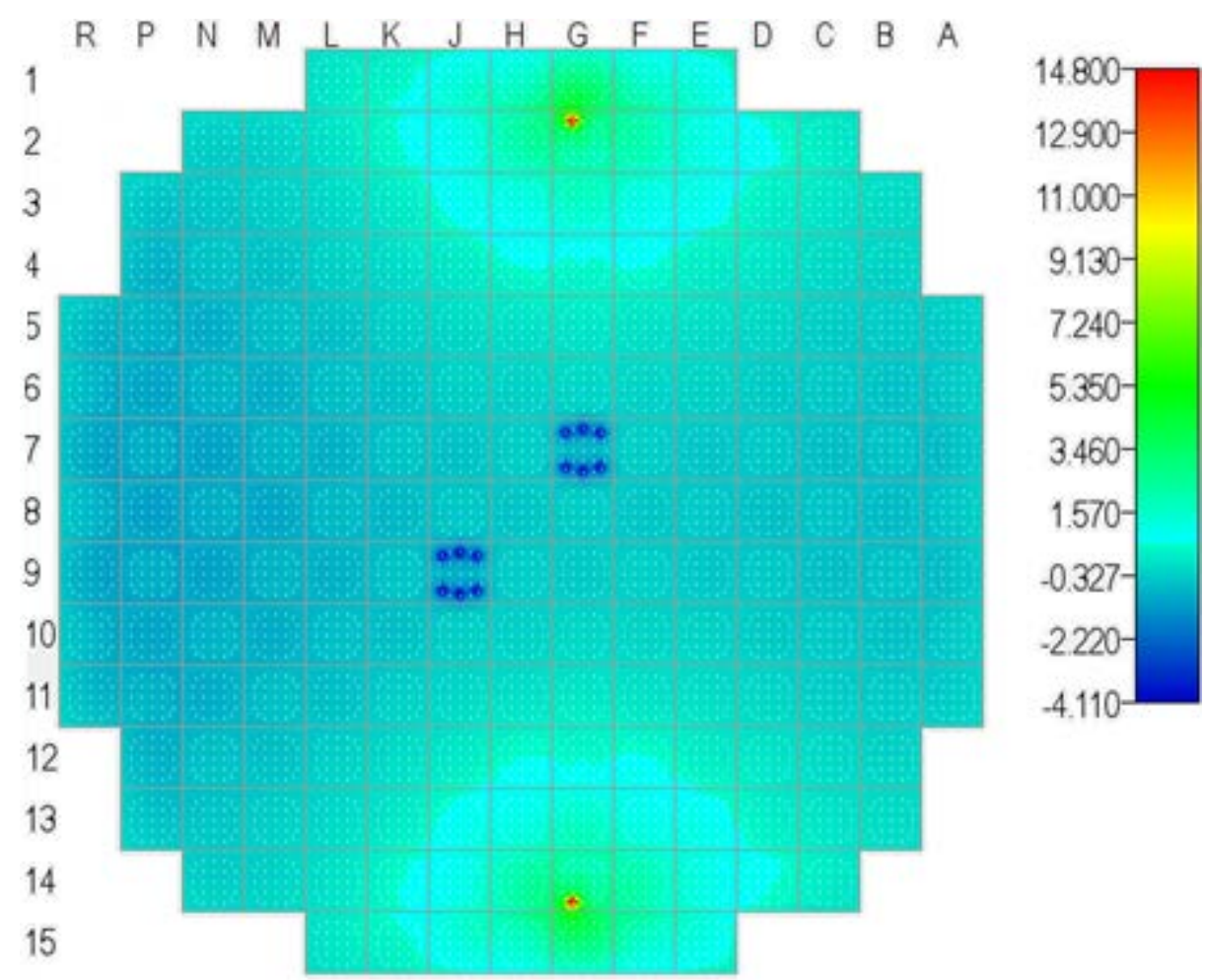

Figure C-1. Asymmetrical Effects (\% power) of Source Rods on Pin Power Distribution.

Figure C-1 indicates pin power differences of up to $15 \%$ in fuel rods adjacent to the primary source rod locations, compared to a quarter-core model where a WABA is used. It also shows that the displaced moderator in the secondary source locations reduces the power in the adjacent fuel rods by approximately 4\%. The effect on radial assembly power is shown in Figure C-2. 


\begin{tabular}{|l|l|l|l|l|l|l|l|}
\hline$-0.4 \%$ & $-0.3 \%$ & $-0.4 \%$ & $-0.4 \%$ & $-0.5 \%$ & $-0.5 \%$ & $-0.6 \%$ & $-0.4 \%$ \\
\hline$-0.3 \%$ & $-0.3 \%$ & $-0.3 \%$ & $-0.4 \%$ & $-0.4 \%$ & $-0.5 \%$ & $-0.5 \%$ & $-0.5 \%$ \\
\hline$-0.2 \%$ & $-0.1 \%$ & $-0.1 \%$ & $-0.2 \%$ & $-0.3 \%$ & $-0.4 \%$ & $-0.5 \%$ & $-0.3 \%$ \\
\hline $0.1 \%$ & $0.2 \%$ & $0.1 \%$ & $0.0 \%$ & $-0.1 \%$ & $-0.3 \%$ & $-0.3 \%$ & $-0.3 \%$ \\
\hline $0.6 \%$ & $0.6 \%$ & $0.6 \%$ & $0.3 \%$ & $0.1 \%$ & $0.0 \%$ & $-0.2 \%$ & \\
\hline $1.1 \%$ & $1.5 \%$ & $1.1 \%$ & $0.8 \%$ & $0.4 \%$ & $0.1 \%$ & $0.0 \%$ & \\
\hline $2.1 \%$ & $3.2 \%$ & $1.9 \%$ & $1.1 \%$ & $0.6 \%$ & $0.2 \%$ & & \\
\hline $1.7 \%$ & $2.8 \%$ & $1.6 \%$ & $0.9 \%$ & & & & \\
\hline
\end{tabular}

Figure C-2. Asymmetrical Effects (\% power) of Source Rods on Quarter-Core Assembly Powers.

For each flux map in Section 4.6, a full-core restart was performed from the quarter-core depletion to insert the instrument thimbles, insert the primary and secondary sources, and in some cases recalculate the distribution of xenon for equilibrium conditions. A comparison of the difference between the full core result and original quarter-core results in included below for the $10^{\text {th }}$ flux map. The results are in quarter-core symmetry. The difference in critical boron concentration is only 0.4 ppmB. The pin power differences range from $7.8 \%$ higher to $5.2 \%$ lower in Figure C-3, with the largest decreases in power being associated with insertion of the stainless steel instrument thimbles. The assembly power differences range from 1.8\% higher to $1.5 \%$ lower in Figure C-4.
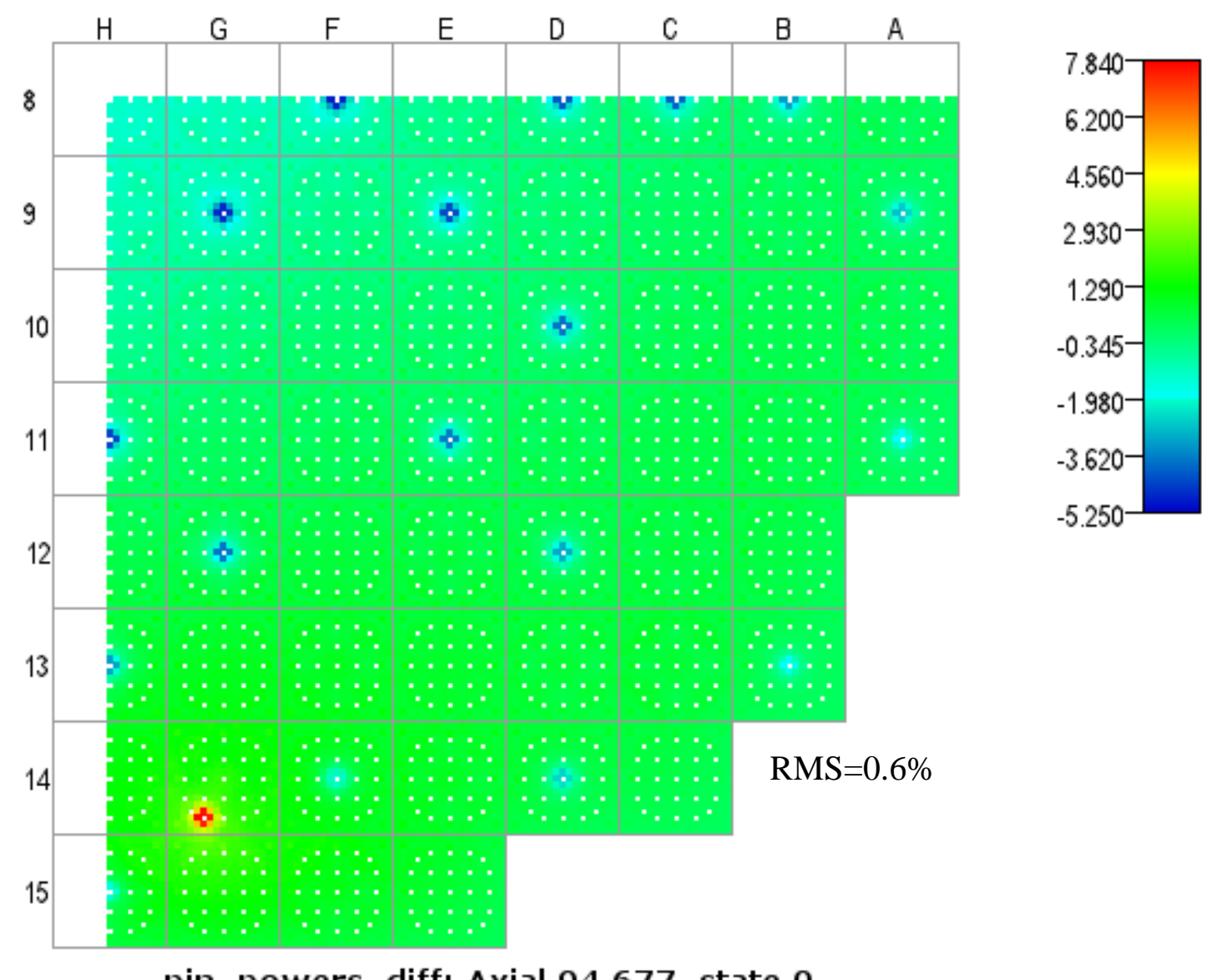

pin_powers_diff: Axial 94.677, state 0

Figure C-3. Pin Power Differences between Full and Quarter-Core Simulations for Map 10. 


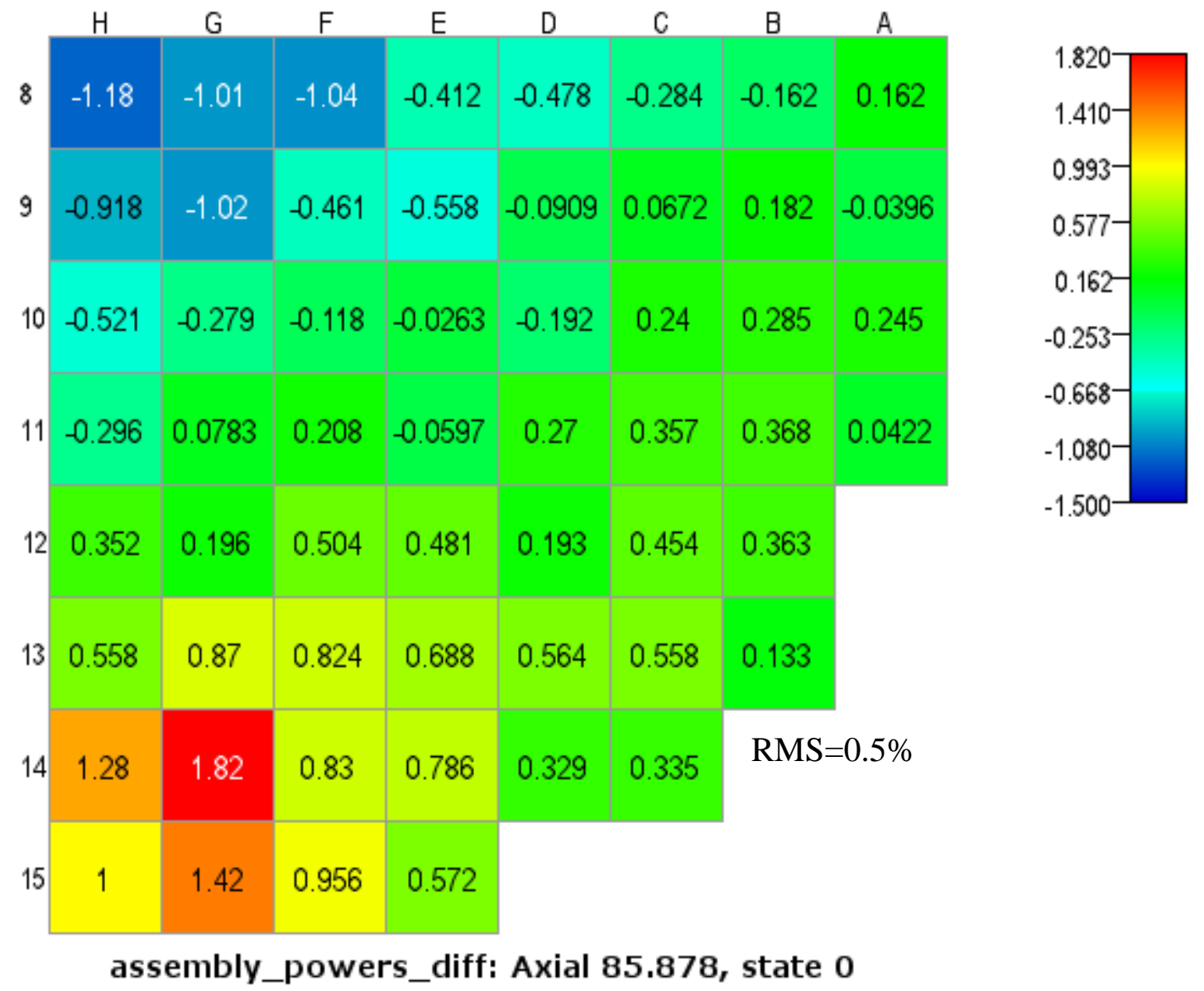

Figure C-4. Assembly Power Differences between Full and Quarter-Core Simulations for Map 10.

Based on these results, it is reasonable to conclude that the error associated with the modelling approach of quarter-core depletion followed by full-core expansion should be significantly less than $0.5 \%$ effect on the instrument radial RMS. There is no significant effect expected in the axial dimension. 


\section{APPENDIX D: NOMINAL CYCLE DEPLETION}

A nominal cycle depletion of WBN2 was performed to compare VERA with the designed full power cycle length of 406 EFPDs. The job was executed with the latest models, code version, and cross section library, using the default (original) BISON fuel temperature table. A summary of the depletion is shown on the following page. For the most recent flux map, VERA is approximately -18 ppmB below measurement, using the ${ }^{10} \mathrm{~B}$ depletion model described in Section 4.5.9. There are very little differences between the recently calculated critical borons for nominal depletion and the cases with the actual startup history. The nominal depletion results in an end-of-cycle (EOC) critical boron concentration of only $14 \mathrm{ppmB}$. Since this value is close to zero, it provides more confidence that VERA is accurately representing WBN2 and doing well at calculating the cycle depletion.

The EOC fuel rod average exposures are shown in Figure D-1, and the assembly exposures are shown in D-2.
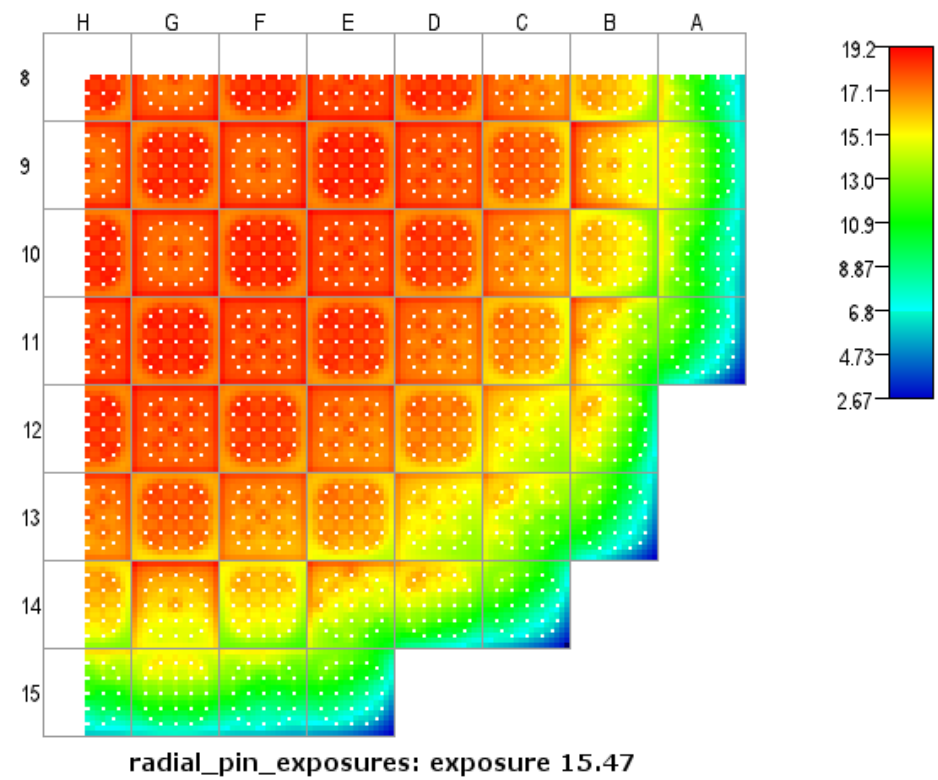

Figure D-1. Calculated Fuel Rod Exposures at End-of-Cycle 1.
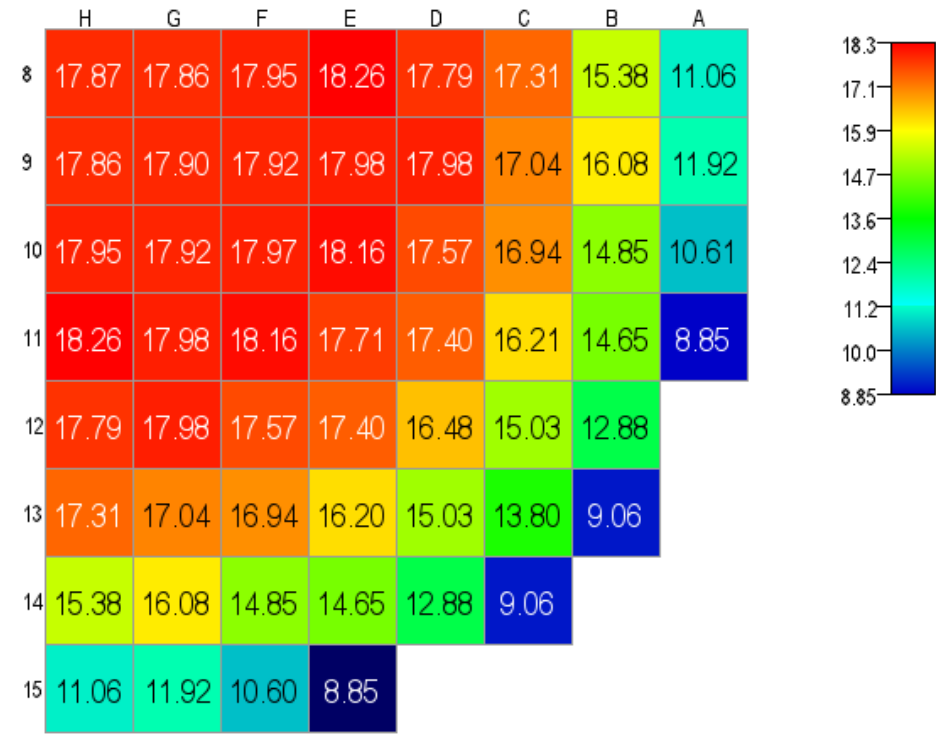

radial_asy_pin_exposures: exposure 15.47

Figure D-2. Calculated Fuel Assembly Exposures at End-of-Cycle 1. 


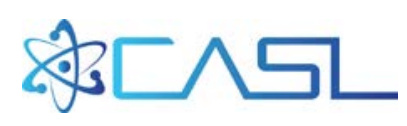

Table D-1. WBN2 Cycle 1 Nominal Depletion Summary

\begin{tabular}{|c|c|c|c|c|c|c|c|c|c|c|c|c|c|c|c|c|c|c|c|c|c|}
\hline \# & EFPD & Ecyc & Ecore & Emax & $k$-eff & Boron & AO & Pavg & Fassy & $\mathrm{FdH}$ & $\mathrm{Fq}$ & Power & $\operatorname{Tin}(\mathrm{F})$ & $\operatorname{Tavg}(F)$ & Tout (F) & pin & pavg & pout & $\operatorname{Tf}(\mathrm{K})$ & $\operatorname{Tfmx}(\mathrm{K})$ & Oute \\
\hline 1 & $\odot . \odot$ & ००० & 000 & 000 & 000 & 44.7 & $-1.11 \%$ & 100 & .2056 & 1.4051 & 1.7032 & 100.0 & $55 \mathrm{c}$ & 590. & 619.8 & .74 & $\odot .699$ & $\odot .656$ & 907.4 & 1063 & \\
\hline 2 & 3.9 & 150 & 150 & 209 & & & & & & 1.3871 & & $100.0 \%$ & & & & & & & & 1048.4 & 4 \\
\hline 3 & 26.2 & 000 & 1 & 372 & $\odot 000 \odot$ & 0.5 & $5.83 \%$ & & & 1.3546 & 1.6742 & $100.0 \%$ & 559.0 & 591.7 & 619. & 0.740 & & & & & \\
\hline 4 & 52.5 & 2.000 & 2.000 & 2.707 & .00000 & 674.7 & $-5.25 \%$ & .0000 & .2322 & 1.3362 & 1.6342 & $100.0 \%$ & 559.0 & 591.6 & 619.8 & 0.740 & 998 & & 7.3 & 26.5 & \\
\hline 5 & 78.7 & 3.000 & 3.000 & 4.011 & .00000 & 81.0 & $-4.80 \%$ & $.000 \odot$ & 1.2284 & 1.3253 & 1.6196 & $100.0 \%$ & 9.0 & .5 & & 0.740 & & & & 5.2 & \\
\hline 6 & 104.9 & 000 & 0 & 307 & & & & & & 1.3 & 1.5982 & & & & & & & & & & \\
\hline 7 & 131.1 & 5.000 & 5.00 & 610 & & & -4.2 & & & 1.3 & 1.5 & & & & & & & & & 94.2 & \\
\hline 8 & 157.4 & 6.000 & 6.000 & 7.899 & & 4 & $-3.79 \%$ & & 1.22 & 1.29 & 1.5 & . \% & .0 & & & 740 & 98 & & & 35.5 & \\
\hline 9 & 183.6 & & 7.000 & & & & & & & 1.28 & & & & & & & & & & & \\
\hline 10 & 209.8 & & & & & & & & & & & & & & & & & & & & \\
\hline 11 & 236.1 & 9.000 & 9.000 & 54 & & 490.2 & -1.7 & & 1.21 & 1.25 & 1.42 & & & & & 0.740 & 0.698 & & & & \\
\hline 12 & 262.3 & 10.000 & & & & & & & & & & & & & & & & & & & \\
\hline 13 & 38.5 & & & & & & & & & 1.2 & & & & & & & & & & & \\
\hline 14 & 314.7 & 1 & & & & & & & & 1.2 & 1.3 & & & & & & & & & 9.7 & \\
\hline 15 & 1.0 & & & & & & & & & & & & & & & & & & & & \\
\hline 16 & 367.2 & $\odot$ & 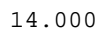 & & & & & & & 1.18 & 1.33 & & & & & & & & & 3.2 & \\
\hline 17 & 393.4 & & & & & & & & & & & & & & & & & & & & \\
\hline 18 & 5.8 & .470 & .470 & 9.200 & 1.00000 & 14.4 & $-0.83 \%$ & 1.0000 & 1.1331 & 1.1866 & 1.3476 & $100.0 \%$ & 559.0 & 591.2 & 619.9 & 0.740 & 0.698 & 0.656 & 869.6 & 949.7 & \\
\hline
\end{tabular}

Results are based on the nominal fuel temperature tables generated from BISON results described in Section 3.4. This nominal depletion does not include the actual startup power history 
